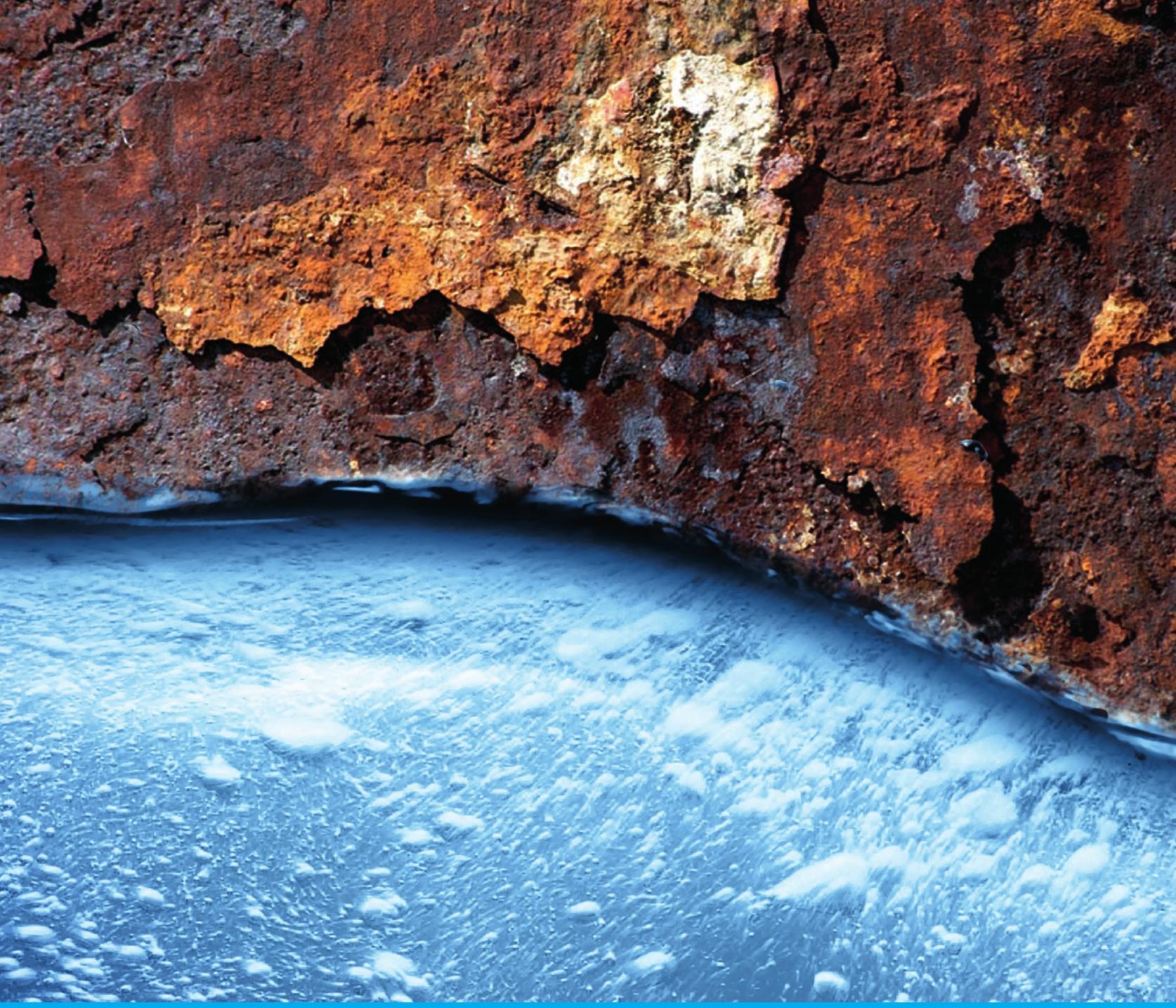

Sergio Chiva Vicent / Jose Guillermo Berlanga Clavijo

Raúl Martínez Cuenca / Javier Climent Agustina (eds.)

\title{
Procesos de oxidación avanzada en el ciclo integral del agua
}

Col-lecció: Cátedra FACSA de Innovación en el Ciclo Integral del Agua 


\title{
Col-lecció
}

Cátedra FACSA de Innovación en el Ciclo Integral del Agua de la Universitat Jaume I

\section{1}

www.catedradelagua.uji.es

\section{PROCESOS DE OXIDACIÓN AVANZADA EN EL CICLO INTEGRAL DEL AGUA}

\author{
Sergio Chiva Vicent \\ Jose Guillermo Berlanga Clavijo \\ Raúl Martínez Cuenca \\ Javier Climent Agustina
}

\section{I UNIVERSTAT}

Cátedra FACSA de Innovación en el ciclo integral del agua 


\section{BIBLIOTECA DE LA UNIVERSITAT JAUME I. Dades catalogràfiques}

Procesos de oxidación avanzada en el ciclo integral del agua / [editor] Sergio Chiva Vicent. -Castelló de la Plana : Publicacions de la Universitat Jaume I, D.L. 2017

p. ; cm. - (Cátedra FACSA de Innovación en el Ciclo Integral del Agua de la Universitat Jaume I ; 1 )

Ponències presentades a la I Jornada Técnica sobre Procesos de Oxidación Avanzada en el Ciclo Integral del Agua celebrada a Castelló de la Plana el 15 de gener de 2016

Bibliografia

ISBN 978-84-16546-30-5 (paper)

1. Aigües residuals - Depuració -- Oxidació. 2. Oxidació. I.Chiva Vicent, Sergio, ed. Il. Jornada Técnica sobre Procesos de Oxidación Avanzada en el Ciclo Integral del Agua (1a : 2016 : Castelló de la Plana). III. Universitat Jaume I. Publicacions. IV. Títol. V. Sèrie.

628.349 .094 .3

66.094 .3

TQSR1

TQSW1

Publicacions de la Universitat Jaume I és una editorial membre de l'unE, cosa que en garanteix la difusió i comercialització de les obres en els àmbits nacional $\mathrm{i}$ internacional. www.une.es

Aquest text està subjecte a una llicència Reconeixement-Compartirlgual de Creative Commons, que permet copiar, distribuir i comunicar públicament l'obra sempre que s'especifique l'autor i el nom de la publicació fins i tot amb objectius comercials i també permet crear obres derivades, sempre que siguen distribuïdes amb aquesta mateixa llicència. http://creativecommons.org/licenses/by-sa/3.0/legalcode

Direcció de la col·lecció: Sergio Chiva Vicent

Comité científic: Sergio Chiva Vicent. Universitat Jaume I Javier Navarro Laboulaix. Universitat Politècnica de València José Enrique Juliá Bolívar. Univesitat Jaume I

(c) Del text: els autors, 2017

(c) De la present edició: Publicacions de la Universitat Jaume I, 2017

Edita: Publicacions de la Universitat Jaume I. Servei de Comunicació i Publicacions Campus del Riu Sec. Edifici Rectorat i Serveis Centrals. 12071 Castelló de la Plana Fax: 964728832

http://www.tenda.uji.es e-mail:publicacions@uji.es

ISBN: 978-84-16546-30-5

DOI: http://dx.doi.org/10.6035/UJ.FACSA.2017.1 
La cátedra universidad-empresa FACSA de Innovación en el Ciclo Integral del Agua de la Universitat Jaume I de Castellón nace el 24 de marzo de 2015 con el propósito de promover actividades de investigación, innovación, transferencia de conocimiento, docencia y cultura en el ámbito del ciclo integral del agua. La cátedra pretende ser un foro abierto que fomente, entre investigadores, estudiantes, docentes, técnicos y Administración, el intercambio de ideas, la trasferencia de conocimiento y el encuentro entre todos los actores del ciclo integral del agua. Esto se debe a que el estudio del agua ha de ser necesariamente abarcado desde muchos ángulos y solo desde una aproximación muy trasversal, en la que se tengan en cuenta todos los puntos de vista, se podrá avanzar en soluciones a los retos importantes que se plantean en el futuro inmediato. Por tanto, es necesario que foros como el que ofrece esta cátedra se mantengan abiertos y faciliten el acceso a la información de calidad, sin sesgos, aportada por expertos reconocidos y expuesta de forma clara y sencilla. Es en este contexto en el que se enmarca la colección de publicaciones «Cátedra FACSA de Innovación en el Ciclo Integral del Agua de la Universitat Jaume |», que pretende aglutinar los diferentes estudios, jornadas, avances e innovaciones en los que la cátedra trabaja.

La I Jornada Técnica sobre Procesos de Oxidación Avanzada en el Ciclo Integral del Agua se celebró en enero del 2016 en la Universitat Jaume I de Castellón, auspiciada por la recién creada cátedra. La jornada reunió a expertos del ámbito académico y empresarial que, ante más de cien asistentes, expusieron los avances actuales en el uso de la oxidación avanzada en el tratamiento de aguas. Fruto de la exposición de cada experto, y el posterior intercambio de ideas y comentarios, cada ponente ha desarrollado un capítulo de este libro en que plasma las ideas que aportó, así como las conclusiones generadas.

Con más de $5000 \mathrm{hm}^{3}$ depurados, más de 2900 EDAR en funcionamiento y un mercado que supera los 1200 millones de euros, la depuración de aguas ha alcanzado un alto grado de madurez. Tanto la técnica como la tecnología necesarias están muy bien implementadas, y el nivel de conocimiento de técnicos, explotadores, Administración e investigadores es más que satisfactoria. El avance en las técnicas analíticas de cuantificación y una mayor concienciación en el respeto al medio ambiente han provocado el afloramiento de nuevos contaminantes en las aguas que se desean controlar, 
los cuales no podrían ser tratados con las técnicas de depuración actuales de las EDAR. Pero los llamados contaminantes emergentes no son todos nuevos, ya que muchos de ellos llevan años en el agua tratada, pero hasta la fecha no habían sido cuantificados por varias razones, como puede ser por carecer de técnicas analíticas que de forma clara los detectaran, porque el coste analítico no resultaba razonable para realizar campañas significativas de medida o, simplemente, porque en muchos no se habían aportado pruebas fehacientes e independientes que mostrasen su efecto dañino y en qué concentración debía limitarse. En los últimos años se ha realizado una gran labor investigadora y existen ya listados de contaminantes perjudiciales, y en qué grado debería limitarse su contaminación; pero, aún así, la comunidad internacional sigue sin ponerse de acuerdoy, aunque hay avances significativos en el consenso, todavía no existe un decreto claro que marque cuáles son los que prioritariamente han de eliminarse, los regule y delimite la concentración de los mismos.

Para combatir los contaminantes emergentes, los investigadores ya han desarrollado posibles estrategias, preparándose para que se puedan cumplir con los nuevos límites que marque el futuro decreto. Entre ellos, los procesos de oxidación avanzada (POA) se han revelado como uno de los métodos más efectivos para combatir estos contaminantes emergentes. Estos procesos, aplicados en el tratamiento terciario mayoritariamente, permiten atacar con solvencia los contaminantes difícilmente biodegradables y pueden ayudar a la eliminación de la contaminación microbiológica remanente. Estas técnicas de oxidación se basan en procesos fisicoquímicos que involucran la generación y uso, principalmente, del radical hidroxilo $(\mathrm{OH} \cdot)$, el cual posee alta efectividad para la oxidación de materia orgánica. Estos procesos ya hace años que han saltado de los laboratorios de las universidades y centros de investigación a la industria. Por tanto, existen ejemplos en la industria actual que hacen uso de las mismas para degradar contaminantes recalcitrantes o difícilmente biodegradables.

A lo largo de los diferentes capítulos se expondrán los últimos avances en POA presentados por investigadores referentes en este campo. En ellos se realizará un recorrido por las principales técnicas asociadas, los resultados, sus límites y las posibles aplicaciones. Se trata de un estado del arte actualizado y comentado por los investigadores que las han desarrollado. En los últimos capítulos se mostrarán ejemplos de éxito de las aplicaciones al campo industrial. 
Por último nos gustaría agradecer a todos los ponentes de la jornada su participación, sus interesantes comentarios, el fructífero debate e intercambio de ideas que se produjo durante el transcurso de la jornada y el esfuerzo realizado para sintetizar de forma comprensible sus experiencias en los capítulos de este libro. También mencionar a los asistentes a la jornada que hicieron de catalizador para poder plasmar en un libro el desarrollo de la jornada.

Sergio Chiva Vicent

Director de la Cátedra Facsa de Innovación en el Ciclo Integral del Agua de la Universitat Jaume I 


\section{ÍNDICE}

1. Introducción

2. Descontaminación de aguas mediante oxidación avanzada con radiación solar: un proceso doblemente sostenible

2.1. Introducción

2.2. Procesos solares avanzados de oxidación

2.2.1. Fotocatálisis solar con $\mathrm{TiO}_{2}$

2.2.2. Foto-Fenton solar

2.3. Aspectos tecnológicos de la fotocatálisis solar

2.3.1. Equipamiento para POA solares

2.3.2. Plantas para tratamiento fotocatalítico solar

2.4. Tratamiento de aguas residuales industriales

2.4.1. Determinación de toxicidad y biodegradabilidad

2.4.2. Tratamiento de aguas industriales combinando POA y biotratamiento

2.5. Tratamiento de efluentes secundarios de EDAR

3. Proceso foto-Fenton: estrategias de aplicación en condiciones próximas a la neutralidad

3.1. Introducción

3.2. Estrategias para aplicar el proceso foto-Fenton en condiciones próximas a la neutralidad

3.2.1. Efecto de los ácidos húmicos sobre el proceso foto-Fenton en condiciones próximas a la neutralidad

3.2.2. Síntesis y aplicación de sustancias bioorgánicas solubles (sBo) para aplicación de procesos foto-Fenton en condiciones próximas a la neutralidad

4. Procesos electroquímicos de oxidación avanzada para el tratamiento de contaminantes orgánicos en aguas

4.1. Introducción

4.2. Fundamentos de los procesos electroquímicos de oxidación avanzada 
4.3. Degradación de contaminantes en una celda tipo tanque de $100 \mathrm{~mL}$

4.3.1. Ácido salicílico

4.3.2. Ibuprofeno

4.4. Degradación en planta de flujo a escala de laboratorio

4.4.1. Mecoprop

4.4.2. Amarillo ácido 36

4.5. Planta de flujo solar autónoma

4.6. Métodos electroquímicos acoplados o combinados

4.7. Conclusiones

5. Aplicación del ozono para el tratamiento de aguas residuales urbanas .

5.1. El ozono: propiedades, generación y aplicaciones

5.1.1. Propiedades del ozono

5.1.2. Generación del ozono

5.1.3. Reactividad del ozono

5.1.4. Aplicaciones de la ozonización

5.1.5. Ventajas y desventajas de la ozonización

5.2. El reuso de aguas y los contaminantes emergentes

5.2.1. Uso del ozono para el tratamiento de efluentes de EDAR

5.2.2. Efecto del ozono en la eliminación de los contaminantes emergentes

5.2.3. Efecto del ozono sobre la materia orgánica de efluentes de depuradora

5.3. Conclusiones

6. Sistemas no convencionales para procesos fotoquímicos de oxidación

6.1. Introducción.

6.2. Fotocatalizadores unidos a polímeros de manera covalente

6.3. Fotocatalizadores unidos a polímeros de manera no covalente

6.4. Conclusiones 
7. Eliminación de compuestos orgánicos en agua potable a partir de procesos mixtos Fenton-fotocatalíticos

7.1. Introducción.

7.2. Experimental

7.2.1. Desarrollo de catalizador de $\mathrm{TiO}_{2}$

7.2.2. Reactivo Fenton

7.2.3. Degradación de los compuestos orgánicos

7.3. Resultados

7.3.1. Caracterización del catalizador de $\mathrm{TiO}_{2}$

7.3.2. Selección del catalizador

7.3.3. Eliminación de contaminantes orgánicos

7.4. Discusión

7.5. Conclusiones

8. Caso práctico: aplicaciones POA mediante tecnología $\mathrm{H}_{2} \mathrm{O}_{2} / \mathrm{UV}$ y foto-Fenton en aguas procedentes de una industria química

8.1. Introducción

8.2. Objetivo

8.3. Materiales y método

8.4. Resultados

8.5. Conclusiones 


\section{Introducción}

Una de las preocupaciones sociales más importantes de la actualidad es la protección y conservación del agua como recurso natural. Como sabemos, el agua es un bien preciado y escaso, por lo que se debe realizar un adecuado uso y reciclaje del mismo, teniendo en cuenta que las normativas relacionadas con la potabilización, depuración y adecuación de aguas son cada vez más estrictas.

Una estación depuradora de aguas residuales (EDAR) suele estar formada por las siguientes etapas: pretratamiento, tratamiento primario y tratamiento secundario. Debido a la situación hídrica de nuestro país, en muchas ocasiones las EDAR necesitan implantar tratamientos terciarios en sus instalaciones con el objetivo de poder regenerar y reutilizar las aguas depuradas. De hecho, España es el primer país europeo en capacidad de reutilización, produciendo más de $450 \mathrm{hm}^{3} /$ año de agua tratada, que representan aproximadamente el $10 \%$ de los caudales de las aguas empleadas para el abastecimiento urbano. Así, cabe destacar el uso del riego entre las principales actividades de aplicación del agua reutilizada. La selección de las tecnologías de tratamiento se realiza de acuerdo con los requerimientos de los usos asignados. Así mismo, es necesario garantizar la correcta operación y mantenimiento de la instalación previa de agua residual con objeto de garantizar la calidad del agua de entrada a los sistemas de regeneración.

Los procesos de oxidación avanzada (POA) encuentran su aplicación principal en el tratamiento terciario, siendo el objetivo de estos procesos eliminar compuestos difícilmente biodegradables e incluso mejorar la eliminación de contaminación microbiológica. LOS POA se basan en procesos fisicoquímicos capaces de producir cambios profundos en la estructura química de los contaminantes, que involucran la generación y uso de especies poderosas transitorias, principalmente el radical hidroxilo $(\mathrm{OH} \cdot)$. Este radical puede ser generado por medios fotoquímicos (incluida la luz solar) $u$ otras formas de energía, y posee alta efectividad para la oxidación de materia orgánica. Algunos 
POA, como la fotocatálisis heterogénea y otras técnicas avanzadas, utilizan, además, reductores químicos que permiten transformaciones en contaminantes tóxicos, poco susceptibles a la oxidación, como iones metálicos o compuestos halogenados. Las tecnologías de oxidación avanzada se están consolidando como la opción más eficaz en el tratamiento de efluentes contaminados por sustancias recalcitrantes o tóxicas.

La I Jornada Técnica sobre Procesos de Oxidación Avanzada en el Ciclo Integral del Agua está dirigida a expertos académicos y profesionales industriales en tecnologías de tratamiento mediante procesos de oxidación avanzada, jefes de departamentos de ingeniería, profesionales del sector del agua y estudiantes de grados y másteres técnicos interesados en este tipo de procesos. La jornada se divide en dos sesiones: la primera está dedicada a una introducción a los POA, donde se destaca la alta versatilidad de estos procesos debido a las diferentes tecnologías de las que se dispone y el amplio abanico de posibilidades que estas ofrecen al combinarse con las tecnologías más convencionales. Posteriormente, se abordan los avances en las diferentes líneas de investigación que las universidades y centros de investigación están desarrollando en la actualidad para su aplicación al tratamiento de aguas, donde cabe destacar las dos áreas de investigación emergentes como son el uso de la energía solar y la utilización de la oxidación avanzada como un pretratamiento a los sistemas biológicos. La segunda sesión está dedicada a los casos prácticos de aplicación de los POA por diferentes empresas, con lo que se complementará la visión académica de la primera sesión desde un punto de vista más práctico del panorama actual. Esta combinación teórico-práctica da pie a discutir sobre los principales retos de futuro, entre los cuales destaca el aumento del rendimiento de los procesos y la eficiencia económica, por lo que es necesario promover la implementación comercial de las tecnologías.

Los POA se pueden definir como las técnicas de tratamiento basadas en la acción de especies altamente reactivas, los radicales hidroxilos, que conducen a la oxidación completa de los contaminantes. Las tecnologías de POA pueden clasificarseen procesos heterogéneos (energéticosysinenergía)y homogéneos, con capacidad de oxidar a gran variedad de contaminantes, pudiendo llegar a la mineralización si el proceso se prolonga lo suficiente o quedándose en estados de oxidación intermedios que permitan un acoplamiento con otros métodos de depuración como pueden ser procesos biológicos. Sixto Malato 
proporciona una visión general de los diferentes procesos e insiste en la idea de que es evidente que cada agua real precisa de un estudio completo y siempre es interesante ensayar varios procesos o combinaciones de los mismos para tratar un mismo tipo de agua con el fin de escoger la opción más apropiada. Por tanto, resulta interesante recurrir a la integración de varios procesos con el fin de aunar de manera sinérgica las ventajas de cada etapa. En los últimos 30 años se ha desarrollado mucho conocimiento sobre los POA debido a la variedad de tecnologías disponibles y el amplio campo de aplicaciones posibles. Entre los POA se incluyen, entre otros, la fotocatálisis homogénea y heterogénea en presencia de radiación solar ultravioleta (uv) o radiación visible. El uso de energía solar se presenta como una alternativa sostenible, ya que el coste de instalación y operación de los POA es relativamente alto. Así, la fotocatálisis solar resulta especialmente interesante para la eliminación de contaminantes por el empleo de la energía solar como única fuente de energía, lo que economiza la aplicación de procesos para la depuración de efluentes industriales y hace factible su estudio para la implantación industrial o como tratamiento terciario de EDAR. Ana M. a Amat Payá describe las numerosas ventajas que presenta este método frente a otros tratamientos alternativos, entre las que cabe destacar la capacidad de captación de fotones en un amplio intervalo del espectro solar y, por tanto, su mayor eficiencia. En contrapartida, presenta como principal inconveniente que las condiciones óptimas de su aplicación son a $\mathrm{pH}$ ácidos (en torno a 3). Esto complica y encarece su aplicación a efluentes que se encuentren a $\mathrm{pH}$ superiores o que deban ser vertidos posteriormente a dichos $\mathrm{pH}$. Por ello, en los últimos años han surgido numerosos estudios enfocados a estudiar estrategias de aplicación del proceso foto-Fenton en $\mathrm{pH}$ que se encuentren en el entorno de la neutralidad. Por ello expone las distintas posibilidades de aplicación del proceso foto-Fenton y su eficiencia cuando se emplean diferentes estrategias para aplicarlo a pH mayores de 3.

Enric Brillas presenta los fundamentos y principales aplicaciones de los procesos electroquímicos avanzados de oxidación (EAOP) que se están desarrollando para el tratamiento de aguas contaminadas con compuestos orgánicos. LOS EAOP se basan en la electrogeneración de radicales hidroxilo que poseen un gran poder oxidante por su elevado potencial estándar de reducción. Se describirá, en primer lugar, la oxidación anódica o electrooxidación, donde los radicales $\mathrm{OH} \cdot$ se forman en la superficie de un ánodo de alto sobrepotencial 
$\mathrm{de}_{2}$, poniéndose especial énfasis en el uso de los ánodos de diamante dopado con boro (DDB) que son los más potentes en esta tecnología. Posteriormente, se incide en procesos acoplados con la luz como los procesos fotoelectroFenton, matizando el gran interés que tiene en ellos el uso de la energía solar por ser renovable y gratuita. Para todas las tecnologías descritas, se expondrán ejemplos que muestren su capacidad oxidativa sobre contaminantes comunes como herbicidas, fármacos y colorantes. Cabe destacar que se describirán tratamientos a distintas escalas, desde celdas de $100 \mathrm{~mL}$ hasta plantas de flujo de 2,5 y 10 L. Por último, detalla el uso de una planta de flujo solar autónoma de $10 \mathrm{~L}$ alimentada con una placa fotovoltaica y la combinación de procesos para mejorar la degradación de los contaminantes.

La acumulación de contaminantes emergentes en el medio ambiente es un problema ampliamente extendido y preocupante de la actualidad. La llegada de estos se produce principalmente por medio de microcontaminantes que provienen de las EDAR urbanas o mixtas. Por tanto, este es el mejor lugar donde aplicar tratamientos avanzados para remoción de estos contaminantes como la ozonización. Carmen Sans Mazón describe la aplicación de la ozonización para la eliminación de contaminantes emergentes, así como los efectos del ozono sobre la materia orgánica del efluente de las EDAR. El ozono se puede utilizar para la mineralización (eliminación de carbono orgánico total) de moléculas orgánicas, aunque en muchos casos implica el uso de altas dosis de ozono y el encarecimiento del proceso, por lo que una buena estrategia es la utilización de la ozonización como pretratamiento, ya que los productos de la oxidación parcial con ozono son generalmente más fácilmente biodegradables que sus precursores. Así, la preozonización puede reducir el tiempo de retención requerido en el tratamiento biológico de fangos activados, lo que representa una mejora sustancial en términos de proceso y un medio económico para el tratamiento de productos químicos orgánicos biorecalcitrantes en las aguas residuales. Además, se tratarán otros aspectos ingenieriles importantes en la operación del proceso de ozonización como son la trasferencia de materia del ozono al agua y el IOD (immediate ozone demand).

La combinación de luz y catalizadores (fotocatálisis) en procesos de oxidación ha sido muy estudiada hasta la fecha, siendo el material más estudiado durante los últimos 40 años el dióxido de titanio $\left(\mathrm{TiO}_{2}\right)$. Sin embargo, otros materiales se continúan proponiendo como alternativas, al menos desde 
el punto de vista académico. Como ejemplo de esto, Francisco Galindo presenta una recopilación de los últimos avances sobre fotocatalizadores basados en polímeros. Considerando la enorme prevalencia del $\mathrm{TiO}_{2}$ en procesos de oxidación avanzada, puede considerarse dichos polímeros fotoactivos como sistemas no convencionales, dado que representan una alternativa minoritaria. Sin embargo, dada la versatilidad de la síntesis orgánica, podrían ser de utilidad para aplicaciones específicas. Por ello muestra ejemplos extraídos de la bibliografía así como desarrollos propios realizados en fechas recientes.

En cuanto a casos prácticos de aplicación de POA a la industria, Juan Ibañez y Raúl Berenguer trasladan una idea del estado actual: bondades, inconvenientes y posibilidades de la electroquímica para el tratamiento de agua a escala industrial. Para ello se realiza una retrospectiva del intenso desarrollo realizado por la empresa Geodesic los últimos años en los dos campos considerados de mayor relevancia: por un lado, la desinfección mediante electroporación y la generación de oxidantes sin sal ni otros aditivos y, por otro, la eliminación de nitrógeno amoniacal mediante oxidación directa y mediante generación/destrucción de cloraminas. Para ambos casos se presentará la evolución desde la escala piloto hasta la escala a nivel industrial haciendo incidencia en la problemática encontrada en la técnica y en el propio escalado de la instalación, así como en las soluciones a adoptar. Para terminar la ponencia se hablará sobre los retos de investigación y desarrollo en relación al control, los materiales y los costes, así como la necesidad del fomento y el fortalecimiento de la relación entre centros de investigación y empresas para que los productos generados en la investigación puedan encontrar mejor salida al mercado y para que los desarrollos a nivel industrial puedan tener el mejor soporte técnico.

Otra aplicación práctica de la tecnología de POA es la que tiene lugar en estaciones de tratamiento de agua potable (ETAP), en las cuales se debe garantizar la calidad del agua máxima posible dentro de los límites legales. Existen diferentes vías por las que las aguas potables pueden estar contaminadas o pueden contaminarse de productos orgánicos perjudiciales para la salud humana. Así, muchos productos y compuestos orgánicos, los cuales pueden llegar en forma de vertidos a ríos o pantanos, no se eliminan con los oxidantes clásicos como puede ser el cloro, el ozono, el permanganato potásico o el dióxido de cloro; el carbón activo tampoco lo adsorbe. Javier García Castillo describe la aplica- 
ción de POA en ETAP, focalizada en la eliminación de estos contaminantes del agua potable a través de diferentes procesos fisicoquímicos. Entre estos, se distinguen los de tipo fotoquímico y no fotoquímico. La principal diferencia es que en el primer caso se necesita una radiación ultravioleta visible (uv-vis) mientras que en el segundo se requiere el uso de compuestos químicos $\left(\mathrm{O}_{3^{\prime}}\right.$ $\mathrm{H}_{2} \mathrm{O}_{2^{\prime}} \mathrm{Fe}_{2}^{+}$) o procesos eléctricos (electroquímicos, en este caso). Se presenta un estudio interesante sobre la eficacia de estos dos procesos simultáneos, fotoquímicos y no fotoquímicos, sobre la eliminación de compuestos orgánicos en agua potable. Para ello se ha utilizado tanto $\mathrm{TiO}_{2}$ como el reactivo Fenton y se ha estudiado la influencia en la cantidad degradada.

Entre las aplicaciones prácticas de POA a la industria, Alex Vila Girbal muestra diferentes instalaciones existentes con tecnología AOP-Uv. El primer caso práctico consiste en una planta de tratamiento de microcontaminantes y desinfección con uv para agua potable, PWN Water Supply Company (Holanda). Posteriormente, una instalación que opera en una industria de fabricación de TFT-LCD (Thin-Film-Transistor Liquid-Crystal-Display) en la recuperación de efluentes mediante la reducción de contaminantes específicos no divulgables. Finalmente, presenta una instalación para reducción de voc-aldehídos en una fábrica de tableros de fibra MDF.

Siguiendo con las aplicaciones prácticas y entre la gran variedad de tecnologías disponibles, Javier Donato presenta el caso práctico de aplicación POA (en concreto, la tecnología $\mathrm{H}_{2} \mathrm{O}_{2} /$ uv y foto-Fenton) en el tratamiento del efluente de una industria química, con una significativa contaminación refractaria residual y baja biodegradabilidad. Desde la empresa SITRA se ha desarrollado un tratamiento terciario para la descontaminación de aguas residuales de una industria química del sector perfumero con alta carga orgánica y refractaria que no pueden ser tratados por un método convencional. Se explica el desarrollo y la aplicación de un nuevo proceso que permite eliminar los contaminantes no biodegradables de las aguas residuales efluentes de esta industria. El estudio se inicia en ensayos de laboratorio para llegar a escala industrial. Finalmente, se discute la viabilidad final del proyecto marcada por las consideraciones económicas, dado el coste elevado de inversión y de operación de planta. 


\title{
Descontaminación de aguas mediante oxidación avanzada con radiación solar: un proceso doblemente sostenible
}

\author{
S. Malato \\ Plataforma Solar de Almería, CIEMAT \\ Carretera Senes km 4, 04200 Almería, España
}

Contacto: sixto.malato@psa.es

\section{Sixto Malato}

Nacido en Almería el 10 de mayo de 1964. Doctor en Ciencias Químicas (Ingeniería Química). Responsable de la Unidad de Tratamientos Solares de Agua hasta diciembre del 2012. Director de la Plataforma Solar de Almería desde septiembre del 2012. Su labor científica ha estado fundamentalmente relacionada con proyectos de I+D centrados en la descontaminación de aguas mediante procesos de oxidación avanzada. Ha coordinado o participado en 22 proyectos nacionales y 18 proyectos internacionales (3rd7th y H2020 EU Framework Programmes). Coautor de más de doscientas publicaciones en revistas científicas internacionales con índice de impacto, 5 patentes. Ha dirigido 13 tesis doctorales. H-index (de acuerdo con http:// www.scopus.com,): 59. Editor asociado de Environmental Chemistry Letters (editorial Spinger), Journal of Advanced Oxidation Technologies (Science and Technology Network, Inc.) y Photochemical and Photobiological Sciences (RSC Publishing). Miembro del comité editorial de Catalysis Today (editorial Elsevier). Premio Jaime I de Protección del Medio Ambiente, 2011. http:// www.fvea.es/medioambiente.html. Gran Premio del Jurado del Premio Europeo de Innovación, 11 de diciembre de 2004, Mónaco. http://www. european-grandprix.com/index_en.htm. Director de la Plataforma Solar de Almería (www.psa.es). Subdirector de centro mixto UAL-CIEMAT de investigación de la energía solar (CIESOL) http://www.ciesol.es. 


\section{Resumen}

Este trabajo recoge los principales aspectos de los procesos de oxidación avanzada (POA) basados en fotocatálisis homogénea y heterogénea en presencia de radiación solar ultravioleta o radiación visible. Los POA tienen como principal aplicación el tratamiento de aguas residuales industriales o bien el tratamiento terciario en EDAR, la producción de agua ultrapura, el tratamiento de compuestos orgánicos volátiles, etc. Cada agua real precisa de un estudio completo y siempre es interesante ensayar varios procesos o combinaciones de los mismos para tratar un mismo tipo de agua con el fin de escoger la opción más apropiada. Para determinar la opción de diseño es preciso fijar objetivos de calidad final del efluente, incluir estudios económicos y evaluar los impactos ambientales de cada proceso.

\subsection{Introducción}

La revolución industrial del siglo xIx llevó a los problemas medioambientales relacionados con la contaminación que hoy conocemos. Después de la segunda guerra mundial, comenzó a aparecer la preocupación por el medio ambiente, en un inicio relacionado con la contaminación radioactiva y, después, más general. Diferentes desastres ocurrieron en el siglo xx, como el envenenamiento por mercurio en la bahía de Minamata (Japón, 1956), el desastre de las dioxinas de Seveso (Italia, 1976), el escape de gas de Union Carbide en Bhopal (India, 1984) o los desastres nucleares de Chernóbil y Fukushima, así como los múltiples vertidos de combustible en el mar. Esto se ha complementado con el uso de Agente Naranja durante la guerra de Vietman (más de $75000 \mathrm{~m}^{3}$ ), la lluvia ácida, etc. Todos estos acontecimientos han provocado el crecimiento de una conciencia medioambiental cada vez más generalizada, lo que ha provocado la aparición de legislación ambiental en todos los estados modernos. En contraste con estos grandes desastres medioambientales, el impacto de una descarga continua de residuos industriales, fertilizantes, plaguicidas y compuestos farmacéuticos no fue considerado relevante ya que a menudo se diluía y no se prestaba atención a su efecto a medio y largo plazo. Solo en la 
década de los cuarenta se empezaron a describir efectos de perturbación endocrina provocada por ciertos compuestos químicos (Sluczewski y Roth, 1948) y apareció el primer informe sobre compuestos farmacéuticos en efluentes de plantas de tratamiento (Hignite y Azarnoff, 1977). Durante los últimos 30 años la química ambiental ha enfocado esta contaminación convencional, pero que solo es una pequeña parte de los contaminantes que se pueden detectar hoy en día en el medio natural (Daughton y Ternes, 1999).

Las plantas de tratamiento convencionales utilizan fangos activos para eliminar la demanda química de oxígeno (DQO) biodegradable, pero no suelen ser efectivas con elevadas DQO o con compuestos biorrecalcitrantes que, si además son tóxicos, pueden dañar a los microorganismos de los fangos activados. Esto se puede resolver con oxidación química antes o después del biotratamiento (Oller y otros, 2011), pero debe minimizarse en su aplicación mediante protocolos de optimización en la combinación de tratamientos, ya que suelen ser más costosos que los biotratamientos (Esplugas y Ollis, 1997). Los procesos de oxidación química modernos están basados en POA, que se definen como aquellos que generan radicales hidroxilo y que pueden degradar los compuestos orgánicos debido a su elevado potencial de oxidación $\left(\mathrm{HO} \cdot+\mathrm{H}^{+}+\mathrm{e}^{-} \rightarrow \mathrm{H}_{2} \mathrm{O}\right.$; $\left.\mathrm{E}^{\circ}=2,33 \mathrm{~V}\right)$.

La mayoría de los POA hacen uso de combinaciones de oxidantes $\left(\mathrm{O}_{3} / \mathrm{H}_{2} \mathrm{O}_{2}\right)$, de un oxidante y un catalizador $\left(\mathrm{Fe}^{2+} / \mathrm{H}_{2} \mathrm{O}_{2}\right)$, un oxidante y radiación $\left(\mathrm{uv} / \mathrm{H}_{2} \mathrm{O}_{2}\right)$ o bien de radiación y catalizador ( $\left(\mathrm{Uv} / \mathrm{TiO}_{2}\right)$; aunque hay POA que combinan todo lo anterior con otros procesos (Gogate y Pandit, 2004). Una de las principales desventajas de estos procesos es su elevado consumo energético, fundamentalmente eléctrico, que los hace económicamente muy exigentes. Esta es la principal razón por la que su aplicación es todavía escasa. Una de las estrategias para reducir estos costes es su combinación con otras tecnologías, o bien el uso de energías renovables, como puede ser la fotocatálisis con $\mathrm{TiO}_{2}$ y foto-Fenton que utilizan radiación solar. También los avances en fotorreactores, modos de operación y estrategias de control pueden permitir reducir los costes (Malato y otros, 2009).

El desarrollo de técnicas analíticas avanzadas como cromatografía de gases o líquidos acoplada a espectrometría de masas (GC-MS, LC-MS, LC-TOF/MS) ha empujado los límites de detección y cuantificación por debajo del nanogramo, permitiendo la determinación de nuevas sustancias orgánicas y sus 
metabolitos a extremadamente baja concentración (Petrovic y Barceló, 2006; Robles-Molina y otros, 2010). Los así llamados contaminantes emergentes o, mejor dicho, contaminantes de preocupación emergente (EC) son definidos como sustancias orgánicas que no están sujetas a restricciones o legislación, pero que pueden serlo en el futuro, dependiendo de lo que se vaya descubriendo en cuanto a efecto en la salud humana, la vida acuática y la presencia en el medio ambiente. Un buen número de compuestos es considerado Ec: detergentes, medicamentos y sus metabolitos, retardantes de llama, productos de higiene personal y hormonas, entre otros. La principal característica de estos contaminantes es que no es necesario que sean muy persistentes en el medio ambiente para causar efectos nocivos, ya que su posible degradación es compensada por su continuo vertido en el medio ambiente. Estos contaminantes entran en el medioambiente fundamentalmente a través de aguas residuales urbanas sin tratar, pero también de las tratadas, ya que la mayoría de las EDAR no están diseñadas para eliminar EC. También son grandes responsables la agricultura y la ganadería, debido al uso de plaguicidas de todo tipo y el abuso de medicamentos, respectivamente. El vertido sin tratar de los fangos activados procedentes de las EDAR también es una fuente de EC.

Este trabajo pretende revisar no solo los principales POA solares, sino su aplicación en el tratamiento de aguas industriales conteniendo contaminantes convencionales y de efluentes de EDAR conteniendo EC.

\subsection{Procesos solares avanzados de oxidación}

Las constantes de reacción $\left(\mathrm{k}_{\mathrm{HO}^{\prime}} \mathrm{r}=\mathrm{k}_{\mathrm{HO}}\right.$ [HO-] C) para la mayoría de las reacciones de radicales hidroxilo en agua son del orden de $10^{6}$ a $10^{9} \mathrm{M}^{-1} \mathrm{~s}^{-1}$. Estos radicales también se caracterizan por su poca selectividad, que los hace muy útiles para el tratamiento de aguas residuales y otros problemas de contaminación. La versatilidad de los POA también está basada en que hay muy diferentes procesos por los que se generan radicales hidroxilo. En la aplicación de POA en descontaminación de aguas, los objetivos pueden ser diversos: $a$ ) eliminar compuestos biorrecalcitrantes y tóxicos, b) aumentar la biodegradabilidad del agua residual antes de aplicar tratamientos biológicos convencionales, c) eliminar la toxicidad y $d$ ) desinfectar el agua como método alternativo a la clo- 
ración, que puede generar subproductos carcinogénicos y mutagénicos como halometanos (Rizzo, 2011). La fotocatálisis heterogénea y foto-Fenton están basados en el uso de un semiconductor y en la combinación de sales de hierro y $\mathrm{H}_{2} \mathrm{O}_{2^{\prime}}$ respectivamente y el uso de irradiación uv-vis. Ambos procesos son de especial interés ya que pueden llevarse a cabo con luz solar. Las publicaciones basadas en estos procesos aumentan continuamente desde hace años, llegando a 9000 en el 2015, y específicamente con sol más de 1000. La figura 2.1 muestra la evaluación de las publicaciones en este campo desde hace más de quince años.

\subsubsection{Fotocatálisis solar con $\mathrm{TiO}_{2}$}

La fotocatálisis se define como «cambio en la velocidad de una reacción o su iniciación por el efecto de la radiación uv, visible o infraroja en la presencia de una sustancia, el fotocatalizador, que absorbe los fotones y participa en la trasformación química de los reactantes» (Braslavsky y otros, 2007). En 1972, Fujishima y Honda descubrieron la posibilidad de la disociación del agua en una celda fotoelectroquímica que consistía en un ánodo de $\mathrm{TiO}_{2}$ y

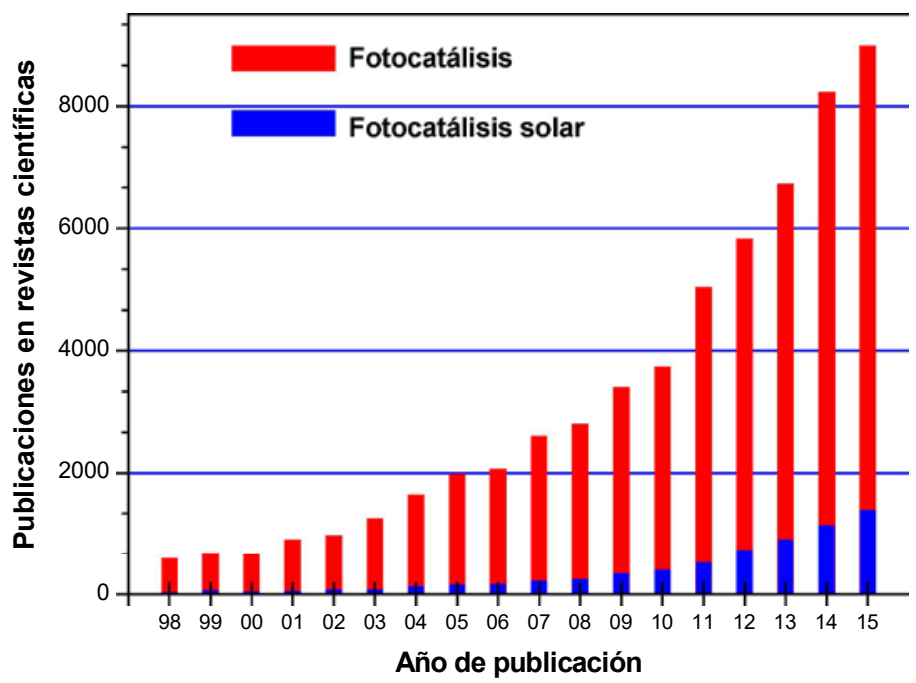

Figura 2.1. Publicaciones sobre fotocatálisis y, entre ellas, las enfocadas en fotocatálisis solar (fuente: www.scopus.com, abril del 2016) 
un electrodo de Pt (Fujishima y Honda, 1972). La descontaminación de agua mediante $\mathrm{TiO}_{2}$ fue descrita por primera vez por Frank y Bard para la eliminación de cianuro y sulfito (Frank y Bard, 1977). Las aplicaciones de la fotocatálisis heterogénea incluyen la purificación de aire, las superficies autolimpiantes, la síntesis orgánica, la disociación de agua, la desinfección o la terapia del cáncer (Fujishima y otros, 2000). El proceso se denomina heterogéneo al constar el medio de reacción de dos fases, el sólido (catalizador) y el líquido (reactivo). Un catalizador idóneo debe ser química y biológicamente inerte, fotoactivo, fotoestable, barato e inocuo y debe activarse por luz solar. Aunque existen diferentes calcogenuros semiconductores (óxidos y sulfuros), la mayoría de los estudios se han enfocado en $\mathrm{TiO}_{2}$ a pesar de sus limitaciones, como su baja eficiencia y baja respuesta a la luz debido a su ancho de banda (unos 3,2 eV, correspondiente a luz $<390 \mathrm{mn}$ ). Las aplicaciones más habituales del $\mathrm{TiO}_{2}$ son como pigmentos blancos en pinturas, plásticos, papel, fibras, comida y compuestos farmacéuticos y de cuidado personal, sobre todo por su capacidad de desviar la luz y su elevado índice de refracción (Skojaj y otros, 2011). El más utilizado en aplicaciones fotocatalíticas es Degussa P25, hoy en día Evonik P25 (conocido COMO AEROXIDE ${ }^{\oplus} \mathrm{TiO}_{2}$ P25).

Los mecanismos de degradación fotocatalítica de contaminantes orgánicos están bien descritos en la literatura científica (Herrmann, 2010). El proceso supone la absorción de un fotón con suficiente energía (igual o superior al ancho de banda del semiconductor). A partir de ahí, un electrón se desplaza desde la banda de valencia a la banda de conducción generando un hueco $(\mathrm{h}+)$ en la banda de valencia y un electrón en la banda de conducción (e-). Estos pueden migrar a la superficie del $\mathrm{TiO}_{2}$, donde pueden participar en reacción de oxidación y reducción con los contaminantes o bien recombinarse. El hueco fotogenerado puede reaccionar con agua o bien aniones $\mathrm{HO}^{-}$para formar radicales $\mathrm{HO}$. (reacciones 2.1 y 2.2). Cuando hay oxigeno disponible, este se absorbe en la superficie de $\mathrm{TiO}_{2}$ y puede capturar un electrón y formar radical anión superóxido $\left(\mathrm{O}_{2}^{-}\right.$, reacción 2.3).

\begin{tabular}{|c|c|}
\hline$h^{+}+\mathrm{H}_{2} \mathrm{O} \rightarrow \mathrm{TiO}_{2}+\mathrm{HO}^{\cdot}+\mathrm{H}^{+}$ & (2.1) \\
\hline$h^{+}+\mathrm{HO}^{-} \rightarrow \mathrm{TiO}_{2}+\mathrm{HO}$ & (2.2) \\
\hline $\mathrm{e}^{-}+\mathrm{O}_{2} \rightarrow \mathrm{TiO}_{2}+\mathrm{HO}_{2}^{--}$ & (2.3) \\
\hline
\end{tabular}


Sin embargo, una limitación en fotocatálisis solar es el pobre solape entre el espectro solar y el espectro de absorción de $\mathrm{TiO}_{2}(<5 \%)$. El dopado de $\mathrm{TiO}_{2}$ con no metales, iones metálicos o bien con colorantes se ha aplicado para mejorar la eficiencia fotocatalítica. Esto produce una mejor absorción en la región del visible mejorando el rendimiento cuántico, pero supone un aumento de coste relevante en el fotocatalizador (Zhang y otros, 2009).

\subsubsection{Foto-Fenton solar}

Los procesos de Fenton y similares a Fenton están probablemente entre los procesos de oxidación avanzada más aplicados en el tratamiento de aguas industriales (Suty y otros, 2004). Las primeras aplicaciones se remontan a los años sesenta. Pero no fue hasta los años noventa que aparecieron las primeras publicaciones basadas en foto-Fenton (Pignatello y otros, 2006). La mayoría de la literatura científica en este campo incluye la posibilidad de utilizar como fuente de radiación el sol, porque los aquo complejos de hierro, y especialmente los complejos con ácidos orgánicos del hierro, absorben sustancialmente en la parte visible del espectro solar y no solo en la franja uv (Malato y otros, 2009).

El peróxido de hidrógeno se descompone en agua y oxígeno en la presencia de $\mathrm{Fe}(\mathrm{II})$ en la reacción de Fenton en disolución acuosa (reacción 2.4), como indicó Fenton en su publicación pionera del siglo xIx (Fenton, 1894). Las reacciones 2.4-2.6 muestran los procesos básicos en ausencia de otros iones o sustancias orgánicas. La regeneración de Fe(II) desde Fe(III) mediante las reacciones 2.5 y 2.6 son las limitantes del proceso de Fenton si el hierro se añade en pequeñas cantidades y se pretende que actúe como catalizador.

\begin{tabular}{|c|c|}
\hline $\mathrm{Fe}^{2+}+\mathrm{H}_{2} \mathrm{O}_{2} \rightarrow \mathrm{Fe}^{3+}+\mathrm{OH}^{-}+\mathrm{HO}$ & (2.4) \\
\hline $\mathrm{Fe}^{3+}+\mathrm{HO}_{2}^{-} \rightarrow \mathrm{Fe}^{2+}+\mathrm{O}_{2}+\mathrm{H}^{+}$ & (2.5) \\
\hline $\mathrm{Fe}^{3+}+\mathrm{O}_{2}^{--} \rightarrow \mathrm{Fe}^{2+}+\mathrm{O}_{2}$ & (2.6) \\
\hline
\end{tabular}

Si están presentes sustancias orgánicas (como en muchas aguas residuales), reaccionan mediante diferentes mecanismos con los radicales hidroxilo 
generados. Los radicales orgánicos generados continúan reaccionando, prolongando la reacción en cadena y contribuyendo a reducir el consumo de oxidantes mediante Fenton, y también en foto-Fenton. En el caso de contaminantes aromáticos, el anillo es usualmente hidroxilado antes de romperse debido a la oxidación, formando productos de degradación que contienen estructuras de quinona e hidroquinona. En cualquier caso, esto finalmente provoca la mineralización de la molécula original. Una importante desventaja del proceso de Fenton para mineralizar contaminantes es que los intermedios basados en ácidos carboxílicos no se pueden degradar. Tanto los ácidos carboxílicos como los dicarboxílicos forman complejos estables con el hierro, que inhiben la reacción con el peróxido de hidrógeno (Kavitha y Palanivelu, 2004). Por tanto, el proceso catalítico se detiene antes de alcanzar la mineralización completa.

$$
\mathrm{Fe}^{3+}+n L \rightarrow\left[\mathrm{FeL}_{n}\right]^{x+} \stackrel{\mathrm{H}_{2} \mathrm{O}_{2} \text { oscuridad }}{\longrightarrow} \text { no reacción }
$$

El primer paso en la fotorreducción de Fe(III) es una reacción de trasferencia de carga ligando-metal en la que los complejos intermedios se disocian tal cual se muestra en la reacción 2.8. El ligando puede ser cualquier base de Lewis capaz de formar complejos con Fe(III) como $\mathrm{HO}-, \mathrm{H}_{2} \mathrm{O}_{2} \mathrm{HO}_{2}^{-}, \mathrm{Cl}^{-}, \mathrm{R}-\mathrm{COO}$, $\mathrm{R}-\mathrm{OH}, \mathrm{R}-\mathrm{NH}_{2}$, etc.). Dependiendo del ligando, el producto puede ser un radical hidroxilo como en la reacción 2.9 u otro radical derivado del ligando. La oxidación del ligando orgánico también es posible, como se muestra para los ácidos carboxílicos en la reacción 2.10.

\begin{tabular}{|c|c|}
\hline$\left[\mathrm{Fe}^{3+}+L\right]+h v \rightarrow\left[\mathrm{Fe}^{3+} L\right]^{*} \rightarrow \mathrm{Fe}^{2+}+L^{\cdot}$ & (2.8) \\
\hline$\left[\mathrm{Fe}^{3+}+\mathrm{OH}\right]^{2+}+h \rightarrow \mathrm{Fe}^{2+}+\mathrm{OH} \cdot$ & (2.9) \\
\hline$[\mathrm{Fe}(\mathrm{OOC}-\mathrm{R})]^{2+}+\mathrm{hv} \rightarrow \mathrm{Fe}^{2+}+\mathrm{CO}_{2}+R^{\cdot}$ & (2.10) \\
\hline
\end{tabular}

Los complejos de Fe(III) tienen una absorbancia diferente en función del ligando y, por tanto, la reacción 2.8 se produce con diferentes rendimientos cuánticos a diferentes longitudes de onda. Consecuentemente, el pH juega un papel crucial en la eficacia de la reacción, ya que afecta sustancialmente a 
los complejos formados. Por tanto, $\mathrm{pH} 2,8$ se ha postulado como el óptimo en foto-Fenton, ya que no hay precipitación de hierro y la especie predomínate es $[\mathrm{Fe}(\mathrm{OH})]^{2+}$, el más fotoactivo de todos los complejos acuosos (reacción 2.9). Los complejos con ácidos carboxílicos tienen una especial importancia ya que se forman a partir de los intermedios de oxidación y suelen tener un rendimiento cuántico mayor que los complejos con agua. Estos complejos tienen una mayor absorción molar en uv cercano y visible que los complejos acuosos, con eficiencia cuántica entre 0,05 y 0,95 (Pignatello y otros, 2006), permitiendo que el proceso de foto-Fenton sea muy adecuado para llevarlo a cabo con energía solar.

\subsection{Aspectos tecnológicos de la fotocatálisis solar}

\subsubsection{Equipamiento para POA solares}

La tecnología y el equipamiento necesarios para aplicaciones fotocatalíticas tienen mucho en común con las aplicaciones térmicas. Consecuentemente, tanto reactores como otros componentes de las plantas fotocatalíticas siguieron en un principio el diseño de captadores solares térmicos, como captadores cilindro-parabólicos y captadores sin concentración (Dillert y otros, 1999). Pero, a partir de los primeros desarrollos, empezaron a divergir (Malato y otros, 2002), porque: $a$ ) el fluido debe estar expuesto a la radiación uv solar y, por tanto, el absorbedor debe ser trasparente, $\mathrm{y} b$ ) la temperatura no juega un papel relevante en el proceso $y$, por tanto, las plantas no precisan aislamiento. Al contrario de los captadores térmicos, que deben capturar grandes cantidades de fotones de cualquier longitud de onda para alcanzar cierta temperatura, la fotocatálisis solar debe basarse en captar solo fotones de baja longitud de onda y elevada energía para promover fotorreacciones (figura 2.2). Los procesos fotocataliticos utilizan uv o bien radiación visible hasta $580 \mathrm{~nm}$.

Los primeros fotorreactores solares estaban basados en captadores cilindroparabólicos a los que se les sustituyó el absorbedor por un tubo de vidrio Pyrex donde se circulaba el agua (Goswami, 1997). Las principales desventajas de estos captadores se evaluaron en los años noventa (Alfano y otros, 2000): 


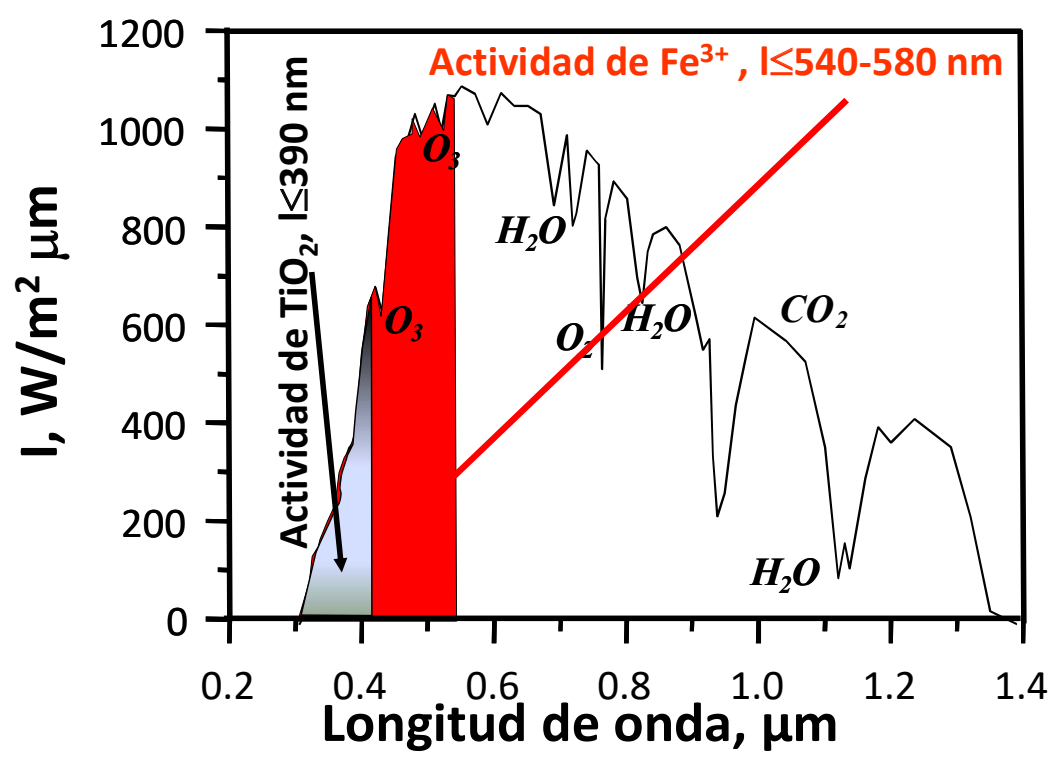

Figura 2.2. Irradiancia solar normal (I) en la superficie de la Tierra (ASTM E891-87, masa de aire $1,5)$, principales componentes atmosféricos que absorben radiación y absorción de luz por especies de $\mathrm{Fe}(\mathrm{III})$ y $\mathrm{TiO}_{2}$

a) solo podían utilizar radiación directa, b) eran caros, c) tenían poca eficiencia óptica (debido al seguimiento solar y la reflexión de la luz) y d) su eficiencia cuántica era baja (debido a la concentración de la radiación solar). La principal conclusión fue que este tipo de captadores no eran adecuados para fotocatálisis. En esa misma época se utilizaron también captadores sin concentración ya que, en principio, eran más sencillos que los captadores cilindroparabólicos, sin seguimiento solar y sin reflexión y concentración de la radiación solar. Hubo un esfuerzo intensivo de diseño y construcción de este tipo de captadores (Bahnemann, 2004). Sin embargo, el diseño de un captador robusto y fiable de este tipo no es trivial, ya que debe resistir bien las condiciones de intemperie, ser químicamente inerte y trasmitir bien la radiación uv. Además, este tipo de captador precisa un fotorreactor mucho mayor que los fotorreactores instalados en captadores con concentración y, como consecuencia, en instalaciones industriales de cientos o miles de metros cuadrados el agua debe circular sometida a presiones elevadas para atravesar fotorreactores de 


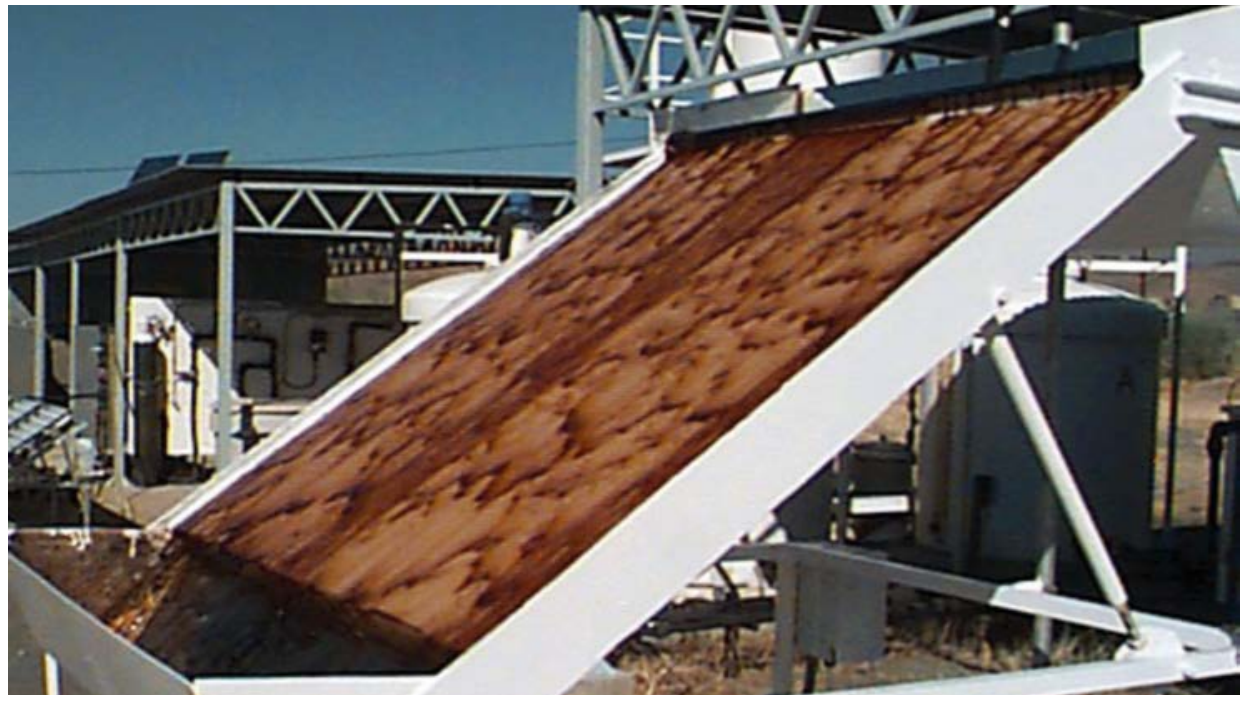

Figura 2.3. Fotorreactor sin concentración desarrollado durante los años noventa para aplicaciones de foto-Fenton

dimensiones similares a los captadores solares. Por otro lado, en fotorreactores sin concentración donde el agua esté directamente expuesta a la radiación solar, tanto reactivos como catalizador pueden ser contaminados o dañados con facilidad (figura 2.3). Como consecuencia, el uso de estos fotorreactores se abandonó en esa misma época.

Un captador solar para aplicaciones fotocatalíticas debe cumplir las siguientes características básicas: 1) captar adecuadamente la radiación uv y visible, 2) mantener el agua a una temperatura lo más cercana posible a la ambiente para evitar vaporización de contaminantes, 3) tener en cuenta que la eficiencia cuántica disminuye con la intensidad de radiación, 4) tener en cuenta que el absorbedor recibe 1/RC de la radiación difusa (el factor de concentración, $\mathrm{RC}$, es la relación entre el área del absorbedor y el área del captador). Por tanto, en aplicaciones fotocatalíticas, debe cumplirse que $\mathrm{RC}=1$. Finalmente, deben ser sencillos y económicos y trabajar con poca pérdida de carga. De esta forma, el uso de absorbedores (fotorreactores) tubulares tiene claras ventajas $y$, además, se dispone de ellos en diferentes tamaños y materiales, siendo la elección más obvia en sistemas que trabajan bajo condiciones de presión. 
Un tipo de captador de baja concentración son los denominados captadores parabólicos compuestos ( $\mathrm{CPC}$ ), que también se utilizan en aplicaciones térmicas de baja y media temperatura. Son una opción muy interesante para aplicaciones fotocatalíticas en agua ya que cuentan con las ventajas de los captadores planos y de los cilindroparabólicos, pero sin sus inconvenientes. Los CPC son captadores estáticos que se pueden diseñar con un factor de concentración $\mathrm{RC}=1$ para un fotorreactor cilíndrico de diferentes diámetros (Ajona y Vidal, 2000); pueden, por tanto, captar eficientemente tanto la radiación directa como la difusa sin necesidad de seguimiento solar y no hay evaporación de contaminantes ya que el agua no se calienta. Su eficiencia óptica es elevada al tener un absorbedor que tiene un área superficial muy similar al área del captador y esto, además, permite que no haya una alta concentración fotónica, con lo que el rendimiento cuántico es alto. Evidentemente, al ser un fotorreactor tubular, permite un flujo turbulento $y$, por tanto, una buena trasferencia de masa. De hecho, son considerados los captadores de vanguardia para aplicaciones fotocatalíticas (Colina-Márquez y otros, 2010). Los CPC están hechos de aluminio pulido montados sobre una estructura que permite la conexión de los absorbedores tubulares (figura 2.4).

Uno de los parámetros más importantes es el diámetro del fotorreactor, ya que debe garantizarse que todos los fotones que alcanzan el seno de la reacción no atraviesen el fotorreactor sin activar el catalizador. La dispersión y absorción de la luz hace que la densidad fotónica disminuya conforme atraviesa el fotorreactor que contiene el catalizador. Además, a mayor intensidad de

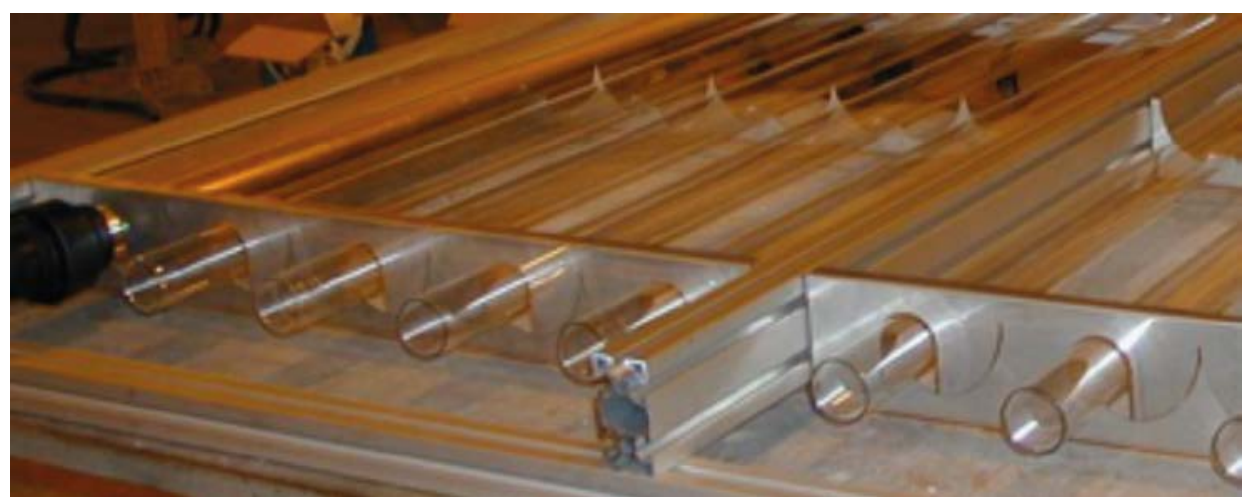

Figura 2.4. Vista de CPC con los absorbedores (fotorreactores) montados sobre la estructura 
radiación, la concentración de catalizador puede ser mayor. El modelado de la radiación absorbida ha sido fruto de multitud de estudios (Cassano y Alfano, 2000; Colina y otros, 2010).

Los diámetros más habituales y, de hecho, más prácticos están entre 25 y $50 \mathrm{~mm}$. Diámetros mucho menores o mucho mayores generarían perdidas de carga muy grandes y precisarían elevadas concentraciones de catalizador o impedirían una correcta iluminación del interior del fotorreactor, respectivamente. Después de un largo recorrido en experimentación, evaluación y modelado, puede concluirse que la concentración óptima de $\mathrm{TiO}_{2}$ es de unos pocos cientos de $\mathrm{mg} / \mathrm{L} \mathrm{y}$, en el caso de foto-Fenton, la concentración óptima es de $0,2-0,5 \mathrm{mmol} / \mathrm{L}$ (Spasiano y otros, 2015).

\subsubsection{Plantas para tratamiento fotocatalítico solar}

Las primeras plantas se desarrollaron en los años noventa reconvirtiendo captadores solares cilindro-parabólicos para aplicaciones térmicas en fotorreactores. Desde entonces se han propuesto multitud de conceptos diferentes incluyendo captadores sin concentración y CPC (Malato y otros, 2009). El diseño debe incluir decisiones como la selección del reactor, el tipo de catalizador y su concentración, la configuración del campo de captadores (serie o paralelo), el tipo de operación (en continuo o por cargas), la dosificación de reactivos, el pH, etc. Habitualmente, una planta contiene varios módulos con varios captadores cada uno de ellos, con válvulas que permitan usarlos todos o

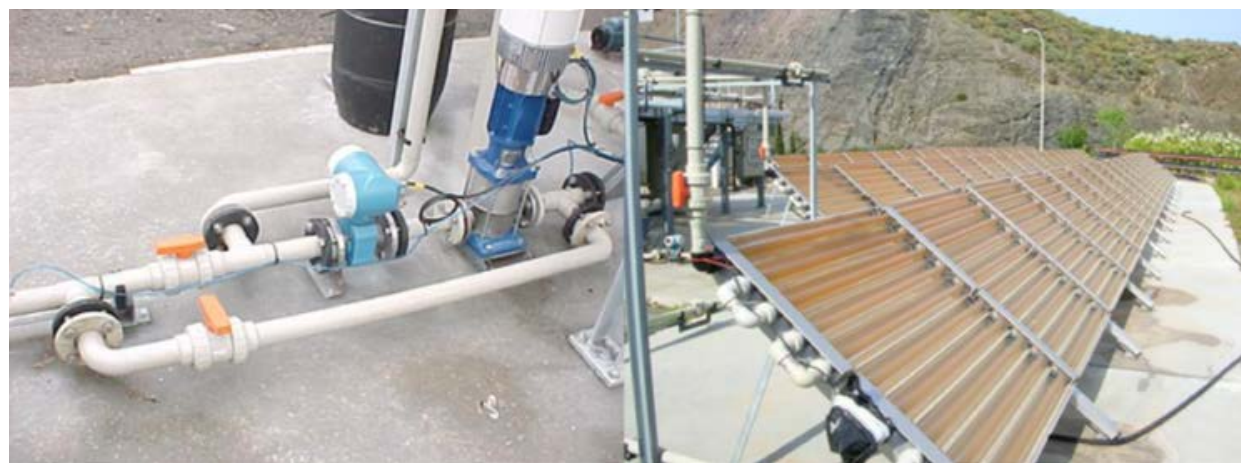

Figura 2.5. Planta de tratamiento para aplicaciones fotocataliticas basadas en foto-Fenton 
parte de ellos, bombas para circular el agua, sensores de presión, oxígeno, pH, sensores para medir radiación, lazos de control que permitan alimentar agua a tratar y descargar la tratada, etc. Estas plantas se suelen operar con tanques de recirculación que permitan recircular el agua hasta alcanzar el nivel de tratamiento deseado.

El proyecto de la UE SOLARDETOX (Solar Detoxification Technology for the Treatment of Industrial Non-Biodegradable Persistent Chlorinated Water Contaminants), coordinado por la Plataforma Solar de Almería, fue el primer paso en la comercialización de estas plantas, basándose en CPC. Se construyó una planta de demostración (Blanco y otros, 2000), que permitía tratar hasta un metro cúbico de agua contaminada con disolventes clorados. Consistía en dos módulos de 21 captadores cada uno y una superficie de $98 \mathrm{~m}^{2}$ para trabajar con $\mathrm{TiO}_{2}$ con CPC de 29,2 mm de diámetro interno. La operación era completamente automática basada en la medición e integración de UVA, que permitía decidir el final del tratamiento y vaciar y rellenar del nuevo el sistema con otra carga de agua contaminada. Otras plantas se han instalado desde entonces tanto basadas en $\mathrm{TiO}_{2}$ como foto-Fenton (Malato y otros, 2009; Chong y otros, 2010).

\subsection{Tratamiento de aguas residuales industriales}

Los tratamientos biológicos convencionales no producen a menudo resultados satisfactorios, especialmente con aguas residuales industriales, ya que muchas de las sustancias orgánicas producidas por la industria química son tóxicas o resistentes al tratamiento biológico. En este caso, el uso de POA está reconocido como un tratamiento adecuado para este tipo de aguas, pero, en cambio, son soluciones costosas para la mineralización completa del contaminante. Una alternativa viable y económicamente atractiva es utilizar los POA para convertir los contaminantes biorrecalcitrantes en compuestos más biodegradables que puedan tratarse posteriormente mediante oxidación biológica (Oller y otros, 2011). La mineralización debe ser mínima durante este tratamiento para minimizar el gasto en energía y reactivos, aunque suficiente para que los intermedios generados puedan ser biodegradables. Es importante conocer la eficiencia del tratamiento químico y biológico y, para ello, deben utilizarse diferentes técnicas analíticas y microbiológicas. Los paráme- 
tros químicos que se deben determinar incluyen el carbono orgánico total y la demanda química de oxígeno, pero también los contaminantes originales (mediante técnicas cromatográficas como HPLC-UV O MS) y la mineralización de los heteroátomos contenidos en los contaminantes como $\mathrm{Cl}, \mathrm{NO}_{3}{ }^{-}, \mathrm{PO}_{4}{ }^{3-}$. Es importante también determinar la toxicidad (mediante Vibrio fischeri, Daphnia magna o fangos activados) y la biodegradabilidad (mediante técnicas respirométricas como Zahn-Wellens). Una buena evaluación de estos parámetros puede permitir el diseño de una estrategia de acople entre tratamiento químico y biológico.

\subsubsection{Determinación de toxicidad y biodegradabilidad}

Hay diferentes procedimientos pare evaluar la biotoxicidad, pero ninguno de ellos tiene una respuesta de aplicabilidad universal y, por tanto, para aumentar la fiabilidad se deben utilizar organismos de diferentes grupos taxonómicos y adaptados a las condiciones locales donde se pretenda aplicar el tratamiento (Rizzo, 2011). En algunos casos se ha demostrado que la toxicidad aumenta durante los primeros momentos del tratamiento $y$, por tanto, es importante mantener el tratamiento de oxidación el tiempo que sea necesario para evitar esto. Por otro lado, se ha demostrado fehacientemente que la demanda de oxígeno medida mediante procesos respirométricos es un excelente parámetro que muestra la actividad y la viabilidad de los microorganismos presentes en un fango activado. Además, permite evaluar la toxicidad aguda que diferentes aguas industriales puedan provocar en los fangos activados de plantas de tratamiento municipales ante un vertido de este tipo en el sistema de saneamiento (Vilar y otros, 2009).

En general, las técnicas de toxicidad no exigen una fuerte inversión en equipamiento o entrenamiento exhaustivo del operador, pero sí tienen un fuerte impacto en mano de obra. Un ejemplo se puede ver en la figura 2.6, con muestras tomadas durante un tratamiento de foto-Fenton.

Aunque la evolución del consumo de oxígeno es un buen parámetro para estimar la toxicidad aguda, no lo es para estimar el efecto a medio y largo plazo. Por tanto, un método más prolongado basado en el consumo acumulado de oxígeno como la demanda bioquímica de oxígeno a cinco días $\left(\mathrm{BOD}_{5}\right)$ se hace 


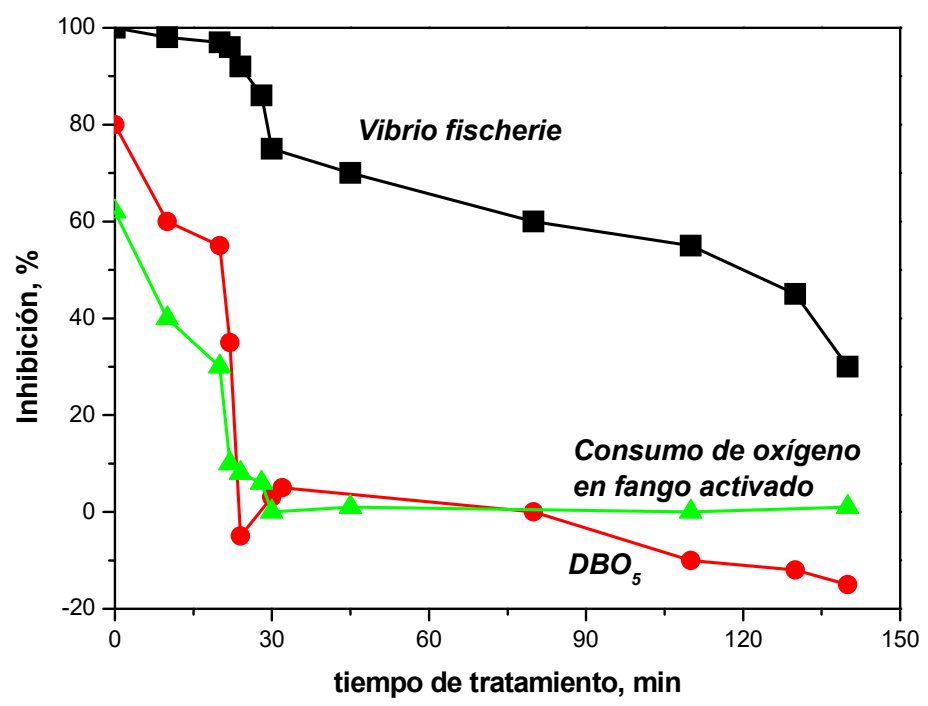

Figura 2.6. Evolución de la toxicidad durante un tratamiento de foto-Fenton mediante tres metodologías diferentes en función del tiempo de iluminación en el POA

necesario. La figura 2.6 muestra la evolución positiva de ambos parámetros durante el tratamiento, complementada por una técnica de toxicidad muy sensible como la inhibición de la luminiscencia de $V$. fischeri que, además, no disminuye hasta valores muy bajos al final del tratamiento. Es importante remarcar que los microorganismos puros suelen mostrar mayor toxicidad que un consorcio como un fango activado, obtenido de una planta de tratamiento y que suele haberse adaptado a efluentes de diferentes tipos. A la vista de los resultados, se puede concluir que la completa descontaminación del efluente no se ha alcanzado durante el foto-Fenton, pero sí se ha conseguido que sea compatible con una planta de tratamiento municipal.

Cuando se considera combinar la oxidación química y la biológica para tratar contaminantes recalcitrantes, la evaluación de la biodegradabilidad se debe realizar durante todo el proceso. En este sentido, la biodegradabilidad y su evolución puede medirse mediante diferentes técnicas (Sarria y otros, 2003):

- Parámetros generales como DBOX, demanda química de oxígeno (DQO) y carbono orgánico total (сОт). 
- Evolución de la relación DBO/DQO o bien del estado medio de oxidación. La evolución de estos datos proporciona un índice aproximado de la proporción de sustancias orgánicas presentes en el agua que son biodegradables en condiciones aeróbicas (Sarria y otros, 2002).

- Evolución de la biodegradabilidad a largo plazo mediante fangos activados como el método de Zahn-Wellens, que permite evaluar contamínantes solubles y no volátiles. Es un método que exige ensayos de 28 días a temperatura estable $\left(20-25^{\circ} \mathrm{C}\right)$ y bajo radiación difusa (United States Environmental Protection Agency, 1996).

- Evolución del oxígeno en medidas respirométricas, que suelen precisar un contacto de unos 20 minutos entre el fango activado y el agua evaluada. Se pueden discernir diferentes fracciones de la demanda química de oxígeno como la parte biodegradable, la no biodegradable, la insoluble, etc. (Lagarde y otros, 2005).

\subsubsection{Tratamiento de aguas industriales combinando poA y biotratamiento}

Las aguas residuales industriales son muy diversas, incluso dentro de la misma instalación industrial. Mucho más diversas que las aguas residuales municipales, que tienen bastantes similitudes entre ellas, tanto cualitativa como cuantitativamente. Scott y Ollis (1995) identificaron cuatro tipos de aguas residuales que pudieran ser tratables mediante combinaciones entre POA $y$ biotratamiento: aguas conteniendo compuestos biorrecalcitrantes como macromoléculas que incluyen polímeros solubles que no son biodegradables porque no tienen centros activos; aguas residuales biodegradables pero que contienen una pequeña cantidad de compuestos biorrecalcitrantes; aguas que contienen compuestos inhibidores del desarrollo biológico o bien directamente tóxicos, y aguas conteniendo compuestos resistentes al tratamiento pero básicamente inertes que pueden acumularse en el medio e inhibir el desarrollo de microorganismos a medio y largo plazo.

Compuestos inhibidores de los cultivos de microorganismos son los plaguicidas, que siendo solubles en agua pueden dañar seriamente el agua superficial y subterránea, propagándose con facilidad en el medio ambiente. Una fuente importante de esta contaminación no procede de actividades 
agrícolas directamente, sino de descargas accidentales o bien del lavado de equipos de aplicación (Brown y van Beinum, 2009). La contaminación desde estas fuentes puede ser tan alta como $500 \mathrm{mg} / \mathrm{L}$. Habitualmente responden bien a un pretratamiento que mejora sustancialmente su biodegradabilidad (Zapata y otros, 2010). Las aguas residuales conteniendo compuestos farmacéuticos también son una fuente particularmente importante de preocupación ya que son especialmente resistentes al tratamiento bilógico y pueden generar serios problemas de toxicidad y otros efectos sobre la salud humana y otros seres vivos. Un tratamiento mediante foto-Fenton solar se mostró efectivo para un efluente de industria farmacéutica con un contenido orgánico elevado (COT $=775 \mathrm{mg} / \mathrm{L}$ ) pero biodegradable y conteniendo $45 \mathrm{mg} / \mathrm{L}$ de ácido nalidíxico completamente biorrecalcitrante. Se demostró que, en este caso, era más eficiente un tratamiento biológico previo a la eliminación del ácido nalidíxico mediante foto-Fenton (Sirtori y otros, 2009).

La industria textil es un fuerte consumidor de agua $\left(80-100 \mathrm{~m}^{3} /\right.$ tonelada de producto terminado) que, además, incluye la adición de colorantes y sales. Esto supone la presencia de sólidos en suspensión, DQo muy estable y fuerte coloración (Chandrakant y otros, 2016). La eliminación del color es el primer objetivo, pero el problema ambiental es más general, ya que esto no supone la eliminación de DQO (115-175 kg de COD / tonelada de producto terminado) (Savin y otros, 2008). Un agua residual textil suele tener DQo de 150 a $12000 \mathrm{mg} / \mathrm{L}$, nitrógeno de 70 a $80 \mathrm{mg} / \mathrm{L}$ y Dво de 80 a $6000 \mathrm{mg} / \mathrm{L}$. LOS POA Se han aplicado con éxito a este tipo de aguas, incluyendo la fotocatálisis solar (Singh y Arora, 2011). Otro tipo de aguas en las que se han aplicado POA Son: aguas de papelera, de almazara, lixiviados de vertedero, aguas de industria vitivinícola y alcoholera, etc.

\subsection{Tratamiento de efluentes secundarios de EDAR}

Como se comentó en la introducción, existe una preocupación creciente respecto a los Ec. Aunque su concentración está habitualmente en el orden de $\mu \mathrm{g} / \mathrm{l}$ o menor, son un problema serio hoy en día en todas las fuentes de agua (Kümmerer, 2009; Pal y otros, 2010). Se desea a menudo reutilizar agua tratada procedente de EDAR, aunque el tema de los EC no está resuelto. Es por 
tanto fundamental eliminar estos contaminantes antes de verterlos al medio ambiente, y más todavía si el agua se va a reutilizar. Los POA pueden intervenir de manera relevante en resolver este problema y, particularmente, el proceso de foto-Fenton con el que ya hay bastante experiencia en esto (Klamerth y otros, 2010; Miralles-Cuevas y otros, 2015). Sin embargo, para esta aplicación no es consistente operar el proceso a su pH óptimo (alrededor de 2,8 ) ni a concentraciones de hierro elevadas, ya que estamos hablando de caudales enormes de agua con concentraciones de contaminantes pequeñas.

Tabla 2.1. Ejemplo de concentración inicial de micro-contaminantes en el efluente de una EDAR

\begin{tabular}{|c|c|c|c|c|c|}
\hline N. ${ }^{\circ}$ & Micro-contaminante & $C_{0}(n g / L)$ & N. ${ }^{\circ}$ & Micro-contaminante & $C_{0}(\mathrm{ng} / \mathrm{L})$ \\
\hline 1 & Cafeína & 20200 & 20 & Trimetoprima & 210 \\
\hline 2 & 4-AAA & 4300 & 21 & Metronidazol & 40 \\
\hline 3 & Carbamacepina & 6600 & 22 & 4-AA & 180 \\
\hline 4 & 4-FAA & 2300 & 23 & Sotalol & 30 \\
\hline 5 & Naproxeno & 4500 & 24 & Famotidina & 30 \\
\hline 6 & Antipirina & 1300 & 25 & Propranolol & 30 \\
\hline 7 & Norfloxacino & 2300 & 26 & Citalopram & 60 \\
\hline 8 & Sulfametoxazol & 870 & 27 & Primidona & 40 \\
\hline 9 & Ofloxacino & 860 & 28 & Clorfenvinfos & 30 \\
\hline 10 & Atenolol & 560 & 29 & Indometacina & 40 \\
\hline 11 & Ciprofloxacino & 450 & 30 & Metoprolol & 20 \\
\hline 12 & Eritromicina & 380 & 31 & Lincomicina & 30 \\
\hline 13 & Acitromicina & 270 & 32 & Terbutalina & 10 \\
\hline 14 & Ranitidina & 260 & 33 & Sulfatiazol & 10 \\
\hline 15 & Keteprofeno & 160 & 34 & Mepivacaína & 10 \\
\hline 16 & Sulfapiridina & 260 & 35 & Salbutamol & 10 \\
\hline 17 & Ácido Fenofibrico & 270 & & & \\
\hline 18 & Venlafaxina & 160 & & & \\
\hline 19 & Nadolol & 100 & & & \\
\hline \multicolumn{6}{|c|}{ Suma total $=46880 \mathrm{ng} / \mathrm{L}$} \\
\hline
\end{tabular}


Los resultados de la tabla 2.1 muestran un análisis cuantitativo y cualitativo de microcontaminantes en efluente de una EDAR. En general, la concentración total de estos compuestos en estos efluentes alcanza valores que van desde unas decenas de $\mu \mathrm{g} / \mathrm{L}$ a varios centenares, siendo la composición una mezcla de productos farmacéuticos, productos de higiene personal, hormonas, plaguicidas, tensioactivos... muchos de ellos considerados EC y otros ya considerados como contaminantes prioritarios o preocupantes desde hace tiempo.

En aguas naturales la concentración de hierro disuelto es baja y la mayor parte del hierro se encuentra complejado con ligandos orgánicos, tales como ácidos policarboxílicos. Los policarboxilatos tales como citrato, maleato y oxalato son los constituyentes más comunes de las aguas naturales y se llegan a encontrar en aguas superficiales, en precipitaciones, niebla e incluso en suelos. Estos pueden formar complejos con Fe(III) e incrementar la disolución del hierro en las aguas, además de llevar a cabo reacciones fotoquímicas muy rápidas bajo radiación solar que conducen a la generación de especies oxidantes. Por ello, el estudio de la fotoquímica de los complejos de Fe(III) está tomando en los últimos años un papel muy importante para poder llevar a cabo el proceso foto-Fenton solar en condiciones de pH cercano a la neutralidad (De Luca y otros, 2014; Wu y otros, 2014). Los ácidos aminopolicarboxílicos presentan un comportamiento similar a los ácidos policarboxílicos. Entre ellos, el ácido etilendiaminotetraacético (EDTA) ha sido el agente quelante más ampliamente utilizado para estos procesos, si bien presenta la desventaja de que se trata de un contaminante no biodegradable y además se encuentra en la lista de contaminantes prioritarios.

En general, los complejantes de hierro para estas aplicaciones deben: a) formar especies fotoactivas con el hierro, b) no ser contaminantes y c) ser biodegradables. El grupo de investigación del profesor Gilles Mailhot CNRS (Centre National de la Recherche Scientifique, París, Francia) empezó a trabajar con el ácido (S,S)-Etilendiamino-N,N'-disuccinico (EDDS), ya que este es un isómero estructural del EDTA, y demostró que el complejo es estable en solución acuosa bajo condiciones de $\mathrm{pH}$ neutro y fotoquímicamente eficiente. Existen tres estereoisómeros del EDDS, entre los cuales el más fácilmente biodegradable es [S, S']- EDDS (Huang y otros, 2012). En estudios realizados por nuestro grupo de 
investigación se obtuvieron resultados prometedores con el EDDS alcanzando tasas de degradación mayores del $80 \%$ en tiempos de iluminación menores 10 minutos (Klamerth y otros, 2012) debido posiblemente a que la fotólisis del complejo promueve la generación de radicales hidroxilo (reacciones 2.11 y 2.12).

\begin{tabular}{|c|c|}
\hline$\left[\mathrm{Fe}^{\prime \prime \prime}(E D D S)\right]^{-} \stackrel{h v}{\rightarrow} \mathrm{Fe}^{\prime \prime}+E D D S$ & $(2.11)$ \\
\hline$E D D S^{3-}+\mathrm{HO}^{-} \rightarrow E D D S^{4-}+\mathrm{HO}$ & \\
\hline
\end{tabular}

La figura 2.7 muestra que la utilización del EDDS como complejante del hierro (Fe(III): EDDS, 1:2) para el tratamiento foto-Fenton a pH cercano a la neutralidad permite el tratamiento de los microcontaminantes en unos pocos minutos con un consumo de peróxido de hidrógeno de alrededor de $50 \mathrm{mg} / \mathrm{L}$.

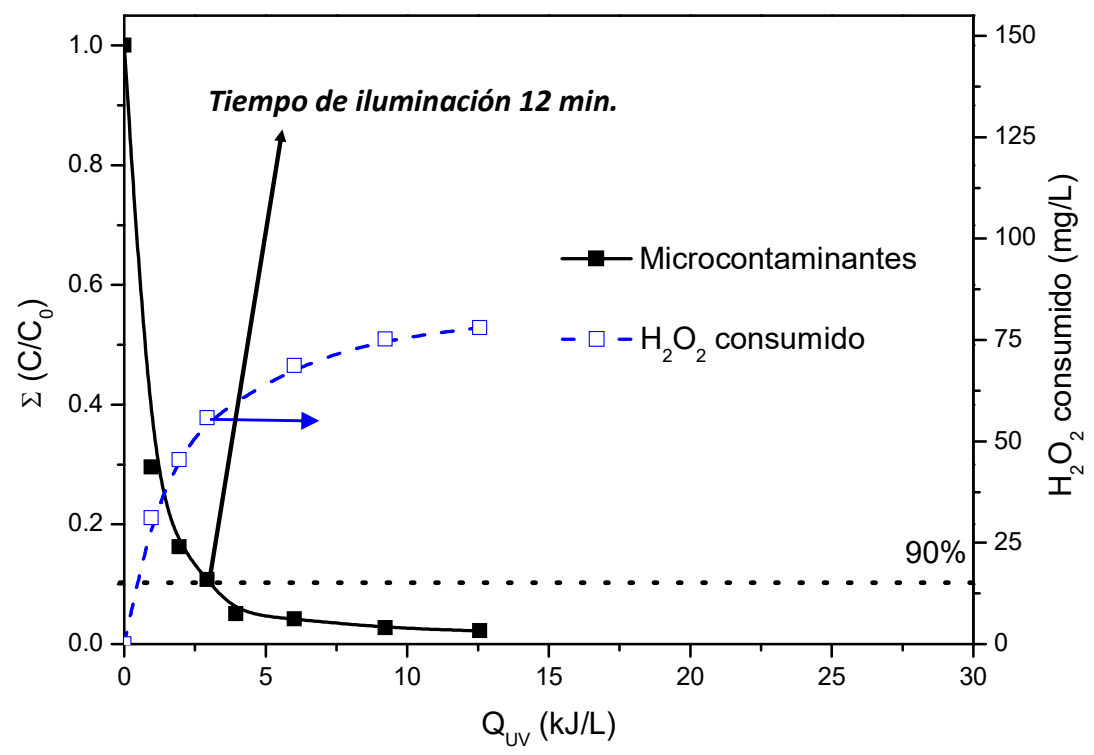

Figura 2.7. Tratamiento de efluente de EDAR en fotorreactores CPC mediante foto-Fenton a pH cercano a la neutralidad con Fe 0,1 mM y EDDS $(0,2 \mathrm{mM})$. Degradación de la suma de todos los contaminantes en función de la irradiancia solar 


\section{Agradecimientos}

El autor quiere agradecer al Ministerio de Economía y Competitividad de España la financiación de este trabajo a través del proyecto tRICERATOPS (referencia CTQ2015-69832-C4-1-R).

\section{Referencias}

AJonA, J.A. y VIDAL, A. (2000). «The use of CPC collectors for detoxification of contaminated water design, construction and preliminary results». Solar Energy, 68, pp. 109-120.

Alfano, O.M., Bahnemann, D., Cassano, A.E., Dillert, D. y Goslich, R. (2000). «Photocatalysis in water environments using artificial and solar light». Catalysis Today, 58, pp. 199-230.

BAHNemAnN, D. (2004). «Photocatalytic water treatment: Solar energy Applications». Solar Energy, 77, pp. 445-459.

Blanco, J., Malato, S., Fernández, P., Vidal, A., Morales, A, Trincado, P., de Oliveira, J.C., Minero, C., Musci, M., Casalle, C., Brunotte, M., Tratzky, S., Dischinger, N., Funken, K.H., Sattler, C., Vincent, M., Collares-Pereira, M., Mendes, J.F. y Rangel, C.M. (2000). «Compound parabolic concentrator technology development to commercial solar detoxification Applications». Solar Energy, 67, pp. 317330.

Blanco-Gálvez, J. y Malato-Rodriguez, S. (2003). Solar Detoxification. Unesco Publishing, France.

Bousselmi, L., GeisSen, S.U. y SCHROeder, H. (2004). «Textile wastewater tratment and reuse by solar photocatalysis results from a pilot plant in Tunisia». Water Science and Technology, 49, pp. 331-337.

BRASLAVSKY, S.E. (2007). «Glossary of terms used in photochemistry». Pure and Applied Chemistry, 79, pp. 293-465.

BRoWn, C.D. y van BeINum, W. (2009). «Pesticide transport via sub-surface drains in Europe». Environmental Pollution, 157, pp. 3314-3324.

CAssano, A.E. y Alfano, O.E. (2000). «Reaction engineering of suspended solids heterogeneous photocatalytic reactors». Catalysis Today, 58, pp.167-197. 
Colina-Márquez, J., Machuca-Martínez, F.y Li Puma, G. (2010). «Radiation adsorption and optimisation of solar photocatalytic reactors for environmental Applications». Environmental Science and Technology, 44, pp. 5112-5120.

Chandrakant, R., Holkar, C.R., Jadhav, A.J., Pinjarl, D.V., Mahamuni, N.M. y Pandit, A.B. (2016). «A critical review on textile wastewater treatments: Possible approaches». Journal of Environmental Management, 182, pp. 351-366.

Chong, M.N., JIN, B., Chow, C.W.K. y SaINT, C. (2010). «Recent developments in photocatalytic water treatment technology a review». Water Research, 44, pp. 2997-3027.

Daughton, C.G. y TeRnes, T.A. (1999). «Pharmaceuticals and Personal Care Products in the environment Agents of subtle change?». Environmental Health Perspective, 107, pp. 907-938.

De Luca, A., Dantas, R.F. y Esplugas, S. (2014). «Assessment of iron chelates efficiency for photo-Fenton at neutral pH». Water Research, 61, pp. 232-242.

Dillert, R., Cassano, A.E., Goslich, R. y Bahnemann, D. (1999). «Large scale studies in solar catalytic wastewater treatment». Catalysis Today, 54, pp. 267-282.

EsplugAS, S. y OluIS, D.F. (1997). «Economic aspects of integrated (chemical + biological) processes for water treatment». Journal of Advanced Oxidation Technologies, 2, pp. 197-204.

Fenton, H.J.H. (1894). «Oxidation of tartaric acid in presence of iron». Journal of the Chemical Society, 65, pp. 899-910.

Frank, S N. y BARD, A. (1977). «Heterogeneous photocatalytic oxidation of cyanide ion in aqueous solutions at titanium dioxide powder». Journal of the American Chemical Society, 99, pp. 303-304

FuJISHIMA, A. y HonDA, K. (1972). «Electrochemical Photolysis of Water at a Semiconductor Electrode». Nature, 238, pp. 37-38.

FuJISHIMA, A., RAO, T.N. y TRYK, D.A. (2000). «Titanium dioxide photocatalysis». Journal of Photochemistry and Photobiology C: Photochemistry Reviews, 1, pp. 1-21.

Gogate, P.R. y Pandit, A.B. (2004). «A review of imperative technologies for wastewater treatment. I oxidation technologies at ambient conditions». Advances in Environmental Research, 8, pp. 501-551.

GoswamI, D.Y. (1997). «A review of engineering developments of aqueous phase solar photocatalytic detoxification and disinfection processes». Journal of Solar Energy Engineering. Trans. ASME, 119, pp. 101-107. 
HerRmann, J.M. (2010). «Photocatalysis fundamentals revisited to avoid several misconceptions». Applied Catalysis B: Environmental, 99, pp. 461-468.

Hignite, C. y AzARnOfF, D.L. (1977). «Drugs and drug metabolites as environmental contaminants chlorophenoxyisobutyrate and salicylic acid in sewage water efluents». Life Sciences, 20, pp. 337-341.

Huang, W., Brigante, M., Wu, F., Hanna, K. y Mailhot, G. (2012). «Development of a new homogenous photo-Fenton process using Fe(III) -EDDS complexes». Journal of Photochemistry and Photobiology A: Chemistry, 239, pp. 17-23.

Kavitha, V. y Palanivelu, K. (2004). «The role of ferrous ion in Fenton and photoFenton processes for the degradation of phenol». Chemosphere, 55, pp. 1235-1243.

Klamerth N., Malato S., Maldonado M.I., Agüera A. y Fernández-Alba A.R. (2010). «Application of photo-Fenton as a tertiary treatment of emerging contaminants in municipal wastewater». Environmental Science and Technology, 44, pp. 1792-1798.

Klamerth N., Malato S., Agüera A., Fernández-Alba A. y Mallhot G. (2012). «Treatment of Municipal Wastewater Treatment Plant Effluents with Modified PhotoFenton As a Tertiary Treatment for the Degradation of Micro Pollutants and Disinfection». Environmental Science and Technology, 46, pp. 2885-2892. KÜMMERER, K. (2009). «Antibiotics in the aquatic environment - A review - part l». Chemosphere, 75, pp. 435-441.

Lagarde, F., Tusseau-Vuillemin, M.H., Lessard, P., Hèduit, A., Dutrop, F. y Mouchel, J.M. (2005). «Variability estimation of urban wastewater biodegradable fractions by respirometry». Water Research, 39, pp. 4768-4778.

Malato, S., BLAnCo, J., VIDAL, A.y Richter, C. (2002). «Photocatalysis with solar energy at a pilot-plant scale: an overview». Applied Catalysis B: Environmental, 37, pp. 1-15.

Malato, S., Fernández-Ibañez, P., Maldonado, M.I., Blanco, J. y Gernjak, W. (2009). "Decontamination and disinfection of water by solar photocatalysis Recent overview and trends». Catalysis Today, 147, pp. 1-59.

Miralles-Cuevas, S., Oller, I., Agüera, A., Ponce-Robles, L., Sánchez Pérez, J.A. Y MaLATO, S. (2015). "Removal of microcontaminants from MWTP effluents by combination of membrane technologies and solar photo-Fenton at neutral pH». Catalysis Today, 252, pp. 78-83. 
OlleR, I.,Malato,S.y Sánchez-Pérez,J.A.(2011). «Combination of advanced oxidation processes and biological treatments for wastewater decontamination-a review». Science of the Total Environment, 409, pp. 4141-4166.

Pal, A., Yew-Hoong Gin, K., Yu-Chen Lin, A. y Reinhard, M. (2010). «Impacts of emerging organic contaminants on freshwater resources. Review of recent occurrences, sources, fate and effects». Science of the Total Environment, 408, pp. 6062-6069.

Petrovic, M. y Barceló, D. (2006). «Liquid chromatography-mass spectrometry in the analysis of emerging contaminants». Analytical and Bioanalytical Chemistry, 385, pp. 422-424.

Pignatello, J., Oliveros, E. y McKay, A. (2006). «Advanced oxidation processes for organic contaminant destruction based on the Fenton reaction and related chemistry». Critical Reviews in Environmental Science and Technology, 36, pp. 1-84.

Rizzo, L. (2011). «Bioassays as a tool for evaluating advanced oxidation processes in water and wastewater treatment». Water Research, 45, pp. 4311-4340.

Robles-Molina, J., Gilbert-López, B., García-Reyes, J.F. y Molina-Díaz, A. (2010). "Determination of organic pollutants in sewage treatment plant effluents by gas chromatography high-resolution mass spectrometry». Talanta, 82 , pp. 1318-1324.

Sarria, V., Parra, S., Adler, N., Péringer, P.y Pulgarín, C. (2002). «Recent developments in the coupling of photoassisted and aerobic biological processes for the treatment of biorecalcitrant compounds». Catalysis Today, 76, pp. 301-315. SarRia, V., Kenfack, S., Guillod, O. y Pulgarin, C. (2003). «An innovative coupled solarbiological system at field pilot scale for the treatment of biorecalcitrant pollutants». Journal of Photochemistry and Photobiology A: Chemistry, 159, pp. 89-99.

Savin, I.I. y Butnaru, R. (2008). «Wastewater characteristics in textile finishing mills». Environmental Engineering and Management Journal, 7, pp. 859-864. ScotT, J.P. y OLLIS, D.F. (1995). «Integration of chemical and biological oxidation processes for water treatment review and recommendations». Environmental Progress and Sustainable Energy, 14, pp. 88-103.

SINGH, K. y ARORA, S. (2011). «Removal of synthetic textile dyes from wastewaters A critical review on present treatment tecnologies». Critical Reviews in Environmental Science and Technology, 41, pp. 807-878. 
Sirtori, C., Zapata, A., Oller, I., Gernjak, W., Agüera, A. y Malato, S. (2009). «Solar photo-Fenton as finishing step for biological treatment of a pharmaceutical wastewater». Environmental Science and Technology, 43, pp. 1185-1191.

SkocaJ, M., Filipic, M., PetKovic, J. y Novak, S. (2011). «Titanium dioxide in our everyday life; is it safe?». Radiology and Oncology, 45, pp. 227-247.

Sluczewskl, A. y Roth, P. (1948). "Effects of androgenic and estrogenic metamorphoses of amphibians». Obstetrics and Gynaecology, 47, pp. 164176.

Spasiano, D., Marotta, R., Malato, S., Fernandez-lbañez, P. y Di Somma, I. (2015). «Solar photocatalysis Materials, reactors, some commercial, and preindustrialized applications. A comprehensive approach». Applied Catalysis B: Environmental, 170, pp. 90-123.

Suty, H., De Traversay, C. y Cost, M. (2004). «Applications of advanced oxidation processes present and future». Water Science and Technology, 49, pp. 227233.

United States Environmental Protection Agency (1996). Fate, transport and transformation test guidelines OPPTS 835.3200 Zahn-Wellens/EMPA Test. EPA 712-C-96- 084. Prevention, pesticides and toxic substances (7101).

Vilar, V.J.P., Maldonado, M.I., Oller, I., Malato, S. y Boaventura, R.A.R. (2009). Solar treatment of cork boiling and bleaching wastewaters in a pilot plant. Water Research, 43, pp. 4050-4062.

Wu, Y., Passananti, M., Brigante, M., Dong, W. y Mailhot, G. (2014). «Fe(III)-EDDS complex in Fenton and photo-Fenton processes from the radical formation to the degradation of a target compound». Environmental Science and Pollution Research, 21, pp. 12154-12162.

Zapata, A., Oller, I., Sirtori, C., Rodriguez, A., Sánchez-Pérez, J.A., López, A., Mezcua, M. y MALATO, S. (2010). «Decontamination of industrial wastewater containing pesticides by combining large-scale homogeneous solar photocatalysis and biological treatment». Chemical Engineering Journal, 160, pp. 447-456.

ZHANG, W., Zou, L. y WANG, L. (2009). «Photocatalytic TiO2/adsorbent nanocomposites prepared via wet chemical impregnation for wastewater treatment A review». Applied Catalysis A: General, 371, pp. 1-9. 


\title{
Proceso foto-Fenton: estrategias de aplicación en condiciones próximas a la neutralidad
}

\author{
A. M. Amat, A. Arques, R. Vicente, R. F.Vercher, A. Doménech, L. Santos- \\ Juanes, M. Mora, S. García-Ballesteros \\ Grupo de Procesos de Oxidación Avanzada \\ Universitat Politècnica de València \\ Plaza Ferrandiz y Carbonell 1, 03801 Alcoy, España
}

Contacto: aamat@txp.upv.es

\section{Ana M. a Amat Payá}

Doctora en Farmacia desde 1988. Adscrita a la Universitat Politècnica de València (UPV) desde noviembre de 1989, donde ocupa una plaza de catedrática de Universidad desde el 2010. Tiene concedidos cuatro tramos de méritos docentes y tres tramos de actividad investigadora. Es responsable de la creación y coordinación del grupo de investigación de Procesos de Oxidación Avanzada (AOP) de la uPV desde 1998 hasta la actualidad. Ha liderado sobre 40 proyectos de investigación financiados en convocatorias competitivas. En los últimos años, ha participado en un proyecto de la Unión Europea y en un proyecto Horizonte 2020. Fruto de esa investigación son 60 artículos de investigación en revistas citadas en el JCR, algunas de especial relevancia y la mayoría situadas en el primer cuartil de su área, algún artículo de revisión en revistas como Chemical Reviews, varias publicaciones en revistas técnicas de divulgación, 27 capítulos de libro en editoriales internacionales o nacionales competitivas de relevancia (Springer) y más de 150 comunicaciones en congresos especializados del área. Los intereses y objetivos científico-técnicos actuales de su investigación se centran en la aplicación de procesos de oxidación avanzada, para la eliminación de contaminantes presentes en aguas. Ha dirigido 8 tesis doctorales, 12 trabajos de investigación de doctorado para la obtención del DEA o trabajos Fin de 
Master y más de 45 proyectos Fin de Carrera y TFG. Desde el 2004 hasta el 2012 desempeña el cargo de subdirectora de Investigación del Campus de Alcoy de la upv y desde julio del 2012 hasta la actualidad, el de directora de Departamento de la upv.

\section{Resumen}

En este capítulo se quiere presentar el problema que supone el necesario pH ácido $(2,8)$ para aplicar el proceso foto-Fenton en condiciones óptimas para la degradación de contaminantes presentes en aguas y las estrategias desarrolladas para solucionar este problema. Todas ellas buscan alternativas para mantener en disolución cantidades de hierro suficientes, por formación de complejos fotoactivos, que permitan que el proceso tenga lugar de forma efectiva. Entre estas estrategias destaca la aplicación de extractos orgánicos solubles (SBO) procedentes de diferentes residuos agrícolas o de lodos de EDAR, lo que supone una doble ventaja al permitir una revalorización de estos residuos.

\subsection{Introducción}

Los procesos de oxidación fotoquímicos para el tratamiento de aguas residuales se han convertido en una alternativa prometedora para efluentes que no pueden ser tratados por medios convencionales, como los que contienen compuestos tóxicos o no biodegradables (Oller y otros, 2011). Estos procesos se basan en la generación in situ de especies altamente reactivas, como oxígeno singlete o radical hidroxilo. Para ello, se requiere irradiación en el rango uv-vis y, en algunos casos, también la presencia de un fotocatalizador (Legrini y otros, 1994).

El uso de la luz solar como fuente de irradiación es especialmente atractivo por las ventajas económicas y ecológicas que supone (Malato y otros, 2002 y 2009). Sin embargo, solo la radiación con longitudes de onda superiores a $300 \mathrm{~nm}$ alcanza la superficie terrestre, lo que supone que únicamente los fotocatalizadores que absorban en el rango uvA-visible del espectro serán 
eficientes. Entre los sistemas que cumplen estas condiciones están algunos sólidos semiconductores (en particular, el dióxido de titanio) (Gaya y Abdullah, 2008), moléculas orgánicas fotoactivas (Marín y otros, 2012) y procesos basados en el reactivo de Fenton (Pignatelo y otros, 2006).

El proceso foto-Fenton ha mostrado ser una de las técnicas más eficientes que se pueden realizar bajo luz uva-visible. Se puede resumir como una combinación de sales de hierro y peróxido de hidrógeno: los cationes hierro catalizan la descomposición del peróxido en especies más reactivas, principalmente el radical hidroxilo $(\cdot \mathrm{OH})$; el proceso se acelera por la irradiación, que lo convierte en fotocatalítico. Aunque el mecanismo es muy complejo, todavía no está completamente dilucidado y puede depender de las condiciones experimentales; se puede simplificar en dos reacciones principales (ecuaciones 3.1- 3.2):

\begin{tabular}{|c|c|}
\hline $\mathrm{Fe}^{2+}+\mathrm{H}_{2} \mathrm{O}_{2} \rightarrow \mathrm{Fe}^{3+}+\mathrm{OH}+\cdot \mathrm{OH}$ & (3.1) \\
\hline $\mathrm{Fe}(\mathrm{OH})^{2+}+\mathrm{hv} \rightarrow \mathrm{Fe}^{2+}+\cdot \mathrm{OH}$ & (3.2) \\
\hline
\end{tabular}

La mejora de rendimiento del proceso foto-Fenton en comparación con Fenton en oscuridad se debe principalmente a la ecuación 3.2.; Fe $(\mathrm{OH})^{2+}$ se descompone, provocando la fotorreducción de hierro (III) a hierro (II) y la generación de cantidades adicionales de $\cdot \mathrm{OH}$. El papel clave del Fe $(\mathrm{OH})^{2+}$ también explica el pH ácido requerido para foto-Fenton (óptimo a 2,8), ya que, bajo estas condiciones, se favorece la formación del complejo de hierro fotoactivo. Por otro lado, a valores de pH más altos, el hierro se puede encontrar predominantemente como óxido o hidróxido, que no son activos para el proceso foto-Fenton.

\subsection{Estrategias para aplicar el proceso foto-Fenton en condiciones próximas a la neutralidad}

El pH muy ácido requerido por el proceso foto-Fenton es una de sus principales desventajas, ya que en la mayoría de los efluentes se requiere la adición de ácido, seguido de una neutralización antes de que el agua pueda ser vertida. Por lo tanto, las modificaciones del reactivo de Fenton y del pro- 
ceso foto-Fenton para permitir su aplicación a condiciones más suaves de $\mathrm{pH}$ han sido objeto de interés de los investigadores en los últimos años, y se han seguido diferentes estrategias para este fin.

Una posibilidad es el uso de hierro en fase heterogénea. Existen estudios en los que el hierro cero-valente se ha empleado a valores de $\mathrm{pH}$ suaves. En este proceso, el hierro se oxida para formar cationes de hierro in situ, lo que, a su vez, favorece el proceso foto-Fenton (Nie y otros, 2007). Otras formas de heterogeneizar el proceso es soportar el catión de hierro en diferentes sólidos, como las zeolitas (Fukuchi y otros, 2014) o películas de diferente naturaleza (Mazille y otros, 2010).

En algunos casos muy concretos, se pueden utilizar otros metales presentes en las aguas y que pueden actuar como fotocatalizadores. Este es el caso de las aguas de la industria de recubrimientos metálicos que posee cantidades apreciables de cobre, entre otros metales, con esta característica (Santos-Juanes y otros, 2008).

En el tratamiento de estas aguas, el peróxido de hidrógeno ha demostrado ser un agente oxidante eficaz para eliminar cianuros libres y complejos. El proceso es muy rápido bajo irradiación solar, posiblemente debido al efecto fotocatalítico de los iones de cobre presentes. Además, se produce la precipitación del catión de metal, cuando el complejo desaparece. Una vez que se completa la eliminación de $\mathrm{Cu}^{2+}$ y $\mathrm{CN}^{-}$se logra una detoxificación completa de la solución frente a fangos activos de EDAR, lo que está de acuerdo con la alta toxicidad que estas dos especies manifiestan hacia el lodo activado. Se pueden observar estos efectos en la figura 3.1 que nos muestra la degradación de cianuro, carbono total y cobre. El insert de la gráfica nos muestra los detalles de la detoxificación frente a fangos activos y Vibrio fischery.

Otras investigaciones se centran en el uso de la pequeña fracción de hierro que permanece soluble en medio cercano a la neutralidad con objeto de intentar eliminar compuestos en concentraciones bajas, como contaminantes emergentes en la salida de las plantas de tratamiento de aguas residuales (EDAR). Estos productos químicos alcanzan concentraciones que van desde $\mathrm{ng} / \mathrm{L}$ a unos pocos $\mathrm{mg} / \mathrm{L}$. Por ello, para tratar esos efluentes, debería ser suficiente un tratamiento corto a esos $\mathrm{pH}$, en el que pequeñas cantidades de hierro permanecen todavía en solución. Esta estrategia se ha aplicado para el trata- 


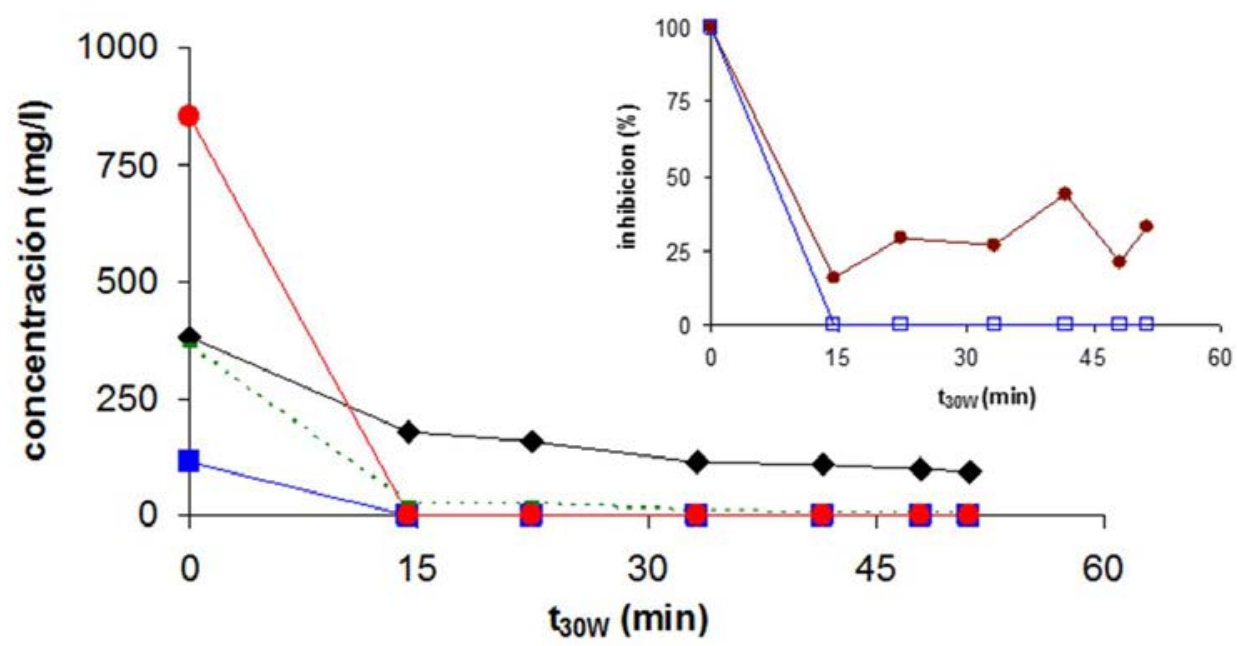

Figura 3.1. Sol con $\mathrm{H}_{2} \mathrm{O}_{2}$. Degradación de cianuro $(\bullet)$, cianuro libre $(\square)$, carbono total $(\diamond)$. Degradación del cobre ( $\mathbf{\Delta})$. Toxicidad (Vibrio fischeri) $(\Theta)$, toxicidad en fangos activos $(\square)$

miento de efluentes reales (Klamerth y otros, 2010; Bernabeu y otros, 2011 a) o disoluciones acuosas de estos contaminantes (Bernabeu y otros, 2012).

Una estrategia alternativa, que ha sido ampliamente estudiada, consiste en el uso de compuestos capaces de prevenir la formación de óxidos o hidróxidos de hierro, generalmente mediante la formación de complejos fotoquímicamente activos. La capacidad de algunos carboxilatos, tales como oxalato, para mejorar el proceso de foto-Fenton ha sido muy estudiada (Monteagudo y otros, 2008). Recientemente, los complejos entre el hierro y los ligandos orgánicos, como citrato (Hong y otros, 2011; Silva y otros, 2007), ácido etilendiamina-N, N'disuccinico (EDDS) (Huang y otros, 2013; Klamerth y otros, 2013) O EDTA (De Luca y otros, 2014) han demostrado ser capaces de ampliar el intervalo de $\mathrm{pH}$ de foto-Fenton hasta valores por encima de 5 en algunos casos.

Se ha planteado una modificación del mecanismo en tales condiciones atribuyendo un papel clave en el proceso a otras especies diferentes al radical hidroxilo, tales como superóxido (Huang y otros, 2013; Hug y Leupin, 2003). A 
pesar de los buenos rendimientos obtenidos en algunos casos, este enfoque también presenta inconvenientes, como la estabilidad limitada del agente complejante y la potencial toxicidad de los auxiliares químicos empleados en los procesos de estabilización del hierro.

\subsubsection{Efecto de los ácidos húmicos sobre el proceso foto-Fenton en condiciones próximas a la neutralidad}

Las sustancias húmicas (SH) también son candidatas para la aplicación del proceso foto-Fenton a $\mathrm{pH}$ neutro. Las SH son macromoléculas de origen natural, que se originan principalmente de restos vegetales y son los materiales orgánicos más ampliamente distribuidos en el medio ambiente (Chin y otros, 1994). Estas sustancias contienen grupos funcionales que son capaces de formar complejos con el hierro (Mikutta y Kretzschmar, 2011). Esta capacidad ha sido empleada con éxito en la eliminación de sustancias químicas por proceso Fenton en la oscuridad (Lipczynska-Kochany y Kochany, 2008), que se ha extendido a un rango de $\mathrm{pH}$ de 5-8 (Georgi y otros, 2007). Se ha propuesto que la especie responsable de favorecer el proceso es un complejo formado entre el hierro y las sustancias húmicas.

\subsubsection{Eliminación de contaminantes emergentes de EDAR}

Aunque el uso de $\mathrm{SH}$ no ha sido muy ampliamente estudiado en el proceso foto-Fenton, existe alguna información sobre su uso en procesos solares para eliminar los contaminantes a baja concentración presentes a la salida de una planta de tratamiento de aguas residuales (Klamerth y otros, 2011). Un artículo reciente publicado por nuestro grupo de investigación ha demostrado que estas sustancias muestran un papel positivo en un proceso foto-Fenton bajo simulador solar a $\mathrm{pH}=7,2$ usando una mezcla de productos farmacéuticos y pesticidas (a una concentración inicial de $5 \mathrm{mg} \mathrm{L}^{-1}$ cada uno) como disolución a tratar (Bernabeu y otros, 2012). La tabla 3.1 muestra el porcentaje de eliminación alcanzado después de 180 minutos de irradiación en un simulador solar 
con $(10 \mathrm{mg} / \mathrm{L})$ y $\sin$ las sustancias húmicas. En presencia de $\mathrm{sH}$, tres contaminantes fueron totalmente eliminados después de tres horas de irradiación; se consiguió la eliminación de más del $80 \%$ de los otros dos y el acetamiprid se mostró como el más resistente alcanzando únicamente el $46 \%$ de fotodegradación. La eficiencia del proceso sin SH fue significativamente más baja, ya que solo el ácido clofibrico redujo su concentración por debajo del $80 \%$ inicial. Sin embargo, estos resultados están muy lejos de los obtenidos a $\mathrm{pH}=2,8$, como es lógico; en esas condiciones, se alcanzó la reducción completa de las seis contaminantes en unos pocos minutos.

Tabla 3.1.Fotodegradación (\%) de una mezcla de 6 contaminantes (concentración inicial $5 \mathrm{mg} / \mathrm{L}$ de cada uno) bajo simulador solar

\begin{tabular}{|c|c|c|}
\hline Contaminantes & Sin Hs & Con Hs \\
\hline ácido clofibrico & $93 \%$ & $>99 \%$ \\
\hline amoxicillina & $77 \%$ & $>99 \%$ \\
\hline acetaminofeno & $49 \%$ & $46 \%$ \\
\hline acetemiprid & $24 \%$ & $82 \%$ \\
\hline cafeina & $36 \%$ & $90 \%$ \\
\hline carbamazepina & $53 \%$ & \\
\hline
\end{tabular}

Cuando la matriz acuosa utilizada es la propia agua de la EDAR, fortificada con $0,05 \mathrm{mg} / \mathrm{L}$ de cada contaminante emergente a estudio, también se aprecia una mejora en el rendimiento de eliminación de los contaminantes: se consigue eliminar el acetaminofeno y la amoxicilina (hidrólisis en 120 minutos) y, además, se incrementan los porcentajes de degradación del resto de contaminantes: cafeína (42\%), carbamazepina (36\%), acetamiprid (25\%) y ácido clofíbrico (21\%) (figura 3.2).

Sin embargo, cuando la concentración de los contaminantes tratados fue menor (varios $\mathrm{mg} / \mathrm{L}$ ), las $\mathrm{SH}$ jugaron un papel negativo, muy probablemente debido a un efecto competitivo entre ellas y los contaminantes. Este efecto ya ha sido observado por otros autores (Khan y otros, 2013), lo que demuestra 

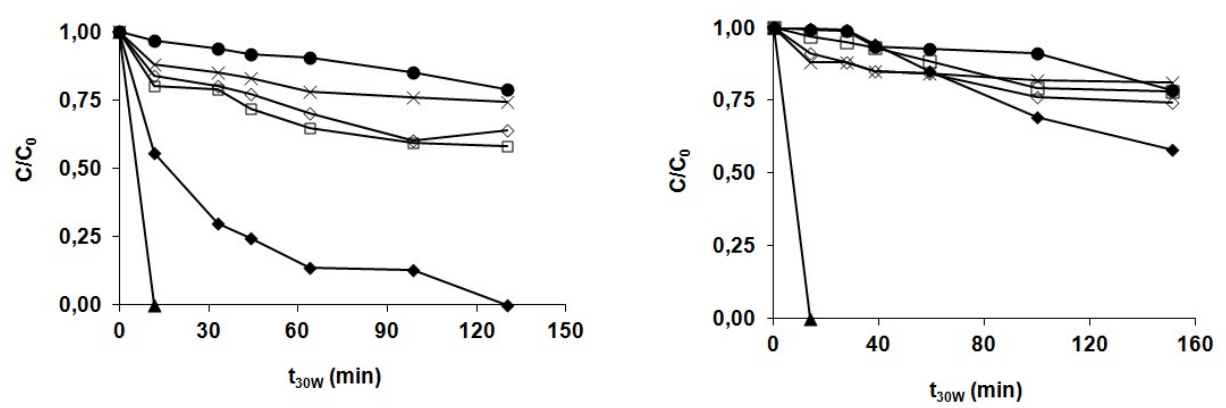

$\leftarrow$ Acetaminofeno $\bullet$ Cafeina $\quad$-Amoxicilina
$\leftarrow$ Acetamiprid $\leftarrow$ Carbamazepina $\rightarrow$ Ácido clofíbrico

Figura 3.2. Concentración relativa de contaminantes emergentes (planta piloto) en función de $t_{30 w^{*}}$. Foto-Fenton a pH neutro en agua de EDAR $\left(0,05 \mathrm{mg} / \mathrm{L}\right.$ de cada CE) $\left(\mathrm{Fe}^{2+} 5 \mathrm{mg} / \mathrm{L} \mathrm{y}_{2} \mathrm{O}_{2} 5\right.$ $\mathrm{mg} / \mathrm{L}$ ). Izquierda: sin ácidos húmicos. Derecha: con ácidos húmicos (sH $10 \mathrm{mg} / \mathrm{L}$ )

que el efecto real de la materia orgánica disuelta en el proceso foto-Fenton podría depender en gran medida de las condiciones experimentales y explicaría los resultados discrepantes que se muestran en la literatura.

Se han realizado estudios para clarificar el papel del radical hidroxilo en el mecanismo de reacción de estos procesos. Los mismos experimentos realizados en medio ácido, medio neutro sin $\mathrm{SH}$ y medio neutro $\mathrm{Con} \mathrm{SH}$, con y sin adición de terbutanol (conocido atrapador de radicales hidroxilo), demuestran que en medio ácido el mecanismo de degradación mayoritario transcurre a través de radical hidroxilo, puesto que se produce una reducción de la velocidad de degradación próxima al $100 \%$ en ambos casos. Sin embargo, en medio neutro (presencia/ausencia $\mathrm{HA}$ ), la reducción es menor, ya que la relación de constantes es mayor. Por todo ello, en medio neutro deben estar interviniendo otras especies reactivas en el proceso, distintas al radical hidroxilo, como, por ejemplo, especies ferrilo. La tabla 3.2 muestra la relación de constantes cinéticas con y sin adición de terbutanol sobre la degradación de dos contaminantes emergentes tomados como ejemplo (amoxicilina y cafeína). 
Tabla 3.2. Relación de constantes cinéticas de pseudo primer orden. Ácidos húmicos (нА), terbutanol (тв), $\mathrm{k}$ (con тв), $\mathrm{k}_{0}(\sin т в)$

\begin{tabular}{|c|c|c|}
\cline { 2 - 3 } \multicolumn{1}{c|}{} & AMOXICILINA & CAFEÍNA \\
\hline Tratamiento & $\mathbf{k} / \mathbf{k}_{\mathbf{0}}$ & $\mathbf{k} / \mathbf{k}_{\mathbf{0}}$ \\
\hline $\mathrm{pH}$ ácido & 0,04 & 0,04 \\
\hline $\mathrm{pH}$ neutro & 0,69 & 0,41 \\
\hline $\mathrm{pH}$ neutro HA & 0,77 & 0,67 \\
\hline
\end{tabular}

\subsubsection{Eliminación de larvas de Dreissena polymorpha}

Otro ejemplo del efecto de estas sustancias húmicas en el proceso foto-Fenton en condiciones suaves de $\mathrm{pH}$ es el tratamiento de las larvas de Dreissena polymorpha (mejillón zebra). Este proceso podría ser una interesante alternativa para la eliminación de esta especie invasora de nuestros ríos. El tratamiento con luz solar y $5 \mathrm{mg} / \mathrm{L}$ de hierro de muestras de aguas del río Ebro con larvas de esta especie provocó el daño en aproximadamente el $90 \%$ de larvas en solo 3 horas de irradiación en presencia de $\mathrm{H}_{2} \mathrm{O}_{2}(10 \mathrm{mg} / \mathrm{l})$, demostrando que la fotocatálisis solar puede ser una alternativa prometedora para erradicar el mejillón cebra de las instalaciones de riego (véase la figura 3.3). Además, el proceso se ha mejorado en un pH ligeramente ácido $(5,5)$ que puede ser compatible con el uso de agua tratada para el riego. Este proceso fue claramente más eficaz que la irradiación de la luz solar, el $\mathrm{H}_{2} \mathrm{O}_{2}$, o Fenton en oscuridad.

Sin embargo, se necesita más investigación sobre este tema antes de pasar a instalaciones a escala real; principalmente son necesarias pruebas de fitotoxicidad de los efluentes tratadas con el fin de descartar su potencial efecto tóxico sobre los cultivos a regar (Bernabeu y otros, 2011 b).

Se han realizado estudios sobre el mecanismo de estos procesos pero los resultados no son concluyentes, como es esperable para un sistema tan complejo. Sin embargo, se ha publicado que el $\cdot \mathrm{OH}$ podría no ser la única especie que participa en el proceso y, por lo tanto, otras especies oxidantes 

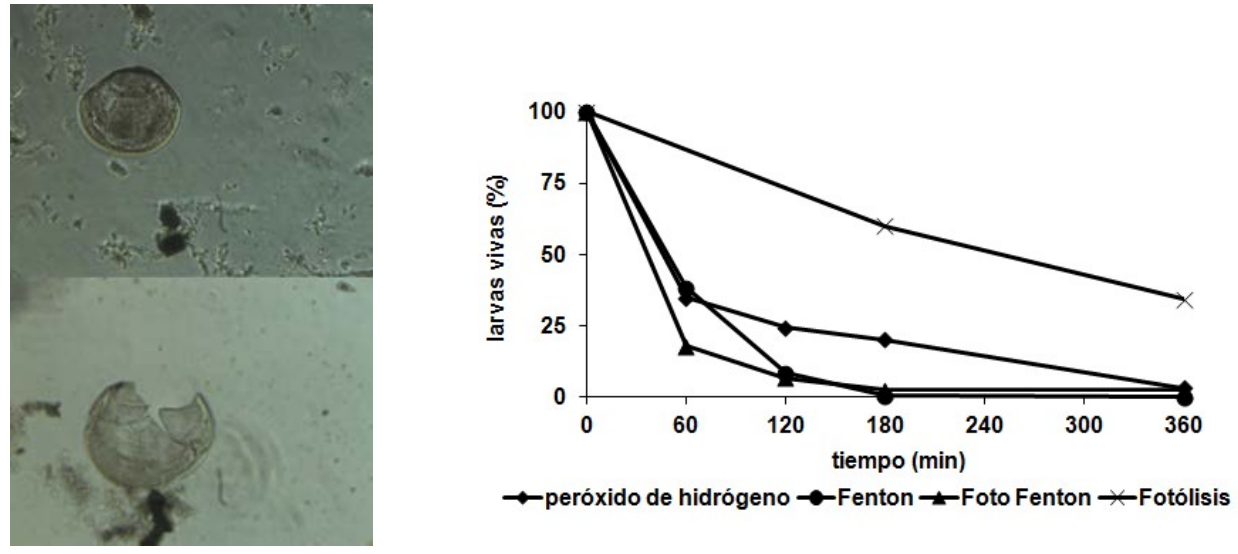

Figura 3.3. Izquierda: fotografía de una larva veligera sana de $D$. polymorpha (arriba) y una larva dañada (abajo). Derecha: tratamiento foto-Fenton ( $5 \mathrm{mg} / \mathrm{l}$ de hierro y $10 \mathrm{mg} / \mathrm{l} \mathrm{de} \mathrm{H}_{2} \mathrm{O}_{2^{\prime}}$ luz solar), Fenton ( $5 \mathrm{mg} / \mathrm{l}$ de hierro y $10 \mathrm{mg} / \mathrm{l} \mathrm{de}_{2} \mathrm{O}_{2}$ ) ( ), foto- Fenton (sol y $5 \mathrm{mg} / \mathrm{l}$ de hierro y 10 $\left.\mathrm{mg} / \mathrm{l} \mathrm{de} \mathrm{H}_{2} \mathrm{O}_{2}\right)(\boldsymbol{\Delta}), 10 \mathrm{mg} / \mathrm{l} \mathrm{de} \mathrm{H}_{2} \mathrm{O}_{2}(\diamond)$ y experimento control $(X)$

podrían ser responsables de la oxidación de contaminantes (Vermilyea y Voelker, 2009).

\subsubsection{Síntesis y aplicación de sustancias bioorgánicas solubles (sBo) para aplicación de procesos foto-Fenton en condiciones próximas a la neutralidad}

Los residuos que genera el hombre en diferentes actividades han merecido la atención de los investigadores, ya que pueden ser una fuente sostenible de materiales con una amplia gama de potenciales aplicaciones (Arancon y otros, 2013). Uno de estos residuos en particular, las sustancias orgánicas solubles de origen biológico (sBo), se ha aislado a partir de desechos orgánicos sólidos (procedentes de diferentes fuentes), obtenidos en condiciones de fermentación aerobia, tras un proceso que implica la extracción de la fracción soluble a pH básico y posterior precipitación en medio ácido (Montoneri y otros, 2011). Las SBO están constituidas por una mezcla de macromoléculas, cuyo peso molecular medio oscila entre 67 y $463 \mathrm{~kg} \mathrm{~mol}^{-1}$, y que consisten en largas cadenas alifáticas, anillos aromáticos y grupos funcionales que contienen oxígeno y nitrógeno (Montoneri y otros, 2011). 
Por lo tanto, estos materiales muestran similitudes estructurales básicas con algunas macromoléculas que se encuentran en la materia natural orgánica (NOM), tales como los ácidos húmicos y fúlvicos, que desempeñan un papel importante en los procesos fotoquímicos que conducen a la autorrecuperación de los ecosistemas (Khetan y Collins, 2007). En este contexto, parece interesante determinar el uso potencial de las SBO para la detoxificación del agua, ya que puede ser considerado como un proceso ecológico al valorizar los residuos sólidos como fuentes de materiales fotoactivos con propiedades similares a los menos disponibles NOM. La información sobre este tema es muy escasa y solo se han publicado algunos trabajos recientes sobre la capacidad de estos compuestos para actuar como fotocatalizadores en la degradación de los clorofenoles (Bianco-Prevott y otros, 2013; Avetta y otros, 2013), ácidos sulfónicos (Gomis y otros, 2013; Fan y otros, 2011), colorantes o compuestos farmacéuticos (Gomis y otros, 2014; Bianco Prevott y otros, 2010). La actividad de las SBO puede estar relacionada con una mejor fotogeneración de especies reactivas; sin embargo, el fuerte efecto pantalla producido por el color de estos materiales afecta negativamente a la degradación de los contaminantes que pueden someterse a fotólisis directa. Cuando se empleó como fuente de irradiación luz solar simulada, el efecto pantalla se hizo predominante, lo que hace poco atractiva la función de las SBO como fotocatalizadores solares (Gomis y otros, 2014).

Una aplicación de las SBo, teniendo en cuenta su estructura, rica en grupos carboxílicos y amidas, puede ser emplearlas como agentes complejantes para aplicar el proceso foto-Fenton en condiciones de $\mathrm{pH}$ suaves. Este enfoque podría ser especialmente útil para tratar contaminantes emergentes (EC), donde una cierta pérdida de eficiencia en la generación de especies reactivas podría ser aceptable, ya que los EC se encuentran normalmente a baja concentración y, por lo tanto, se necesitan menores cantidades de especies oxidantes (Carra y otros, 2013).

Además, las SBO contienen cantidades significativas de hierro en su composición (0,1-0,8\%) y, por lo tanto, se podría esperar que facilitaran un proceso foto-Fenton, incluso sin adición de hierro. Para comprobar esta propiedad se han realizado algunos ensayos, como la decoloración de violeta cristal (vc), un colorante catiónico que se ha estudiado en la presencia de un tipo de SBO (сVT 230) (Gomis y otros, 2013). La figura 3.4 muestra las constantes 


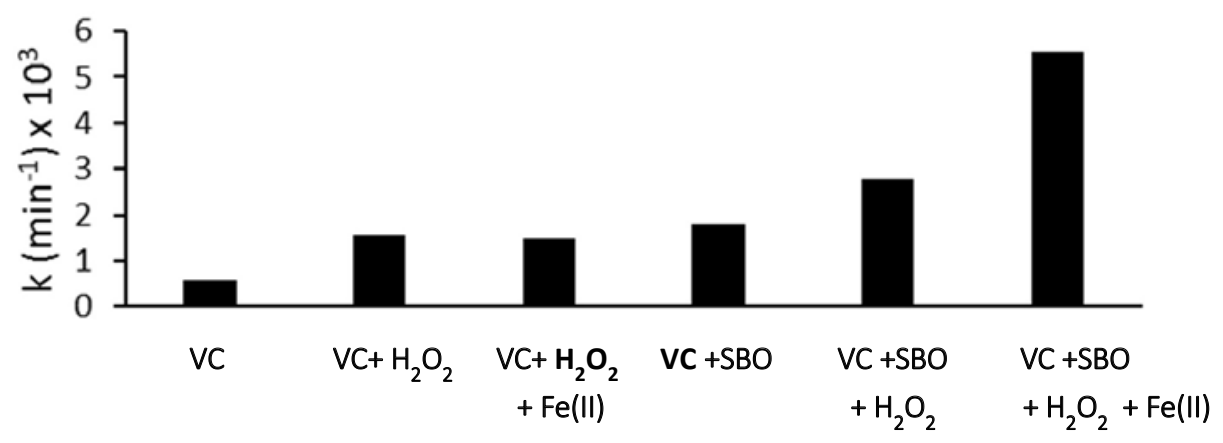

Figura 3.4. Constantes cinéticas de pseudo primer orden obtenidas en la decoloración de disoluciones del colorante violeta cristal (concentración inicial $\mathrm{vc}=10 \mathrm{mg} / \mathrm{L}$ ) a $\mathrm{pH}$ neutro bajo irradiación con lámpara de mercurio de media presión $(\lambda>300 \mathrm{~nm})$ con o sin los siguientes aditivos: $\left[\mathrm{H}_{2} \mathrm{O}_{2}\right]=8,3 \mathrm{mg} / \mathrm{L} ;[\mathrm{Fe}(\mathrm{II})]=5 \mathrm{mg} / \mathrm{L} ;[\mathrm{sBO}]=100 \mathrm{mg} / \mathrm{L}$

de velocidad de pseudo primer orden obtenidas para la decoloración de vc, bajo diferentes condiciones experimentales, combinando sBo, $\mathrm{Fe}$ (II) $\mathrm{y}_{2} \mathrm{O}_{2}$ con vc a pH neutro.

Los resultados indican que a pesar de que vc experimenta alguna fotolisis, es muy baja $\left(\mathrm{k}<10^{-3} \mathrm{~min}^{-1}\right)$. La adición de $\mathrm{H}_{2} \mathrm{O}_{2}$ O sBo mejoró algo el proceso, con $\mathrm{k}$ ligeramente por debajo de $2 \cdot 10^{-3} \mathrm{~min}^{-1}$; se obtuvieron resultados similares con el reactivo de Fenton en ausencia de $\mathrm{SBO}\left[\mathrm{vC}+\mathrm{H}_{2} \mathrm{O}_{2}+\mathrm{Fe}\right.$ (II)]. Por otra parte, la combinación de peróxido de hidrógeno у зво fue capaz de acelerar la decoloración de vc; esto podría ser atribuible a un proceso tipo foto-Fenton a $\mathrm{pH}$ neutro, en el que está involucrado el hierro presente en la composición de SBO. La adición de cantidades adicionales de hierro (5 mg/L) a la mezcla $\mathrm{H}_{2} \mathrm{O}_{2} /$ SBO aumenta en mayor medida la velocidad de reacción, lo que indica que solo el hierro presente en el sво no es capaz de producir un proceso foto-Fenton de forma eficiente, pero estas sustancias son capaces de estabilizar el hierro en el medio, formando especies fotoquímicamente activas, muy probablemente complejos de sBo-Fe.

Con objeto de determinar la participación de especies reactivas en el proceso, se realizaron experimentos con diferentes sondas químicas. 2-propanol, un agente con alta reactividad con el radical hidroxilo, tuvo un escaso efecto sobre la tasa de decoloración de vc; esto está de acuerdo con la posibilidad de 
que especies alternativas al $\cdot \mathrm{OH}$ jueguen un papel importante en el proceso. Por otra parte, la adición de fenol resultó en una disminución de la velocidad de reacción; como el fenol inhibe los procesos que implican iones ferrilo, estos resultados podrían indicar que la participación de las especies de hierro altamente oxidadas podrían predominar en esas condiciones.

Los procesos foto-Fenton con SBO también se ensayaron usando un efluente simulado que consiste en una mezcla de seis contaminantes de relevancia ambiental: acetaminofeno (analgésico), cafeína (agente estimulante), acetemiprid (insecticida), ácido clofíbrico (metabolito de clofibrato, también se emplea como herbicida), carbamacepina (psicofármaco) y amoxicilina (antibiótico) a una concentración de $5 \mathrm{mg} \mathrm{L}^{-1}$ cada uno (Gomis y otros, 2014). Las irradiaciones se realizaron con un simulador solar, cuyo espectro de emisión es semejante al de la luz solar que llega a la superficie de la Tierra.

Para ensayar el efecto de las SBO a dos valores de $\mathrm{pH}$ diferentes, 2,8 y 5,3,

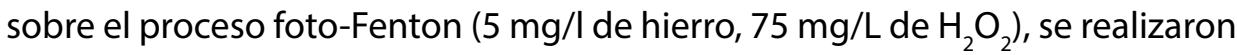
pruebas paralelas con y sin SBO y se calculó la constante de velocidad de pseudoprimer orden en ambos casos; la relación entre la constante de velocidad obtenida en la presencia de sво (ksвo) у en su ausencia (ko) se muestran en la tabla 3.3.

Tabla 3.3. Relación entre constantes cinéticas de pseudoprimer ordenobtenidas para la degradación de 6 contaminantes en presencia de SBO (sBo) y en su ausencia $\left(\mathrm{K}_{0}\right)$ a $\mathrm{pH} 2,8$ y 5,3

\begin{tabular}{|c|c|c|}
\cline { 2 - 3 } \multicolumn{1}{c|}{} & $\mathbf{k}_{\mathbf{S B O}} / \mathbf{k}_{\mathbf{0}} \mathbf{a ~} \mathbf{~ H H}=\mathbf{2 , 8}$ & $\mathbf{k}_{\mathbf{S B O}} \mathbf{/} \mathbf{k}_{\mathbf{0}} \mathbf{a} \mathbf{~ p H}=\mathbf{5 , 3}$ \\
\hline acetaminofeno & 0,73 & 8,81 \\
\hline cafeina & 0,77 & 8,43 \\
\hline amoxicillina & 0,87 & 6,15 \\
\hline acetamiprid & 0,65 & 8,37 \\
\hline carbamacepina & 0,75 & 8,75 \\
\hline ácido clofibrico & 0,88 & 8,28 \\
\hline
\end{tabular}


$\mathrm{A} \mathrm{pH}=5,3$ las relaciones estuvieron siempre muy por encima de 1 (sobre 8 en la mayoría de los casos), lo que muestra que la sвo fue capaz de acelerar significativamente el proceso foto-Fenton, muy probablemente debido a su capacidad para aumentar la disponibilidad de especies de hierro fotoquímicamente activas mediante la prevención de la formación de óxidos o hidróxidos de hierro. Sin embargo, a pH =2,8, las relaciones estaban ligeramente por debajo de 1 , lo que indica que el papel de la sво era perjudicial. A este $\mathrm{pH}$, la precipitación de hierro no se produce y, por lo tanto, la presencia de SBo no da como resultado una generación adicional de especies reactivas. Por el contrario, esta sustancia orgánica compite con los contaminantes por la especie oxidante y también puede producir algún efecto pantalla, disminuyendo las cantidades de fotones que llegan al fotocatalizador.

El efecto de algunas variables operativas, esto es, $\mathrm{pH}$, la concentración de sвO y la concentración de hierro, se investigó usando una metodología de diseño experimental basada en matrices Doehler (Ferreira y otros, 2004). La mezcla de contaminantes descrita anteriormente ( $5 \mathrm{mg} / \mathrm{l}$ de cada uno) se irradió con un simulador solar en presencia de Sво (entre 15 у $25 \mathrm{mg} / \mathrm{L}$ ), hierro (III) (2-6 mg/L) a valores de pH en el rango de 3-7. La concentración de peróxido de hidrógeno adicionada fue la mitad de la cantidad estequiométrica requerida para la mineralización de los contaminantes (Gomis y otros, 2015). La respuesta analizada fue el tiempo requerido para disminuir la concentración de cada contaminante a la mitad del valor inicial ( $\mathrm{t} 50 \%$ ).

Se obtuvo una respuesta de tres dimensiones de superficie para cada contaminante, que se puede observar en las ecuaciones 3.3-3.8, donde [Fe] y [sвo] se expresan en $\mathrm{mg} / \mathrm{L}$ y $\mathrm{t} 50 \%$ en min:

\begin{tabular}{|l|l|}
\hline $\boldsymbol{t}_{50 \%}$ (carbamacepina) $=248,38-40,37 \cdot[\mathrm{Fe}]-8,52 \cdot[\mathrm{sBO}]-$ & \\
$51,39 \cdot \mathrm{pH}+1,90 \cdot[\mathrm{Fe}]^{2}+0,07[\mathrm{Fe}][\mathrm{sBO}]+5,14 \cdot[\mathrm{Fe}] \cdot \mathrm{pH}+0,43[\mathrm{sBO}]^{2}$ & $\mathbf{3 . 3}$ \\
$-2,08 \cdot[\mathrm{sBO}] \cdot \mathrm{pH}+10,28 \cdot \mathrm{pH}^{2}$ & \\
\hline $\boldsymbol{t}_{50 \%}$ (acetaminofeno $)=318,33-15,36 \cdot[\mathrm{Fe}]-22,79 \cdot[\mathrm{sBO}]-$ & \\
$32,82 \cdot p H+0,82 \cdot[\mathrm{Fe}]^{2}+0,30[\mathrm{Fe}][\mathrm{sBO}]+0,50[\mathrm{Fe}] \mathrm{pH}+0,45[\mathrm{sBO}]^{2}+$ & $\mathbf{3 . 4 )}$ \\
$0,71 \cdot[\mathrm{sBO}] \cdot \mathrm{pH}+3,64 \cdot \mathrm{pH}^{2}$ & \\
\hline
\end{tabular}




\begin{tabular}{|c|c|}
\hline $\begin{array}{l}\boldsymbol{t}_{50 \%}(\text { amoxicilina })=56,92-41,63 \cdot[\mathrm{Fe}]+3,80 \cdot[\mathrm{sBO}]-19,34 \cdot \mathrm{pH} \\
+1,28 \cdot[\mathrm{Fe}]^{2}+0,08[\mathrm{Fe}][\mathrm{sBO}]+6,23 \cdot[\mathrm{Fe}] \cdot \mathrm{pH}+0,36[\mathrm{sBO}]^{2}- \\
4,19 \cdot[\mathrm{sBO}] \cdot \mathrm{pH}+10,69 \cdot p \mathrm{H}^{2}\end{array}$ & (3.5) \\
\hline $\begin{array}{l}\boldsymbol{t}_{50 \%}(\text { acetamiprid })=966,42-83,28 \cdot[\mathrm{Fe}]-40,02 \cdot[\mathrm{SBO}]- \\
206,76 \cdot \mathrm{pH}+1,19 \cdot[\mathrm{Fe}]^{2}+0,91 \cdot[\mathrm{Fe}] \cdot[\mathrm{SBO}]+12,29 \cdot[\mathrm{Fe}] \cdot \mathrm{pH}+0,69 \cdot[\mathrm{SBO}]^{2} \\
+1,77 \cdot[\mathrm{SBO}] \cdot \mathrm{pH}+18,59 \cdot p \mathrm{H}^{2}\end{array}$ & (3.6) \\
\hline $\begin{array}{l}\boldsymbol{t}_{50 \%} \text { (ácido clofíbrico) }=242,78-40,30 \cdot[\mathrm{Fe}]-9,39 \cdot[\mathrm{sBO}]- \\
44,58 \cdot \mathrm{pH}+1,44 \cdot[\mathrm{Fe}]^{2}+0,13[\mathrm{Fe}][\mathrm{sBO}]+5,70 \cdot[\mathrm{Fe}] \cdot \mathrm{pH}+0,44[\mathrm{sBO}]^{2} \\
-2,06 \cdot[\mathrm{sBO}] \cdot \mathrm{pH}+9,40 \cdot \mathrm{pH}^{2}\end{array}$ & (3.7) \\
\hline $\begin{array}{l}\boldsymbol{t}_{50 \%}(\text { cafeína })=702,53-79,39 \cdot[\mathrm{Fe}]-25,36 \cdot[\mathrm{SBO}]-147,13 \cdot p H+ \\
2,02 \cdot[\mathrm{Fe}]^{2}+0,41[\mathrm{Fe}][\mathrm{sBO}]+12,04 \cdot[\mathrm{Fe}] \cdot p H+0,50 \cdot[\mathrm{SBO}]^{2}+0,65[\mathrm{sBO}] \\
p H+12,44 \cdot p H^{2}\end{array}$ & (3.8) \\
\hline
\end{tabular}

Como era de esperar, el pH fue el parámetro más significativo. Este efecto puede ser mejor apreciado por medio de líneas de contorno. Mediante la fijación de una de las tres variables se puede obtener la gráfica que se presenta en la figura 3.5 que muestra, como ejemplo, las líneas de contorno obtenidas para la carbamazepina a una concentración de sBO de $15 \mathrm{mg} / \mathrm{L}$. Se puede observar que el valor de $\mathrm{t} 50 \%$ no cambió significativamente en el rango de $\mathrm{pH}$ 3-5 y la concentración de hierro no tuvo un efecto notable en el proceso foto-Fenton. Representaciones similares pueden obtenerse para los demás contaminantes. Esto implica que las SBO se pueden considerar como compuestos auxiliaries útiles para extender el proceso foto-Fenton hasta valores de $\mathrm{pH}$ cercanos a 5 .

La gráfica de contorno obtenida en algunos casos, por ejemplo carbamacepina a una concentración elevada de Sво (por ejemplo, $25 \mathrm{mg} / \mathrm{L}$ ), muestra un desplazamiento del rango de $\mathrm{pH}$ óptimo hacia valores mayores (cercanos o incluso por encima de 4). Esto podría indicar que hay una modificación del mecanismo del proceso foto-Fenton, donde $\mathrm{Fe}(\mathrm{OH})^{2+}$, que alcanza su concentración máxima a $\mathrm{pH}=2,8$, se sustituye como la especie reactiva principal, muy probablemente por un complejo de Fe- sвO. 


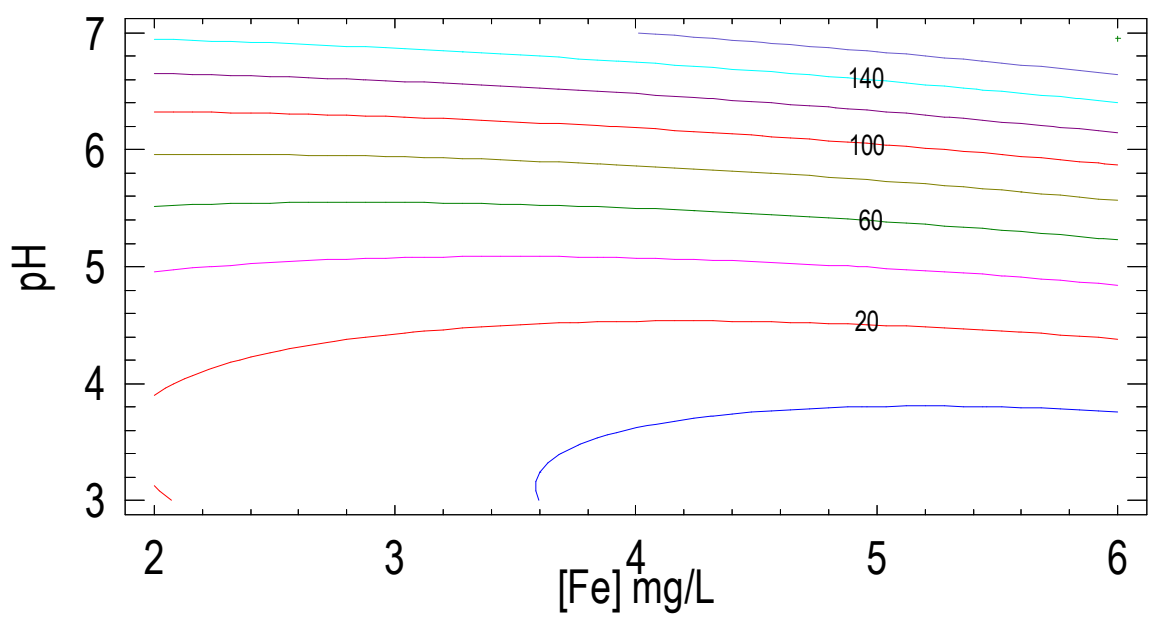

Figura 3.5. Trazado del contorno de t50 \% ( $\mathrm{min}$ ) obtenido en la degradación foto-Fenton de carbamacepina en presencia de $15 \mathrm{mg} / \mathrm{L}$ de sво.

Si el pH se fija en el valor de 5, se puede estudiar el efecto del hierro y la concentración de SBо. La concentración de hierro en el rango estudiado (2-6 mg/L) no tuvo ningún efecto significativo sobre la velocidad de degradación. Por otro lado, los mejores resultados se alcanzaron con la concentración de $\mathrm{SBO}$ ligeramente por encima de $20 \mathrm{mg} / \mathrm{L}$; más allá de este punto, la SBO jugó un papel negativo, ya sea por el efecto pantalla o como competidor de los contaminantes por las especies reactivas.

El tipo de sво también podría ser importante para el proceso foto-Fenton. Con el fin de comprobar este punto, el proceso foto-Fenton se ha ensayado con la mezcla de seis contaminantes. Se emplearon tres tipos diferentes de sво, dependiendo de su origen: $a$ ) FORSUD, aislada de la fracción orgánica humídica de residuos urbanos, mezclado con el digestato de un reactor anaeróbico; $b$ ) CVT230, obtenido a partir de residuos de poda aireados durante 230 días y c) CVDFT110, aislado de una mezcla 35/55/10 (w / w / w) de FORSUD, residuos de poda y la mezcla de los lodos de aguas residuales urbanas, aireada durante 110 días. Algunas características se resumen en la tabla 3.4 (Gomis y otros, 2015). 
Tabla 3.4. Principales características de las SBO empleadas en estos estudiós

\begin{tabular}{|c|c|c|c|}
\cline { 2 - 4 } \multicolumn{1}{c|}{} & FORSUD & CVDFT110 & CVT230 \\
\hline Carbón $(\%, w / w)$ & 45,1 & 35,5 & 38,2 \\
\hline Carbón alifático & 43 & 31 & 37 \\
\hline Acidos carboxílicos & 7 & 9 & 12 \\
\hline Relación lipófila/hidrófila & 9,3 & 5,3 & 3,6 \\
\hline Relación alifática/ aromática & 3,3 & 1,3 & 1,8 \\
\hline Relación $\mathrm{E}_{2} / \mathrm{E}_{3}$ & 3,83 & 2,31 & 2,38 \\
\hline
\end{tabular}

Se estudió la fotodegradación de los seis contaminantes usando los tres tipos de sвo. Se calculó el porcentaje de fotodegradación alcanzado después de 5 minutos de tratamiento foto-Fenton a $\mathrm{pH}=5,2$ para cada contaminante $y$ cada sво (figura 3.6). Se puede observar que el orden de reactividad de los contaminantes no depende del tipo de sвo empleada, aunque pueden apreciarse ligeras diferencias cuantitativas atribuidas a diferencias en la composición, como menores porcentajes del grupo carboxílico, capaz de complejar hierro.

$\square$ CVT $230 \square$ CVDFT $110 \quad \square$ FORSUD

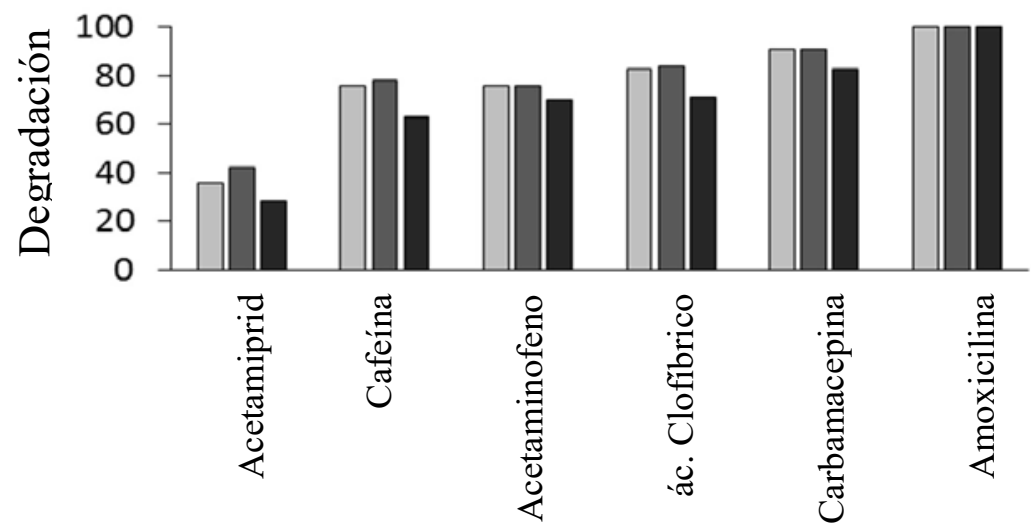

Figura 3.6. Porcentaje de fotodegradación de 6 contaminantes obtenidos tras 5 minutos de tratamiento foto-Fenton en presencia de diferentes tipos de sвo 
Con objeto de una posible aplicación de estos compuestos en tratamientos de aguas reales, se considera necesario determinar la toxicidad, la biodegradabilidad y la estabilidad de las SBO. Para comprobar la toxicidad, se Ilevaron a cabo tres bioensayos diferentes, utilizando bacterias ( $V$. fischeri), algas (P. subcapitata) y crustáceos (D. magna). La toxicidad fue muy baja en todos los casos a las concentraciones en que se pueden utilizar en un proceso fotoFenton (alrededor de $20 \mathrm{mg} / \mathrm{L}$ ). Su biodegradabilidad fue muy baja, como se indica por la relación de la demanda biológica de oxígeno / demanda química de oxígeno (BOD/DQO), que estaba por debajo de 0,1, mientras que el límite para una buena biodegradabilidad se considera comúnmente por encima de 0,4.

También es interesante conocer el efecto de los tratamientos fotoquímicos sobre las Sво. Para este propósito, se irradiaron en presencia de la cantidad estequiométrica de $\mathrm{H}_{2} \mathrm{O}_{2}$ necesaria para mineralizar estos compuestos. Los datos obtenidos antes y después de la irradiación se muestran en la tabla 3.5. Los resultados indican que se produce una ligera mineralización de las muestras, como se aprecia por la disminución de COD (20-30\%) y algo de oxidación, indicado por la variación y una ligera mejora de la biodegradabilidad que se muestra por la relación DBO/DQO y la relación E2/E3 que aumenta significativamente. Todos estos resultados están de acuerdo con una escisión de la sвo inicial para liberar sustancias más pequeñas, más oxidadas y más hidrófilas.

Tabla 3.5. Irradiación de una SBO (cVT230) en presencia de peróxido de hidrógeno: principales parámetros antes y después de irradiación

\begin{tabular}{|c|c|c|}
\cline { 2 - 3 } \multicolumn{1}{c|}{} & Antes de irradiar & Después de irradiar \\
\hline $\operatorname{COD}(\mathrm{mg} / \mathrm{l})$ & 28,2 & 23,5 \\
\hline $\mathrm{DQO}(\mathrm{mg} / \mathrm{l})$ & 95 & 63 \\
\hline $\mathrm{DBO} / \mathrm{DQO}$ & 0,04 & 0,14 \\
\hline Relación $\mathrm{E}_{2} / \mathrm{E}_{3}$ & 2,38 & 3,89 \\
\hline
\end{tabular}




\section{Agradecimientos}

El autor quiere agradecer al Ministerio de Economía y Competitividad de España la financiación de este trabajo a través del proyecto TRICERATOPS (referencia CTQ2015-69832-C4-4-R) y a la Comisión Europea, Horizon 2020 H2020-MSCA-RISE-2014 Topic: Proposal Number: SEP-2101569 (MAT4TREAT), y Sara García-Ballesteros al Ministerio de Economía y Competitividad de España por su beca (BES-2013-066201).

\section{Referencias}

Arancon, R.A.D, Lin, C.S.K., Chan, K.M., Kwan, T.H. y Luque, R. (2013). «Advances on waste valorization: new horizons for a more sustainable society». Energy Science and Engineering, 1, pp. 53-71.

Avetta, P., Bella, F., Bianco Prevot, A., Laurenti, E., Montoneri, E., Aroues, A. y Carlos, L. (2013). «Waste Cleaning Waste: Photodegradation of Monochlorophenols in the Presence of Waste-Derived Photosensitizer». Sustainable Chemistry and Engineering, 1, pp. 1545-1550.

Avetta, P., Bianco Prevot, A., Fabbri, D., Montonerl, E. y Tomasso, L. (2012). «Photodegradation of naphthalene sulfonic compounds in the presence of a bio-waste derived sensitizer». Chemical Engineering Journal, 197, pp. 193-198.

Bernabeu, A., Vercher, R.F., Santos-Juanes, L., Simón, P.J., Lardín, C., Martínez, M.A., Vicente, J.A., González, R., Llosá, C., Arques, A. y Amat, A.M. (2011 a). «Solar photocatalysis as a tertiary treatment to remove emerging pollutants from wastewater treatment plant effluents». Catalysis Today, 161, pp. 233-240.

Bernabeu, A., Vicente, R., Peribáñez, M.A., Arques, A. y Amat, A. (2011 b). «Exploring the applicability of solar driven photocatalytic processes to control infestation by zebra mussel». Chemical Engineering Journal, 171 pp. 490- 494.

Bernabeu, A., Palacios, S., Vicente, R., Vercher, R.F., Malato, S., Arques, A. y Amat, A.M. (2012). "Solar photo-Fenton at mild conditions to treat a mixture of six emerging pollutants». Chemical Engineering Journal, 198-199, pp. 65-72. 
Bianco Prevot, A., Fabbri, D., Pramauro, E., Baiocchi, C., Medana, C., Montoneri, E. y Boffa, V. (2010). "Sensitizing effect of bio-based chemicals from urban wastes on the photodegradation of azo-dyes». Journal of Photochemistry and Photobiology A: Chemistry, 209, pp. 224-231.

Bianco Prevot, A., Avetta, P., Fabbri, D., Laurenti, E., Marchis, T., Perrone, D.G., Montoneri, E. y Boffa, V. (2011). "Waste-Derived Bioorganic Substances for LightInduced Generation of Reactive Oxygenated Species». ChemSusChem, 4, pp. 85-90.

Carra, I., Casas López, J.L., Santos-Juanes, L., Malato, S. y Sánchez Pérez, J.A. (2013). «Iron dosage as a strategy to operate the photo-Fenton process at initial neutral Ph». Chemical Engineering Journal, 224, pp. 67-74.

CHIN, Y.P., AIKEN, G. y O'LoughLIN, E. (1994). «Molecular weight, polydispersity, and spectroscopic properties of aquatic humic substances». Environmental Science Technology, 28, pp. 1853-1858.

De Luca, A., Dantas, R.F. y Esplugas, S. (2014). «Assessment of iron chelates efficiency for photo-Fenton at neutral pH». Water Research, 61, pp. 232242.

FAN, C., Tsul, L. y LIAO, M. (2011). «Parathion degradation and its intermediate formation by Fenton process in neutral environment». Chemosphere, 82, pp. 229-236.

FerReira, S.L.C., Dos Santos, W.N., Quintella, C.M, Neto, B.B. y Bosque-Sendra, J.M. (2004). «Doehler matrix: A chemometric tool for analytical chemistry. Review». Talanta, 63, pp. 1061-1067.

FuкuCH, S., Nisнimoto, R., Fukushima, M. у Zнu, Q. (2014). «Effects of reducing agents on the degradation of 2,4,6-tribromophenol in a heterogeneous Fenton-like system with an iron-loaded natural zeolite». Applied Catalysis B: Environmental, 147, pp. 411-419.

GAYA, U.I. y ABDulLaH, AH. (2008). «Heterogeneous photocatalytic degradation of organic contaminants over titanium dioxide: a review of fundamentals, progress and problems». Journal of Photochemistry and Photobiology C: Photochemistry Reviews, 9, pp. 1-12.

Greorgi, A., Schierz, A., Trommler, U., Horwitz, C.P., Collins, T.J. y Kopinke, F.D. (2007). «Humic modified Fenton reagent for enhancement of the working $\mathrm{pH}$ range». Applied Catalysis B: Environmental, 72, pp. 26-36. 
Gomis, J., Vercher, R., Amat, A.M., Mártire, D.O., González, M.C., Bianco Prevot, A., Montoneri, E., Amat, A.M., Arques, A. y Carlos, L. (2013). «Application of soluble bio-organic substances (SBO) as photocatalysts for wastewater treatment: Sensitizing effect and photo-Fenton-like process». Catalysis Today, 209, pp. 176-180.

Gomis, J., Bianco Prevot, A., Montonerl, E., González, M.C., Amat, A.M., Mártire, D.O., Arques, A. y CARlos, L. (2014). «Waste sourced bio-based substances for solar-driven wastewater remediation: Photodegradation of emerging pollutants». Chemical Engineering Journal, 235, pp. 236-243.

Gomis, J., Carlos, L., Bianco Prevot, A., Teixeira, A.C.S.C., Mora, M., Amat, A., Vicente, R. y ARQues, A. (2015). «Bio-based substances from urban waste as auxiliaries for solarphoto-Fenton treatment under mild conditions: Optimization of operational variables». Catalysis Today, 240, pp. 39-45.

Hong, J., Lu, S., ZHANG, C., Qı, S. y WANG, Y. (2011). «Removal of Rhodamine B under visible irradiation in the presence of $\mathrm{Fe} 0, \mathrm{H}_{2} \mathrm{O}_{2}$, citrate and aeration at circumneutral pH». Chemosphere, 84, pp. 1542-1547.

Huang, W., Brigante, M., Wu, F., Hanna, K. y Mallhot, G. (2013). «Effect of ethylenediamine- $\mathrm{N}, \mathrm{N}^{\prime}$-disuccinic acid on Fenton and photo Fenton processes using goethite as an iron source: optimization of parameters for bisphenol A degradation». Environmental Science and Pollution Research, 20, pp. 39-50.

HuG, S.J. y LeuPIN, O. (2003). «Iron-catalyzed oxidation of arsenic (III) by oxygen and by hydrogen peroxide: $\mathrm{pH}$-dependent formation of oxidants in the Fenton reaction». Environmental Science and Technology, 37, pp. 27342742.

Khan, J.A., He, X., Khan, H.M., Shah, N.S. y Dionysiou, D.D. (2013). "Oxidative degradation of atrazine in aqueous solution by $\mathrm{UV} / \mathrm{H}_{2} \mathrm{O}_{2} / \mathrm{Fe}^{2+}$ and UV/ $\mathrm{HSO}_{5}{ }^{-} / \mathrm{Fe}^{2+}$ processes: A comparative study». Chemical Engineering Journal, 218, pp. 376-383.

Khetan, S.K. y Collins, T.J. (2007). «Human Pharmaceuticals in the Aquatic Environment: A Challenge to Green Chemistry». Chemical Reviews, 107, pp. 2319-2364. 
Klamerth, N., Rizzo, L., Malato, S., Maldonado, M.I., Agüera, A. y Fernández-Alba, A. (2010). «Degradation of fifteen emerging contaminants at $1 \mu \mathrm{g} L-1$ initial concentrations by mild solar photo-Fenton in MWTP effluents». Water Research, 44, pp. 545-554.

Klamerth, N., Malato, S., Maldonado, M.I., Agüera, A. y Fernández-Alba, A.R. (2011). «Modified photo-Fenton for degradation of emerging contaminants in municipal wastewater effluents». Catalysis Today, 161, pp. 241-246.

Klamerth, N., Malato, S., Agüera, A. y Fernández-Alba, A.R. (2013). «Photo-Fenton and modified photo-Fenton at neutral $\mathrm{pH}$ for the treatment of emerging contaminants in wastewater treatment plant effluents: A comparison». Water Research, 47, pp. 833-840.

Legrinl, O., Oliveros, E. y Braun, A.M. (1994). «Photochemical processes for water treatment». Chemical Reviews, 93, pp. 671-698.

LIPCZYNSKA-KoCHANY, E. y KoCHANY, J. (2008). «Effect of humic substances on the Fenton treatment of wastewater at acidic and neutral $\mathrm{pH}$ ». Chemosphere, 73, pp. 745-750.

Malato, S., Blanco, J., Vidal, A.y Richter, C. (2002). «Photocatalysis with solar energy at a pilot-plant scale: an overview». Applied Catalysis B: Environmental, 37 , pp. 1-15.

Malato, S., Fernández-Ibánezz, P., Maldonado, M.I., Blanco, J. y Gernjak, W. (2009). «Decontamination and disinfection of water by solar photocatalysis: recent overview and trends». Catalysis Today, 147, pp. 1-59.

Marín, M.L., Arques, A., Santos-Juanes, L., Amat, A.M. y Miranda, M.A. (2012). «Organic photocatalysis for the oxidation of pollutants and model compounds». Chemical Reviews, 112, pp.1710-1750.

Mazillee, F., Schoettl, T., Klamerth, N., Malato, S. y Pulgarin, C. (2010). «Field solar degradation of pesticides and emerging water contaminants mediated by polymer films containing titanium and iron oxide with synergistic heterogeneous photocatalytic activity at neutral pH». Water Research, 44, pp. 3029-3038.

MikUtTA, C. y KRETZSCHMAR, R. (2011). «Spectroscopic evidence for ternary complex formation between arsenate and ferric iron complexes of humic substances». Environmental Science and Technology, 45, pp. 9550-9557. 
Monteagudo, J.M., Durán, A.M. y López-Almodóvar, C. (2008). «Homogeneus ferrioxa-late-assisted solar photo-Fenton degradation of Orange II aqueous solutions». Applied Catalysis B: Environmental, 83, pp. 46-55.

Montoneri, E., Mainero, D., Boffa, V., Perrone, D.G. y Montoneri, C. (2011). «Biochemenergy: a project to turn an urban wastes treatment plant into biorefinery for the production of energy, chemicals and consumer's products with friendly environmental impact». International Journal of Global Environmental Issues, 11, pp. 70-196.

Oller, I., Malato, S. y Sánchez-Pérez, J.A. (2011). «Combination of Advanced Oxidation Processes and biological treatments for wastewater decontamination - A review». Science of the Total Environment, 409, pp. 4141-4146.

Pignatello, J.J., Oliveros, E. y Mackay, A. (2006). «Advanced oxidation processes for organic contaminant destruction based on the Fenton reaction and related chemistry». Critical Reviews in Environmental Science and Technology, 36, pp. 1-84.

Nie, J., Hu, C., Qu, J., Zhou, L. y Hu, X. (2007). «Photoassisted degradation of azo dyes over FexH2x-3/FeO in the presence of $\mathrm{H}_{2} \mathrm{O}_{2}$ at neutral values». Environmental Science and Technology, 41, pp. 4715-4719.

Santos-Juanes, L., Amat, A.M., Arques, A., Bernabeu, A., Silvestre, M., Vicente, R. y Añó, E. (2008). «Activated sludge respirometry to assess solar detoxification of a metal finishing effluent». Journal of Hazardous Materials, 153, pp. 905910.

Silva, M.R.A., Trovó, A.G. y NogueiRA, R.F.P. (2007). «Degradation of the herbicide tebuthiuron using solar photo-Fenton process and ferric citrate complex at circumneutral $\mathrm{pH}$. Journal of Photochemistry and Photobiology A: Chemistry, 191, pp. 187-192.

VerMILYEA, W. y VoeLKER, B.M. (2009). «Photo-Fenton reaction at near neutral pH». Environmental Science and Technology, 43, pp. 6927-6933. 


\title{
Procesos electroquímicos de oxidación avanzada para el tratamiento de contaminantes orgánicos en aguas
}

\author{
Enric Brillas \\ Laboratori d'Electroquímica de Materials i del Medi Ambient \\ Departament de Química Física \\ Universitat de Barcelona \\ C/ Martí i Franquès 1-11, 08028 Barcelona, España
}

Contacto: brillas@ub.edu

\section{Enric Brillas}

Es licenciado en Ciencias Químicas en 1974 y doctor en Ciencias Química en 1977 por la Universitat Autònoma de Barcelona. Catedrático de bachillerato de Física y Química en el INB de Mollet del Vallés (Barcelona) en 1978-1980. En 1980 se incorporó como profesor adjunto al Departamento de Química Física de la Universitat de Barcelona. En 1982 completó sus estudios en la Università degli Studi di Padova (Italia) en electroquímica orgánica. Desde 1987 es catedrático de Química Física en la Universitat de Barcelona. Ha sido director del Departamento de Química Física en 20002008 y presidente del Grupo Especializado de Electroquímica de la Real Sociedad Española de Química en 2004-2008. Actualmente, es director del Laboratori d'Electroquímica dels Materials i del Medi Ambient en la Universitat de Barcelona. Su investigación se ha centrado en electroquímica orgánica, cinética química, catálisis química, fotocatálisis, electrocatálisis y tratamiento electroquímico de contaminantes orgánicos en aguas, donde ha desarrollado varios procesos electroquímicos de oxidación avanzada como el electro-Fenton, el fotoelectro-Fenton uva y solar y la peroxicoagulación. En 1995 recibió el premio internacional Chemviron Carbon por su investigación inicial sobre la degradación electro-Fenton con un electrodo de difusión de gas. En el 2015 ha recibido el premio CIDETEC-2014 a la trayectoria 
científica en electroquímica. Desde el 2008 es editor asociado de la revista Chemosphere de Elsevier. Ha dirigido 20 tesis doctorales, ha publicado 312 artículos en revistas JCR, 8 libros y 18 capítulos de libro y ha presentado 248 comunicaciones, con 34 conferencias invitadas, en congresos científicos nacionales e internacionales. Sus artículos poseen unas 10100 citaciones con un índice $\mathrm{h}=55$.

\section{Resumen}

Se describen las características y aplicaciones de procesos electroquímicos avanzados de oxidación como la oxidación anódica, el electro-Fenton y el fotoelectro-Fenton uva y solar para tratar contaminantes orgánicos en aguas residuales. Se presentan ejemplos sobre la degradación de colorantes, pesticidas y fármacos a escala de laboratorio de $100 \mathrm{~mL}$ y en plantas de flujo de 2,5 y $10 \mathrm{~L}$. Se remarca el reciente interés en el uso de plantas solares autónomas alimentadas con placas fotovoltaicas y de métodos acoplados con la fotocatálisis y la electrocoagulación.

\subsection{Introducción}

Un elevado número de compuestos orgánicos sintéticos, incluyendo colorantes, pesticidas y fármacos, son eliminados diariamente en grandes volúmenes de aguas residuales, entrando así en el ciclo de las aguas naturales donde se acumulan en el medioambiente acuático (Voudrias y otros, 2012; Brillas y Martínez-Huitle, 2015). Esta contaminación, que proviene de actividades humanas urbanas, industriales y agroalimentarias, no puede ser destruida completamente por los métodos convencionales utilizados en las estaciones depuradoras de aguas residuales (EDAR) dado que la mayoría de compuestos orgánicos son recalcitrantes y altamente estables a la luz solar, al ataque microbiano y a la temperatura. De este modo, se han detectado bajas cantidades de muchos compuestos sintéticos, usualmente a niveles de $\mu \mathrm{g}$ $\mathrm{L}^{-1}$, en ríos, lagos, océanos e incluso en el agua corriente de todo el mundo 
(Etchepare y van der Hoek, 2015). Para preservar las consecuencias nocivas de esta contaminación sobre los seres vivos, se están realizando grandes esfuerzos para degradar compuestos orgánicos mediante tecnologías seguras, efectivas y de bajo coste.

En las dos últimas décadas, se han desarrollado muchos procesos de oxidación avanzada (POA) que han despertado gran interés por la eficiente destrucción de contaminantes tóxicos o refractarios en aguas residuales (Anglada y otros, 2009; Sirés y Brillas, 2012). Los POA son tecnologías potentes, amigables ambientalmente y que incluyen métodos químicos, fotoquímicos, fotocatalíticos, electroquímicos y fotoelectroquímicos. Su denominador común es que generan radicales hidroxilo $(\cdot \mathrm{OH})$ con un elevado potencial estándar de reducción $\left(\mathrm{E}^{\mathrm{O}}\left(\cdot \mathrm{OH} / \mathrm{H}_{2} \mathrm{O}\right)=2.80 \mathrm{~V} / \mathrm{SHE}\right)$. Ello asegura su reactividad no selectiva con muchos compuestos orgánicos, dando lugar a derivados deshidrogenados o hidroxilados hasta su total mineralización, es decir, su conversión en $\mathrm{CO}_{2}$, agua e iones inorgánicos (Panizza y Cerisola, 2009; Sirés y otros, 2014; Vasudevan y Oturan, 2014). Nosotros nos centraremos en los procesos electroquímicos de oxidación avanzada (PEOA), que presentan ventajas tecnológicas tales como compatibilidad medioambiental, versatilidad, alta eficiencia, bajo coste, fácil manejo incluso automatizado y seguridad, porque se opera en condiciones ambientales (Sirés y otros, 2014). El PEOA más sencillo es la electrooxidación u oxidación anódica (OA), basado en la destrucción de los compuestos orgánicos bajo la acción del ánodo de la celda electrolítica. Cuando se genera $\mathrm{H}_{2} \mathrm{O}_{2}$ en el cátodo alimentado con $\mathrm{O}_{2}$ o aire, se utiliza la oA con $\mathrm{H}_{2} \mathrm{O}_{2}$ electrogenerado (Sirés y otros, 2014). Si bajo estas últimas condiciones se añade $\mathrm{Fe}^{2+}$ a la solución con un $\mathrm{pH}$ ácido, se opera con el proceso electro-Fenton (EF). Se ha encontrado que la capacidad oxidativa tanto en $\mathrm{OA}$ como en EF depende del material anódico, siendo el diamante dopado con boro (DDB) el que ha mostrado un mejor rendimiento. La eficiencia del proceso ef puede mejorarse iluminando la solución con luz UVA o solar, correspondiendo a los métodos denominados fotoelectro-Fenton UVA (FEF) y fotoelectro-Fenton solar (FEFS).

En este capítulo se presentan las características y aplicaciones de los anteriores PEOA a la degradación de contaminantes orgánicos usando ánodos de DDB. Se examinarán ejemplos sobre el tratamiento de colorantes, pesticidas y herbicidas efectuados con distintos sistemas en nuestro laboratorio de la Universitat de Barcelona. También se describirá el uso de una planta solar 
autónoma alimentada con placas fotovoltaicas y de PEOA acoplados con los métodos de fotocatálisis y electrocoagulación. En un principio, se describirán los fundamentos de lOS PEOA para poder analizar mejor sus propiedades oxidativas.

\subsection{Fundamentos de los procesos electroquímicos de oxidación avanzada}

En la oA se utilizan celdas electrolíticas divididas o sin dividir con un ánodo de alto sobrevoltaje de $\mathrm{O}_{2}$ para favorecer la formación de radicales hidroxilo. La figura 4.1 presenta un esquema de una celda de flujo dividida con una membrana de intercambio catiónico para que los $\mathrm{H}^{+}$originados en exceso en el anolito pasen al catolito y neutralicen al exceso de $\mathrm{OH}^{-}$. Por este último compartimento circula una disolución acuosa con el electrólito de fondo y el agua se reduce en el cátodo a $\mathrm{H}_{2}$ gas e ion hidróxido. Por el anolito pasa la solución a tratar con el compuesto orgánico $\mathrm{R}$, de modo que sobre el ánodo se generan radicales $\cdot \mathrm{OH}$ por oxidación del agua junto con $\mathrm{H}^{+}$. Los radicales $\cdot \mathrm{OH}$ atacan al compuesto $\mathrm{R}$ hasta mineralizarlo a $\mathrm{CO}_{2}$. El mejor ánodo para la oA es el DDB que produce radicales $\cdot \mathrm{OH}$ mediante la siguiente reacción (Marselli y otros, 2003; Panizza y Cerisola, 2009):

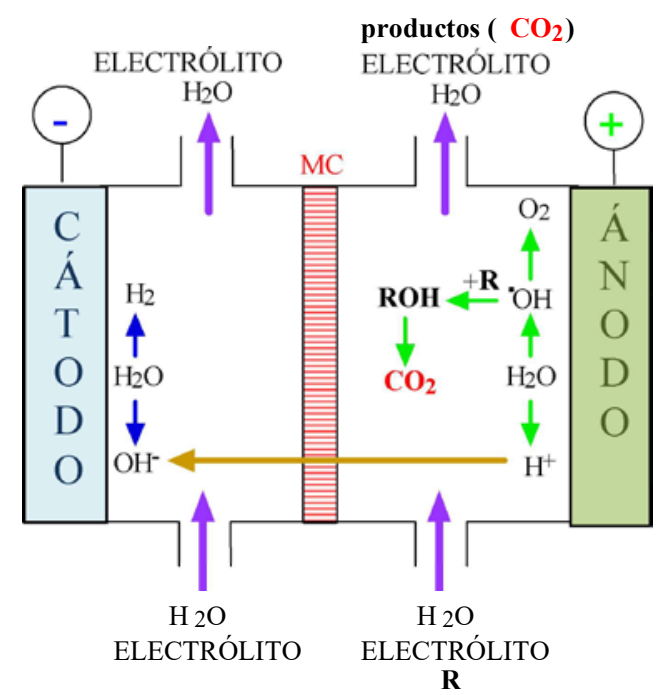

Figura 4.1. Esquema de una celda dividida para $O A$ 


$$
\mathrm{DDB}+\mathrm{H}_{2} \mathrm{O} \rightarrow \mathrm{DDB}(\cdot \mathrm{OH})+\mathrm{H}^{+}+\mathrm{e}^{-}
$$

El ánodo de DDB se caracteriza por poseer un gran dominio electroquímico (hasta unos $3 \mathrm{Ven}_{2} \mathrm{SO}_{4} 1 \mathrm{M}$ ), una lenta evolución del oxígeno (alto sobrevoltaje de $\mathrm{O}_{2}$ ), una alta estabilidad y resistencia química en medios ácido y alcalino y una interacción débil tanto con el radical $\cdot \mathrm{OH}$ como con los contaminantes orgánicos. Todo ello le confiere una mayor producción de radicales reactivos -OH que otros ánodos comunes de Pt y de óxidos metálicos, poseyendo mayor poder de oxidación sobre los contaminantes orgánicos y conduciéndolos a su mineralización total.

El uso de cátodos carbonáceos permite la acumulación de $\mathrm{H}_{2} \mathrm{O}_{2}$ en el medio por la reducción bielectrónica de $\mathrm{O}_{2}$ puro o procedente del aire (Sirés y otros, 2014):

$$
\mathrm{O}_{2(\mathrm{~g})}+2 \mathrm{H}^{+}+2 \mathrm{e}^{-} \rightarrow \mathrm{H}_{2} \mathrm{O}_{2}
$$

Cuando se aplica el método de $\mathrm{OA}-\mathrm{H}_{2} \mathrm{O}_{2}$ con este tipo de cátodo, la principal especie oxidante sigue siendo el radical $\cdot \mathrm{OH}$, aunque otros oxidantes más débiles como el $\mathrm{H}_{2} \mathrm{O}_{2}$ o su producto de oxidación anódica, el radical hidroperoxilo $\left(\mathrm{HO}_{2} \cdot\right)$, también puede ayudar a degradar los contaminantes orgánicos (Sirés y otros, 2014).

El poder oxidante del $\mathrm{H}_{2} \mathrm{O}_{2}$ se incrementa enormemente en presencia del ion $\mathrm{Fe}^{2+}$, que actúa como catalizador de la conocida reacción de Fenton para producir ion $\mathrm{Fe}^{3+} \mathrm{y}$ radical $\cdot \mathrm{OH}$ (Vasudevan y Oturan, 2014):

$$
\mathrm{Fe}^{2+}+\mathrm{H}_{2} \mathrm{O}_{2} \rightarrow \mathrm{Fe}^{3+}+\cdot \mathrm{OH}+\mathrm{OH}^{-}
$$

En el proceso ef se genera pues $\mathrm{H}_{2} \mathrm{O}_{2}$ en el cátodo y se adiciona una pequeña cantidad de $\mathrm{Fe}^{2+}$ a la solución a tratar con un $\mathrm{pH}$ óptimo de 3. La figura 4.2 muestra un esquema de las principales reacciones que tienen lugar en el proceso ef haciendo uso de un cátodo de carbón-PTFE de difusión de gas $\left(\mathrm{O}_{2} \mathrm{O}\right.$ aire), habitual en nuestro laboratorio. Puede verse que se generan dos tipos de radicales $\cdot \mathrm{OH}$, los heterogéneos sobre el ánodo por la reacción (4.1) 


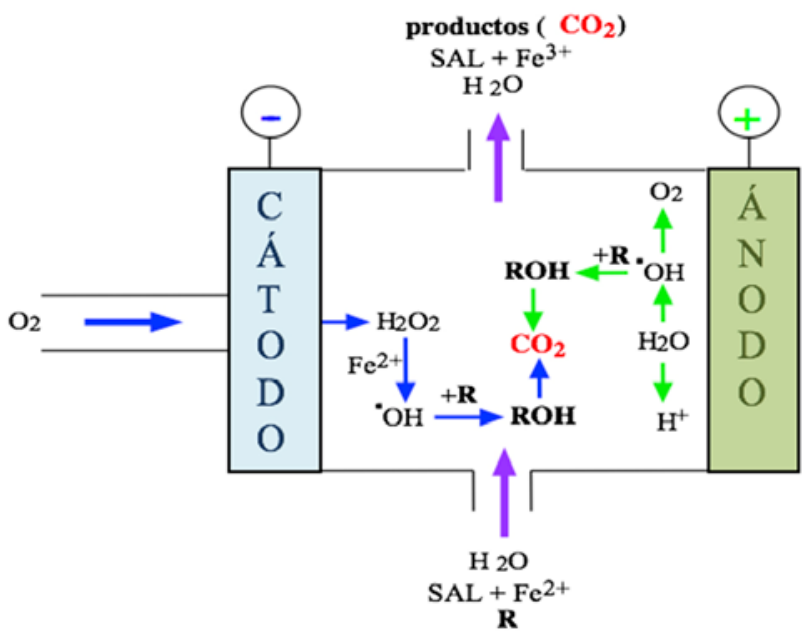

Figura 4.2. Celda de flujo para el proceso ef con un cátodo de difusión de $\mathrm{O}_{2}$

y los homogéneos en el medio mediante la reacción de Fenton (4.3). El poder oxidante de estos radicales varía según el tipo de contaminante $\mathrm{R}$ a tratar, como veremos más adelante.

Una desventaja importante del proceso ef al degradar compuestos aromáticos es que se originan ácidos carboxílicos alifáticos de cadena corta que forman complejos de Fe(III) tan estables que no pueden ser destruidos fácilmente por los radicales $\cdot \mathrm{OH}$, tanto homogéneos como heterogéneos (Brillas y Martínez Huitle, 2015). Para resolver este problema, en nuestro laboratorio hemos planteado el uso alternativo de los procesos fef y feFs (Garcia-Segura y Brillas, 2014).

LoS procesos FEF y FEFS consisten en la irradiación de la solución bajo tratamiento EF por luz artificial uva o luz solar, respectivamente. Esta irradiación puede ayudar a destruir los contaminante orgánicos mediante 2 acciones en paralelo: $a$ ) la producción de más radicales $\cdot \mathrm{OH}$ en el medio por la fotólisis de las especies $\mathrm{Fe}(\mathrm{OH})^{2+}$ según la reacción (4.4) y b) la fotodescarboxilación de complejos Fe(III)-carboxilato originados como productos de reacción (Sirés y otros, 2014) según la reacción (4.5). 


\begin{tabular}{|c|c|}
\hline $\mathrm{Fe}(\mathrm{OH})^{2+}+h v \rightarrow \mathrm{Fe}^{2+}+\cdot \mathrm{OH}$ & (4.4) \\
\hline $\mathrm{Fe}(\mathrm{OOCR})^{2+}+h v \rightarrow \mathrm{Fe}^{2+}+\mathrm{CO}_{2}+\mathrm{R} \cdot$ & (4.5) \\
\hline
\end{tabular}

\subsection{Degradación de contaminantes en una celda tipo tanque de $100 \mathrm{~mL}$}

La figura 4.3 esquematiza una celda tipo tanque utilizada en nuestro laboratorio para degradar soluciones de $100 \mathrm{~mL}$ de contaminantes orgánicos en aguas residuales mediante los anteriormente mencionados PEOA. Puede verse que la solución se mantiene agitada, así como termostatizada gracias a una camisa externa por la que circula agua con temperatura regulada por un termostato. El ánodo es de DDB, mientras que el cátodo, de carbón-PTFE, se encuentra en el borde inferior de un soporte cilíndrico de polipropileno por el que se alimenta gas $\mathrm{O}_{2}$ para generar $\mathrm{H}_{2} \mathrm{O}_{2}$ según la reacción (4.2). En los procesos FEF y FEFs, la solución se ilumina con una lámpara uVA de $6 \mathrm{~W}$ o directamente a la luz solar, respectivamente.

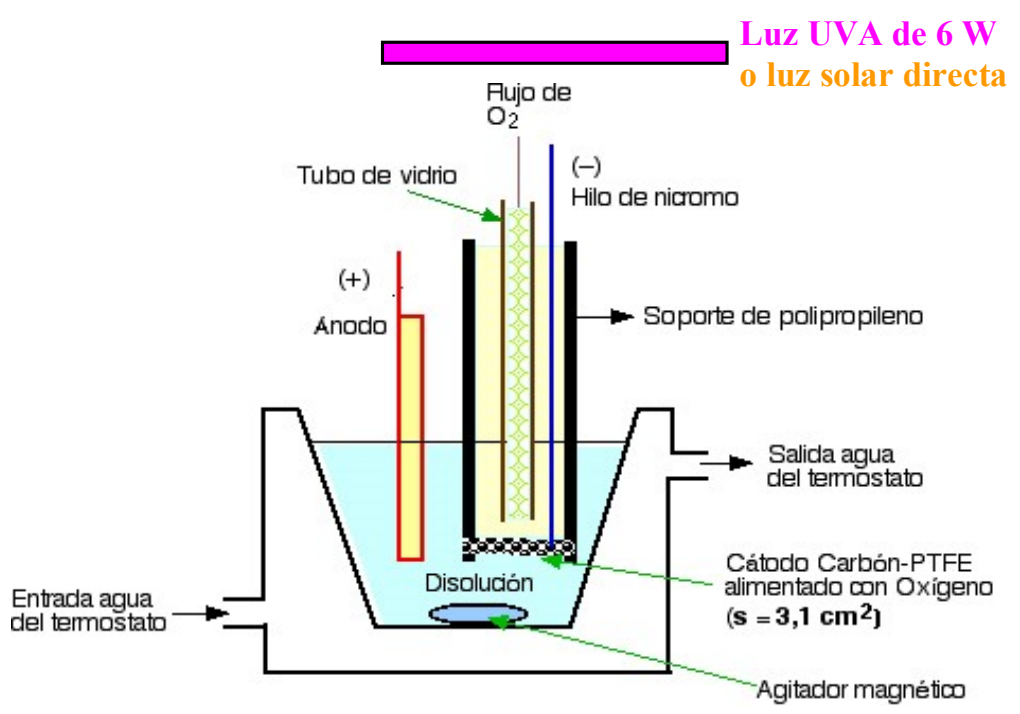

Figura 4.3. Celda tipo tanque de $100 \mathrm{~mL}$ utilizado en el laboratorio para los PEOA 


\subsection{1. Ácido salicílico}

La figura 4.4a muestra el decaimiento del carbono orgánico total (сот) de la solución con la carga específica para $100 \mathrm{~mL}$ de $164 \mathrm{mg} \mathrm{L}^{-1}$ de ácido salicílico (forma hidrolizada de la aspirina) en $\mathrm{Na}_{2} \mathrm{SO}_{4} 0,05 \mathrm{M}$ a pH 3,0 para una densidad de corriente de $33 \mathrm{~mA} \mathrm{~cm}^{-2}$ y $35^{\circ} \mathrm{C}$ degradados por PEOA (Guinea y otros, 2008). Se aprecia que el poder oxidante de los métodos crece según $\mathrm{OA}<\mathrm{EF}<\mathrm{FEF}<\mathrm{FEFS}$.

El método menos potente es la OA donde solo los radicales $\cdot \mathrm{OH}$ formados por la reacción (4.1) actúan como oxidantes. La capacidad oxidativa aumenta en EF por la acción en paralelo de los radicales $\cdot \mathrm{OH}$ originados por la reacción de Fenton (4.3). En el proceso fEF la solución es completamente mineralizada en $3 \mathrm{~h}$ debido a la fotólisis de los complejos de Fe(III)-carboxilato bajo la luz UVA, la cual es aún más rápida en fefs dada la mayor intensidad de la luz uv suministrada por la irradiación solar. Este último método es tan potente que puede mineralizar totalmente la solución en $2 \mathrm{~h}$ a $33,3 \mathrm{~mA} \mathrm{~cm}{ }^{-2}$ y tan solo en $1 \mathrm{~h}$ a $150 \mathrm{~mA} \mathrm{~cm}^{-2}$, como evidencia la figura 4.4(b). Ello se explica por la aceleración de todas las reacciones electródicas que dan lugar a una mayor cantidad de radicales $\cdot \mathrm{OH}$, los cuales producen más rápidamente complejos de Fe(III)-carboxilato que son más rápidamente fotodescarboxilados por la luz solar.

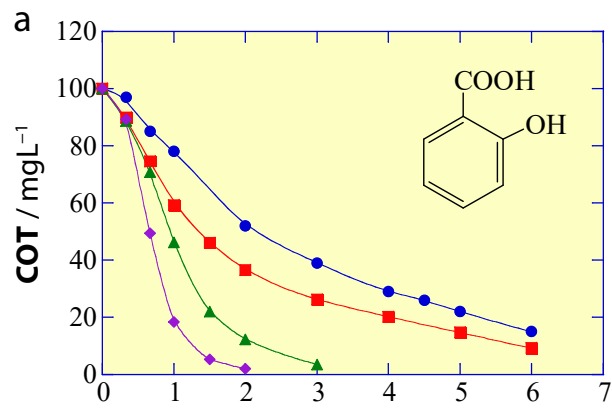

Carga específica / Ah $\mathrm{L}^{-1}$

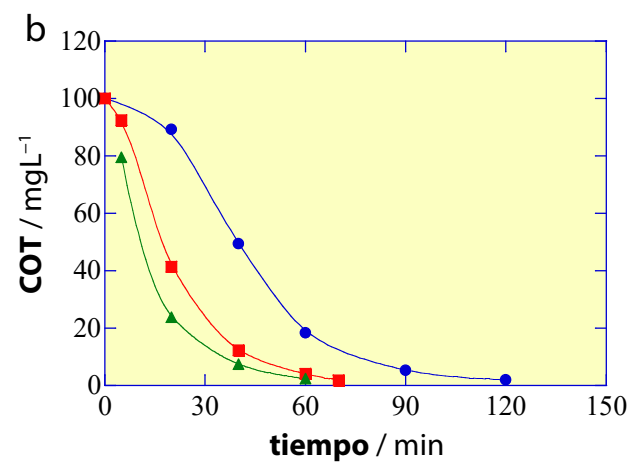

Figura 4.4. (4.4a) Descenso del сот con la carga específica para $100 \mathrm{~mL}$ de $164 \mathrm{mg} \mathrm{L}^{-1}$ de ácido

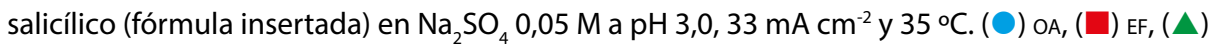
FEF y $(\diamond)$ FEFs con un ánodo de DDB. En los tres últimos casos, se añadió $\mathrm{Fe}^{2+} 0,50 \mathrm{mM}$. (4.4b) Efecto de la densidad de corriente sobre la reducción del cot con el tiempo de electrólisis en FEFs. (O) $33.3,(\square) 100$ y ( $(\Delta) 150 \mathrm{~mA} \mathrm{~cm}^{-2}$ (Guinea y otros, 2008) 


\subsubsection{Ibuprofeno}

La figura 4.5a pone de manifiesto que el proceso ef elimina lentamente el сот de una solución saturada del antiinflamatorio ibuprofeno en $\mathrm{Na}_{2} \mathrm{SO}_{4}$ $0,05 \mathrm{M} \mathrm{y} \mathrm{Fe}^{2+} 0,50 \mathrm{mM}$ a pH 3,0, $33 \mathrm{~mA} \mathrm{~cm}^{-2}$ y $25^{\circ} \mathrm{C}$ usando la celda de DDB/ difusión de $\mathrm{O}_{2}$, hasta un $80 \%$ de mineralización en $6 \mathrm{~h}$. En cambio, la fotólisis de los intermedios por la luz UVA acelera el proceso degradativo alcanzándose un $95 \%$ de mineralización mediante el proceso fEF al mismo tiempo. También se desprende de la figura 4.5a que el feFs es mucho más potente al reducir el сот en un $90 \%$ en tan solo $2 \mathrm{~h}$, pero sin lograr una mayor mineralización debido a la formación de productos altamente recalcitrantes que no pueden ser destruidos ni por los radicales $\cdot \mathrm{OH}$ ni por la luz Uva. La figura $4.5 \mathrm{~b}$ revela que el ibuprofeno desaparece de la disolución a los 30 min del tratamiento fEF e incluso en menor tiempo para el FEFs, hecho que indica que la luz solar induce la producción de más radicales $\cdot \mathrm{OH}$ por la reacción fotolítica (4.4).

Los intermedios aromáticos se identificaron por HPLC de fase inversa y se encontró que el producto mayoritario era la 4-isobutilacetofenona. La figura 4.6a muestra que este derivado del ibuprofeno se acumula y destruye más rápidamente de acuerdo con la capacidad oxidativa del método utilizado, es decir, EF < FEF < FEFS. Los ácidos carboxílicos alifáticos finales, detectados por HPLC de exclusión iónica, presentaban un comportamiento bien diferente. La
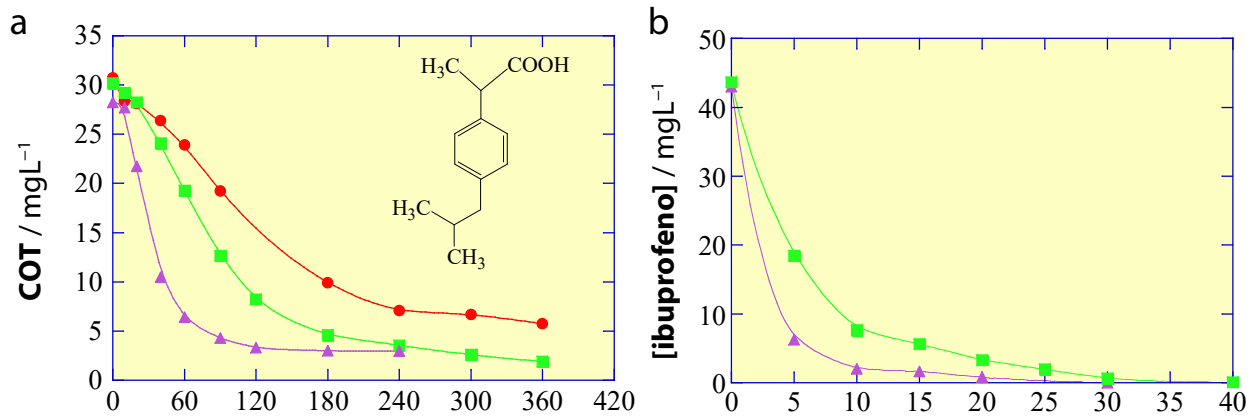

Figura 4.5. (4.5a) Descenso del cot con el tiempo de electrólisis para $100 \mathrm{~mL}$ de $43 \mathrm{mg} \mathrm{L}^{-1}$ de ibuprofeno (fórmula insertada) en $\mathrm{Na}_{2} \mathrm{SO}_{4} 0,05 \mathrm{M} \mathrm{y} \mathrm{Fe}^{2+} 0,50 \mathrm{mM}$ a pH 3,0, $33 \mathrm{~mA} \mathrm{~cm}^{-2} \mathrm{y}$

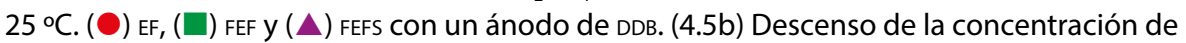
ibuprofeno (solución saturada) por ( $\square$ ) FEF y (A) FEFs (Skoumal y otros, 2009) 

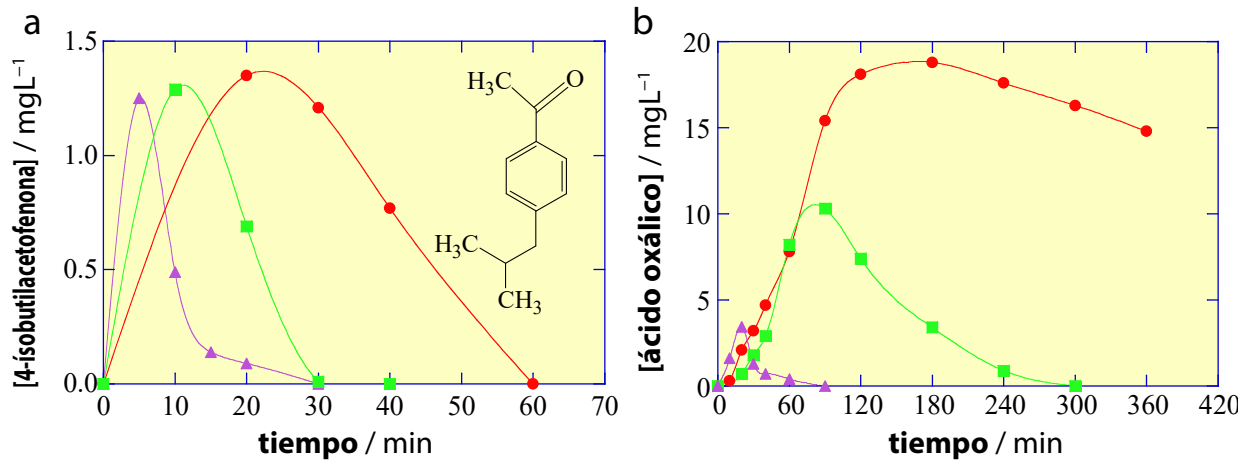

Figura 4.6. Evolución (4.6a) de la 4-ísobutilacetofenona y (4.6b) del ácido oxálico detectados durante los procesos mostrados en la figura 3.5. (O) EF, ( $\square$ ) FEF y ( $\mathbf{\Delta})$ fEFs (Skoumal y otros, 2009)

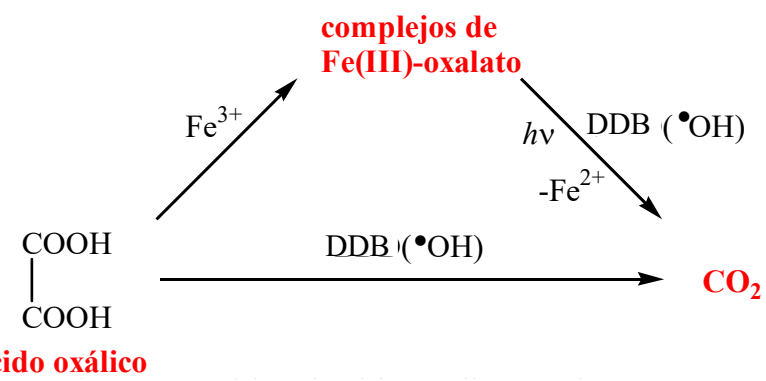

Figura 4.7. Caminos de reacción para oxidar el ácido oxálico por los PEOA (Skoumal y otros, 2009)

figura 4.6b evidencia que los complejos de Fe(III) del producto final, el ácido oxálico, son destruidos muy lentamente por los radicales $\cdot \mathrm{OH}$, primordialmente el $\mathrm{DDB}(\cdot \mathrm{OH})$, mientras que son fácilmente fotolizados en FEF y mucho más rápidamente fotodescarboxilados en FEFs. En base a estos resultados, en la figura 4.7 se proponen los caminos de reacción para el ácido oxálico por los PEOA. 


\subsection{Degradación en planta de flujo a escala de laboratorio}

Con objeto de mostrar la viabilidad de los PEOA para su posible aplicación a escala industrial, hemos construido una planta de flujo para tratar $2,5 \mathrm{~L}$ de soluciones con contaminantes orgánicos. La figura 4.8 presenta un esquema de los componentes de esta planta prepiloto, mientras que la figura 4.9a muestra una foto de la planta y la figura $4.9 \mathrm{~b}$ de la celda filtro prensa incorporada a ella. La solución se introduce en el depósito y recircula por todo el sistema gracias a una bomba peristáltica, operando así en modo batch. La velocidad de flujo se regula con un caudalímetro y la temperatura se mantiene constante mediante dos intercambiadores de calor. La solución atraviesa después la celda electroquímica, que contiene un ánodo de DDB y un cátodo de difusión de aire, ambos de $20 \mathrm{~cm}^{2}$ de área. Los ensayos se han efectuado a densidad de corriente constante suministrada por una fuente de alimentación. Para aplicar los procesos FEF y FEFS, la solución pasa finalmente por un fotorreactor planar, iluminado con una lámpara uva en el primer caso y directamente por la luz solar en el segundo caso.

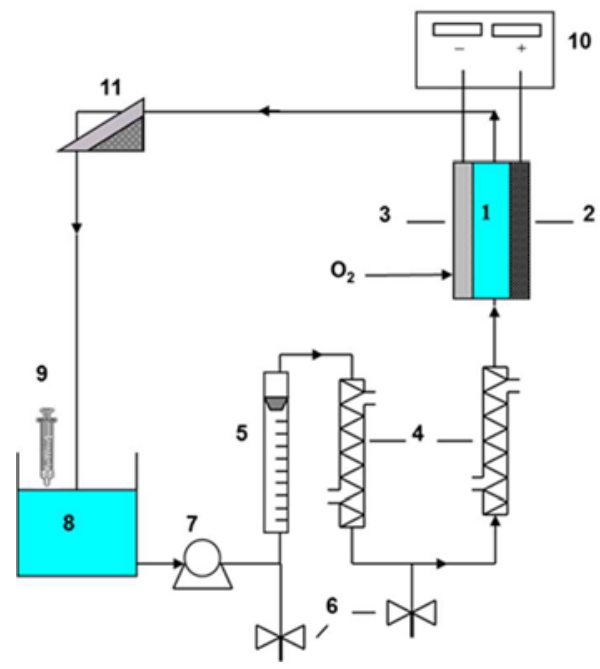

Figura 4.8. Esquema de una planta de flujo a escala de laboratorio para tratar $2,5 \mathrm{~L}$ de soluciones de contaminantes orgánicos por PEOA. 1) Celda electroquímica de filtro prensa, 2) ánodo de $\mathrm{DDB}$ de $20 \mathrm{~cm}^{2}, 3$ ) cátodo de difusión de $\mathrm{O}_{2}$ o aire de $20 \mathrm{~cm}^{2}, 4$ ) intercambiadores de calor, 5) caudalímetro, 6) válvula de purga, 7) bomba peristáltica, 8) depósito, 9) muestreo, 10) fuente de alimentación y 11) fotorreactor solar para FEFS 

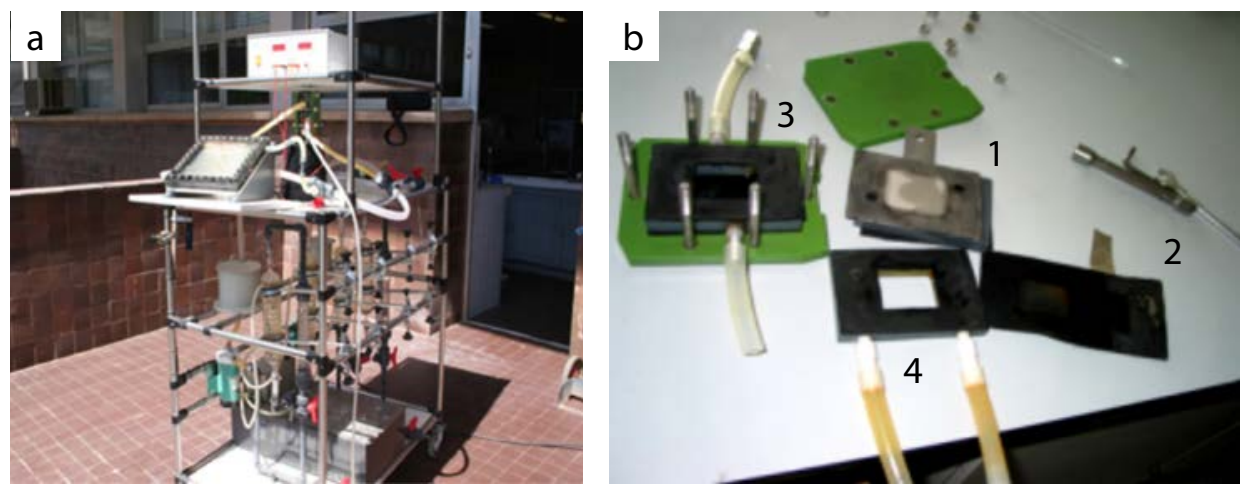

Figura 4.9. Fotografía (4.9a) de una planta de flujo de $2,5 \mathrm{~L}$ con un fotorreactor planar solar y (4.9b) de los componentes de su celda filtro prensa con 1) un ánodo de DDB y 2) un cátodo de difusión de $\mathrm{O}_{2} \mathrm{O}$ aire, mostrando el compartimento 3) del gas detrás del cátodo y 4) del líquido entre los electrodos

\subsubsection{Mecoprop}

El gran poder oxidante de los PEOA en la planta de flujo de $2,5 \mathrm{~L}$ se ha puesto de manifiesto para la degradación de soluciones de $100 \mathrm{mg} \mathrm{L}^{-1}$ del herbicida mecoprop en $\mathrm{Na}_{2} \mathrm{SO}_{4} 0,05 \mathrm{M} \mathrm{y} \mathrm{Fe}^{2+} 0,50 \mathrm{mM}$ a pH 3,0, $50 \mathrm{~mA} \mathrm{~cm}{ }^{-2}$ y $35^{\circ} \mathrm{C}$, con una velocidad de flujo de $200 \mathrm{~L} \mathrm{~h}^{-1}$ (Flox y otros, 2007). Se aprecia en la figura 4.10a que, como era de esperar, el poder oxidante de los procesos incrementa en el orden EF < FEF < FEFS. Sin embargo, para el proceso más potente de FEFS, se observa que el cot decae hasta un $83 \%$ en 2 h de electrólisis, pero su posterior mineralización es tan lenta que la solución no llega a descontaminarse completamente después de $9 \mathrm{~h}$. El proceso de degradación del mecoprop da lugar a la pérdida de su átomo de $\mathrm{Cl}$ en la forma de ion $\mathrm{Cl}-$, el cual es oxidado gradualmente $\mathrm{Cl}_{2}$ gas sobre el ánodo de DDB, tal como puede verse en la figura 4.10b.

Se ha estudiado el efecto de varios parámetros operacionales sobre el rendimiento del proceso FEFS. La figura 4.11 a evidencia que el poder oxidante de este método es muy parecido para mineralizar soluciones de $100 \mathrm{mg} \mathrm{L}^{-1}$ de mecoprop con concentraciones de $\mathrm{Fe}^{2+}$ entre 0,25 y 5,0 mM y densidades de corriente entre 25 y $150 \mathrm{~mA} \mathrm{~cm}^{-2}$. Estos resultados confirman la gran capacidad oxidativa del método FEFs, permitiéndole operar con bajos contenidos de $\mathrm{Fe}^{2+} \mathrm{y}$ bajas densidades de corriente para minimizar los costes operacionales. 

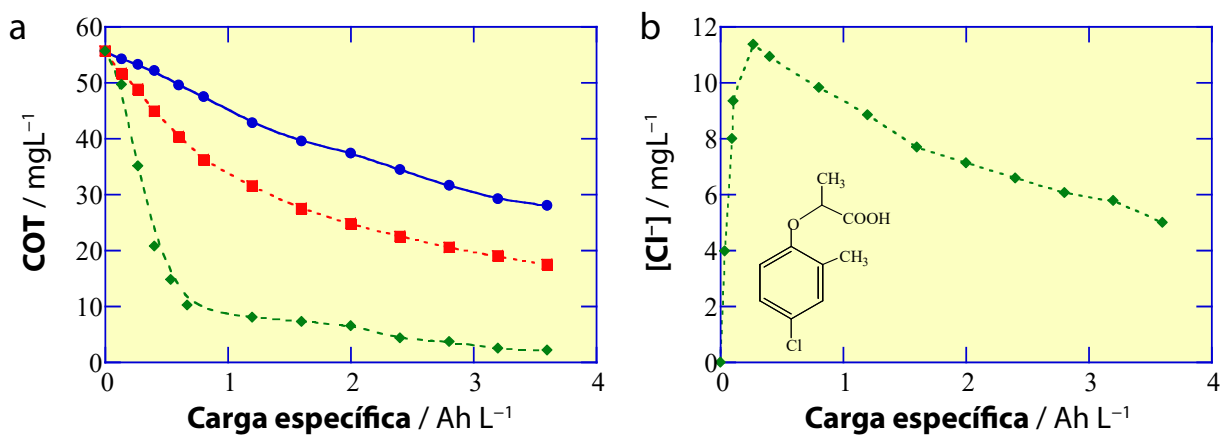

Figura 4.10. (4.10a) Descenso del cot y (4.10b) evolución del ion cloruro liberado con la carga específica para la degradación de $2,5 \mathrm{~L}$ de $100 \mathrm{mg} \mathrm{L}^{-1}$ de mecoprop (fórmula insertada) en $\mathrm{Na}_{2} \mathrm{SO}_{4} 0,05 \mathrm{M} \mathrm{y} \mathrm{Fe}^{2+} 0,50 \mathrm{mM} \mathrm{a} \mathrm{pH} \mathrm{3,0,50} \mathrm{mA} \mathrm{cm}{ }^{-2}$ y $35^{\circ} \mathrm{C}$. ( $(\bullet) \mathrm{EF},(\square)$ FEF y $(\diamond)$ feFs (Flox y otros, 2007)
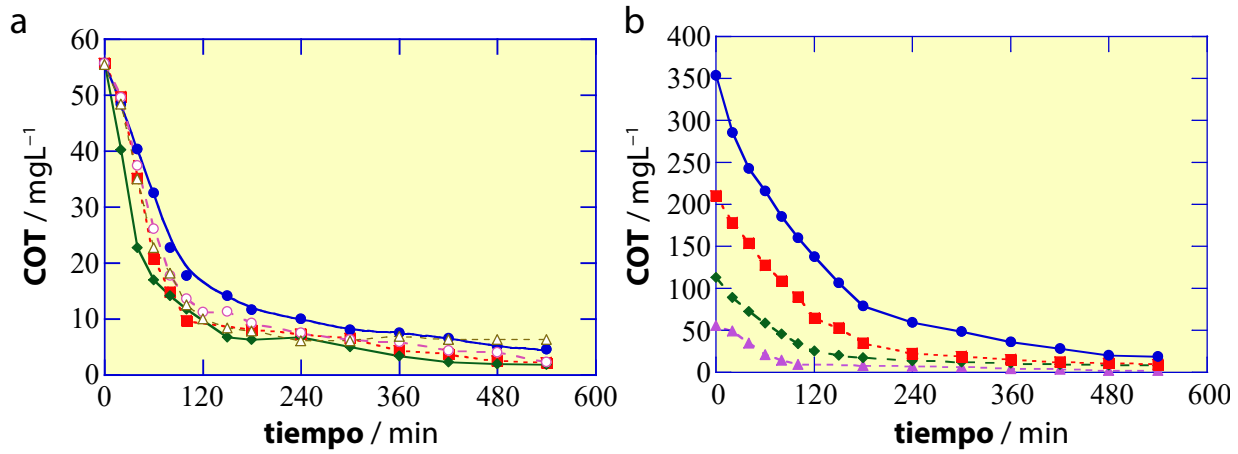

Figura 4.11. (4.11a) Descenso del сот y (4.11b) evolución del ion cloruro liberado con la carga específica para la degradación de $2,5 \mathrm{~L}$ de $100 \mathrm{mg} \mathrm{L}^{-1}$ de mecoprop (fórmula insertada) en $\mathrm{Na}_{2} \mathrm{SO}_{4} 0,05 \mathrm{M} \mathrm{y} \mathrm{Fe}^{2+} 0,50 \mathrm{mM}$ a pH 3,0,50 mA cm${ }^{-2}$ y $35^{\circ} \mathrm{C}$. ( $(\bullet)$ EF, ( $\left.\square\right)$ FeF y $(\diamond)$ feFs (Flox y otros, 2007)

El gran poder oxidante del proceso fEFs también se corroboró al tratar soluciones más concentradas de mecoprop. La figura $4.11 \mathrm{~b}$ revela que incluso una solución saturada del herbicida puede ser eficientemente mineralizada hasta un $97 \%$ operando a $50 \mathrm{~mA} \mathrm{~cm}^{-2}$ en $9 \mathrm{~h}$, con un coste energético de $46 \mathrm{kWh} \mathrm{m}^{-3}$ similar a menores concentraciones hasta $50 \mathrm{mg} \mathrm{L}^{-1}$. Este comportamiento pone de manifiesto que el proceso fEFs se torna más eficiente a medida que aumenta el contenido de contaminante. 

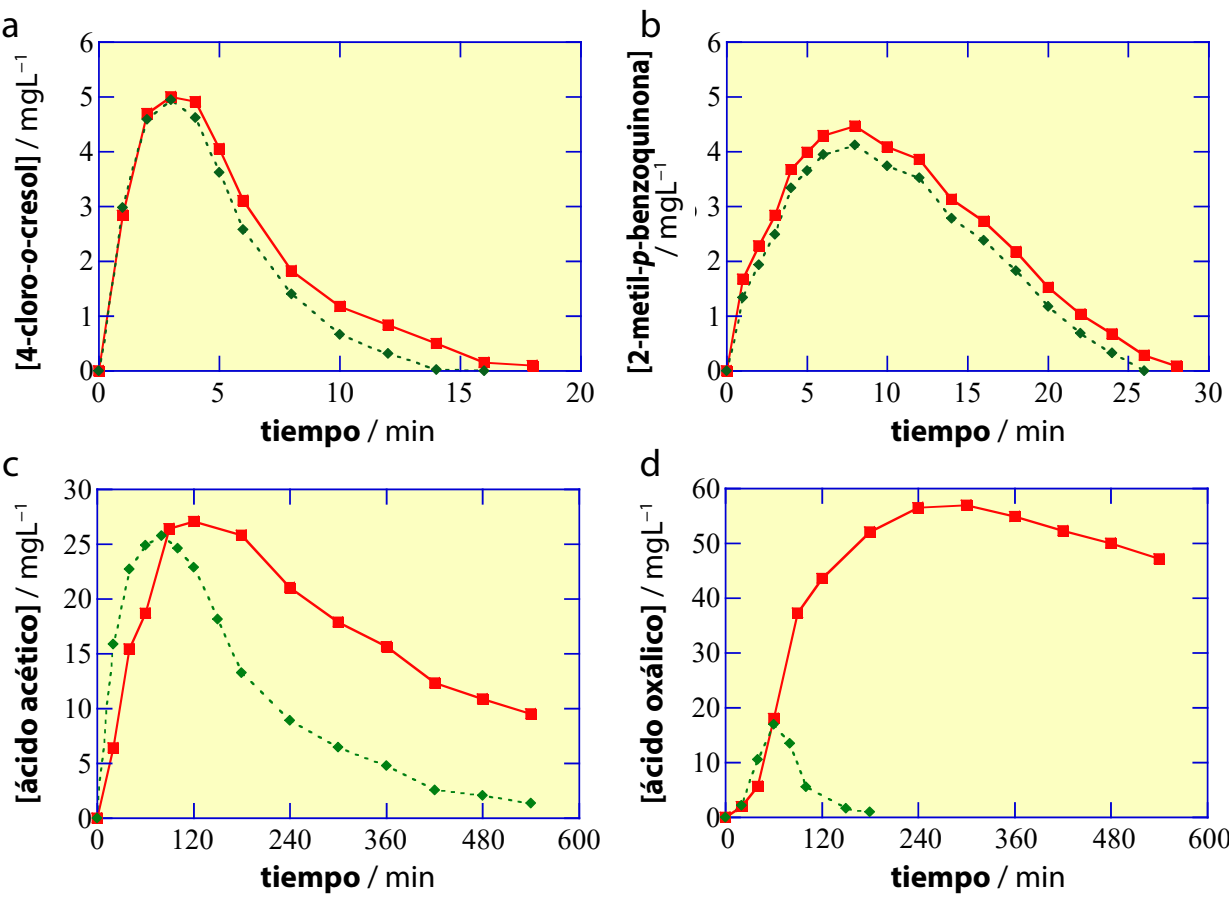

Figura 4.12. Evolución de: (4.12a) 4-cloro-o-cresol, (4.12b) 2.metil-p-benzoquinona, (4.12c) ácido acético y (4.12d) ácido oxálico para $2,5 \mathrm{~L}$ de $100 \mathrm{mg} \mathrm{L}^{-1}$ mecoprop en $\mathrm{Na}_{2} \mathrm{SO}_{4} 0,05 \mathrm{M}$ y Fe$^{2+}$ $0,50 \mathrm{mM}$ a pH $3,0,50 \mathrm{~mA} \mathrm{~cm}^{-2}$ y $35^{\circ} \mathrm{C}$. ( $\square$ ) ef y $(\diamond)$ FeFs (Flox y otros, 2007)

a

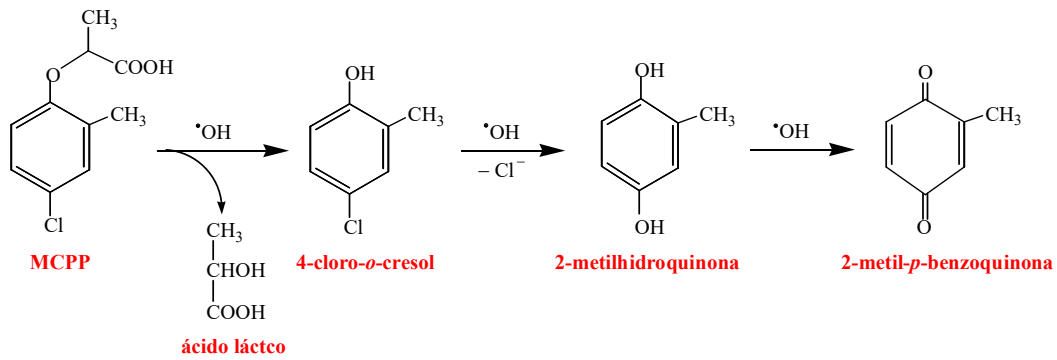

b

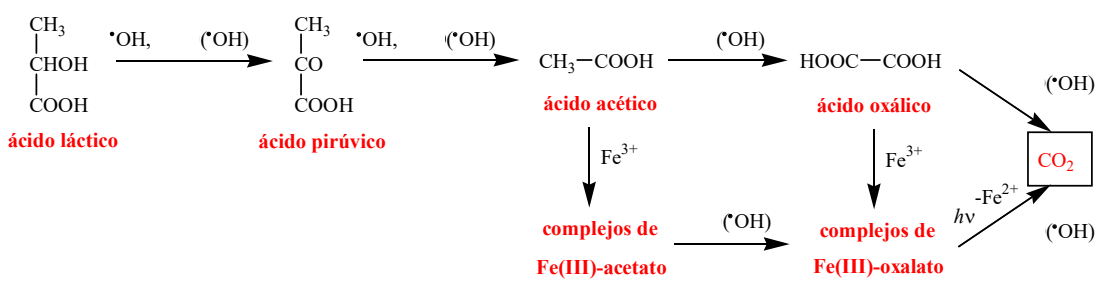

Figura 4.13. Caminos de reacción para la mineralización del herbicida mecoprop por FEFS.

(4.13a) Proceso inicial. (4.13b) Ácidos carboxílicos finales (Flox y otros, 2007) 
El cambio de concentración de los principales intermedios se siguió por HPLC. La figura 4.12a y la figura 4.12b muestran una evolución similar por EF y fEFs para los dos derivados aromáticos más importantes, el 4-cloro-ocresol y la 2.metil-p-benzoquinona. Ello indica que ambos compuestos son primordialmente destruidos por los radicales $\mathrm{OH}$ producidos por la reacción de Fenton (4.3). El comportamiento es muy diferente para los ácidos carboxílicos finales. La figura 4.12c revela que existe poca diferencia en la evolución del ácido acético por ambos métodos, sugiriendo que los complejos de $\mathrm{Fe}(\mathrm{III})$ acetato son oxidados por los radicales DDB $(\cdot \mathrm{OH})$ formados por la reacción (4.1). La figura $4.12 \mathrm{~d}$ pone de manifiesto que estos últimos radicales destruyen muy lentamente los complejos de Fe(III)-oxalato en EF, mientras que estos complejos son rápidamente fotodescarboxiladas por la luz uv de la luz solar en FEFs, tal como se ha mencionado anteriormente. Estos resultados permiten concluir que después de $2 \mathrm{~h}$ de feFs (véase la figura 4.10a) solo queda ácido acético en la solución y su lenta destrucción explica la inhibición del descenso del cot de la solución a tiempos entre 2 y $9 \mathrm{~h}$ de electrólisis.

En base a los intermedios obtenidos se han propuesto los caminos de reacción para la mineralización del mecoprop por el método FEFs. La figura 4.13a ilustra que el compuesto inicial se convierte en 4-cloro-o-cresol con pérdida de ácido láctico, siendo luego consecutivamente oxidado a 2-metilhidroquinona y 2-metil-p-benzoquinona, todos ellos bajo la acción de los radicales $\cdot \mathrm{OH}$. La figura 4.13b muestra la oxidación sucesiva del ácido láctico en los ácidos pirúvico, acético y oxálico. Todos estos ácidos forman complejos de Fe(III) que son atacados por los radicales $\cdot \mathrm{OH}$ o DDB $(\cdot \mathrm{OH})$, mientras que los complejos de Fe(III)-oxalato son más fácilmente fotolizados por la luz solar.

\subsubsection{Amarillo ácido 36}

La planta de flujo de 2,5 L también ha permitido demostrar la viabilidad del proceso fers para degradar colorantes. De la figura 4.14a y figura $4.14 \mathrm{~b}$ se desprende que los tratamientos EF y feFs de una solución de $108 \mathrm{mg} \mathrm{L}^{-1}$ del colorante azoico Amarillo ácido 36 conducen a una eficiencia de decoloración y un decaimiento del colorante muy parecidos (Ruiz y otros, 2011). Comparando ambas figuras, se deduce que la solución se decolora totalmente a tiempos 
a

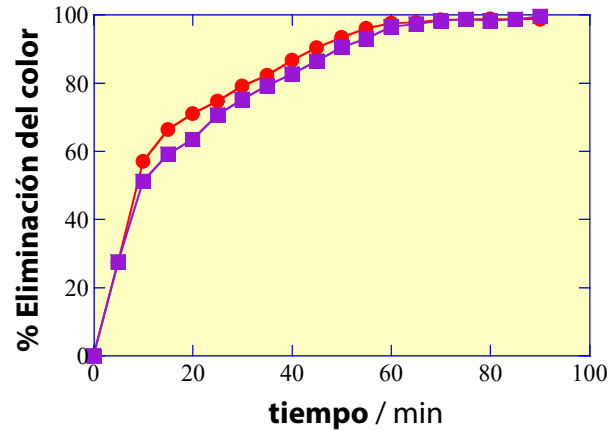

$\mathrm{b}$

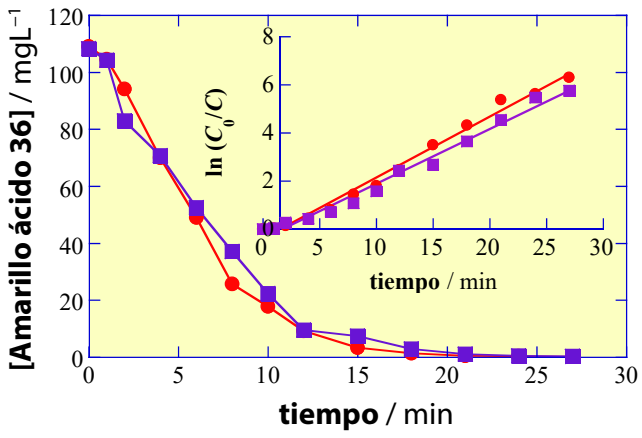

Figura 4.14. (4.14a) Eficiencia de decoloración y (4.14b) descenso de la concentración del

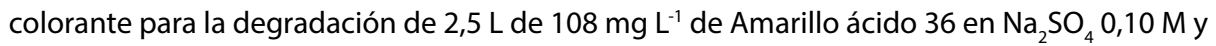
$\mathrm{Fe}^{2+} 0,50 \mathrm{mM}$ a pH $3,0,50 \mathrm{~mA} \mathrm{~cm}{ }^{-2}$ y $35^{\circ} \mathrm{C}$. (O) ef y ( $\square$ ) FeFs. En el panel insertado se presenta el análisis cinético suponiendo que el colorante sigue una reacción de pseudo primer orden (Ruiz y otros, 2011)

a

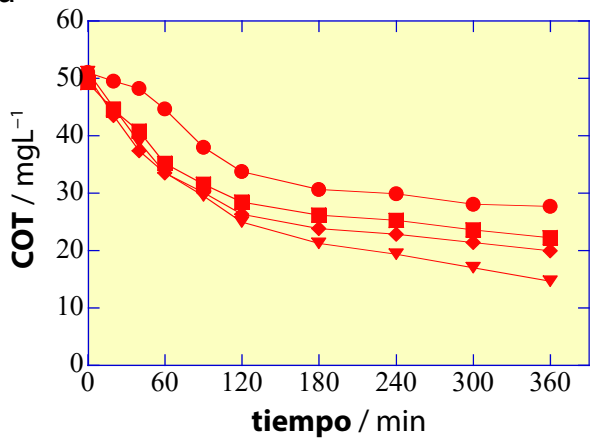

b

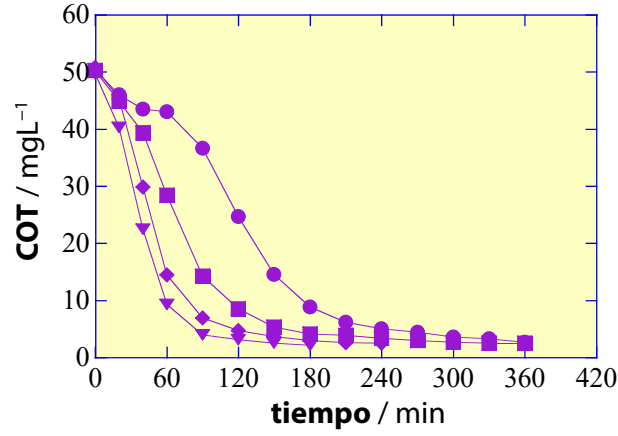

Figura 4.15. Descenso del cot con el tiempo de electrólisis para la degradación de $2,5 \mathrm{~L}$ de 108 mg L-1 de Amarillo ácido 36 en Na2SO4 0,10 M y Fe2+ 0,50 mM a pH 3,0 y $35^{\circ} \mathrm{C}$. (4.15a) ef y (4.15b) fers. Densidad de corriente: $(\bullet, \bullet) 25,(\square, \square) 50,(\diamond, \diamond) 100$ y $(\nabla, \nabla) 150 \mathrm{~mA} \mathrm{~cm}-2$ (Ruiz y otros, 2011)

muy superiores a los de la desaparición del colorante. Ello indica que se generan especies aromáticas coloreadas, similares en ambos casos, que retardan la decoloración de la solución, siendo los radicales $\cdot \mathrm{OH}$ presentes en el seno de la disolución los principales agentes oxidantes del Amarillo ácido 36 y sus derivados aromáticos. 


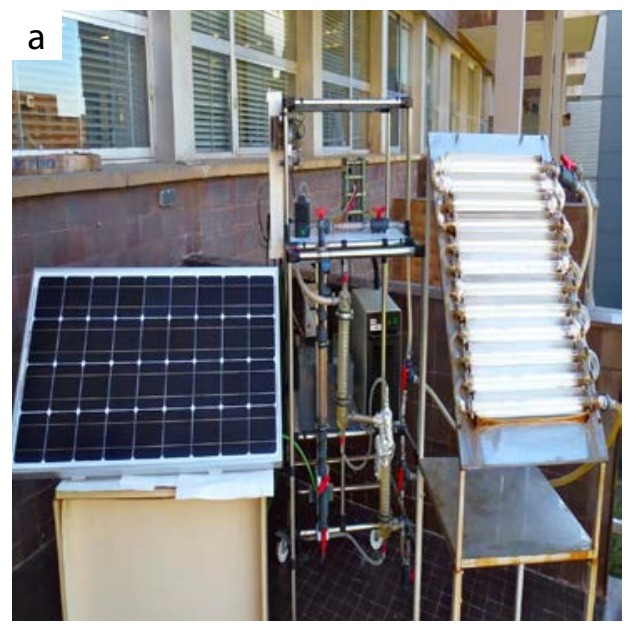

$\mathrm{b}$

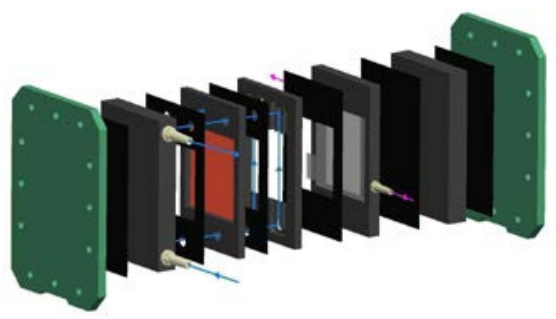

Figura 4.16. (4.16a) Fotografía de una planta de flujo solar autónoma de 10 L con un panel fotovoltaico y un fotorreactor CPC. (4.16b) Esquema de la celda filtro prensa en esta planta. 1) Ánodo de Pt, 2) compartimento del líquido, 3) cátodo de difusión de aire, 4) entrada del líquido y 5) entrada del aire

En cambio, el abatimiento del сот es mucho mayor para el proceso FEFS. Mientras la figura 4.15a muestra que la solución solo sufre una mineralización parcial usando EF, la figura 4.15b evidencia que se alcanza una mineralización total en FEFs. También se aprecia en ambas figuras que el aumento de la densidad de corriente de 25 a $150 \mathrm{~mA} \mathrm{~cm}^{-2}$ siempre acelera la mineralización del colorante como resultado de la concomitante producción de más radicales $\cdot \mathrm{OH}$.

\subsection{Planta de flujo solar autónoma}

Como antes se ha mencionado, el coste energético de los PEOA es uno de los principales inconvenientes para su posible escalado industrial. El uso del FEFS es un primer paso muy importante para rebajar el coste que supone el empleo de lámparas artificiales UVA en FEF, siendo el proceso FEFs incluso más potente por la mayor intensidad uv de la luz solar. Con objeto de aplicar un procedimiento aún más económico y que sea más atractivo industrialmente, 
en nuestro laboratorio se ha construido una planta de flujo solar que pueda actuar de forma autónoma y que podría usarse en lugares remotos, sin acceso a la red eléctrica. La figura 4.16a muestra una fotografía de esta planta con una capacidad de tratamiento de $10 \mathrm{~L}$ de un efluente. Los componentes de esta planta son los mismos que los de la figura 4.8, con la diferencia que todos ellos están dimensionados para la circulación de un mayor volumen de líquido y que la fuente de alimentación es una placa fotovoltaica que suministra directamente la corriente a la celda electrolítica bajo irradiación solar. En este sistema se ha utilizado un fotorreactor CPC solar que permite que el efluente pueda absorber más eficientemente la luz uv de esta radiación. La celda de filtro prensa, esquematizada en la figura $4.16 \mathrm{~b}$, contiene un ánodo de Pt de $90,7 \mathrm{~cm}^{2}$ de área útil puesto que en nuestros estudios hemos encontrado que en FEFs no es necesario utilizar el DDB como mejor ánodo, dado que el gran poder oxidativo de la luz solar permite mineralizar de forma rápida y eficaz aquellos productos de reacción que son fotolizables.

La buena capacidad oxidativa de la planta de flujo solar autónoma se ha mostrado para el tratamiento del colorante Amarillo directo 4 (Garcia-Segura y Brillas, 2014). En la figura 4.17a se aprecia que una solución 1,06 mM de este compuesto se decolora completamente en 90 min a una intensidad de corriente de $3 \mathrm{~A}$ y tan solo en 60 min al aplicar 5 A. Así mismo, en la figura 4.17b
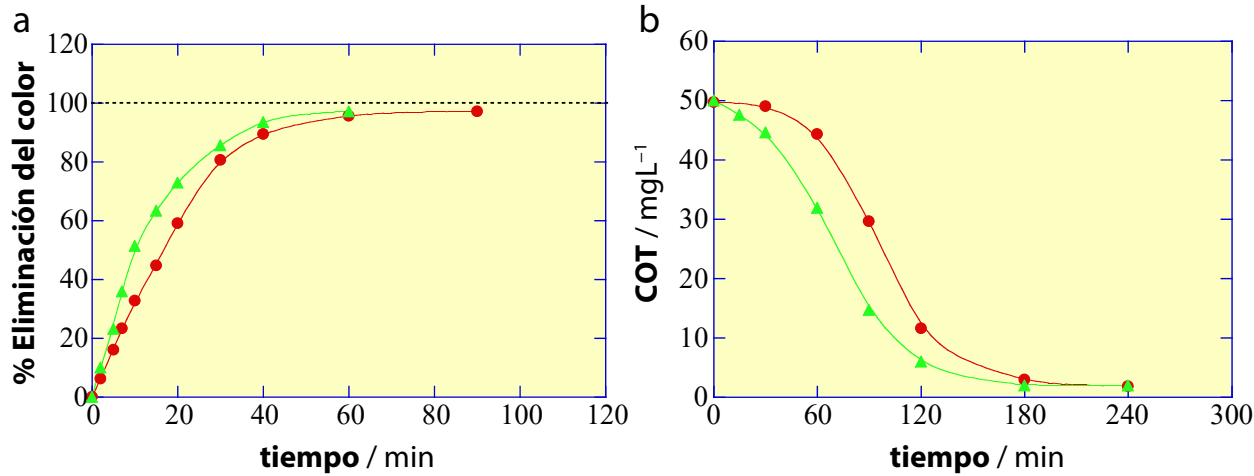

Figura 4.17. (4.17a) Eficiencia de decoloración y (4.17b) descenso del сот para la degradación por feFs de $10 \mathrm{~L}$ de Amarillo directo $41,06 \mathrm{mM}$ en $\mathrm{Na}_{2} \mathrm{SO}_{4} 0,05 \mathrm{M}$ y Fe$^{2+} 0,50 \mathrm{mM}$ a pH 3,0 y $35^{\circ} \mathrm{C}$

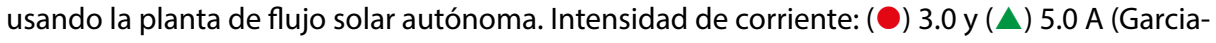


se ve que para ambas corrientes se precisa de 180 a 240 min para alcanzar su mineralización completa, siendo la descontaminación más rápida para la corriente mayor. Aunque la eficiencia de corriente de mineralización es superior a $3 \mathrm{~A}$, los anteriores resultados permiten inferir que la planta de flujo solar autónoma permite utilizar el método feFs con una intensidad de corriente mucho mayor para acelerar la degradación, ya que el proceso no conlleva ningún coste energético.

\subsection{Métodos electroquímicos acoplados o combinados}

También se ha ensayado a escala de laboratorio con celdas tipo tanque el acoplamiento o combinación de métodos electroquímicos para destruir más rápidamente los contaminantes de las aguas residuales. Un primer ejemplo lo constituye el acoplamiento de la fotocatálisis solar heterogénea con $\mathrm{TiO}_{2}$ y los PEOA (Garza-Campos y otros, 2014). La figura 4.18a ilustra el esquema de este sistema donde el $\mathrm{TiO}_{2}$ se encuentra depositado sobre esferas de vidrio por el método sol-gel y los PEOA se llevan a cabo con electrodos de DDB, inyectando aire a la celda para generar $\mathrm{H}_{2} \mathrm{O}_{2}$ cuando este material se usa como cátodo. En la figura $4.18 \mathrm{~b}$ se presentan los resultados obtenidos para la degradación de

a

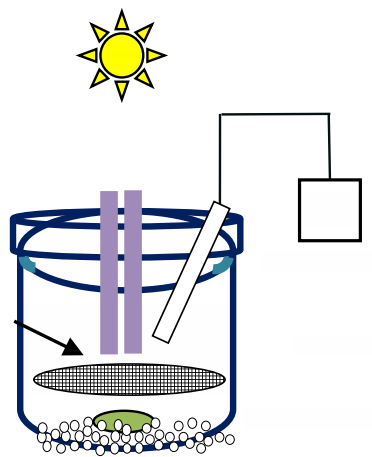

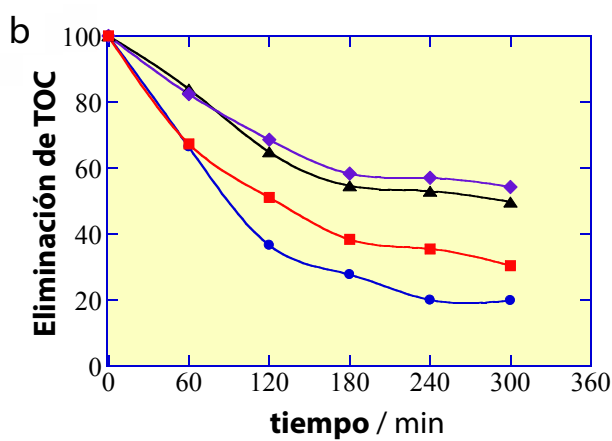

Figura 4.18. (4.18a) Esquema del sistema acoplado de fotocatálisis solar con $\mathrm{TiO}_{2}$-FEFs con una celda DDB/DDB para la degradación de $200 \mathrm{~mL}$ de $20 \mathrm{mg} \mathrm{L}^{-1}$ de atrazina en $\mathrm{Na}_{2} \mathrm{SO}_{4} 0,05 \mathrm{M} \mathrm{a}$ pH 3,0 y 100 mA. (4.18b) Porcentaje de eliminación del сот para $(\diamond)$ OA con una celda DDB/Pt,

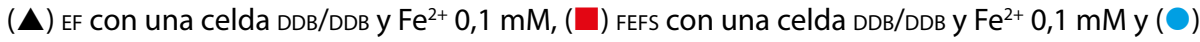
fotocatálisis-FEFs acoplado (Garza-Campos y otros, 2014) 
$200 \mathrm{~mL}$ de $20 \mathrm{mg} \mathrm{L}^{-1}$ del hebicida atrazina en $\mathrm{Na}_{2} \mathrm{SO}_{4}$ 0,05 M a pH 3,0 y $100 \mathrm{~mA}$. Se aprecia que la eliminación del cot para los PEOA incrementa en la secuencia OA < EF < FEFS, alcanzándose para el último método un 69 \% de mineralización en 300 min. En cambio, al aplicar el método acoplado se ha logrado hasta un $80 \%$ de mineralización, debido a la acción adicional de los radicales $\cdot \mathrm{OH}$ originados sobre la superficie del $\mathrm{TiO}_{2}$. En consecuencia, este método acoplado da mejores prestaciones que el uso individual del feFs para la descontaminación de aguas residuales.

Otro ejemplo de sistema combinado consiste en el uso de un método electroquímico de separación como la electrocoagulación (EC) con celda Fe/ Fe seguido de un proceso fef para descontaminar el efluente de una industria de curtidos conteniendo $1800 \mathrm{mg} \mathrm{L}^{-1}$ de сот (Isarain-Chávez y otros, 2014). El esquema de la simple celda tipo tanque de DDB/ DDB y el sistema empleado para el proceso feF con una lámpara UvA de $6 \mathrm{~W}$ se muestra en la figura 4.19a. La figura $4.19 \mathrm{~b}$ presenta el decaimiento del cOT para varios procesos ECFEF a $330 \mathrm{~mA}$. Puede verse que después de $360 \mathrm{~min}$ de aplicar este método combinado se consigue un $90 \%$ de destrucción de la materia orgánica inicial, lo que supone un excelente resultado para el tratamiento de este tipo de aguas de tenería.

a

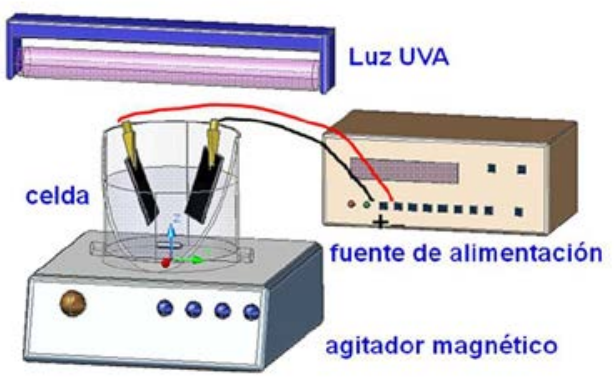

b

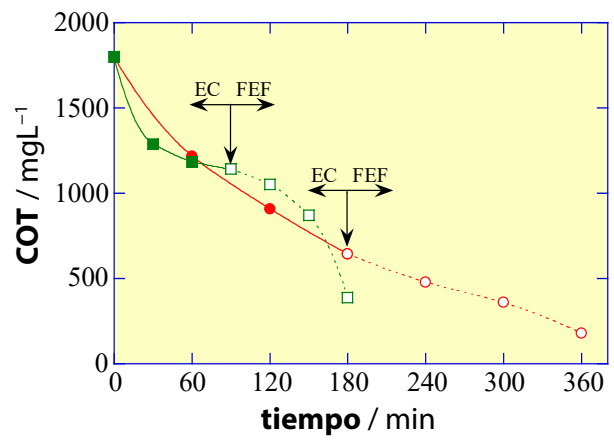

Figura 4.19. (4.19a) Esquema del sistema utilizado para el tratamiento consecutivo de electrocoagulación (EC) con una celda Fe/Fe y de FEF con una celda DDB/DDB y una lámpara UVA de $6 \mathrm{~W}$ a $330 \mathrm{~mA}$ de $250 \mathrm{~mL}$ de un efluente de una industria de curtidos. ( $\square$ ) Ec durante 90 min seguido por $(\square)$ fEF durante 90 min y $(\bigcirc)$ EC durante 180 min seguido por $(\bigcirc)$ FEF durante 180 min (Isarain-Chávez y otros, 2014) 


\subsection{Conclusiones}

1. Se ha puesto de manifiesto que los procesos electroquímicos avanzados de oxidación son muy atractivos para el tratamiento de aguas residuales.

2. En los métodos ef y feF los contaminantes aromáticos se oxidan preferencialmente por los radicales hidroxilo generados por la reacción de Fenton, siendo eliminados con mayor celeridad que en la OA.

3. Los complejos de Fe(III) con ácidos carboxílicos finales $\mathrm{C} 2$ perduran en $\mathrm{EF}$ porque son difícilmente oxidados con los radicales hidroxilo. Algunos de ellos, como los del ácido oxálico, son fotodescompuestos por la luz UVA EN FEF.

4. El proceso fefs es más eficiente por la gran intensidad de luz uv de la radiación solar. Puede ser viable a escala industrial por su bajo coste energético para alcanzar la mineralización total si solo se forman ácidos carboxílicos fotolizables como el oxálico. El uso de paneles fotovoltaicos solares permite que el proceso pueda efectuarse sin costes operativos.

5. La combinación del método fotoelectro-Fenton con la fotocatálisis solar o la electrocoagulación mejora los procesos de degradación de contaminantes orgánicos y abre nuevas puertas a tratamientos más eficientes de aguas residuales en el próximo futuro.

\section{Referencias}

AngladA, A., Urtiaga, A. y Ortiz, I. (2009). "Contributions of Electrochemical Oxidation to Wastewater Treatment: Fundamentals and Review of Applications». Journal of Chemical Technology and Biotechnology, 84(12), pp. 1747-1755.

Brillas, E. y Martínez-Huitle, C.A. (2015). «Decontamination of Wastewaters Containing Synthetic Organic Dyes by Electrochemical Methods. An Updated Review». Applied Catalysis B: Environmental, 166-167, pp. 603643.

Etchepare, R. y van der Hoek, J.P. (2015). «Health Risk Assessment of Organic Micropollutants in Greywater for Potable Reuse». Water Research, 72, pp. 186-198. 
Flox, C., Garrido, J.A., Rodriguez, R.M., Cabot, P.L., Centellas, F., Arias, C. y Brillas, E. (2007). «Mineralization of Herbicide Mecoprop by Photoelectro-Fenton with UVA and Solar Light». Catalysis Today, 129, pp. 29-36.

Garcia-Segura, S. y Brillas, E. (2014). «Advances in Solar Photoelectro-Fenton: Decolorization and Mineralization of the Direct Yellow 4 Diazo Dye Using an Autonomous Solar Pre-Pilot Plant». Electrochimica Acta, 140, pp. 384395.

Garza-Campos, B.R., Guzmán-Mar, J.L., Reyes, L.H., Brillas, E., Hernández-Ramírez, A. y Ruiz-Ruiz, E.J. (2014). «Coupling of Solar Photoelectro-Fenton with a BDD Anode and Solar Heterogeneous Photocatalysis for the Mineralization of the Herbicide Atrazine». Chemosphere, 97, pp. 26-33.

Guinea, E., Arias, C., Cabot, P.L., Garrido, J.A., Rodriguez, R.M., Centellas, F. y Brillas,

E. (2008). «Mineralization of Salicylic Acid in Acidic Aqueous Medium

by Electrochemical Advanced Oxidation Processes Using Platinum and Boron-Doped Diamond as Anode and Cathodically Generated Hydrogen Peroxide». Water Research, 42(1-2), pp. 499-511.

Isarain-Chávez, E., de la Rosa, C., Godínez, L., Brillas, E. y Peralta-Hernández, J.M. (2014). «Comparative Study of Electrochemical Water Treatment Processes for a Tannery Wastewater Effluent». Journal of Electroanalytical Chemistry, 713, pp. 62-69.

Marselli, B., Garcia-Gomez, J., Michaud, P.-A., Rodrigo, M.A. y Comninellis, Ch. (2003). «Electrogeneration of Hydroxyl Radicals on Boron-Doped Diamond Electrodes». Journal of the Electrochemical Society, 150(3), pp. D79-D83.

Panizza, M. y Cerisola, G. (2009). «Direct and Mediated Anodic Oxidation of Organic Pollutants». Chemical Reviews, 109(12), pp. 6541-6569.

Ruiz, E.J., Arias, C., Brillas, E., Hernández-Ramírez, A. y Peralta-Hernández, J.M. (2011). «Mineralization of Acid Yellow 36 Azo Dye by Electro-Fenton and Solar Photoelectro-Fenton Processes with a Boron-Doped Diamond Anode». Chemosphere, 82(4), pp. 495-501.

SIRÉS, I. y BRILlAS, E. (2012). "Remediation of Water Pollution Caused by Pharmaceutical Residues Based on Electrochemical Separation and Degradation Technologies: A Review». Environment International, 40, pp. 212-229. 
Sirés, I., Brillas, E., Oturan, M.A., Rodrigo, M.A. y Panizza, M. (2014). «Electrochemical Advanced Oxidation Processes: Today and Tomorrow. A Review». Environmental Science Pollution Research, 21(19), pp. 8336-8367.

Skoumal, M., Rodriguez, R.M., Cabot, P.L., Centellas, F., Garrido, J.A., Arias, C.y Brillas, E. (2009). «Electro-Fenton, UVA Photoelectro-Fenton and Solar PhotoelectroFenton Degradation of the Drug Ibuprofen in Acid Aqueous Medium Using Platinum and Boron-Doped Diamond Anodes». Electrochimica Acta, 54(7), pp. 2077-2085.

Vasudevan, S. y Oturan, M.A (2014). «Electrochemistry: as Cause and Cure in Water Pollution-An Overview». Environmental Chemistry Letters, 12(1), pp. 97-108.

Voudrias, E., Goudakou, L., Kermenidou, M. y Softa, A. (2012). «Composition and Production Rate of Pharmaceutical and Chemical Waste from Xanthi General Hospital in Greece». Waste Management, 32(7), pp. 1442-1452. 


\title{
Aplicación del ozono para el tratamiento de aguas residuales urbanas
}

\author{
C. Sans Mazón \\ Departamento de Ingeniería Química y Química Analítica, \\ Facultad de Química \\ Universitat de Barcelona \\ C/ Martí i Franquès, 1, planta 6, 08028 Barcelona, España
}

Contacto: carmesans@ub.edu

\section{Carmen Sans Mazón}

Doctora en Ciencias Químicas por la Universitat de Barcelona (1992) y profesora titular del Departamento de Ingeniería Química de la Universitat de Barcelona desde 1997. Miembro CEQAP (Centro de Ingeniería Química Ambiental y del Producto; centro de la red de transferencia de tecnología de Cataluña, XIT, del CIDEM, Generalitat de Catalunya). Desde 1993, está involucrada en docencia en grado (química, ingeniería química, ciencias ambientales, biotecnología) y máster (ingeniería ambiental). Miembro del Grupo de Innovación Docente QISU-Química en la interfase secundariauniversidad, desde el año 2006.

Su experiencia e intereses en investigación se centran en el campo de la ingeniería ambiental, principalmente en el tratamiento de aguas domésticas e industriales por procesos de oxidación avanzada y su integración con sistemas biológicos. Tiene más de 55 publicaciones en revistas especializadas y más de 100 contribuciones en congresos internacionales. Ha dirigido 5 tesis de doctorado nacionales y ha codirigido dos tesis doctorales de estudiantes de la Universidad Federal de Rio de Janeiro (Brasil). Ha participado y coordinado numerosos proyectos de investigación nacionales, internacionales y con diversas empresas del área de la gestión y tratamiento de agua. 


\section{Resumen}

Actualmente, una de las principales preocupaciones a nivel ambiental es la acumulación de contaminantes emergentes (también llamados microcontaminantes) en aguas naturales. Como consecuencia de ello, se prevé una legislación al respecto cada vez más restrictiva, así como un creciente interés del mundo científico por el estudio de los niveles de concentración de los contaminantes en aguas naturales y efluentes de plantas de tratamiento, sobre su impacto y transporte en el medio ambiente y sobre posibles soluciones tecnologías para su control. Las principales vías de entrada de los microcontaminantes en el medio ambiente ya están bien identificadas. Las estaciones depuradoras de aguas residuales (EDAR) urbanas o mixtas son uno de ellas y constituyen el mejor lugar donde aplicar tratamientos avanzados para eliminar estos contaminantes. Una de estas tecnologías avanzadas es la ozonización. Este trabajo presenta un repaso del tratamiento utilizando ozono, centrándose en la aplicación de la ozonización para la eliminación de contaminantes emergentes, así como en los efectos del ozono sobre la materia orgánica del efluente. Finalmente, se trataran otros aspectos ingenieriles importantes en la operación del proceso de ozonización, como es la trasferencia de ozono de la fase gas a la fase líquida.

\subsection{El ozono: propiedades, generación y aplicaciones}

El ozono fue utilizado por primera vez para el tratamiento de agua potable en 1893 en los Países Bajos. Actualmente, la ozonización es una técnica de oxidación química con una gran variedad de aplicaciones, que incluye: desinfección, oxidación de microcontaminantes orgánicos recalcitrantes (fármacos, pesticidas, contaminantes fenólicos, etc.), oxidación de contaminantes inorgánicos, como hierro, manganeso y sulfitos y eliminación de color y sabor.

El ozono se puede utilizar para la mineralización (eliminación de carbono orgánico total) de compuestos orgánicos, aunque en muchos casos implica el uso de altas dosis de ozono, y el encarecimiento del proceso. Una buena 
estrategia es la utilización de la ozonización como pretratamiento, ya que los productos de la oxidación parcial con ozono son generalmente más fácilmente biodegradables que sus precursores.

\subsubsection{Propiedades del ozono}

El ozono es una molécula triatómica (ec. 5.1), que consta de tres átomos de oxígeno con menos estabilidad que el oxígeno diatómico $\left(\mathrm{O}_{2}\right)$ (Langlais et al. 1991). Es un gas de color azul pálido ligeramente soluble en agua, y la mayoría de la gente puede detectar aproximadamente $0,01 \mathrm{ppm}$ de ozono en el aire, ya que tiene un olor parecido a blanqueador de cloro. Las exposiciones de 0,1 a 1 ppm producen dolores de cabeza, ardor en los ojos y en las vías respiratorias.

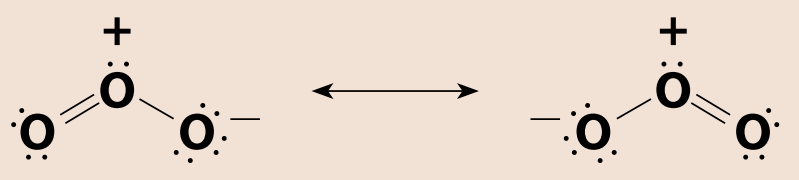

(5.1)

Las principales propiedades moleculares de la molécula de ozono se resumen en la tabla 5.1 .

Tabla 5.1. Propiedades del $\mathrm{O}_{3}$

\begin{tabular}{|c|c|}
\hline Fórmula molecular & $\mathrm{O}_{3}$ \\
\hline Peso molecular $\left(\mathrm{g} \cdot \mathrm{mol}^{-1}\right)$ & 47.998 \\
\hline Densidad ( $g / L)$ & 2.144 (a $0^{\circ} \mathrm{C}$, gas) \\
\hline Temperatura de fusión $\left({ }^{\circ} \mathrm{C}\right)$ & -192.5 \\
\hline Temperatura de ebullición $\left({ }^{\circ} \mathrm{C}\right)$ & -111.9 \\
\hline Solubilidad en agua $\left(g \cdot L^{-1}\right)$ & 0.0105 \\
\hline
\end{tabular}

El ozono es 14 veces más soluble en agua que el oxígeno. Esta solubilidad disminuye con la temperatura y aumenta con la presión. Tiene un elevado 
potencial de oxidación, aunque menor que el radical hidroxilo. En la tabla 5.2 se muestran los potenciales de distintos oxidantes y también su comparación con el del cloro.

Tabla 5.2. Potencial redox de los principales oxidantes

\begin{tabular}{|c|c|c|}
\hline Especie & $\boldsymbol{E}_{\mathbf{0}}(\boldsymbol{V})$ & $\boldsymbol{E}_{\mathbf{0}} / \boldsymbol{E}_{\mathbf{0}}\left(\mathbf{C l}_{\mathbf{2}}\right)$ \\
\hline Flúor & 3.06 & 2.25 \\
\hline Radical Hidroxilo & 2.80 & 2.05 \\
\hline Átomo de Oxígeno & 2.42 & 1.78 \\
\hline Ozono & 2.08 & 1.52 \\
\hline Peróxido de Hidrógeno & 1.78 & 1.30 \\
\hline Permanganato de Potasio & 1.70 & 1.25 \\
\hline Ácido Hipocloroso & 1.49 & 1.10 \\
\hline Cloro & 1.36 & 1 \\
\hline Dióxido de Cloro & 1.27 & 0.93 \\
\hline Oxígeno & 1.23 & 0.90 \\
\hline
\end{tabular}

\subsubsection{Generación del ozono}

Existen diferentes métodos para la producción de ozono que se pueden dividir en tres categorías, según se utilice: (1) la descarga de corona, (2) la descarga electroquímica y (3) los métodos UV. Entre ellas, la descarga de corona es el método de generación más utilizado con diferencia. Éste consiste en pasar de oxígeno entre dos electrodos separados por un material dieléctrico, por lo general de vidrio. Los electrodos están conectados a una fuente de alta tensión capaz de generar una descarga de corona entre los dos electrodos y el oxígeno en el espacio de descarga se convierte en ozono. En una primera etapa, las moléculas de oxígeno se dividen en átomos de oxígeno, y, posteriormente, estos se combinan con las moléculas de oxígeno restantes para formar la molécula de ozono. 


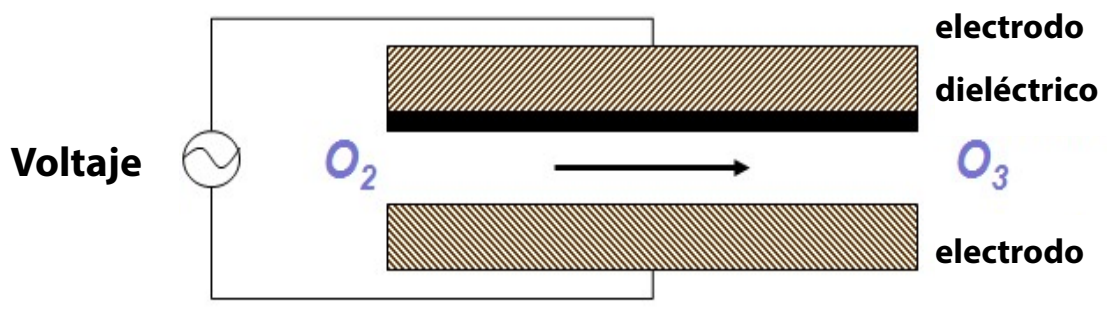

Figura 5.1. Esquema de un sistema de descarga de corona (Lenntech Water Treatment Solutions)

Estos dispositivos de descarga de corona generan gran cantidad de calor que podría provocar la descomposición del ozono producido. Así pues, el sistema de refrigeración de los ozonizadores es muy importante para mantener una temperatura constante del gas dentro de la cámara de descarga. Este sistema se realiza normalmente mediante la circulación de un refrigerante tal como agua o aire. Un esquema de un dispositivo de descarga corona de ozono se puede observar en la figura 5.1.

\subsubsection{Reactividad del ozono}

Una vez que se produce el ozono, este se burbujea en un reactor que contiene la solución a tratar. Este proceso se lleva a cabo utilizando difusores que producen gran cantidad de pequeñas burbujas, aumentando el contacto entre el gas y la fase líquida. Sin embargo, el uso de estos sistemas puede causar la descomposición del ozono por la presencia de sólidos suspendidos o precipitados oxidados, que a su vez también pueden ser causa de obturaciones en los difusores. En estos casos se suelen utilizar inyectores en corrientes laterales, que también proporcionan tasas de flujo de gas de alta y buenas eficiencias de mezcla. (Gogate y Pandit, 2004).

La eficiencia de transferencia de ozono del gas a la fase líquida es uno de los aspectos más críticos durante la ozonización. Esta transferencia viene controlada principalmente por los parámetros físicos tales como la temperatura, 


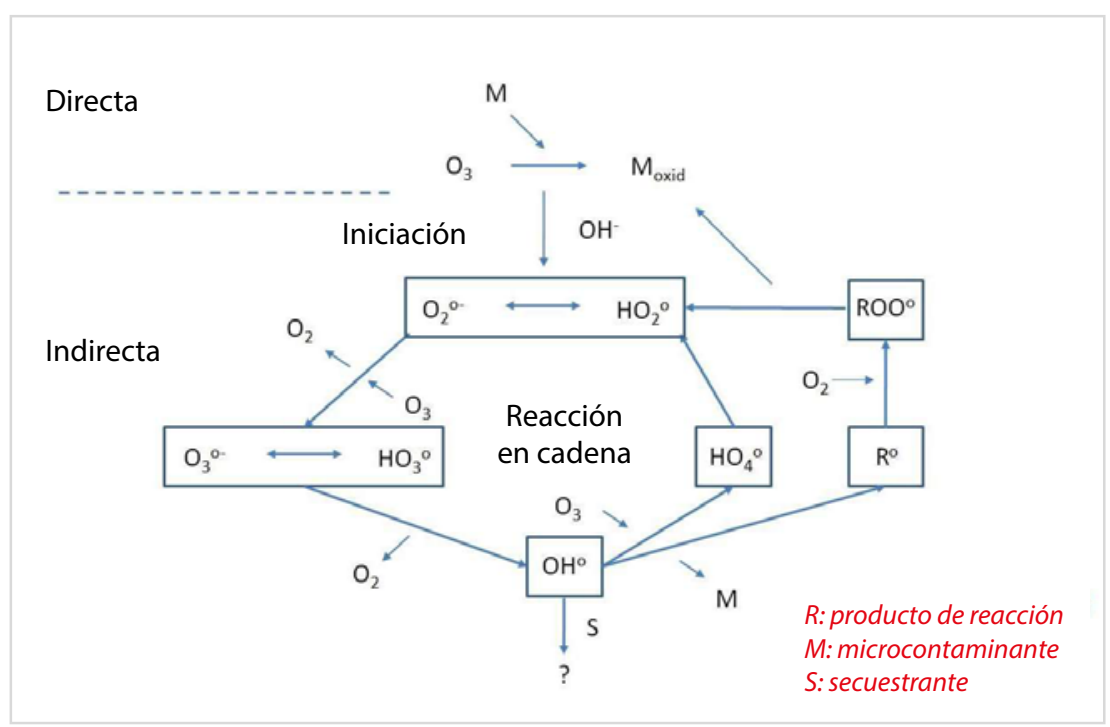

Figura 5.2. Vías de reacción del ozono (adaptado de Gottschalk y otros, 2010)

el caudal de gas, tamaño de la burbuja, la presión parcial de ozono y la geometría del reactor, y también por factores químicos como el pH, la fuerza iónica y la composición de las soluciones acuosas, etc. (Tiwari y Bose, 2007). Un buen seguimiento y control de estos parámetros es fundamental para optimizar la cinética de reacción del ozono y los compuestos orgánicos.

El ozono puede reaccionar con los compuestos a tratar mediante dos mecanismos, la vía directa y la vía indirecta. Estas dos vías de reacción conducen a diferentes productos de oxidación y son controlados por diferentes cinéticas de reacción. Un esquema de estos mecanismos y su interacción se puede observar en la figura 5.2.

\subsubsection{Reacción directa}

El potencial de ozono para actuar como un nucleófilo, electrófilo o dipolo se debe a su estructura resonante y a su capacidad para dislocar electrones, 
representado en la figura 5.1. En general, la degradación de los compuestos orgánicos se lleva a cabo por los grupos insaturados, tales como anillos aromáticos, alquenos, alquinos, etc. (Langlais et al. 1991) y en compuestos alifáticos con grupos funcionales específicos, como aminas y sulfuros (Von Gunten 2003). La figura 5.3 resume las estructuras y especies susceptibles de ser atacados por el ozono molecular. Sin embargo, las constantes cinéticas de todas esas reacciones directas con $\mathrm{O}_{3}$ son más bajas que las que tienen lugar a través de radicales hidroxilo (Hoigne y Bader 1975; Hoigne y Bader 1983; Hoigne et al 1985; Yao y Haag 1991).

Así pues, la oxidación directa de la materia orgánica por el ozono es un mecanismo bastante selectivo que reacciona preferiblemente con materia orgánica con dobles enlaces, aromáticos o aminas. Por otro lado, para la mayoría de compuestos inorgánicos en el agua potable, las velocidades de reacción son relativamente altas. El mecanismo de reacción principal para la oxidación de compuestos inorgánicos viene determinado por transferencia del átomo de oxígeno adicional del ozono a los compuestos inorgánicos. Dentro los compuestos inorgánicos, la velocidad de reacción es mayor para los compuestos ionizados y disociados (Von Gunten, 2003).

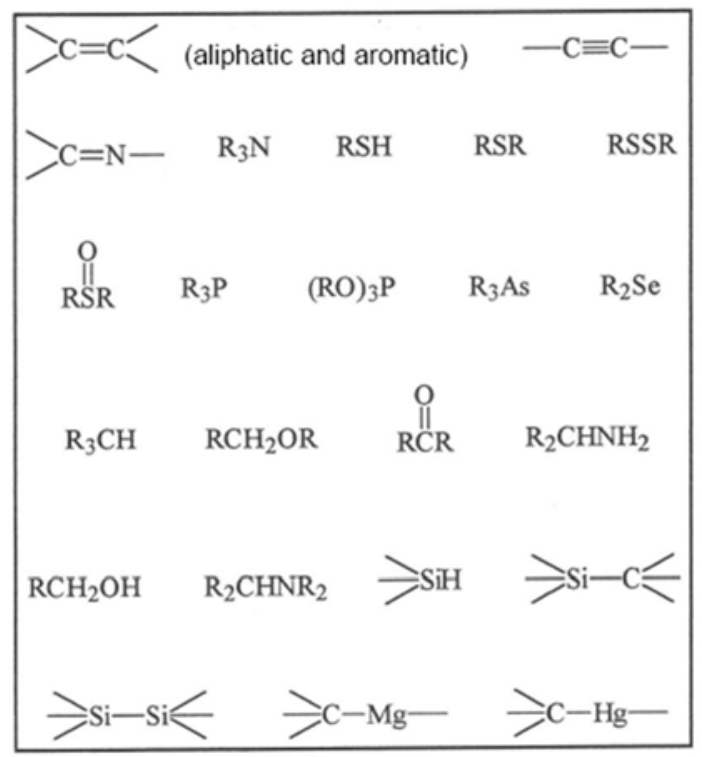

Figura 5.3. Grupos funcionales susceptibles de reaccionar con el ozono molecular (Rice, 1997) 


\subsubsection{Reacción indirecta}

Contrariamente al ataque directo del ozono, las reacciones del radical hidroxilo no son reacciones selectivas. En medio acuoso, el ion hidróxido $\left(\mathrm{OH}^{-}\right)$ promueve la descomposición de ozono, debido a su inherente inestabilidad en agua (Von Gunten 2003), generando una serie posterior de reacciones en cadena que conducen a la formación de radicales hidroxilo, entre otras especies radicales. El mecanismo de reacción es complejo y puede estar sujeto a interferencias de diferentes especies presentes en la solución e incluso viene influenciado por la concentración de los diferentes compuestos en la reacción. El mecanismo de cadena de radicales de ozono se puede dividir en 3 etapas; iniciación, propagación y terminación de la cadena (Hoigne and Bader, 1975; Gottschalk et al, 2010).

En la etapa de iniciación, la reacción entre los iones hidróxido y el ozono conduce a la formación del anión superóxido $\mathrm{O}_{2}{ }^{-}$y un radical hidroperoxilo $\mathrm{HO}_{2}$ (ec.5.2), el cual está en equilibrio con el anión superóxido (ec.5.3).

\begin{tabular}{|ll|l|}
\hline $\mathrm{O}_{3}+\mathrm{OH}^{-} \rightarrow \mathrm{O}_{2} \cdot{ }^{-}+\mathrm{HO}_{2} \cdot$ & $\mathrm{k}_{1}=70 \mathrm{M}^{-1} . \mathrm{s}^{-1}$ & (5.2) \\
\hline $\mathrm{HO}_{2} \cdot \leftrightarrow \mathrm{O}_{2} \cdot+\mathrm{H}^{+}$ & $\mathrm{pK}_{\mathrm{a}}=4.8$ & (5.3) \\
\hline
\end{tabular}

Durante la reacción en cadena radical, el anión superóxido $\mathrm{O}_{2} \cdot-$ reacciona con el ozono para formar el anión ozónido $\mathrm{O}_{3}$.- (ec. 5.4-5.7). Este luego se descompone inmediatamente a través de trióxido de hidrógeno $\mathrm{HO}_{3} \cdot$ en un radical de oxígeno e hidroxilo:

\begin{tabular}{|lc|c|}
\hline $\mathrm{O}_{3}+\mathrm{O}_{2} \cdot \rightarrow \mathrm{O}_{3} \cdot{ }^{-}+\mathrm{O}_{2}$ & $\mathrm{k}_{2}=1.6 \times 10^{9} \mathrm{M}^{-1} \cdot \mathrm{s}^{-1}$ & $(5.4)$ \\
\hline $\mathrm{O}_{3} \cdot{ }^{-}+\mathrm{H}^{+} \rightarrow \mathrm{HO}_{3} \cdot$ & $(\mathrm{pH}<8)$ & $(5.5)$ \\
\hline $\mathrm{HO}_{3} \cdot \leftrightarrow \mathrm{O}_{3}^{-}+\mathrm{H}^{+}$ & $\mathrm{pK}_{\mathrm{a}}=6.2$ & (5.6) \\
\hline $\mathrm{HO}_{3} \cdot \rightarrow \mathrm{OH} \cdot+\mathrm{O}$ & $\mathrm{k}_{3}=1.1 \times 10^{5} . \mathrm{s}^{-1}$ & (5.7) \\
\hline
\end{tabular}


La generación de radicales hidroxilo es el principal promotor de la oxidación de la materia orgánica. Además, el radical $\mathrm{OH} \cdot$ puede reaccionar con el ozono, según (ec. 5.8):

$$
\begin{array}{|l|l|l}
\hline \mathrm{OH} \cdot+\mathrm{O}_{3} \rightarrow \mathrm{HO}_{4} \cdot \quad \mathrm{k}_{4}=2.0 \times 10^{9} \mathrm{M}^{-1} \cdot \mathrm{s}^{-1} & \text { (5.8) }
\end{array}
$$

Y con la transformación del $\mathrm{HO}_{4}$ en oxígeno y radical hidroperoxilo (ec. 5.9), la reacción en cadena puede volver a empezar

$$
\mathrm{HO}_{4} \cdot \rightarrow \mathrm{O}_{2}+\mathrm{HO}_{2} \cdot \quad \mathrm{k}_{5}=2.8 \times 10^{4} \mathrm{~s}^{-1}
$$

Por último, la etapa de terminación se produce cuando las sustancias o bien orgánicas o inorgánicas reaccionan con el $\mathrm{OH} \cdot$ para formar radicales secundarios que no producen radicales superóxido $\mathrm{HO}_{2} \cdot / \mathrm{O}_{2} \cdot$ (por ejemplo, ec. 5.10-5.11). Estos captadores terminan la reacción en cadena e inhiben la descomposición del ozono.

\begin{tabular}{|ll|l|}
\hline $\mathrm{OH} \cdot+\mathrm{CO}_{3}{ }^{2-} \rightarrow \mathrm{OH}^{-}+\mathrm{CO}_{3}{ }^{-}$ & $\mathrm{k}_{6}=4.2 \times 10^{8} \mathrm{M}^{-1} \cdot \mathrm{s}^{-1}$ & $(5.10)$ \\
\hline $\mathrm{OH} \cdot+\mathrm{HCO}_{3}-\mathrm{OH}^{-}+\mathrm{HCO}_{3} \cdot$ & $\mathrm{k}_{7}=1.5 \times 10^{7} \mathrm{M}^{-1} \cdot \mathrm{s}^{-1}$ & (5.11) \\
\hline
\end{tabular}

\subsubsection{Destrucción}

La reacción de ozono en solución podría no ser completa, dependiendo de la dosis de ozono y la cinética de ozono en la solución, por lo que será necesario eliminar el ozono residual. Existen diferentes métodos para descomponer ozono, ya sea por termo-descomposición, por reacción catalítica o por reacción química. Con frecuencia se utilizan ciclos catalíticos, que consiste en una serie de reacciones en las que se agota una familia química o una especie en particular, dejando el catalizador no afectado. Entre ellos, un método catalítico frecuente consiste en la reducción del ozono a oxígeno burbujeando el 
gas a través de una solución de yoduro de potasio saturado (KI) de acuerdo con la siguiente reacción (ec.5.12).

$$
\mathrm{O}_{3}+2 \mathrm{KI}+\mathrm{H}_{2} \mathrm{O} \rightarrow 2 \mathrm{KOH}+\mathrm{O}_{2}+\mathrm{I}_{2}
$$

\subsubsection{Aplicaciones de la ozonización}

La ozonización puede utilizarse para distintas aplicaciones como son, entre otras, potabilizacion de aguas, depuracion de aguas residuales, desinfeccion de corrientes gaseosas, blanqueo de pasta de papel, eliminación de olores, ect.

El ozono se utiliza en la potabilización de agua por diversas razones: es efectivo en la desinfección, es decir, en la inactivación de bacterias y virus. La desinfección de Escherichia coli con ozono es más de 3 veces más rápida que con cloro. Además puede oxidar gran cantidad de compuestos orgánicos como fenoles, detergentes, pesticidas, ácidos húmicos, ácidos fúlvicos, compuestos aromáticos, proteínas, etc. Al mismo tiempo, oxida diversos metales pesados a estados de oxidación mayores, menos solubles, dando lugar a óxidos e hidróxidos que se pueden eliminar fácilmente por sedimentación y/o filtración. También es muy efectivo en la eliminación de sabores, olores y color.

El ozono también se puede utilizar para obtener agua de alta pureza necesaria en distintos tipos de actividades como: industria de bebidas embotelladas y alimentaria, industria farmacéutica, e incluso industria electrónica, donde se hacen lavados en diferentes etapas del proceso con agua ozonizada (0.5-2 ppm) para oxidar los materiales orgánicos presentes en la superficie de componentes electrónicos. También se utiliza para el tratamiento del agua de piscinas y de piscifactorias.

Hoy día el ozono tiene aplicación en muy distintos tipos de aguas residuales y para muy distintas finalidades. Así, se usa en el tratamiento de colorantes poliaromáticos de aguas textiles, de efluentes de la producción de pasta de papel con colorantes naturales y otra materia orgánica, para la eliminación de sustancias tóxicas o biocidas de la industria química y farmacéutica, tensioactivos de la industria de cosméticos y detergentes, compuestos húmicos $u$ orgánicos halogenados de lixiviados de vertedero, entre muchas otras. 
El ozono también se utiliza para la eliminación de olores en corrientes gaseosas, junto con otros contaminantes orgánicos arrastrados por esas corrientes. Por ejemplo, hay instalados muchos ozonizadores para la eliminación de olores de plantas de tratamiento de aguas residuales. En este caso la reacción tiene lugar en la fase gaseosa y el ozono oxida los compuestos responsables de los olores. También se utiliza para la misma finalidad en granjas porcinas.

\subsubsection{Ventajas y desventajas de la ozonización}

Como todas las técnicas de tratamiento de la contaminación, la ozonización presenta una serie de ventajas y desventajas.

Entre las ventajas, cabría citar las siguientes:

- La materia prima utilizada (aire u oxígeno) es muy asequible, y sólo requiere un tratamiento previo no muy complejo (filtración, secado).

- Reacciona rápidamente con contaminantes orgánicos e inorgánicos debido a su elevado potencial redox y reactividad.

- Generalmente, no produce compuestos más tóxicos que los que se desea eliminar, ni introduce sustancias extrañas en el medio.

- Conjuntamente con la disminución de demanda química de oxígeno (DQO) y la desinfección, disminuye el color y la turbidez.

- Los posibles excesos de ozono en el agua se descomponen rápidamente pasando a oxígeno, sin dejar agentes extraños en el medio.

Entre las desventajas estarían:

- El rendimiento energético de la generación de ozono es muy bajo y la concentración de ozono en el gas ozonizado suele ser relativamente baja (2-5\% en aire, 3-4 veces más con oxígeno).

- Se ha de generar «in situ».

- Por lo general, la etapa controlante es la transferencia de materia del ozono a la fase acuosa.

- El ozono es irritante y tóxico a altas concentraciones, por lo que el ozono residual debe eliminarse, aunque su eliminación es fácil. 
- El coste es relativamente elevado.

- El ozono no tiene efectos permanentes en disolución acuosa, ya que se descompone fácilmente.

\subsection{El reuso de aguas y los contaminantes emergentes}

El agua se ha convertido en un recurso limitado en un mundo con una economía y población en expansión, lo que ha acelerado la búsqueda de fuentes de agua alternativas. En este escenario global, muchos profesionales relacionados con los recursos hídricos apuestan por la recuperación de agua después de su tratamiento en estaciones depuradoras de aguas residuales (Hartley, 2006). La reutilización de aguas regeneradas es una buena estrategia frente a los problemas de falta de recursos hídricos y a la necesidad de creación de nuevas fuentes de suministro de agua de alta calidad para usos urbanos, industriales, agrícolas y ambientales (Haering, et al., 2009). La reutilización del agua permite manipular el ciclo del agua, creando los recursos hídricos alternativos necesarios, reduciendo al mismo tiempo la descarga de efluentes al medio ambiente. La reutilización ha convertido en un componente esencial de la gestión integrada de los recursos hídricos y el desarrollo sostenible, no sólo en las áreas secas y deficientes en agua, sino también en las regiones con abundante de agua. El mercado del agua altamente competitivo de las Islas Canarias, los cultivos hidropónicos altamente productivos de la costa sur del Mediterráneo y las demandas más recientes para el riego de campos de golf han contribuido en gran medida a la expansión de la recuperación y reutilización del agua en España.

Sin embargo, también hay que tener en cuenta los riesgos ambientales intrínsecos en la reutilización del agua. La presencia de residuos peligrosos o tóxicos, las sales de los procesos de la industria y los lixiviados en la agricultura pueden poner en peligro la calidad del agua regenerada y crear efectos negativos sobre el medio ambiente e incluso sobre la población. Por lo general, aunque se ha asumido que los posibles agentes contaminantes se eliminan a través de tratamiento de aguas residuales convencionales, en la realidad no es así. Existen numerosos trabajos que demuestras que existe un número importante de compuestos que persisten después del tratamiento convencional 
en una forma inalterada. Entre estos compuestos persistentes se encuentran los denominados contaminantes emergentes, que son aquellos productos químicos de origen muy diverso, caracterizado por su alta producción y cuyo consumo da lugar a su presencia continua en el medio ambiente (Teijon et al., 2010, Ginebrada et al., 2010). Entre ellos se encuentran los medicamentos, fármacos para el diagnóstico médico, esteroides y hormonas, antisépticos, productos de cuidado personal, aditivos de gasolina, metales pesados y metaloides, tensioactivos, disruptores endocrinos, etc., La liberación de estos contaminantes al medio acuático natural se atribuye a su incompleta eliminación mediante los tratamientos convencionales de las aguas residuales (Brixio et al., 2006). A pesar de sus bajas concentraciones, su presencia se ha relacionado con efectos toxicológicos nocivos en especies de peces, y pueden afectar a la salud ecológica o humana. Además, existe una preocupación reciente sobre la proliferación de microorganismos resistentes a los antibióticos, así como al efecto tóxico que la mezcla de muchos de estos compuestos pueda causar. Así, el agua recuperada para su reutlización tiene que estar libre de la presencia de contaminantes emergentes, y en consecuencia, se tienen que implementar tratamientos terciarios eficientes en las planta de tratamiento de agua para su control y eliminación.

\subsubsection{Uso del ozono para el tratamiento de efluentes de EDAR}

Existen diferentes aplicaciones del ozono a lo largo de la línea de tratamiento de las aguas residuales. La más estudiada y aplicada es la utilización de ozono después del tratamiento fisicoquímico o biológico para eliminar color, disminuir la DQO y desinfectar, así como para el control de los contaminantes emergentes antes de la descarga del efluente resultante en zonas sensibles o de su reutilización. Estas aplicaciones trabajan en un rango de dosis de ozono que oscila entre 3-25 $\mathrm{mgL}^{-1}$. Otra de las aplicaciones menos extendidas pero que están despertando interés es el uso de ozono para controlar la proliferación de microorganismos filamentosos, reducir la producción de lodos y, al mismo tiempo, mejorar el proceso de lodos activados.

Existen numerosos trabajos en la bibliografía que demuestran que el ozono es muy efectivo en la oxidación de trazas de contaminantes de aguas 
residuales para la reutilización del agua (Ternes y otros, 2003). El ozono reacciona con los contaminantes orgánicos directamente o mediante la formación de radicales libres, incluyendo el radical hidroxilo. El radical hidroxilo reacciona menos selectivamente que el ozono, proporcionando la oxidación de compuestos recalcitrantes al ozono.

Hay que tener en cuenta, sin embargo, que la alta reactividad del ozono hará que también se produzcan reacciones con la materia orgánica del efluente. De manera similar a la situación que se produce en el tratamiento del agua potable debido a la presencia de materia orgánica natural, la materia orgánica presente en efluentes secundarios puede causar muchos problemas técnicos y medioambientales cuando los efluentes son tratados con fines de recuperación. Esta materia orgánica es la responsable de la mayoría de la demanda de coagulante y desinfectante de las EDAR, que se traduce en un aumento de lodos generados y en la formación de productos de desinfección potencialmente dañinos. Por otra parte, la materia orgánica del efluente puede interferir en la eliminación de otros contaminantes (por ejemplo, compitiendo por los sitios de adsorción en el carbón activado). La materia orgánica es la principal responsable del ensuciamiento de las membranas, contribuye a la corrosión, actúa como un sustrato para el crecimiento bacteriano en los sistemas de distribución y puede causar la eutrofización del agua. Además, la materia orgánica contribuye a problemas de color y olor indeseables y a la formación de subproductos de la desinfección y actúa como un soporte para los metales y productos químicos orgánicos hidrófobos. Aunque la materia orgánica del efluente generalmente no se considera un contaminante, puede comprometer las aplicaciones de reutilización. La ozonización también es un método adecuado para el tratamiento de la materia orgánica de los efluentes secundarios debido a su naturaleza biorrecalcitrante. Además, la eliminación eficiente de la materia orgánica con ozono producirá otros beneficios secundarios (por ejemplo, la desinfección del agua).

En muchos casos y dependiendo del tipo de efluente, la eliminación de la materia orgánica implica el uso de altas dosis de ozono, incrementando el coste del tratamiento. La dosis de ozono a utilizar disminuye considerablemente cuando el objetivo es aumentar la biodegradabilidad del efluente, en vez de buscar la mineralización de la materia orgánica presente. En estos casos, la preozonización permite eliminar compuestos biorecalcitrantes y al mismo tiempo 
reducir el tiempo requerido en el tratamiento biológico. Así, la ozonización puede aplicarse después del tratamiento de lodos activados, como tratamiento terciario, a fin de eliminar los contaminantes emergentes remanentes en el efluente, así como disminuir el contenido de materia orgánica difícilmente biodegradable. En consecuencia, de entre los parámetros más importantes a evaluar durante el tratamiento terciario se encuentran la biodegradabilidad y toxicidad de los productos resultantes de la ozonización, y al mismo tiempo pueden utilizarse para optimizar la dosis de ozono a utilizar. Otros parámetros químicos necesarios para la caracterización del proceso de ozonización incluyen el carbono orgánico total (COT), demanda química de oxígeno (DQO), turbidez, pH, absorbancia UV ${ }_{254^{\prime}}$ sólidos totales (ST), suspendidos (SS) y volátiles (SV), así como los compuestos inorgánicos derivados de la degradación de la materia orgánica. Así mismo, y a fin de controlar las dosis aplicadas de oxidante, conviene calcular la Dosis de Ozono Transferido (TOD). EI TOD es el ozono acumulado transferido a la muestra de agua por unidad de volumen de muestra. Se corresponde con la suma de ozono consumido durante el tratamiento más el ozono disuelto residual al final de la reacción. Se define por la siguiente ecuación:

$$
T O D=\int_{O}^{t} \frac{Q_{g a s}}{V_{l i q}} \cdot\left(\left[O_{3}\right]_{g a s i n}-\left[O_{3}\right]_{\text {gas out }}\right) \cdot d t_{r}
$$

donde $\mathrm{Q}_{\text {gas }}, \mathrm{V}_{\text {liq }} \mathrm{y}$ tr son la tasa de flujo de gas, el volumen del efluente y el tiempo de reacción. $\left[\mathrm{O}_{3}\right]_{\text {gas in }}$ y $\left[\mathrm{O}_{3}\right]_{\text {gas out }}$ son las concentraciones de ozono de la fase gas en la entrada y salida del reactor, respectivamente. Además, si se dispone de los datos de ozono en fase gas (entrada y salida) así como el ozono disuelto, se puede hacer el análisis del balance de masa de ozono obteniéndose tres parámetros fundamentales para la ingeniería del proceso de ozonización: la demanda de ozono instantánea, coeficiente de transferencia de masa de ozono y la constante cinética de descomposición del ozono (Marcé et al. 2016). Su conocimiento es de vital importancia para el diseño de los reactores de ozono y para la determinación de las condiciones de funcionamiento adecuadas. En la figura 5.4 se muestra el esquema de una instalación a escala laboratorio diseñada para el estudio de la ozonización. 


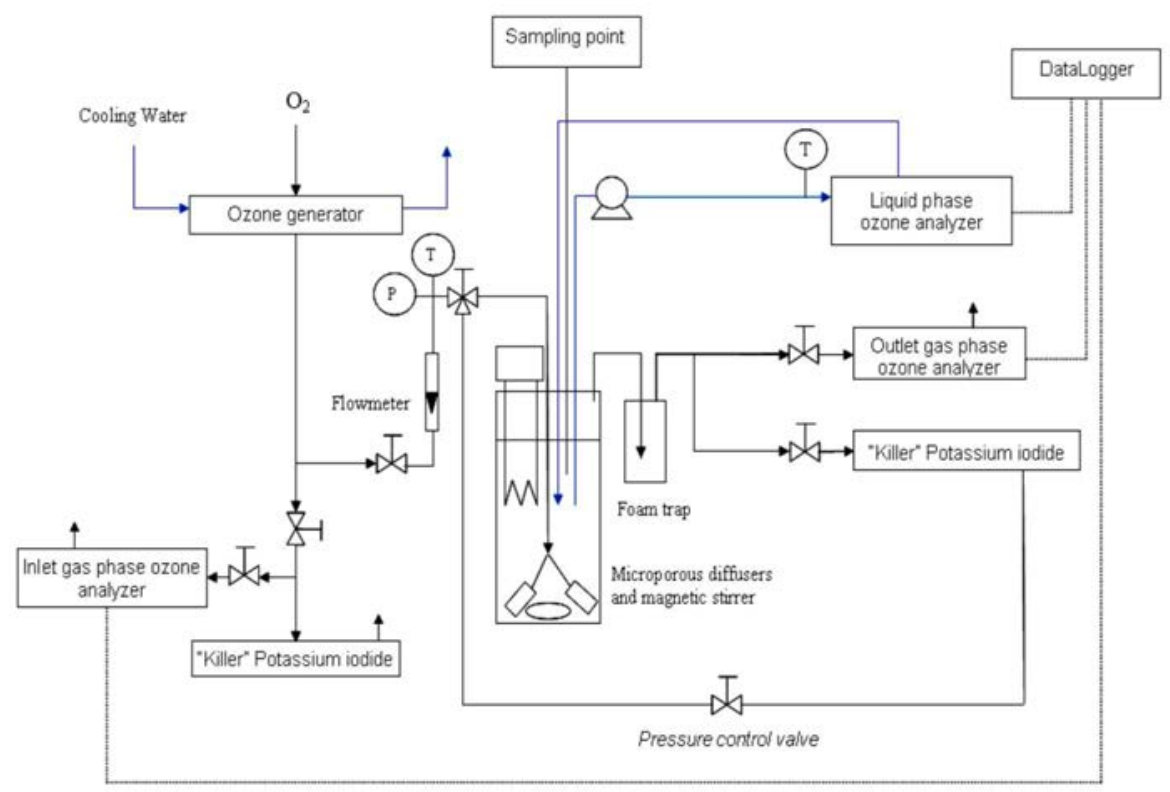

Figura 5.4. Esquema de una instalación de ozonización a escala laboratorio

\subsubsection{Efecto del ozono en la eliminación de los contaminantes emergentes}

Existen numerosos trabajos en la bibliografía que demuestran la gran eficiencia de la ozonización en el control de los contaminantes emergentes presentes en los efluentes de depuradora, tanto a escala laboratorio, planta piloto e incluso a escala industrial. Esta eficiencia depende de muchos factores, incluyendo contaminantes analizados, dosis de ozono aplicadas, tipos de matrices de agua etc. Las constantes de velocidad de segundo orden para la oxidación por ozono de compuestos orgánicos varían más de 10 órdenes de magnitud, entre $<0.1 \mathrm{M}^{-1} \mathrm{~s}^{-1}$ y $7^{*} 10^{9} \mathrm{M}^{-1} \mathrm{~s}^{-1}$. (Von Gunten, 2003). En cambio, los radicales hidroxilo no son selectivos y sus constantes cinéticas de degradación suelen ser $>10^{9} \mathrm{M}^{-1} \mathrm{~s}^{-1}$.

A título de ejemplo, la figura 5.5 muestra las eliminaciones de diferentes fármacos concentrados en el rechazo del tratamiento terciario por membranas de una depuradora urbana. La concentración inicial de dichos fármacos en el rechazo se muestra en la tabla 5.3 (Justo et al., 2013). 
Tabla 5.3. Valores medios de concentración de fármacos en el concentrado de un tratamiento terciario por ósmosis inversa de agua residual urbana

\begin{tabular}{|lc|}
\hline Fármaco & $\begin{array}{c}\text { Conc. } \\
\mu \mathrm{gL}^{-1}\end{array}$ \\
\hline Naproxen & 1080 \\
Indometacin & 895 \\
Diclofenac & 605 \\
Propyphenazone & 258 \\
Paroxetine & 508 \\
Codeine & 673 \\
Carbamazepine & 1038 \\
Sulfamethazine & 635 \\
Sulfamethoxazole & 1638 \\
Trimethoprim & 235 \\
Atenolol & 1028 \\
\hline
\end{tabular}

\section{Dosis de ozono $\left(\mathrm{mgO}_{3} \mathrm{mgC}^{-1}\right)$}

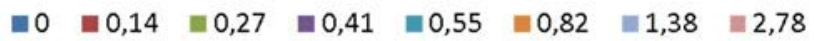
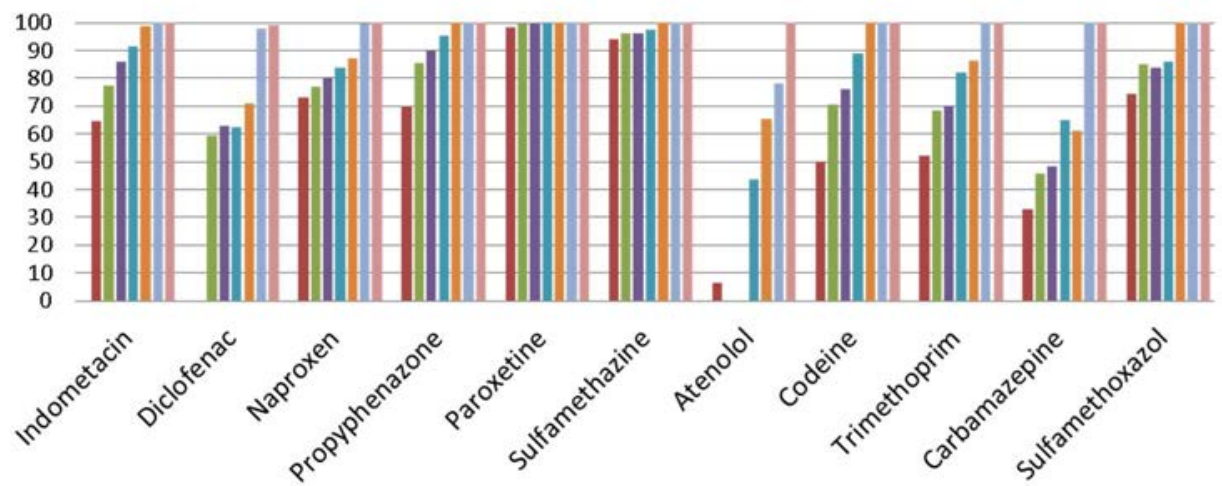

Figura 5.5. Porcentaje de eliminación de los fármacos a diferentes dosis de ozono $\left(\mathrm{mgO}_{3} \mathrm{mgC}^{-1}\right)$ 
Con este tipo de agua, la vía de degradación indirecta viene disminuida ya que, además de concentrar los contaminantes emergentes en el rechazo, el contenido de los secuestrantes de radicales hidroxilo, como son, la materia orgánica el efluente, la alcalinidad y otros compuestos inorgánicos, es también mayor. Así se observa que hay fármacos con altas remociones a bajas dosis de ozono (como el sulfametoxazol, sulfametazina y naproxeno), debido a la presencia en estos compuestos de grupos funcionales ricos en electrones, altamente reactivos con el ozono. Por otra parte, también se observa que otros fármacos como la carbamazepina, el atenolol y el diclofenac necesitan dosis mucho más altas de ozono para conseguir eliminaciones significativas del fármaco. Aunque se han hecho muchos esfuerzos en poder predecir las eficiencias de eliminaciones de los contaminantes emergentes con ozono, la complejidad de las reacciones químicas que se producen y la gran variedad de factores que afectan a dicha reactividad hacen cualquier modelo teórico poco fiable, lo que obliga a obtener datos reales para cada tipo de agua a tratar.

Juntamente con la eliminación de los contaminantes emergentes, está demostrado que el ataque primario del ozono es suficiente para reducir los efectos específicos de los contaminantes, como la capacidad antibactertiana, antiviral, la capacidad disruptiva endocrina, etc. Sin embargo, durante la ozonización difícilmente se consigue la mineralización de todos los contaminantes emergentes, obteniéndose productos de trasformación. De ahí nuevamente la importancia de la obtención experimental de datos para cada agua a tratar así como la optimización de la dosis de ozono a emplear.

Un subproducto que debe que ser evaluado con especial interés durante la ozonización, debido a su alta toxicidad a nivel de trazas, es el bromato. Los bromatos se generan durante la ozonización debido a la oxidación de los bromuros presentes en el agua residual. El valor final de la concentración de bromato debe ser determinado, dependiendo del uso final del agua tratada, ya que la Organización Mundial de la Salud recomienda no superar el valor límite (25 $\left.\mathrm{\mu g} \mathrm{BrO}_{3} \mathrm{~L}^{-1}\right)$ para agua de consumo humano (Von Gunten \& Hoigne, 1994). 


\subsubsection{Efecto del ozono sobre la materia orgánica de efluentes de depuradora}

Como se ha comentado anteriormente, los parámetros de calidad del agua que se utilizan para caracterizar la materia orgánica del agua son: COT, DQO, demanda biológica de oxígeno a 5 días $\left(\mathrm{DBO}_{5}\right)$, y absorbancia $\mathrm{UV}_{254^{\prime}}$ entre otros. Existen otras técnicas más avanzadas, entre ellas la técnica LC-OCD que permiten obtener información cuantitativa y cualitativa específica acerca de las fracciones de materia orgánica disuelta durante el proceso de oxidación. La información cuantitativa se basa en una determinación de la masa de carbono continua que es similar al análisis de TOC. Esta medición se realiza con un detector de carbono orgánico. El análisis cualitativo se compone de un gel de separación cromatográfica de materia orgánica antes del análisis. Esta separación se lleva a cabo mediante cromatografía de exclusión por tamaños. En conjunto, estos análisis se utilizan para identificar las fracciones orgánicas clasificadas según: Biopolímeros (BP), sustancias húmicas (HS), productos de degradación de los ácidos húmicos (BB), ácidos grasos de bajo peso molecular (LMMA) y otros productos neutros de bajo peso molecular (LMMN). La Tabla 5.4 muestra los valores típicos de los principales parámetros de calidad de un efluente del proceso de lodos activados de una depuradora de aguas residuales urbanas y la Figura 5.6 muestra su cromatograma de LC-OCD (González et al., 2013).

Tabla 5.4. Valores medios de los principales parámetros de calidad de efluente del tratamiento secundario de EDAR

\begin{tabular}{|c|c|}
\cline { 2 - 2 } \multicolumn{1}{c|}{} & Efluente secundario \\
\hline $\mathbf{C O T}\left(\mathrm{mg} \mathrm{CL}^{-1}\right)$ & $17.4 \pm 3.4$ \\
\hline $\mathbf{C O D}\left(\mathrm{mg} \mathrm{CL}^{-1}\right)$ & $15.2 \pm 3.8$ \\
\hline $\mathbf{D Q O}\left(\mathrm{mgO}_{2} \mathrm{~L}^{-1}\right)$ & $49.7 \pm 3.3$ \\
\hline $\mathbf{p H}$ & $7.8 \pm 0.1$ \\
\hline $\mathbf{U V}_{254}\left(\mathrm{~m}^{-1}\right)$ & $30.3 \pm 0.9$ \\
\hline Turbidez $\left(\mathrm{NTU}^{\prime}\right)$ & $2.1 \pm 0.56$ \\
\hline Alcalinidad $\left(\mathrm{mg} \mathrm{CaCO}_{3} \mathrm{~L}^{-1}\right)$ & $599 \pm 24$ \\
\hline $\mathbf{C l}\left(\mathrm{mgCl}^{-1}\right)$ & $488 \pm 30$ \\
\hline
\end{tabular}




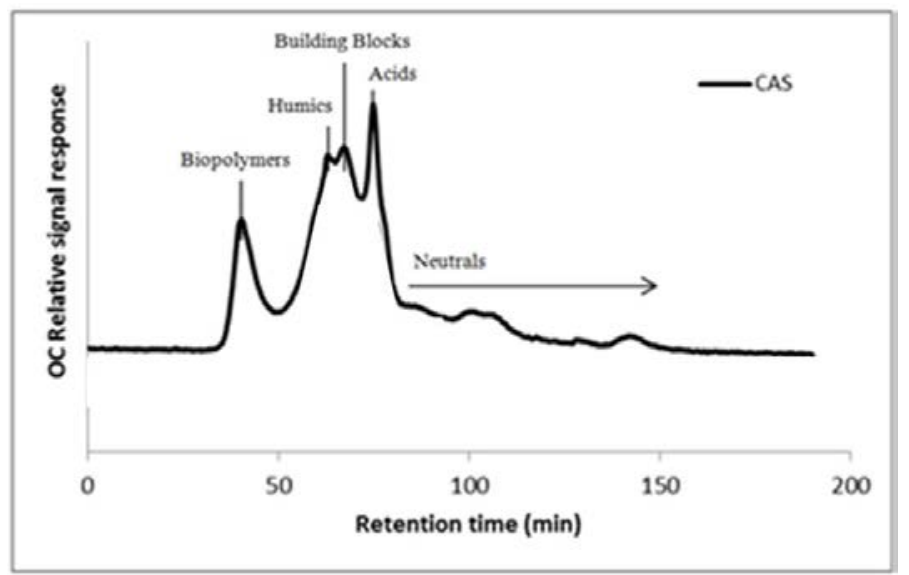

Figura 5.6. Cromatograma LC-OCD de efluente del tratamiento secundario de EDAR

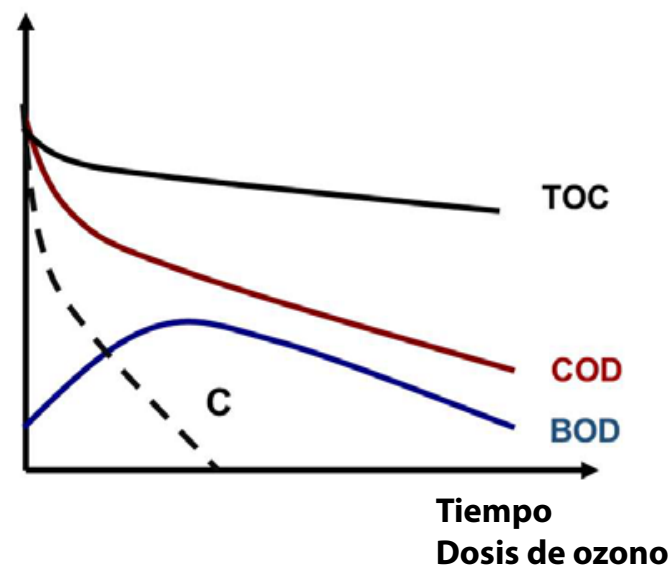

Figura 5.7. Efecto del ozono sobre la materia orgánica del efluente del tratamiento secundario de EDAR

Como se ha comentado, el ozono es eficiente en la oxidación de la materia orgánica del efluente del tratamiento secundario, reflejándose en una disminución tanto del COT como de la DQO, a medida que aumenta el ozono transferido al medio de reacción. Sin embargo, se necesitan altas dosis de ozono para alcanzar la mineralización total. El efecto más importante 
de la ozonización a bajas dosis de ozono es el aumento de la $\mathrm{DBO}_{5}$ y de la biodegradabilidad, entendida como la ratio $\mathrm{DBO}_{5} / \mathrm{DQO}$, debido a la oxidación química de los compuestos biorecalcitrantes transformándolos en compuestos más biodegradables (figura 5.7).

El análisis de LC-OCD permite comprobar que la ozonización es capaz de degradar los compuestos de mayor peso molecular de los efluentes secundarios desde el principio del tratamiento, al mismo tiempo que se acumulan los compuestos de bajo peso molecular, y en particular los compuestos ácidos, considerados mayormente biodegradables (figura 5.8). La alta alcalinidad y la presencia de cloruros y otras especies secuestrantes de radicales hidroxilo favorecen la vía de oxidación directa por reacción del ozono frente a la vía indirecta. Ello podría explicar la menor eficiencia de la ozonización en la oxidación de los ácidos de bajo peso molecular, provocando su acumulación a lo largo del proceso de ozonización y aumentando la biodegradabilidad del efluente tratado.

La biodegradabilidad de los efluentes terciarios resultantes es un parámetro muy importante a tener en cuenta ya que la presencia de materia orgánica fácilmente biodegradable puede convertirse en sustrato para el crecimiento microbiano en los sistemas de distribución de agua para reuso y para la eutrofización de sus sistemas de almacenaje de agua. Por otra parte, la combinación

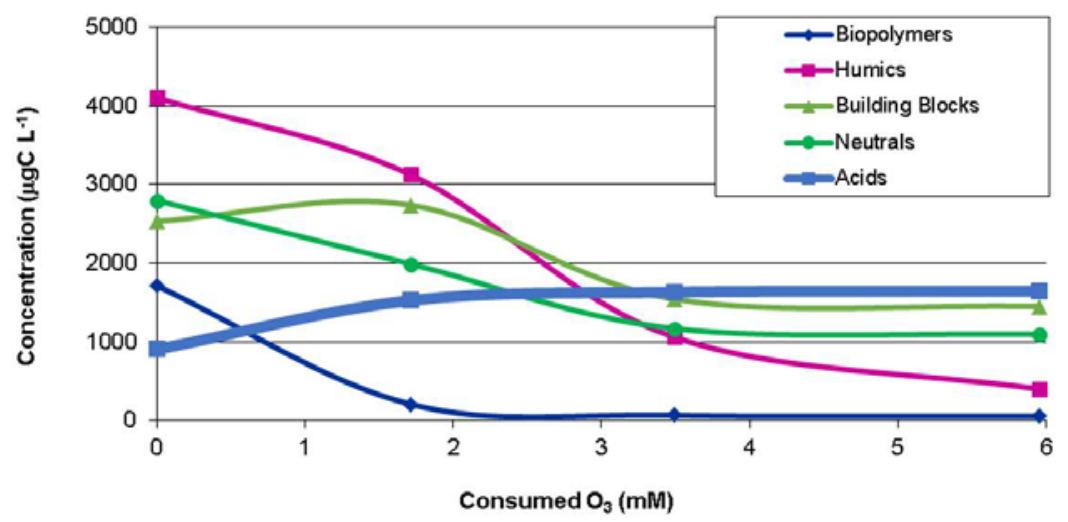

Figura 5.8. Efecto del ozono sobre las distintas fracciones de la materia orgánica del efluente secundario de depuradora 
de la ozonización con un post-tratamiento biológico es la mejor estrategia para la total eliminación de la materia orgánica contenida en los efluentes de depuradora, frente a la utilización de altas dosis de ozono que encarecerían en exceso el tratamiento (Justo et al., 2015).

\subsection{Conclusiones}

De lo expuesto en este capítulo se pueden extraer las siguientes principales conclusiones:

- La ozonización de efluentes de aguas residuales es capaz de reducir la DQO, DOC, Absorbancia UV, turbidez, al mismo tiempo que la concentración de contaminantes emergentes.

- A baja dosis de ozono ya se obtiene un aumento de la biodegradabilidad, DBO/DQO, del efluente.

- Durante la ozonización se producen cambios importantes en la distribución del tamaño molecular de la materia orgánica.

- El ozono es efectivo en la eliminación de contaminantes emergentes, aunque la eficiencia global del proceso depende de muchos parámetros operacionales y del tipo de agua a tratar.

\section{Referencias}

Bixio, D., Thoeye, C., De Koning, J., Joksimovic, D., Savic, D. y Wintgens, T. (2006). «Wastewater reuse in Europe», Desalination, 187, pp. 89-101.

Ginebreda, A., Muñoz, I., de Alda, M.L., Brix, R., López-Doval, J. y Barceló, D. (2010). «Environmental risk assessment of pharmaceuticals in rivers: Relationships between hazard indexes and aquatic macroinvertebrate diversity indexes in the Llobregat River (NE Spain)», Environmental International, 36, pp. 153162.

Gogate, P.R. y PANDit, A.B. (2004). «A review of imperative technologies for wastewater treatment I: Oxidation technologies at ambient conditions». Advances in Environmental Research, 8 (3-4), pp. 501-551. 
González, O., Justo, A., Bacardit, J., Ferrero, E., Malfeito, J.J. y Sans, C. (2013). «Characterization and Fate of Effluent Organic Matter Treated with UV/ $\mathrm{H}_{2} \mathrm{O}_{2}$ and Ozonation». Chemical Engineering Journal, 226, pp. 402-408.

GotTsChalk, C., LibRA, J.A. y SAUPE, A. (2010). Ozonation of water and wastewater. A practical guide to understanding ozone and its application. Wiley- $\mathrm{VCH}$, Weiheim, Germany.

Haering, K.C., Evanyelo, G.K., Benham, B. y Goatley, M. (2009). «Water Reuse: Using Reclaimed Water for Irrigation». Virginia Cooperative Extension, 452 (014), pp. 1-11.

HaRTLEY, T.W. (2006). «Public perception and participation in water reuse». Desalination, 187, pp. 115-126.

HOIGNÉ, J. y BADER, H. (1975). «Ozonation of water: role of hydroxyl radicals as oxidizing intermediates». Science, 190, pp. 782-784.

- (1983) «Rate constant of reaction of ozone with organic and inorganic compounds in water. Part I: Non-dissociating organic compounds». Water Research, 17, pp.173-183.

Hoigné, J., BADER, H., HAaG, W.R. y Staehelin, J. (1985). «Rate constant of reactions of ozone with organic and inorganic compounds in water. Part III: Inorganic compounds and radicals». Water Research, 19, pp.173-183.

Justo, A., Gonzálezz, O., Aceña, J., Pérez, S., Barceló, D., Sans, C. y Esplugas, S. (2013). «Pharmaceuticals and Organic Pollution Mitigation in Reclamation Osmosis Brines by UV/ $\mathrm{H}_{2} \mathrm{O}_{2}$ and Ozone». Journal of Hazardous Materials, 263, pp. 268-274.

Justo, A., González, Sans, C. y Esplugas, S. (2015) «BAC filtration to mitigate micropollutants and EfOM content in reclamation reverse osmosis brines». Chemical Engineering Journal, 279, pp. 589-596.

Marce, M., Domenjoud, B., Esplugas, S. y Baig, S. (2016). «Ozonation treatment of urban primary and biotreated wastewaters: Impacts and modelin». Chemical Engineering Journal, 283, pp. 768-777.

Langlals, B., ReCKHOW, D.A. y Brink, D.R. (1991). Ozone in Water Treatment. Application and Engineering. Lewis Publishers, Chelsea, Michigan, USA.

RICE, R.G. (1997). «Application of ozone for industrial wastewater treatment: a review». Ozone Science and Engineering, 18 (6), pp. 477-515.

Tejon, G., Candela, L., Tamoh, K., Molina-Díaz, A. y Fernández-Alba, A.R. (2010). «Occurrence of emerging contaminants, priority substances (2008/105/ 
CE) and heavy metals in treated wastewater and groundwater at Depurbaix facility (Barcelona, Spain)». Science of Total Environment, 408, pp. 3584-3595.

Ternes, T.A., Stüber, J., Herrmann' N., McDowell' D., Ried, A., Kampmann, M. y Teiser', B. (2003). «Ozonation: A tool for removal of pharmaceuticals, contrast media and musk fragrances from wastewater?». Water Research, 37 (8), pp. 19761982.

TIWARI, G. y BOSE P. (2007). «Determination of ozone mass transfer coefficient in a tall continuous flow counter-current bubble contactor». Chemical Engineering Journal, 132 (1-3), pp. 215-225.Open Access

Von Gunten, U. (2003) «Ozonation of drinking water: Part I. Oxidation kinetics and product formation». Water Research, 37, pp. 1443-1467.

Von GUNTEN, U. y HoIGNÉ, J. (1994). «Bromate formation during ozonation of bromidecontainingwaters: interaction of ozone and hydroxyl radical reactions». Environmental Science and Technololy, 28, pp. 1234-1242.

YAO, D. y HAAG, W.R (1991). «Rate constants for direct reactions of ozone with several drinking water contaminants». Water Research, 25 (7), pp. 761-773. 


\section{Sistemas no convencionales para procesos fotoquímicos de oxidación}

Francisco Galindo

Departamento de Química Inorgánica y Orgánica

Universitat Jaume I de Castellón

Avda. Sos Baynat s/n, 12071 Castellón de la Plana, España

Contacto: francisco.galindo@uji.es

\section{Francisco Galindo}

Profesor Titular de la Universitat Jaume I de Castellón. Se licenció en Ciencias Químicas (1995) en la Universitat de València y realizó su tesis doctoral en la Universitat Politècnica de València (1999), bajo la dirección de los profesores Miguel A. Miranda y Rosa Tormos, en fotoquímica orgánica. La actividad investigadora se ha desarrollado principalmente en el ámbito de las reacciones de transferencia electrónica fotoinducida (PET), tanto en sus aspectos fundamentales como en sus aplicaciones. De los estudios fundamentales cabe destacar aquellos que abordan procesos básicos en sistemas modelo así como la fotosensibilización usando cationes fotoactivos. De los estudios aplicados cabe destacar las sondas fluorescentes intracelulares para bioanálisis de óxido nítrico y $\mathrm{pH}$. Otro ámbito de interés es el de la generación de especies reactivas de oxígeno (ROS, especialmente oxígeno singlete) con nuevos materiales poliméricos y con potencial aplicación en terapia y remediación ambiental. Director de 7 proyectos de investigación y 6 tesis doctorales. Autor de 3 patentes. Estancias de investigación en Columbia University (Nueva York), Rutgers University (New Jersey), Universidade Nova de Lisboa y University of East Anglia (Norwich). Además de la actividad docente en la Universitat Jaume I, ha impartido seminarios y cursos en diversas universidades de Europa, América y Asia. Más información: http://photochemistry.uji.es 


\section{Resumen}

La combinación de luz y catalizadores (fotocatálisis) ha sido muy estudiada hasta la fecha en el ámbito de los procesos de oxidación avanzada. El principal material estudiado en los últimos 40 años es el dióxido de titanio $\left(\mathrm{TiO}_{2}\right)$. Sin embargo, otros materiales se continúan proponiendo como alternativas. En este trabajo se presentará una recopilación de los últimos avances sobre fotocatalizadores orgánicos unidos a polímeros. Se discutirán ejemplos extraídos de la bibliografía así como desarrollos propios realizados en fechas recientes.

\subsection{Introducción}

Los procesos fotocatalíticos para tratamiento de aguas son de gran interés, tanto desde el punto de vista académico como aplicado. El empleo de luz solar puede ser una alternativa económicamente eficiente para la destrucción de contaminantes químicos en medio acuoso, así como de elementos patógenos como virus y bacterias (Malato, 2009). En las últimas décadas se ha desarrollado ampliamente el campo de la fotocatálisis solar usando semiconductores inorgánicos, especialmente el dióxido de titanio $\left(\mathrm{TiO}_{2}\right)$. El $\mathrm{TiO}_{2}$ posee la capacidad de generar eficientemente un par electrón-hueco $\left(\mathrm{e}^{-} / \mathrm{h}^{+}\right)$tras ser irradiado con luz ultravioleta (uv). Tras la generación de dicho $\mathrm{e}^{-} / \mathrm{h}^{+}$puede tener lugar la recombinación para volver al estado original o bien migración del electrón y del hueco, dando lugar a sitios reactivos (reductor y oxidante) que inducen diversos procesos químicos, entre los cuales puede destacarse la formación de radical anión superóxido $\left(\mathrm{O}_{2}{ }^{-}\right)$o radical hidroxilo $(\cdot \mathrm{OH})$, que puede participar en la degradación de contaminantes o patógenos. Numerosos artículos de revisión han sido publicados tratando los aspectos mecanísticos de la fotocatálisis con $\mathrm{TiO}_{2}$ y otros semiconductores (Etacheri, 2015), así como desarrollos prácticos desde el punto de vista del medio ambiente (Daghrir, 2013). Por ello, este tipo de materiales no será tratado con más profundidad en este trabajo y se remite al lector a dichas publicaciones. Otras aproximaciones 
fotocatalíticas de importancia, pero basadas en materiales inorgánicos, como procesos foto-Fenton, tampoco serán tratadas (García-Ballesteros, 2016).

Una de las desventajas del $\mathrm{TiO}_{2}$ es su baja capacidad de absorción de luz visible. La excitación debe realizarse con luz uv $(\lambda<380 \mathrm{~nm})$, la cual es una pequeña fracción de la luz solar que llega a la superficie terrestre (aproximadamente el $10 \%$ ). Sería deseable aprovechar el restante $90 \%$ de luz visible y, para ello, numerosos esfuerzos se están llevando a cabo, principalmente modificando el $\mathrm{TiO}_{2}$ para hacerlo sensible a longitudes de onda mayores. Otra alternativa que se está desarrollando en paralelo consiste en el empleo de fotocatalizadores orgánicos. En comparación con el abrumador número de publicaciones describiendo resultados basados en semiconductores inorgánicos, el empleo de compuestos orgánicos es relativamente minoritario y, por ello, pueden considerarse sistemas no convencionales en el contexto del tratamiento de aguas. Sin embargo, en los últimos años esta aproximación está tomando fuerza. En este sentido se remite al lector al excelente trabajo de revisión sobre fotosensibilizadores orgánicos publicado recientemente (Marín, 2012).

La principal ventaja de los fotocatalizadores orgánicos es la posibilidad de ser diseñados para absorber eficientemente luz visible y, por tanto, aprovechar dicha fracción de la radiación solar. El extenso bagaje acumulado en el campo de la fotoquímica ha permitido conocer con detalle numerosas reacciones que implican la generación de especies oxidantes, bien sea el propio fotocatalizador en estado excitado, bien sea una especie derivada del mismo. En este último sentido, un ejemplo paradigmático es la formación de oxígeno singlete $\left({ }^{1} \mathrm{O}_{2}\right)$. Este es una de las llamadas especies reactivas de oxígeno (ROS, por sus siglas en inglés) capaces de degradar diversos contaminantes acuosos así como patógenos varios. La cadena de procesos mediante los cuales se genera ${ }^{1} \mathrm{O}_{2}$ se muestra en la figura 6.1. El proceso se inicia con la absorción de un fotón por parte del fotocatalizador (o sensibilizador) lo cual lleva a este al estado excitado singlete ('Sens). Seguidamente tiene lugar un proceso de cruce intersistemas (Isc, por sus siglas en inglés) al estado excitado triplete ('Sens). $\mathrm{Y}$, a continuación, la interacción de ${ }^{3}$ Sens con oxígeno molecular da lugar a oxígeno singlete $\left({ }^{1} \mathrm{O}_{2}\right)$. Finalmente, esta especie reactiva es capaz de participar en procesos oxidativos con un sustrato $\mathrm{R}$ (formación de especie oxidada $\mathrm{RO}_{2}$ ). 


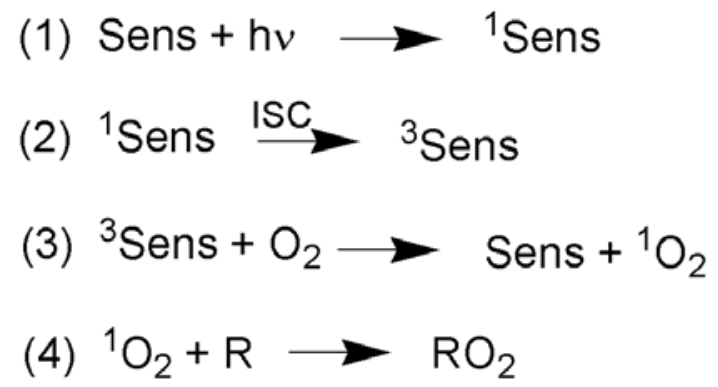

Figura 6.1. Procesos fotofísicos básicos involucrados en la generación de oxígeno singlete $\left({ }^{1} \mathrm{O}_{2}\right)$

En la bibliografía están descritos una gran cantidad de compuestos que participan en la formación de ${ }^{1} \mathrm{O}_{2}$ (Marin, 2012), especialmente porque este es el fundamento de la terapia fotodinámica (anticancer o antibacteriana) (MacDonald, 2001). Sin embargo, el empleo de moléculas en disolución acuosa para el tratamiento de aguas plantea el problema de eliminar el fotocatalizador del medio una vez usado. Para ello se han probado diversas formas de soportar los fotocatalizadores en polímeros orgánicos. Los sistemas soportados en matriz polimérica resultan de gran atractivo desde el punto de vista medioambiental dado que combinan la capacidad de absorber luz solar visible, generar una especie oxidante como ${ }^{1} \mathrm{O}_{2} \mathrm{y}$, a su vez, poder ser eliminados (y reciclados en su caso). En la bibliografía existen algunas publicaciones de revisión sobre materiales orgánicos generadores de oxígeno singlete, pero normalmente orientados a aspectos específicos como la inactivación bacteriana o la síntesis orgánica (Lacombe, 2016; Spagnul, 2015; Wahlen, 2004; Wang, 2004). En este trabajo se hará una recopilación de diversos avances publicados sobre polímeros fotoactivos generadores de ${ }^{1} \mathrm{O}_{2}$ en la última década, con una visión amplia del campo e incluyendo desarrollos propios de la Universitat Jaume I de Castellón. Cabe indicar que la presente revisión es una selección de trabajos que pueden considerarse representativos, con objeto de presentar una visión de un conjunto de aplicaciones fotocatalíticas, especialmente con potencial uso en tratamiento de aguas. Se hará una clasificación en dos bloques, atendiendo al tipo de unión entre el fotocatalizador y la matriz polimérica. En 
primer lugar, se comentarán ejemplos de materiales orgánicos fotoactivos en los cuales la unión es covalente. Después, se describirán ejemplos donde el fotocatalizador se encuentra unido al polímero de manera no covalente (ya sea por atrapamiento o por enlace iónico).

\subsection{Fotocatalizadores unidos a polímeros de manera covalente}

En primer lugar, se describirá el grupo de materiales poliméricos en los cuales el fotosensibilizador se encuentra unido a la matriz mediante un enlace covalente. Este tipo de polímeros fotoactivos es el más numeroso y tiene sus orígenes históricos en los trabajos pioneros de Neckers y Schaap en la década de los 70 del siglo pasado (Blossey, 1973; Schaap, 1974). En aquellos, se describió la utilización del sensibilizador Rosa de Bengala unido a poliestireno de tipo Merrifield (bajo entracruzamiento) para generar ${ }^{1} \mathrm{O}_{2}$. Derivados de aquellas resinas originales se han descrito numerosos materiales. Algunos de los más recientes se describen a continuación. Cada uno de los polímeros fotosensibles citados en el texto puede encontrarse en la tabla 6.1, donde se indica el soporte, el fotosensibilizador y el sistema test, es decir, el objeto de la reacción de oxidación por parte de ${ }^{1} \mathrm{O}_{2}$. Cabe recordar que la mayoría de las reacciones modelo ensayadas son transformaciones bien conocidas y se han empleado como prueba de concepto (por ejemplo, las oxidaciones de terpenos).

Se ha estudiado ampliamente la capacidad oxidativa de porfirinas ancladas covalentemente a poliestireno (Ribeiro, 2007, 2008, 2013; Pineiro, 2010) usando como reacciones test la oxidación de terpenos como a-terpineno, citronelol y linalool, así como 1,5-dihidroxinaftaleno (DHN) y 9,10-dimetilantraceno (DMA). Se ha observado que la eficiencia de las reacciones depende de la distancia que separa el sensibiliador de la matriz polimérica. Además, se ha demostrado la aplicabilidad de estas reacciones bajo condiciones de irradiación solar. Cabe destacar que, aparte de las aplicaciones ambientales derivadas de la generación de una especie oxidante como el oxígeno singlete, las reacciones arriba mencionadas ya son de por sí de interés aplicado, dado que, por ejemplo, el ascaridol (derivado del $\alpha$-terpineno) o la juglona (derivada del DHN) constituyen de por sí importantes compuestos para la industria química. 
El poliestireno usado normalmente para la preparación de fotopolímeros presenta la desventaja de ser muy hidrofóbico. Esto resulta un inconveniente para su aplicación en reacciones que impliquen agua dado que el fotopolímero y los reactivos disueltos en el medio acuoso no se llegan a encontrar eficientemente (por agregación del polímero). Por ello resulta de gran interés preparar materiales que sean compatibles con medios polares como etanol o metanol (e idealmente agua). En la Universitat Jaume I se han modificado fotopolímeros basados en poliestireno y Rosa de Bengala para hacerlos más compatibles con dichos medios (Burguete, 2010 a). Así, un material como P1, mostrado en la figura 6.2, compuesto únicamente por matriz tipo Merrifield y fotosensibilizador, dispone en su estructura de diversos grupos clorometilo que son susceptibles de reaccionar. El tratamiento de P1 con piridina dio lugar a P2, polímero que contiene grupos piridinio en su superficie, cargados positivamente y, por tanto, con posibilidad de solvatación más eficiente por un disolvente polar. Se demostró que P2 es capaz de llevar a cabo la oxidación de ácido 2-furóico al butenólido 5-hidroxi-5H-furan-2-ona en metanol de manera más eficaz que P1 (100 \% y $32 \%$ de rendimiento respectivamente). Todo ello bajo irradiación con luz solar. Incluso el sensibilizador no soportado presenta un valor de rendimiento menor (74\%). Una de las grandes ventajas del empleo de fotocatalizadores soportados es la posibilidad de recuperación de los mismos por filtración y reutilización posterior. En el caso de P2, se consiguió reutilizar el polímero durante 11 ciclos, sin pérdida aparente de fotoactividad.

Otra estrategia para aumentar el contacto entre polímero fotoactivo y oxígeno o sustancias a oxidar consiste en el aumento de la superficie específica

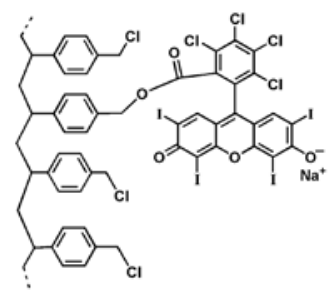

P1

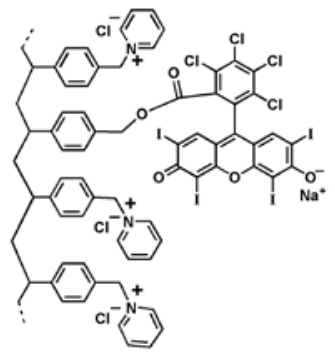

P2

Figura 6.2. Fotopolímeros basados en poliestireno. P1: con Rosa de Bengala. P2: con Rosa de Bengala y grupos piridinio para aumentar compatibilidad en medio polar (Burguete, 2010 a) 
del material. En la Universitat Jaume I se han desarrollado diversos materiales siguiendo esta vía (Burguete, 2009, 2010 b). Así, en lugar de usar una matriz de tipo Merrifield con bajo entrecruzamiento y tamaño de partícula grande (hasta 100 micras), se planteó la posibilidad de utilizar poliestireno macroporoso de alto entrecruzamiento. Este tipo de materiales presenta una alta porosidad, y cuando se moltura mecánicamente queda en forma de pequeños gránulos de tamaño micrométrico (una micra o menos en algunos casos, véase la figura 6.3). Los materiales sintetizados y caracterizados presentaron actividad fotocatalítica tanto para la oxidación de ácido 2-furoico como de 9,10-difenilantraceno (DPA), también empleando Rosa de Bengala como fotocatalizador, con actividades superiores a las del polímero tipo Merrifield control.
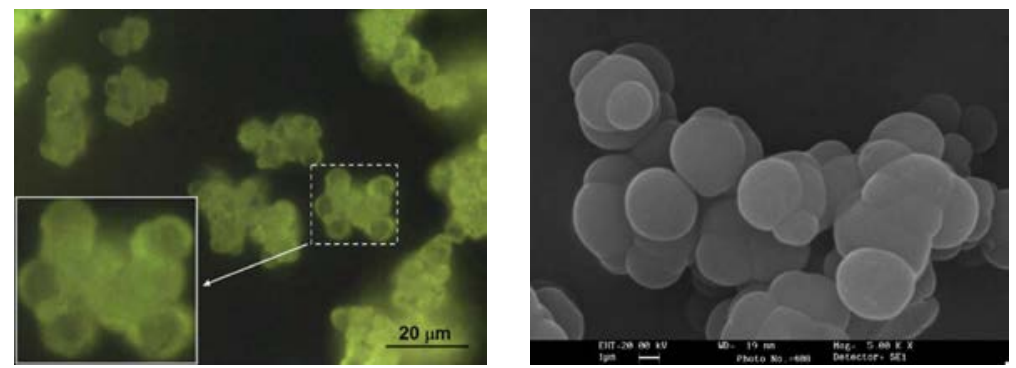

Figura 6.3. Imágenes de microscopía de fotopolímero macroporoso cargado con fotosensibilizador (Burguete, 2010 b). Izquierda: microscopía de fluorescencia; derecha: SEM. Reproducido con permiso: Copyright $\odot$ 2010, Elsevier
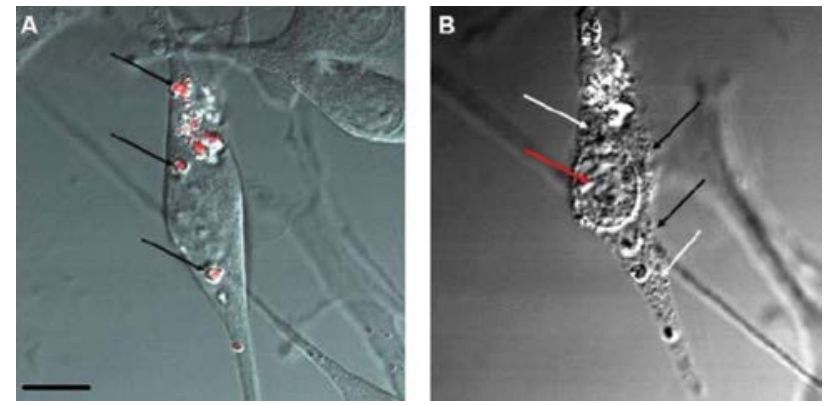

Figura 6.4. Efecto fotodinámico de fotopolímero macroporoso sobre célula de melanoma. Izquierda: antes de irradiar. Derecha: tras irradiación (Burguete, 2009). Reproducido con permiso: Copyright $\odot 2008$, Royal Society of Chemistry 
Los polímeros descritos más arriba fueron ensayados también en terapia fotodinámica (PDT, por sus siglas en inglés), dada la eficiente generación de oxígeno singlete y la gran citotoxicidad de esta especie. Así, se incubaron células de melanoma humano con polímero macroporoso funcionalizado con Rosa de Bengala y se demostró el efecto fototóxico del material, tras irradiación con láser y observación con microscopía confocal (figura 6.4).

Recientemente se ha conseguido hacer los materiales arriba descritos más compatibles con medios polares (Fabregat, 2014). Esto se ha logrado haciendo reaccionar los grupos clorometilo libres en la matriz polimérica original con etilendiamina (polímero P3 en la figura 6.5) y posteriormente con gluconolactona (polímero P4). De esta manera se han obtenido materiales con alta funcionalización de grupos amino o hidroxilo, lo que los hace más compatibles con agua, objetivo último a nivel medioambiental. En todos los casos se observa además un aumento de la estabilidad del Rosa de Bengala a la autooxidación.

Notablemente, la morfología macroporosa (agregados de micropartículas) se mantiene tras los procesos sintéticos (véase en la figura 6.6 una imagen de microscopía electrónica de barrido).

Desde el punto de vista de la reactividad fotoquímica, los nuevos polímeros funcionalizados P3 y P4 son más eficientes en agua que el fotopolímero sin funcionalizar. Así, la reacción de oxidación de ácido 9,10-antracenodipropiónico (ADPA) con fotocatalizador soportado hidrofóbico en agua resulta en una conversión del $85 \%$ mientras que con P3 y P4 es del $100 \%$. Análogamente sucede en metanol/agua para la oxidación de ácido 2-furóico.

El efecto de una mayor superficie también se demuestra con otras morfologías. Así, recientemente se ha descrito un polímero de poliestireno y Rosa de Bengala con forma de panal (Pessoni, 2013). La estructura hexagonal de las celdas permite una mayor interacción con los sustratos a oxidar (a-terpineno y DHN), dando lugar a eficiencias de oxidación hasta 5 veces superiores al polímero control sin estructura porosa.

En ocasiones, la compatibilidad acuosa se desea restringir con objeto de favorecer las interacciones hidrofóbicas en el caso de que el potencial contaminante sea poco soluble en agua. Se ha descrito un fotopolímero que contiene poliestireno con grupos naftilo y Rosa de Bengala que cumplen esta función (Drodz, 2010). En este caso, el contaminante modelo a oxidar fue 1,3-difenilis- 
obenzofurano (DPBF). Además, el polímero se combinó con arcilla para prevenir la agregación de cromóforos que da lugar a la desactivación de los estados excitados.

Otro grupo importante de polímeros fotoactivos para generar ${ }^{1} \mathrm{O}_{2}$ es el basado en poliacrilamida como matriz, dado que es mucho más compatible con agua que poliestireno. Así, el grupo de Shiraishi ha desarrollado un fotopolímero con Rosa de Bengala como fotosensibilizador y estructura de poliacrilamida que es capaz de oxidar fenol y 1 -naftol a quinona y naftoquinona, respectivamente (Koizumi, 2007). Lo más destacado de este material es su

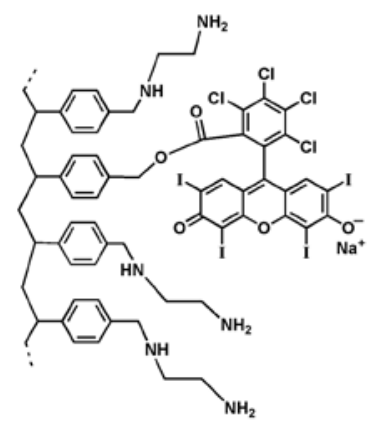

P3

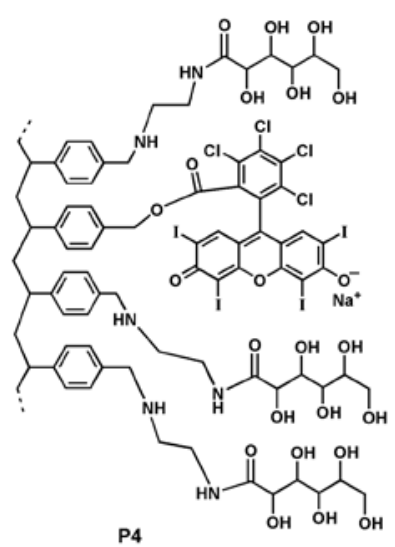

P4

Figura 6.5. Fotopolímeros basados en poliestireno derivatizado con grupos hidrofílicos. P3: con etilendiamina; P4: con etilendiamina y gluconolactona (Fabregat, 2014)

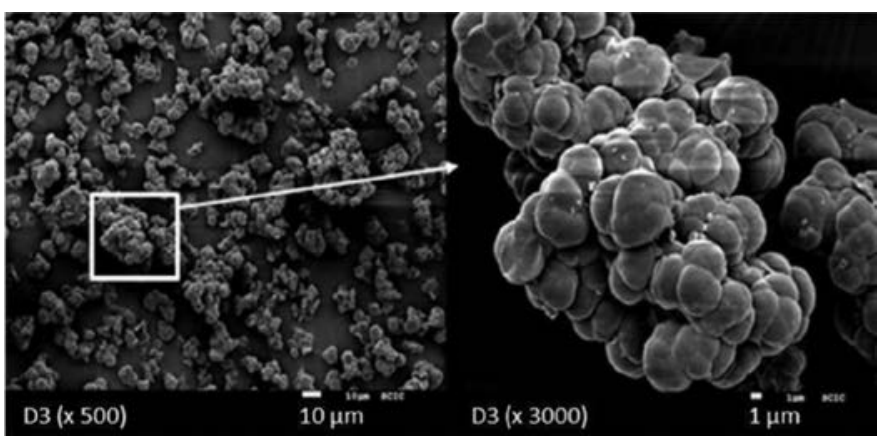

Figura 6.6. Imagen de SEM de fotopolímero macroporoso P4 (Fabregat, 2014). Reproducido con permiso: Copyright $\odot$ 2013, Springer-Verlag 
capacidad para controlar la encapsulación y liberación de los sustratos a oxidar (y, por tanto, su fotooxidación) mediante la temperatura. Los cambios conformacionales inducidos por la temperatura son bien conocidos en química de polímeros, pero en el caso de las poliacrilamidas los efectos son muy notables, y en el caso descrito se trata de una efectiva aplicación de este fenómeno al control de un proceso de fotooxidación.

Utilizando una matriz análoga de poliacrilamida, el grupo de Kopelman ha desarrollado nanopartículas de este material conjugadas al fotosensibilizador Azul de Metileno (Qin, 2011). Se trata de nanopartículas de entre 30 y $100 \mathrm{~nm}$ de tamaño, dependiendo del material. Dichas nanopartículas catalizan la fotooxidación de ADPA en medio acuoso e inducen la muerte de células cancerosas (terapia fotodinámica). El hecho de tener el fotosensibilizador anclado impide la salida de este por lixiviado. Además, la nanopartícula permite la entrada y salida de oxígeno, pero impide la acción enzimática que podría degradar el Azul de Metileno.

Siguiendo dentro del campo de lo nanométrico, otra aproximación descrita ha consistido en la síntesis de membranas nanofibrosas mediante la técnica del electrospinning (Zhu, 2012), en este caso usando como matriz un copolímero de etileno y ácido metacrílico (PE-co-MAA) y porfirina como fotosensibilizador. Además, se emplearon diferentes espaciadores para separar el fotosensibilizador de la matriz. La oxidación de DHN fue empleada para probar el nuevo fotopolímero, encontrándose un notable efecto del espaciador. También se observó moderada reciclabilidad, con 5 ciclos de reacción y un $80 \%$ de actividad al final de los mismos. Sin embargo, la matriz es demasiado hidrofóbica para realizar reacciones en medio acuoso.

Más prometedores, desde el punto de vista de la oxidación en agua, resultan los resultados publicados por el grupo de García describiendo un polímero compatible con medio acuoso basado en una matriz natural como es el quitosano, funcionalizada con Rosa de Bengala (Ferrari, 2014). Este material es capaz de oxidar contaminantes modelo de tipo trihidroxibenceno (Тнв), concretamente 1,3,5 / 1,2,4 / 1,2,3-Тнв y puede ser recuperado por simple precipitación al cambiar el $\mathrm{pH}$. Uno de los aspectos más destacables de este material es que evita la autooxidación del sensibilizador (ya mencionada previamente). Este es un factor clave a la hora de diseñar materiales fotoactivos basados en compuestos orgánicos dado que uno de los principales puntos 
débiles de esta aproximación consiste en la labilidad de los fotosensibilizadores a reacciones de oxidación. En otras palabras, las especies reactivas de oxígeno generadas para degradar sustratos modelo también pueden actuar sobre el propio fotosensibilizador. Esta autooxidación es un proceso recurrentemente descrito en la bibliografía desde las primeras publicaciones sobre este tipo de materiales y podría explicar por qué no hay un número mayor de materiales orgánicos empleados para aplicaciones de descontaminación. Sin embargo, la relevancia de este hecho es cada vez más reconocida y, por tanto, los esfuerzos de investigación se orientan a su solución (Walalawela, 2014). Así pues, el papel que la matriz polimérica juega es clave para la protección frente la autooxidación, como este y otros ejemplos demuestran (Ferrari, 2014; Fabregat, 2014; Burguete, 2009, 2010 a, 2010 b), y, además, puede ser la clave para el desarrollo futuro de materiales orgánicos aplicables a la descontaminación y desinfección de aguas.

En fotocatalizadores soportados la agregación del fotosensibilizador conlleva normalmente la desactivación del mismo (Schaap, 1974). Una manera de evitar este fenómeno ha sido descrita en el caso de un polímero de tipo poliamidoamina funcionalizado con un complejo de iridio como fotosensibilizador (Maggioni, 2015). Esta matriz forma nanoagregados en agua, y el fotosensibilizador tiende a segregarse del medio acuoso quedando aislado. Los polímeros descritos permiten oxidar via ${ }^{1} \mathrm{O}_{2}$ el sustrato $\mathrm{DHN}$, si bien con una velocidad menor que el fotosensibilizador no soportado, hecho atribuible a la menor difusión del oxígeno en la matriz polimérica. No obstante, la generación es esta especie reactiva de oxígeno es suficientemente alta como para permitir ensayos de terapia fotodinámica del cáncer, con resultados positivos.

Para terminar con este apartado, se comentarán tres ejemplos de fotocatalizadores soportados en los que no existe una separación definida entre matriz polimérica y fotosensibilizador anclado covalentemente. En estos casos el elemento fotoactivo se encuentra integrado dentro del esqueleto polimérico. Normalmente se lleva a cabo, en primer lugar, la síntesis de un fotosensibilizador capaz de ser polimerizado, dando origen, en segundo lugar, a la integración de chromóforo fotoactivo y estructura polimérica.

En el caso descrito por el grupo de Vilela se tiene un polímero con estructura intrínsecamente fotosensible (polibenzotiadiazol) capaz de oxidar ácido 2-furóico en agua (Urakami, 2013). Además, el sistema aprovecha una gran 
porosidad (varios cientos de $\mathrm{m}^{2}$ por gramo) para aumentar la superficie de contacto entre fotopolímero y sustrato a oxidar.

Wu y colaboradores describen una membrana de poliporfirina capaz de generar ${ }^{1} \mathrm{O}_{2}$ y oxidar DHN $(\mathrm{Wu}, 2014)$. Si bien el rendimiento cuántico de generación de oxígeno singlete baja notablemente en el polímero $(\varphi=0,26)$ respecto a la porfirina no polimerizada, en disolución $(\varphi=0,62)$, este es suficiente para promover la oxidación de DHN a juglona con rendimientos aceptables (45,1 \% tras 50 min de irradiación). Para poder comparar, el rendimiento de juglona en el caso de la porfirina en disolución resultó $59,1 \%$. Sin embargo, las reacciones descritas se llevan a cabo en disolvente orgánico.

Finalmente, un film polimérico de porfirina obtenido por electropolimerización ha demostrado ser un completo sistema de oxidación (vía ${ }^{1} \mathrm{O}_{2}$ ) dado que es capaz de oxidar DMA en DMF pero también L-triptófano (L-Trp) en agua e inactivar patógenos como E. coli y C. albicans (Funes, 2009).

Tabla 6.1. Selección de fotocatalizadores soportados con unión covalente

\begin{tabular}{|c|c|c|c|}
\hline Soporte & Fotosens. & Sistema test & Referencia \\
\hline PS Merrifield & Porfirinas & DHN, a-terpineno & Ribeiro, 2007 \\
\hline PS Merrifield & Porfirinas & a-terpineno, citronelol & Ribeiro, 2008 \\
\hline PS Merrifield & Porfirinas & a-terpineno, DMA & Pineiro, 2010 \\
\hline PS Merrifield & Porfirinas & $\begin{array}{c}\text { a-terpineno, citronelol, } \\
\text { linalool }\end{array}$ & Ribeiro, 2013 \\
\hline PS (sulfonado) & Rosa de Bengala & DPBF & Drodz, 2010 \\
\hline PS (piridinio) & Rosa de Bengala & ácido 2-furóico & Burguete, 2010 a \\
\hline PS macroporoso & Rosa de Bengala & DPA & Burguete, 2009 \\
\hline PS macroporoso & Rosa de Bengala & ácido 2-furóico & Burguete, 2010 b \\
\hline PS (hidrofílico) & Rosa de Bengala & ADPA, ácido 2-furóico & Fabregat, 2014 \\
\hline Poliacrilamida & Rosa de Bengala & fenol, 1-naftol & Koizumi, 2007 \\
\hline Poliacrilamida & Azul de Metileno & ADPA, células cáncer & Qin, 2011 \\
\hline Poliamidoamina & Complejo de iridio & DHN, células cáncer & Maggioni, 2015 \\
\hline Quitosano & Rosa de Bengala & 1,3,5 / 1,2,4 / 1,2,3-THB & Ferrari, 2014 \\
\hline
\end{tabular}




\begin{tabular}{|c|c|c|c|}
\hline Soporte & Fotosens. & Sistema test & Referencia \\
\hline PE-co-MMA & Porfirinas & DHN & Zhu, 2012 \\
\hline Poliporfirina & Es parte del soporte & DHN & Wu, 2014 \\
\hline Poliporfirina & Es parte del soporte & DMA, L-Trp, E. coli & Funes, 2009 \\
\hline Polibenzotiadiazol & Es parte del soporte & ácido 2-furóico & Urakami, 2013 \\
\hline
\end{tabular}

\subsection{Fotocatalizadores unidos a polímeros de manera no covalente}

A continuación se describirán ejemplos seleccionados de sensibilizadores soportados donde la unión entre el componente fotoactivo y la matriz se produce de manera no covalente. Básicamente, hay dos formas de que esto ocurra: a) por un lado, mediante interacciones iónicas entre una matriz cargada eléctricamente y un fotosensibilizador con carga opuesta, y b) por otro lado, mediante atrapamiento del elemento fotactivo dentro de la matriz. En la tabla 6.2 se indican los principales datos de cada uno de los trabajos comentados.

Henke y colaboradores describen un sistema del primer tipo, donde una matriz de poliestireno con carga negativa es capaz de retener una porfirina cargada positivamente (Henke, 2013) tal y como se muestra en la figura 6.7. En dicha figura se muestra una imagen del material antes de la carga con el fotosensibilizador (film blanco de poliestireno sulfonado) así como después de interaccionar con la porfirina (film oscuro). También se muestra la naturaleza de los grupos funcionales que permiten la interacción: grupos sulfonatos por un lado y piridinios por otro. Este sistema ha sido probado en la oxidación de ácido úrico en medio acuoso, con resultados positivos. Además, el oxígeno singlete generado se ha usado para la inactivación bacteriana de cultivos de E. coli. Como utilidad ambiental adicional se ha encontrado que también es posible eliminar cationes $\mathrm{Pb}$ (II) del medio acuoso, gracias a la coordinación de los grupos negativamente cargados con los cationes metálicos.

En este mismo sentido se ha descrito la unión de porfirinas y ftalocianinas cargadas negativamente (grupos sulfonatos) usando soportes de muy diferente naturaleza (Pepe, 2005) para la fotooxidación de fenol. 

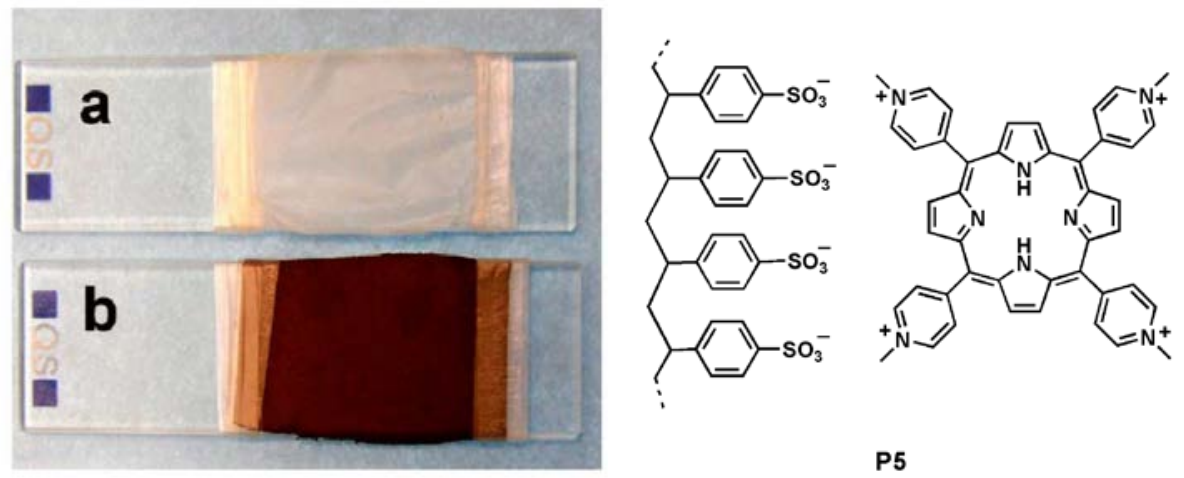

P5

Figura 6.7. Izquierda: imagen de film de poliestireno sulfonado antes ( $a$ ) y después ( $b$ ) de unión a fotosensitilizador. Derecha: estructura de fotocatalizador soportado por unión iónica (Henke, 2013). Reproducido con permiso: Copyright $\odot 2013$, American Chemical Society

La técnica del electrospinning ha permitido obtener nanofibras de poliestireno neutro capaces de atrapar conjugados de nanopartículas de oro con ftalocianina de Zn(II) (Tombe, 2013). Se demostró la participación de oxígeno singlete tras la irradiación de las nanofibras y dicho material ha sido aplicado a la descontaminación de aguas modelo con 4-clorofenol y con el colorante azoico Naranja G.

Otra matriz neutra empleada para encapsular fotosensibilizadores ha sido el poli(metacrilato de hidroxietilo) o pHEMA dado que se trata de un polímero de gran compatibilidad con agua (Craig, 2015). Los hidrogeles de pHemA descritos son capaces de unirse a la porfirina de modo no covalente y producir eficientemente oxígeno singlete y oxidar el sustrato ADPA, si bien todavía no se han empleado en una aplicación ambiental.

Finalmente, un grupo importante de trabajos describiendo materiales fotoactivos sin unión covalente al fotosensibilizador son los resultantes de la investigación del grupo de Orellana, especialmene porque están orientados a la solución de problemas ambientales como la inactivación bacteriana usando luz solar. Así, se ha descrito la inmovilización de un complejo de $\mathrm{Ru}$ (II) generador de ${ }^{1} \mathrm{O}_{2^{\prime}}$ en silicona porosa (Villén, 2006). Se ha comprobado 
cómo este material es capaz de desactivar el $99 \%$ de cierta población de $E$. coli y el 99.9 \% de E. faecalis, bajo condiciones de irradiación solar en reactor parabólico. La naturaleza porosa de la matriz de silicona juega un papel clave en la difusión del oxígeno a través del material.

Tras el empleo en procesos de desinfección, los fotosensibilizadores pueden degradarse por autooxidación, tal y como se ha comentado anteriormente. En el caso de los complejos de Ru(II) inmovilizados en silicona porosa, se dejaron envejecer al sol y se evaluó la posibilidad de recargar la misma matriz con más fotocatalizador (Manjón, 2010). Se encontró que los materiales así regenerados resultaban más fotoactivos frente a $E$. faecalis que los originales (hasta 4 veces más). Este hecho se explicó por la acumulación del complejo de $\mathrm{Ru}(\mathrm{II})$ en la superficie del polímero tras el proceso de recarga.

Otras investigaciones han demostrado la importancia de la naturaleza de la silicona que atrapa el fotosensibilizador (Manjón, 2009). Una comparativa entre silicona cargada positivamente (pSil+) y otra negativamente (pSil-) permitió establecer relaciones estructura-actividad en procesos de inactivación bacteriana. Por ejemplo, cultivos de $E$. faecalis a una concentración inicial de $10^{4} \mathrm{CFU} / \mathrm{mL}$ se desactivaron a velocidades muy diferentes dependiendo del sistema fotoactivo empleado: 3200 cFu/h para la matriz positiva y $24000 \mathrm{cFu} / \mathrm{h}$ para la silicona negativa.

Finalmente, un trabajo que merece ser destacado es el de Perni y colaboradores, que describen films de silicona que contienen Azul de Metileno como fotogenerador de ${ }^{1} \mathrm{O}_{2}$ y nanopartículas de oro (Perni, 2010). Esta combinación es capaz de promover la desactivación de cultivos de $S$. aureus (resistente a la meticilina) y de E. coli, con disminuciones notables (hasta 3,5 unidades logarítmicas en el recuento poblacional). Resulta destacable el corto tiempo de irradiación (5 min) con luz monocromática de un láser de $660 \mathrm{~nm}$. El efecto de las nanopartículas de oro es doble, dado que, por un lado, minimiza el lixiviado del Azul de Metileno y, por otro, se especula que favorece la producción de otras especies reactivas de oxígeno (ROS) diferentes de oxígeno singlete. Esta última idea podría estar en concordancia con recientes investigaciones que apuntan a la citotoxicidad de nanopartículas de oro por generación de diversas ROs (Huang, 2016). 
Tabla 6.2. Selección de fotocatalizadores soportados con unión no covalente

\begin{tabular}{|c|c|c|c|}
\hline Soporte & Fotosens. & Sistema test & Referencia \\
\hline PS (carga negativa) & Porfirinas & ácido úrico, E. coli & Henke, 2013 \\
\hline PS (varios) & Porfirinas & fenol & Pepe, 2005 \\
\hline PS (neutro) & Ftalocianinas & 4-clorofenol, naranja G & Tombe, 2013 \\
\hline PoliHEMA & Porfirinas & ADPA & Craig, 2015 \\
\hline Silicona & Azul de Metileno & Ác. úrico, E. coli, S. aureus & Perni, 2009 \\
\hline Silicona porosa & Complejo de rutenio & E. coli, E. faecalis & Villén, 2006 \\
\hline Silicona cargada & Complejo de rutenio & E. faecalis & Manjón, 2009 \\
\hline Silicona porosa & Complejo de rutenio & E. coli, E. faecalis & Manjón, 2010 \\
\hline
\end{tabular}

\subsection{Conclusiones}

En este trabajo se han recopilado una serie de ejemplos representativos de fotocatalizadores orgánicos soportados sobre matrices poliméricas. Estos sistemas son capaces de generar, en combinación con radiación luminosa, oxígeno singlete, especie reactiva que participa en procesos de oxidación (sustratos orgánicos, contaminantes modelo, bacterias, etc.). Se han clasificado los casos presentados en dos grandes grupos: por un lado, aquellos en los que el fotosensibilizador se encuentra anclado covalentemente al polímero y, por otro, aquellos en los que la unión no es covalente. Se ha discutido la capacidad oxidante de cada material, en especial considerando el efecto de la matriz polimérica. En comparación con el extensivo uso de $\mathrm{TiO}_{2}$ y otros materiales inorgánicos en procesos fotocatalíticos (con absorción uv), los fotopolímeros aquí descritos podrían considerarse como sistemas poco convencionales. Sin embargo, presentan la gran ventaja de poder ser diseñados para absorber luz visible, con el consiguiente aprovechamiento de la radiación solar. 


\section{Agradecimientos}

Fundació Caixa-Castelló/UJl. Proyecto P1·1B2015-76

\section{Referencias}

Blossey, E.C., NeCkers, D.C., Thayer, A.L. y Schaap, A.P. (1973). «Polymer-based sensitizers for photooxidations». Journal of the American Chemical Society, 95, pp. 5820-5822.

Burguete, M.I., Galindo, F., Gavara, R., Luis, S.V., Moreno, M., Thomas, P. y Russell, D.A. (2009). «Singlet oxygen generation using a porous monolithic polymer supported photosensitizer: potential application to the photodynamic destruction of melanoma cells». Photochemical and Photobiologiacl Sciences, 8, pp. 37-44.

Burguete, M.I., Gavara, R., Galindo, F. y Luis, S.V. (2010 a). «New polymer supported photocatalyst with improved compatibility with polar solvents. Synthetic application using solar light as energy source». Catalysis Communications, 11, pp. 1081-1084.

- (2010 b). "Synthetic application of photoactive porous monolithic polymers». Tetrahedron Letters, 51, pp. 3360-3363.

Craig, R.A., McCoy, C.P., Baróid, A.T.D., Andrews, G.P., Gorman, S.P. y Jones, D.S. (2015). "Quantification of singlet oxygen generation from photodynamic hydrogels». Reactive and Functional Polymers, 87, pp. 1-6.

DaghriR, R., Drogui, P. y Robert, D. (2013). «Modified $\mathrm{TiO}_{2}$ for environmental photocatalytic applications: a review». Industrial Engineering Chemistry Research, 52, pp. 3581-3599.

Drodz, D., SzCZUBialka, K. y Nowakowska, M. (2010). «Novel hybrid photosensitizers: photoactive polymer-nanoclay». Journal of Photochemistry and Photobiology, A: Chemistry, 215, pp. 223-228.

Etacheri, V., DiValentin, C., SChneider, J., Bahnemann, D.y Pillal, S.C. (2015). «Visible-light activation of $\mathrm{TiO}_{2}$ photocatalysts: Advances in theory and experiments». Journal of Photochemistry and Photobiology C: Photochemistry Reviews, 25, pp. 1-29. 
Fabregat, V., Burguete M. I., Galindo, F. y Luis, S.V. (2014). "Singlet oxygen generation by photoactive polymeric microparticles with enhanced aqueous compatibility». Environmental Science and Pollution Research, 21, pp. 11884-11892.

Ferrarl, G.V., Andrada, M.E., Natera, J., Muñoz, V.A., Montaña, M.P., Gambetta, C., Boiero, M.L., Montenegro, M.A., Massad, W.A. y García, N.A. (2014). «The Employment of a Removable Chitosan-Derivatized Polymeric Sensitizer in the Photooxidation of Polyhydroxylated Water-Pollutants». Photochemistry and Photobiology, 90, pp. 1251-1256.

Funes, M.D., Caminos D.A., Alvarez, M.G., Fungo, F., Otero, L.A. y Durantini, E.N. (2009). «Photodynamic properties and photoantimicrobial action of electrochemically generated porphyrin polymeric films». Environmental Science and Technology, 43, pp. 902-908.

García-Ballesteros, S., Mora, M., Vicente, R., Sabater, C., Castillo, M.A., Arques, A. y Амат, A.M. (2016). «Gaining further insight into photo-Fenton treatment of phenolic compounds commonly found in food processing industry». Chemical Engineering Journal, 288, pp. 126-136.

Henke, P., Lang, K., Kubát, P., SÝkora, J., Slouf, M. y Mosinger, J. (2013). «Polystyrene Nanofiber Materials Modified with an Externally Bound Porphyrin Photosensitizer». ACS Applied Materials and Interfaces, 5, pp. 3776-3783.

Huang, H., Quan, Y.-Y., Wang, X.-P. y Chen, T.-S. (2016). «Gold Nanoparticles of Diameter $13 \mathrm{~nm}$ Induce Apoptosis in Rabbit Articular Chondrocytes». Nanoscale Research Letters, 11, art. 249.

KoIzUmi, H., KImata, Y., ShIRAISHI, Y. y HiRAl, T. (2007). «Temperature-controlled changeable oxygenation selectivity by singlet oxygen with a polymeric photosensitizer». Chemical Communications, 18, pp. 1846-1848.

LACOMBE, S. y PIGOT, T. (2016). «Materials for selective photo-oxygenation vs. photocatalysis: preparation, properties and applications in environmental and health fields». Catalysis Science and Technology, 6, pp. 1571-1592.

MACDonALD, I.J. (2001). «Basic principles of photodynamic therapy». Journal of Porphyrins and Phtalocyanines, 5, pp. 105-129.

MagGioni, D., Galli, M., D'Alfonso, L., Inverso, D., DozzI, M. V., Sironi, L., IAnncone, M., Collini, M., Ferruti, P., Ranucci, E. y D'Alfonso, G. (2015). «A Luminescent Poly(amidoamine)-Iridium Complex as a New Singlet-Oxygen Sensitizer for Photodynamic Therapy». Inorganic Chemistry, 54, pp. 544-553 
Malato, S., Fernández-lbáñez, P., Maldonado, M. I., Blanco, J. y Gernjak, W. (2009). «Decontamination and disinfection of water by solar photocatalysis: Recent overview and trends». Catalysis Today, 147, pp. 1-59.

Manjón, F., García-Fresnadillo, D. y Orellana, G. (2009). «Water disinfection with $\mathrm{Ru}(\mathrm{II})$ photosensitisers supported on ionic porous silicones». Photochemical and Photobiological Sciences, 8, pp. 926-932.

Manjón, F., Santana-Magaña, M., García-Fresnadillo, D. y Orellana, D. (2010). «Singlet oxygen sensitizing materials based on porous silicone: photochemical characterization, effect of dye reloading and application to water disinfection with solar reactors». Photochemical and Photobiological Sciences, 9, pp. 838-845.

Marín, M.L., Santos-Juanes, L., Arques, A., Amat, A.M. y Miranda, M.A. (2012). «Organic photocatalysts for the oxidation of pollutants and model compounds». Chemical Reviews, 112, pp. 1710-1750.

Pepe, E., Abbas, O., Rebufa, C., Simon, M., Lacombe, S. y Julliard, M. (2005). «Supported photoesensitizers for the visible light activation of phenols towards oxygen». Journal of Photochemistry and Photobiology, A: Chemistry, 170, pp. 143-149.

Perni, S., Piccirillo, C., Pratten, J., Prokopovich, P., Chrzanowski, W., Parkin, I.P. y Wilson, M. (2009). «The antimicrobial properties of light activated polymers containing methylene blue and gold nanoparticles». Biomaterials, 30, pp. 89-93.

Pessoni, L., Lacombe, S., Billon, L., Brown, R. y Save, M. (2013). «Photoactive, Porous Honeycomb Films Prepared from Rose Bengal-Grafted Polystyrene». Langmuir, 29, pp. 10264-10271.

Pineiro, M., Ribeiro, S. M. y Serra, A. C. (2010). «The influence of the support on the singlet oxygen quantum yield of porphyrin supported photosensitizers». ARKIVOC, V, pp. 51-63.

QIn, M., HaH, H.J., Kim, G., Nie, G., LeE, Y.-E.K. y Kopelman, R. (2011). «Methylene blue covalently loaded polyacrylamide nanoparticles for enhanced tumortargeted photodynamic therapy». Photochemical and Photobiological Sciences, 10, pp. 832-841.

Ribeiro S.M., Serra, A.C. y Rocha Gonsalves, A.M. d'A. (2007). "Covalently immobilized porphyrins as photooxidation catalysts». Tetrahedron, 63, pp. 7885-7891. 
- (2008). «Immobilised porphyrins in monoterpene photooxidations». Journal of Catalysis, 256, pp. 331-337.

- (2013). «Efficient Solar Photooxygenation with Supported Porphyrins as Catalysts». ChemCatChem, 5, pp. 134-137.

SchaAp, A.P., Thayer, A.L., Blossey, E.C. y Neckers, D.C. (1975). «Polymer-based sensitizers for photooxidations II». Journal of the American Chemical Society, 97, pp. 3741-3745.

Spagnul, C., TURner, L.C. y Boyle, R.W. (2015). «Immobilized photosensitizers for antimicrobial applications». Journal of Photochemistry and Photobiology, $B$ : Biology, 150, pp. 11-30.

Tombe, S. Antunes, E. y Nrokong, T. (2013). «Electrospun fibers functionalized with phthalocyanine-gold nanoparticle conjugates for photocatalytic applications». Journal of Molecular Catalysis, A: Chemical, 371, pp. 125-134.

URAKAMI, H., Zhang, K.y VILELA, F. (2013). «Modification of conjugated microporous poly-benzothiadiazole for photosensitized singlet oxygen generation in water». Chemical Communications, 49, pp. 2353-2355.

Villén, L., Manjón, F., García-Fresnadillo, D. y Orellana, G. (2006). «Solar water disinfection by photocatalytic singlet oxygen production in heterogeneous medium». Applied Catalysis, B: Environmental, 69, pp. 1-9.

WAHLEN, J., DE Vos, D.E., JACOBS, P.A. y ALSTERS, P.L. (2004). «Solid materials as sources for synthetically useful singlet oxygen». Advanced Synthesis and Catalysis, 346, pp. 152-164.

Walalawela, N. y Greer, A. (2014). «Photoactive chitosan: a step toward a Green strategy for pollutant degradation». Photochemistry and Photobiology, 90, pp. 1216-1218.

Wang, S., Gao, R., Zhou, F. y Selke, M. (2004). «Nanomaterials and singlet oxygen photosensitizers: potential applicatins in photodynamic therapy». Journal of Materials Chemistry, 14, pp. 487-493.

Wu, W.-T., Zhan, L.-Y., Fan, W.-Y., Wu, X.-Y., Wu, X.-Y., Pan, Q.-W., Huang, L., LI, Z.T., ZHeNG, J.-T., WANG, Y.-F. y Wu, M.-B. (2014). «Broadband Absorbing Polyporphyrin Membrane as Singlet Oxygen Photosensitizer for Photooxidation». Macromolecular Chemistry and Physics, 215, pp. 280-285.

ZHu, J. y SuN, G. (2012). "Preparation and photo-oxidative functions of poly(ethylene-co-methacrylic acid) (PE-co-MAA) nanofibrous membrane supported porphyrins». Journal of Materials Chemistry, 22, pp. 10581-10588. 


\section{Eliminación de compuestos orgánicos en agua potable a partir de procesos mixtos Fenton-fotocatalíticos}

F.J. García-Castillo, ${ }^{1,8,}$ M. Amado, ${ }^{2,8}$ J. Sanchis, ${ }^{3,8}$ M. Bartolomé, ${ }^{4,8}$

J. Cabero, ${ }^{5,8}$ A. Castillo, ${ }^{6,8}$ J. Rubio, $^{7}$ A. Tamayo ${ }^{7}$

1. FACSA (Sociedad de Fomento Agrícola Castellonense, S.A.)

C/ Mayor 82-84, 12001 Castellón, España

2. Canal de Isabel II Gestión

C/ Santa Engracia 125, 28003 Madrid, España

3. Aguas de Valencia, S.A.

Gran Vía del Marqués del Turia 19, 46005 Valencia, España

4. Consorcio de Aguas Bilbao-Bizkaia (CABB)

ETAP Venta Alta, 48480 Arrigorriaga, España

5. SUEZ Tratamiento de Aguas

C/ Ibarrekolanda 19, 48019 Bilbao, España

6. Consorcio de Aguas y Residuos de La Rioja

Parque de San Adrián 5, 26007 Logroño, España

7. ICV (Instituto de Cerámica y Vidrio) - CSIC (Consejo Sup. Investigaciones Científicas)

Kelsen, 5. Campus de Cantoblanco, 28049 Madrid, España

8. AEAS, Comisión 1. a, Grupo Trabajo Ingeniería del Tratamiento del Agua

C/ Sor Ángela de la Cruz 2, 28020 Madrid, España

Contacto: jgarcia@facsa.com

\section{F. Javier García Castillo}

Licenciado en Ciencias Químicas por la Universitat de València y técnico superior en PRL. En la actualidad es responsable del Departamento de Tratamiento de Aguas y de la actividad I+D+i del área de Abastecimiento de 
FACSA, con más de 20 años de experiencia y amplia formación en tratamientos de aguas, especialmente por membranas. Con anterioridad ha sido jefe de servicio de aguas en distintos municipios y jefe de planta de distintas instalaciones de tratamiento de aguas, casi todas ellas por ósmosis inversa. Autor de diversos artículos publicados en revistas técnicas de ámbito nacional. Ha participado también como ponente en diversos foros.

\section{Resumen}

Para estar prevenidos ante situaciones diversas que se puedan dar en cauces de agua destinada al consumo humano, es necesario poseer las tecnologías y los medios adecuados ante tales posibilidades. Muchos productos y compuestos orgánicos no se eliminan con los oxidantes clásicos y el carbón activo tampoco los adsorbe.

En este trabajo se ha llevado a cabo un estudio de la eficacia de dos procesos simultáneos sobre la eliminación de compuestos orgánicos en agua potable. Para ello se han utilizado tanto $\mathrm{TiO}_{2}$ como reactivo Fenton y se ha estudiado la influencia en la cantidad degradada.

\subsection{Introducción}

Existen muchas vías por las que las aguas potables pueden estar contaminadas o pueden contaminarse de productos orgánicos perjudiciales para la salud humana. Una de ellas es la que tiene lugar durante los procesos de tratamiento de agua potable para la eliminación de partículas suspendidas, puesto que para tal fin se emplean polímeros orgánicos que actúan como coagulantes primarios o bien como ayudantes de coagulación. Estos polímeros suelen contener cierta cantidad de monómeros que no han reaccionado para formar el respectivo polímero, así como con otras moléculas necesarias para las reacciones de polimerización, y todas estas moléculas pueden reaccionar con otras existentes en el agua (cloro, ozono, etc.) y formar nuevos productos perjudiciales para la salud (Cámara Hurtado, 2012). 
En otros casos, se han detectado, en momentos puntuales, elevadas concentraciones de productos orgánicos, que deben de provenir del vertido incontrolado de ciertos productos residuales, los cuales llevan asociados materia orgánica o productos orgánicos que, al contacto con el agua, se disuelven en ella y que, en muchos casos, son también perjudiciales para la salud.

Para la eliminación de estos contaminantes del agua potable se han desarrollado diferentes tecnologías o procesos fisicoquímicos los cuales se basan en producir cambios en la estructura de las moléculas contaminantes para hacerlas no contaminantes o bien eliminarlas completamente (Domenech y otros, 2001). Estos procesos se pueden clasificar en dos tipos: fotoquímicos y no fotoquímicos. En el primer caso se necesita una radiación ultravioletavisible (UV-vis), mientras que los segundos requieren el uso de compuestos químicos $\left(\mathrm{O}_{3^{\prime}} \mathrm{H}_{2} \mathrm{O}_{2}, \mathrm{Fe}^{2+}\right)$ o procesos eléctricos (electroquímicos, en este caso). Muchos de estos procesos han mostrado ser efectivos en la eliminación de contaminantes de aguas como son detergentes, herbicidas, colorantes, etc.

En los métodos utilizados actualmente se mezclan varios de los dos procesos mencionados anteriormente, los fotoquímicos y no fotoquímicos. Sin embargo, la eficacia todavía no es muy elevada, requiriendo a veces altas concentraciones tanto de reactivos como de radiación UV-vis. A su vez, la adición de reactivos debe estar muy bien controlada ya que pueden quedar en exceso o bien generar nuevos compuestos, también contaminantes, que de nuevo tienen que ser eliminados.

En el presente trabajo de investigación se ha pretendido conseguir una mejora de los procesos fotocatalíticos y no fotocatalíticos para la eliminación de compuestos orgánicos en el agua potable utilizando catalizadores de $\mathrm{TiO}_{2}$ y reactivo Fenton los cuales, una vez seleccionados, serían depositados y quedarían retenidos en la superficie de vidrios transparentes. De esta forma, el agua a descontaminar circularía sobre el vidrio transparente, el cual permitiría que la radiación UV-vis pudiera acceder a toda la superficie del mismo recubierta con el reactivo soportado. Para que el vidrio fuera siempre transparente, las capas de reactivo soportadas en él deberían ser de escala nanométrica. Además, para conseguir una elevada eficacia cuando la concentración de contaminante es muy pequeña, la superficie de contacto vidrio-agua debería ser lo máxima posible, por lo que se examinarán diferentes tamaños de vidrio (polvo, fibras, placas) para determinar la máxima eliminación. 


\subsection{Experimental}

\subsubsection{Desarrollo de catalizador de $\mathrm{TiO}_{2}$}

Para la obtención del catalizador $\mathrm{TiO}_{2}$ se ha utilizado alcóxido de titanio adicionando isopropanol y agua en cantidades adecuadas para conseguir la hidrólisis total de los grupos alcóxido. La reacción se ha llevado a cabo a temperatura ambiente durante 24 horas. Al adicionar el agua sobre el alcóxido se ha formado un precipitado el cual se ha filtrado y secado a 50 y $100{ }^{\circ} \mathrm{C}$. El precipitado en forma de polvo se ha molido y tamizado por debajo de 10 micrómetros y se ha sometido a dos tratamientos térmicos a $500{ }^{\circ} \mathrm{C}$ durante varias horas. El material final se ha caracterizado mediante difracción de rayos $X$ utilizando un equipo Bruker y mediante espectroscopía Raman, empleando un espectrofotómetro Renishaw InVia y fuente de excitación de láser de diodo a $785 \mathrm{~nm}$.

\subsubsection{Reactivo Fenton}

El reactivo Fenton se ha obtenido a partir de productos comerciales: agua oxigenada $\left(\mathrm{H}_{2} \mathrm{O}_{2}\right)$ y sulfato ferroso $\left(\mathrm{Fe}_{2} \mathrm{SO}_{4}\right)$ (Sigma Aldrich).

\subsubsection{Degradación de los compuestos orgánicos}

Las reacciones de fotodegradación se han llevado a cabo en recipientes abiertos con un área de exposición a la radiación UV de $18 \mathrm{~cm}^{2}$. Se prepararon disoluciones de dos productos orgánicos, cloruro de metiltionina (MB) y otro contaminante orgánico, de concentración $10 \mathrm{mg} / \mathrm{l}$ en agua destilada. Se añadieron $50 \mathrm{mg}$ del $\mathrm{TiO}_{2}$ en $50 \mathrm{~mL}$ de la disolución de la sustancia orgánica manteniendo agitación magnética hasta homogeinización. Las suspensiones se sometieron a continuación a un flujo radiante constante de luz UV de $90 \mathrm{~mW}$. Una vez transcurrido el tiempo de exposición, las suspensiones se centrifugaron, se filtraron con filtros Millipore de tamaño de poro inferior a $200 \mathrm{~nm}$ y se determinó el espectro UV con un espectrofotómetro Perkin Elmer Lambda 40. 


\subsection{Resultados}

\subsubsection{Caracterización del catalizador de $\mathrm{TiO}_{2}$}

En la figura 7.1 se muestran los difractogramas de RX del catalizador de $\mathrm{TiO}_{2}$ obtenido a los dos tiempos de tratamiento a $500^{\circ} \mathrm{C}$. En ambos casos, se han identificado los picos de difracción más intensos que corresponden con la fase cristalina de $\mathrm{TiO}_{2}$ anatasa. El ensanchamiento de los picos en el caso del primer tratamiento indica que la fase anatasa no está completamente cristalizada, encontrándose aún una proporción significativa de $\mathrm{TiO}_{2}$ amorfo procedente de la condensación de los alcóxidos. Tras este primer tratamiento, se pueden observar además algunos picos de difracción adicionales que podrían atribuirse a la fase ortorrómbica brookita, que aparece cuando los precipitados de $\mathrm{TiO}_{2}$ amorfo son calcinados a temperaturas inferiores a $500{ }^{\circ} \mathrm{C}$ (Ovenstone y Yanagisawa, 1999). Aumentando el tiempo de permanencia a la máxima temperatura, es posible obtener un material cristalino con una única fase presente.

El espectro Raman del catalizador de $\mathrm{TiO}_{2}$ (figura 7.2) muestra las bandas características de la fase anatasa en el catalizador calcinado a mayor tiempo de tratamiento. Se aprecia un ligero desplazamiento de estas bandas, así como

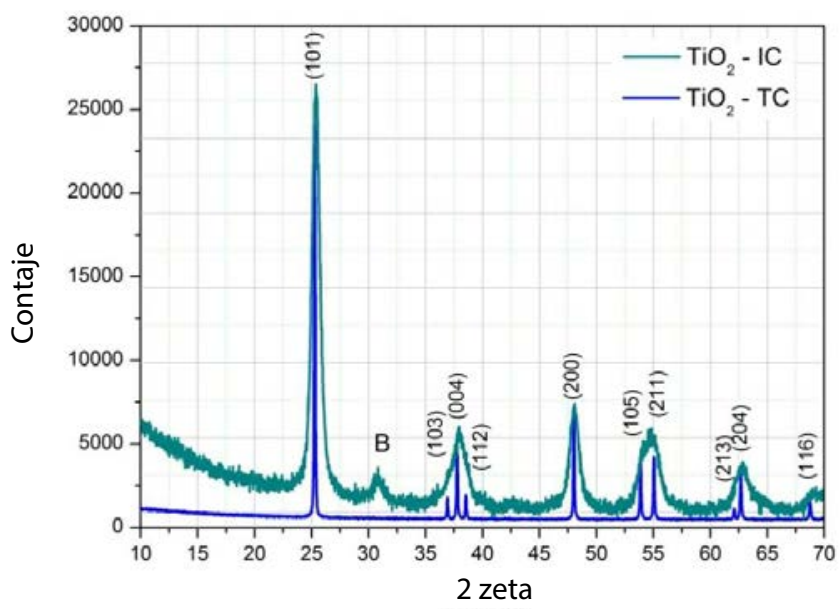

Figura 7.1. Difractograma de RX del catalizador $\mathrm{TiO}_{2}$ obtenido a dos tiempos de tratamiento 


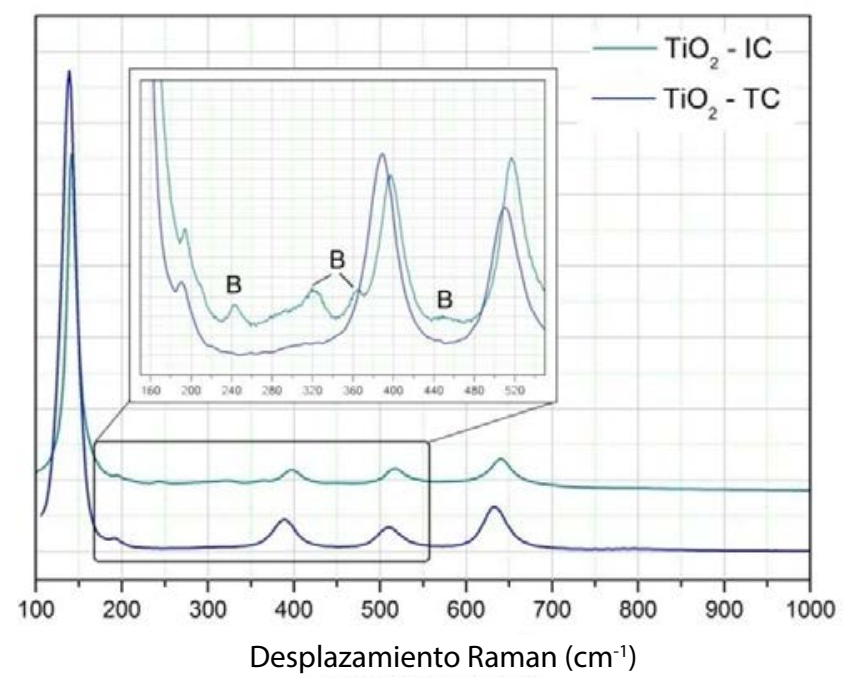

Figura 7.2. Espectro Raman del catalizador de $\mathrm{TiO}_{2}$ obtenido a dos tiempos de tratamiento

la presencia de bandas adicionales asignadas a la fase cristalina brookita en el caso de la muestra denominada $\mathrm{TiO}_{2}-\mathrm{IC}$, que ha sido obtenida a un tiempo de permanencia menor a la temperatura máxima de calcinación. El detalle de la figura 7.2, que muestra una ampliación del espectro entre 150 y $550 \mathrm{~cm}^{-1}$, permite identificar claramente las bandas más intensas y características de la brookita a 245,310 y $358 \mathrm{~cm}^{-1}$ y también una banda algo más débil y centrada alrededor de $450 \mathrm{~cm}^{-1}$.

\subsubsection{Selección del catalizador}

La selección del catalizador de $\mathrm{TiO}_{2}$ más adecuado para la degradación de compuestos orgánicos se ha efectuado mediante el estudio de la degradación de un producto orgánico tradicional: MB. El proceso de fotodegradación de este compuesto ha sido descrito ya por otros autores (Houas y otros, 2001; Lachheb y otros, 2002) como un mecanismo oxidativo activado por la superficie. Se ha comparado la eficiencia de la fotodegradación del MB empleando los dos 

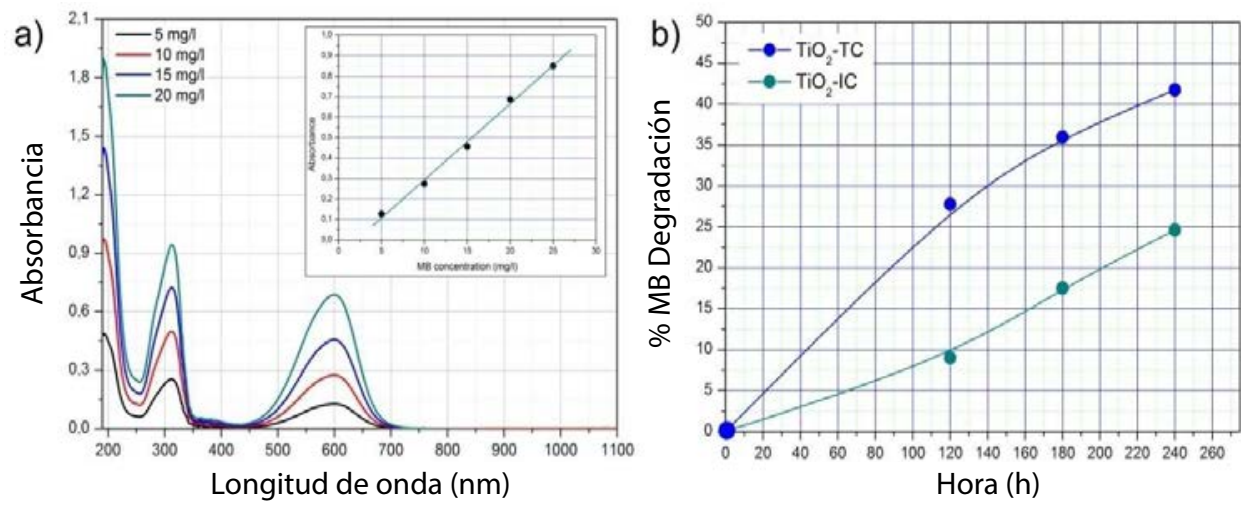

Figura 7.3. (7.3a) Espectros UV de disoluciones de MB a distintas concentraciones y (7.3b) degradación de $\mathrm{MB}$ en función del tiempo de exposición a la luz UV con los dos catalizadores preparados

catalizadores preparados. Se ha determinado la absorbancia uv de una disolución de MB sometida a distintos tiempos de exposición a la luz uv y, a partir de ahí, la concentración de dicha sustancia en la disolución a partir de la curva de calibrado previamente establecida (figura 7.3). La eficiencia de la degradación se ha calculado a partir de:

$$
\text { \% Eficiencia degradación }=\frac{c_{0}-c_{t}}{c_{o}} \times 100
$$

donde $C_{0}$ es la concentración inicial en la disolución y $C_{t}$ es la concentración del componente orgánico a un tiempo de exposición a la luz UV, t.

Tal y como se observa en la figura 7.3, la eficiencia de la degradación del $\mathrm{MB}$ es mayor en el $\mathrm{TiO}_{2}$ que contiene una única fase cristalina, por lo que se selecciona el $\mathrm{TiO}_{2}-\mathrm{TC}$ para su evaluación como catalizador de la eliminación de contaminantes orgánicos. 


\subsubsection{Eliminación de contaminantes orgánicos}

Una vez escogido el $\mathrm{TiO}_{2}$ que se empleará como catalizador de la fotodegradación, se ha procedido a estudiar su efectividad frente a otros contaminantes orgánicos que pudieran estar presentes en las aguas procedentes de ETAP. Se ha estudiado tanto el tiempo de permanencia bajo la radiación uv como la concentración de dicho catalizador en el medio contaminado. Los resultados obtenidos se muestran en la figura 7.4.

La figura 7.4a muestra los espectros UV de la muestra de agua contaminada con un contaminante de tipo orgánico a la que se le han añadido cantidades variables de catalizador y se han sometido a un periodo de exposición a la luz UV de $4 \mathrm{~h}$. Como se aprecia, la cantidad de catalizador añadida es proporcional a la eficacia de la fotocatálisis. Así mismo, el tiempo de exposición a la luz UV también ejerce una importante influencia en el sentido de que, a mayor tiempo de exposición, mayor es la cantidad de contaminante que se ha degradado, como se puede observar en la figura 7.4b.

La figura 7.5a muestra los espectros uv de muestras de agua contaminada con distintos contaminantes de tipo orgánico según el pico (absorbancia) fundamental en el visible $(\mathrm{nm})$ y en función del peso molecular (PM) en la figura 7.5b. Lo que queríamos ver era si la fuente uv utilizada influía en la degradación según fuera la molécula (PM) o según absorbiera $(\mathrm{nm})$ más radiación en el visible. Parece que no influye, aunque se observa que hay una que se degrada bastante más rápido, así que tenemos que intentar ver por qué es, aunque esta observación se deja para un trabajo futuro.
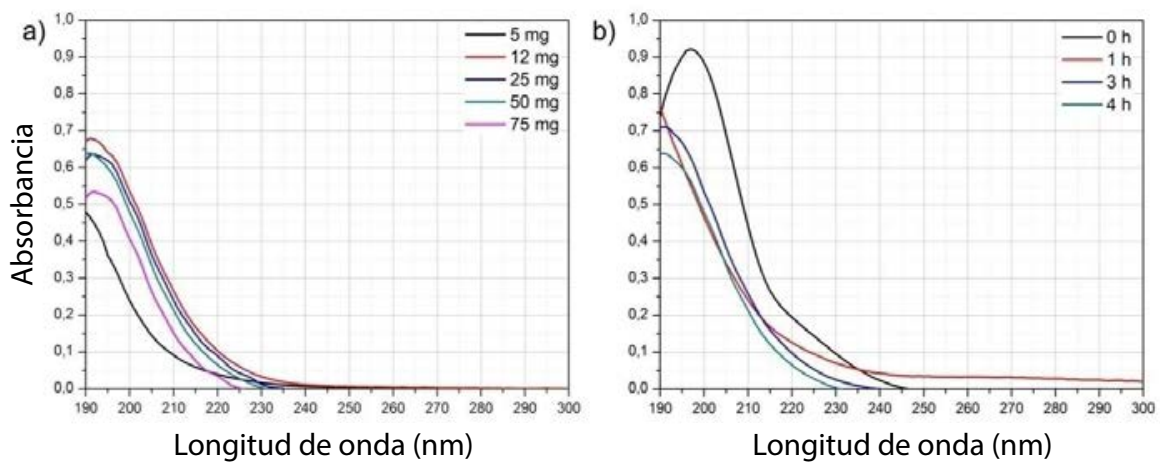

Figura 7.4. Espectros uv de muestra de agua contaminada: (7.4a) con cantidades variables de catalizador de $\mathrm{TiO}_{2}$ y (7.4b) en función del tiempo de permanencia en la cámara UV 
a)

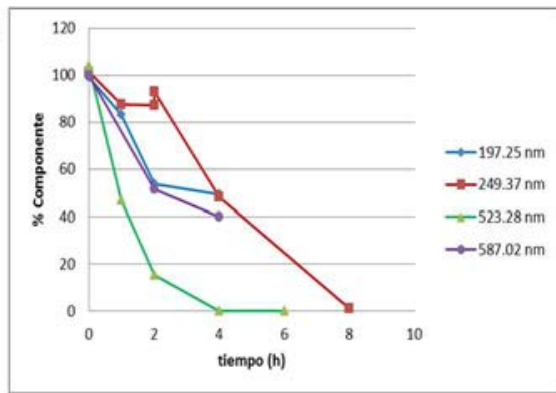

b)

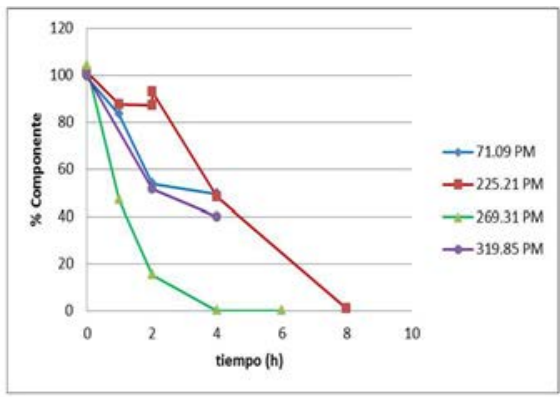

Figura 7.5. Espectros uv de muestra de agua contaminada: (7.5a) con cantidades variables de catalizador de $\mathrm{TiO}_{2}$ y (7.5b) en función del tiempo de permanencia en la cámara uv

\subsection{Discusión}

Es conocido que el proceso de fotocatálisis se basa en una activación de la superficie de los fotocatalizadores mediante energía radiativa en la que se forman pares electrón-hueco que, a su vez, reaccionan con el agua circundante y dan lugar a la generación de radicales activos que son los que van a degradar los contaminantes orgánicos (Litter y Navío, 1996). Las propiedades superficiales de dichos catalizadores van a jugar un papel relevante en su eficacia en la fotocatálisis.

En este trabajo se ha empleado un agente orgánico conocido, el $\mathrm{MB}$, que se adsorbe con relativa facilidad en la superficie del $\mathrm{TiO}_{2}$ gracias a la presencia de grupos hidroxilo en la superficie del material. Estos grupos hidroxilo van a interaccionar con el MB en medios preferentemente alcalinos debido al carácter catiónico del grupo orgánico de dicho producto. Cuando el MB es adsorbido en la superficie del fotocatalizador, la radiación UV llega con más dificultad hasta la superficie, disminuyendo así la eficacia fotocatalítica (Kerkez y Boz, 2015). Por otro lado, la creación de estructuras cristalinas diferentes o la presencia de fases más o menos amorfas disminuye la eficacia fotocatalítica, tal y como se mostró en la figura 7.3. Algunos autores (Peng y otros, 2005) han demostrado además que el grado de cristalinidad del material juega un factor importante en la fotoactividad del $\mathrm{TiO}_{2}$. En el caso del material obtenido a una menor temperatura de tratamiento, la actividad fotocatalítica es significa- 
tivamente más reducida que en el $\mathrm{TiO}_{2}$ obtenido a una mayor temperatura de calcinación y que presenta una cristalización en una única fase. Esta reducción en su actividad fotocatalítica podría atribuirse tanto a una mayor reactividad frente a la adsorción del MB como a su menor índice de cristalinidad.

Kandiel (Kandiel y otros, 2012) demostró que la actividad fotocatalítica de la brookita era mayor que la de la anatasa cuando la cantidad de radiación que llegaba a la superficie de las partículas del $\mathrm{TiO}_{2}$ era la misma. Este hecho se atribuía a que el menor tamaño de los cristales de brookita favorece la separación de los pares electrón-hueco generados fotoactivamente y, por tanto, disminuye la velocidad de recombinación de dichos pares aumentando así la actividad fotocatalítica.

En el presente estudio, la anatasa ha mostrado una mayor actividad frente a la oxidación del MB, hecho que se ha atribuido a una mayor adsorción de componente orgánico en la superficie de la brookita, lo que disminuye la cantidad de radiación efectiva que es capaz de alcanzar la superficie del fotocatalizador. Debe llegarse a un compromiso en la cantidad de componente

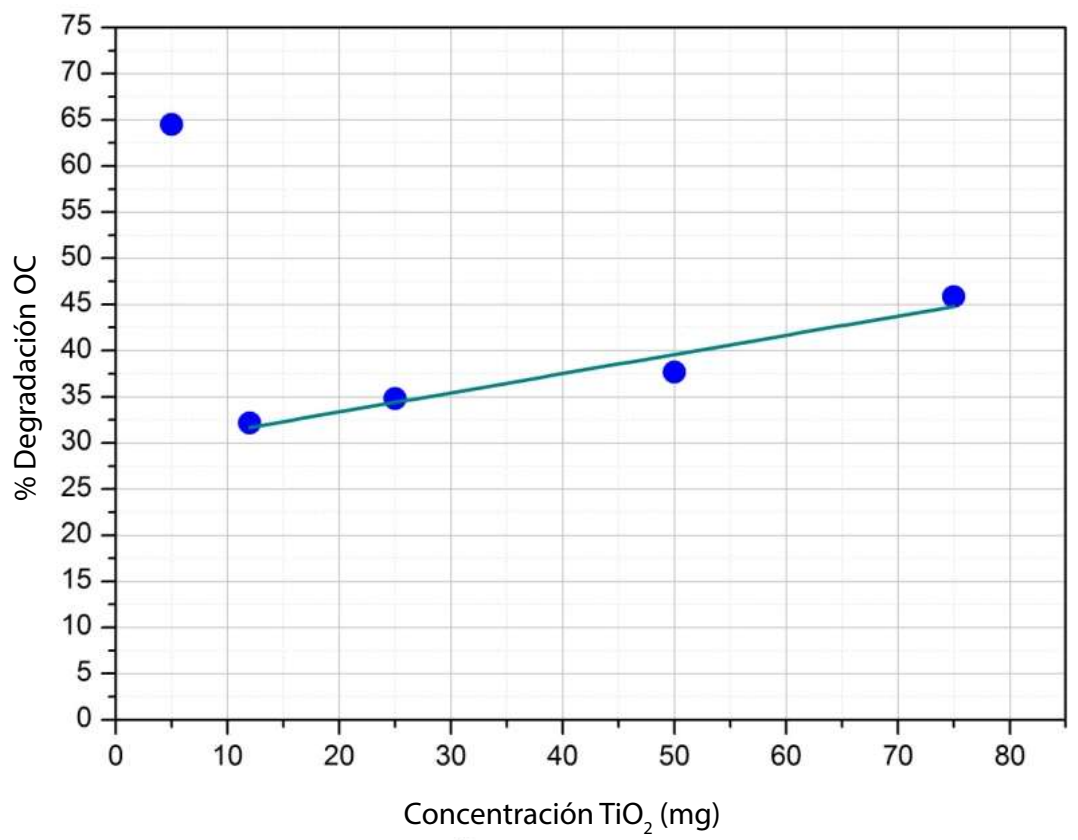

Figura 7.6. Grado de degradación del contaminante orgánico en función de la concentración de $\mathrm{TiO}_{2}$ 
orgánico adsorbido en la superficie y le eficacia fotocatalítica, puesto que es preciso que la cinética de adsorción sea adecuada para que los radicales libres $\mathrm{OH} \cdot$ generados en el proceso de fotocatálisis puedan interaccionar con el contaminante. En procesos de laboratorio, este ajuste se efectúa mediante la modificación del pH del medio de reacción; sin embargo, en la aplicación a aguas potables de ETAP, dicho ajuste debe realizarse mediante la modificación composicional de los vidrios transparentes que soportan el fotocatalizador.

La fotodegradación de otros contaminantes orgánicos ocurre de manera similar al MB. Se ha demostrado que un aumento de la cantidad de $\mathrm{TiO}_{2}$ en suspensión aumenta ligeramente el porcentaje de degradación del contaminante orgánico en la disolución (figura 7.6). Multiplicar por 3 la cantidad de $\mathrm{TiO}_{2}$ únicamente supone un $10 \%$ más de degradación. Sin embargo, a muy bajas cantidades, la cantidad de contaminante orgánico degradado es significativamente superior. Este hecho se ha atribuido nuevamente a la cantidad de radiación UV que llega a la superficie del $\mathrm{TiO}_{2}$. Soluciones más concentradas de $\mathrm{TiO}_{2}$ dificultan la penetración de la luz UV y, por tanto, no todo el $\mathrm{TiO}_{2}$ queda accesible a la radiación.

Se demuestra así que, en catalizadores no soportados, es necesario trabajar con cantidades pequeñas de fotocatalizador con objeto de no bloquear el paso de la radiación a la disolución del contaminante. Sin embargo, en catalizadores soportados, como es el caso de vidrios transparentes de $\mathrm{TiO}_{2^{\prime}}$ aumentar la cantidad de fotocatalizador sí que se traduciría en un aumento de la capacidad fotodegradante siempre y cuando se mantenga la transparencia del vidrio (Mansilla y otros, 2007).

Por último, se ha comparado la efectividad de este fotocatalizador con otros procesos de fotooxidación avanzados basados en la generación de radicales libres con gran capacidad oxidante. Para este estudio se ha escogido el tratamiento Fenton fotoactivado, que es un tratamiento simple, limpio y muy empleado en el tratamiento de aguas contaminadas (Karimi y otros, 2014; Neamtu y otros, 2014). En este método, la generación de radicales hidroxilo, con alta capacidad oxidativa, se produce por la reducción de $\mathrm{H}_{2} \mathrm{O}_{2}$ con iones $\mathrm{Fe}$ (II):

\begin{tabular}{|c|c|}
\hline $\mathrm{Fe}^{2+}+\mathrm{H}_{2} \mathrm{O}_{2} \rightarrow \mathrm{Fe}^{3+}+\mathrm{OH}^{-}+\mathrm{OH}^{*}$ & (7.2) \\
\hline $\mathrm{Fe}^{3+}+\mathrm{hv}+\mathrm{OH}^{-} \rightarrow \mathrm{Fe}^{2+}+\mathrm{OH}^{*}$ & (7.3) \\
\hline
\end{tabular}




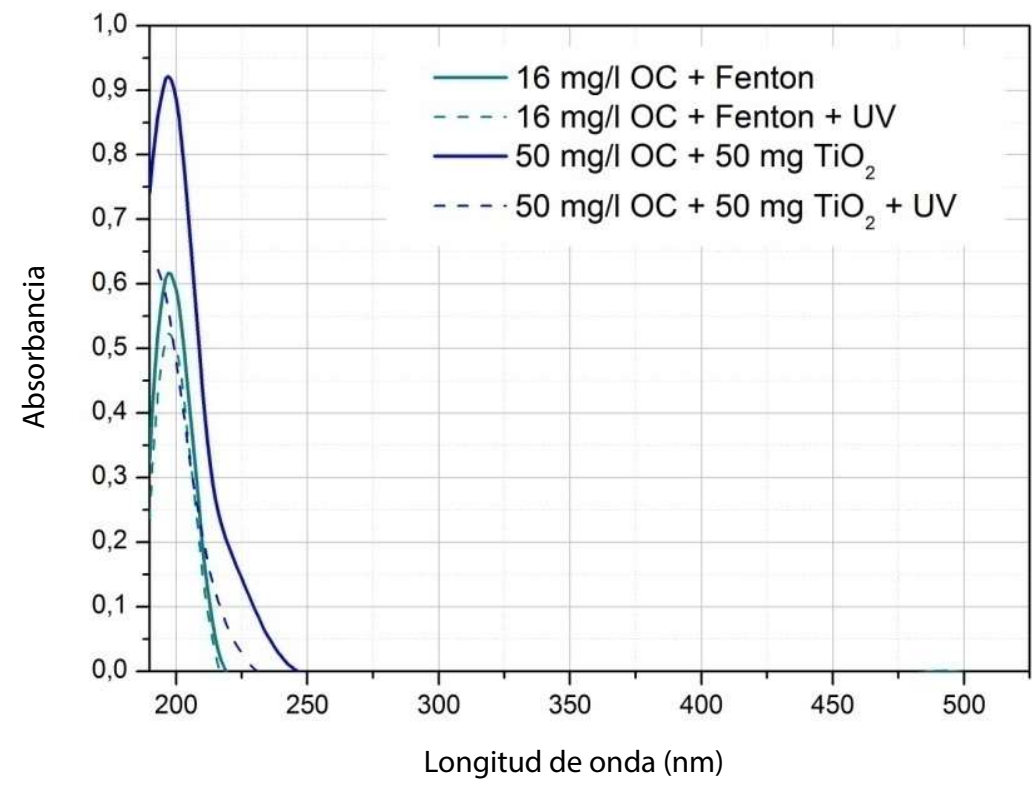

Figura 7.7. Comparación de la capacidad fotocatalítica entre el reactivo Fenton y el $\mathrm{TiO}_{2}$

Se han preparado disoluciones de este reactivo con el contaminante orgánico $(\mathrm{OC})$ en distintas concentraciones y se han sometido al mismo tratamiento de irradiación con luz UV. En la figura 7.7 se muestra que se obtiene la misma absorbancia en el espectro UV en una disolución que contiene $50 \mathrm{mg}$ de $\mathrm{TiO}_{2}$ con $50 \mathrm{mg} / \mathrm{l}$ de contaminante orgánico (OC) que en una disolución de OC de $16 \mathrm{mg} / \mathrm{l}$ en el caso de emplear el reactivo Fenton.

A todos los espectros se les ha restado la línea base correspondiente al fotocatalizador y se ha calculado el porcentaje de degradación respecto a la cantidad original de OC que había en la disolución. Así pues, mientras que el $\mathrm{TiO}_{2}$ degrada más del $40 \%$ del OC en disolución tras un tiempo de exposición de $4 \mathrm{~h}$ bajo la luz UV, el reactivo Fenton en las mismas condiciones tan solo es capaz de degradar un $16 \%$ del mismo contaminante. 


\subsection{Conclusiones}

Se han preparado con éxito fotocatalizadores de $\mathrm{TiO}_{2}$ capaces de fotodegradar un contaminante orgánico en agua potable. Se ha demostrado que, a pesar de la mayor actividad fotocatalítica de la brookita respecto a la anatasa, la mayor adsorción del componente orgánico en la primera produce una reducción en su capacidad de degradación por la menor cantidad de radiación uv que llega a la superficie de las partículas. El componente orgánico cubre la superficie activa del $\mathrm{TiO}_{2}$ inhibiendo la reacción de fotocatálisis.

Así mismo, el aumento de la concentración del fotocatalizador resulta en un aumento de la cantidad de componente orgánico que es capaz de degradar. Sin embargo, el aumento de $\mathrm{TiO}_{2}$ también supone una mayor dificultad para la penetración de la radiación UV, por lo que las suspensiones más diluidas han mostrado una mayor eficiencia fotodegradativa. Este resultado es de gran importancia a la hora de diseñar materiales fotodegradantes soportados y no soportados. En el caso de materiales soportados en vidrios transparentes, aumentar la concentración de $\mathrm{TiO}_{2}$ en el vidrio resultaría beneficioso en tanto en cuanto la transparencia del vidrio no se vea afectada para no disminuir la radiación disponible capaz de activar el proceso fotodegradativo.

Este tipo de materiales han resultado tener una mayor eficacia a la fotodegradación del mismo componente orgánico frente a otros reactivos basados en el mismo proceso. Se ha mostrado que se consigue una degradación del $40 \%$ del contaminante orgánico disuelto empleando $\mathrm{TiO}_{2}$ en suspensión y esta eficacia aumenta hasta más del $65 \%$ en el caso de emplear suspensiones muy diluidas. El reactivo Fenton empleado solo ha conseguido una eficacia del $16 \%$ frente al mismo contaminante, empleando además disoluciones más diluidas, que facilitan el transporte de carga por la disolución.

Como líneas futuras de trabajo se plantean, tras la comprobación de la eficacia de la oxidación con $\mathrm{TiO}_{2}$, la optimización en los tiempos de reacción, elevados a priori, y en soportación del catalizador sobre superficies de vidrio. 


\section{Referencias}

CÁmara HuRtado, R.M. (2012). Inmovilización de $\mathrm{TiO}_{2}$ sobre polímeros transparentes en el UV-A para la eliminación fotocatalítica de tricoloroetileno en aire. Madrid, Universidad Politécnica de Madrid.

DomeneCH, X., JARDim, W.F. y LitTer, M.I. (2001). Procesos avanzados de oxidación para la eliminación de contaminantes. Eliminación de contaminantes por fotocatálisis heterogénea. Capítulo 1, pp. 1-24.

Houas, A., Lachheb, H., Ksibi, M., Elaloul, E., Guillard, C. y Herrmann, J.M. (2001). «Photocatalytic degradation pathway of methylene blue in water». Applied Catalysis B: Environmental, 31, pp. 145-157.

Kandiel, T.A., Robben, L., Alkaim, A. y Bahnemann, D. (2012). «Brookite versus anatase $\mathrm{TiO}_{2}$ photocatalysts: phase transformations and photocatalytic activities». Photochemical and Photobiological Sciences, 12, pp. 602-609.

Karimi, B., Rajael, M.S., Koulivand, A. y Soltanl, R.D.C. (2014). «Performance evaluation of advanced Fe degrees $/ \mathrm{Fe}^{+2} / \mathrm{Fe}^{+3} / \mathrm{H}_{2} \mathrm{O}_{2}$ process in the reduction of nitrate and organic matter from aqueous solution». Desalination and Water Treatment, 52, pp. 6240-6248.

KeRKEz, Ö. y Boz, I. (2015). «Photodegradation of Methylene Blue with $\mathrm{Ag}_{2} \mathrm{O} /$ $\mathrm{TiO}_{2}$ under Visible Light: Operational Parameters». Chemical Engineering Communications, 202, pp. 534-541.

lachieb, H., Puzenat, E., Houas, A., Ksibi, M., Elaloul, E., Gulllard, C. y Herrmann, J.M. (2002). «Photocatalytic degradation of various types of dyes (Alizarin $S$, Crocein Orange G, Methyl Red, Congo Red, Methylene Blue) in water by UV-irradiated titania». Applied Catalysis B: Environmental, 39, pp. 75-90.

LitTeR, M.I. y NAVIO, J.A. (1996). «Photocatalytic properties of iron-doped titania semiconductors». Journal of Photochemistry and Photobiology A:Chemistry, 98, pp. 171-181.

Mansilla, H.D., Mora, A., Pincheira, C., Moncada, M.A., Marcato, P.D., Durán, N. y FrEeR, J. (2007). «New photocatalytic reactor with $\mathrm{TiO}_{2}$ coating on sintered glass cylinders». Applied Catalysis B: Environmental, 76, pp. 57-63. 
Neamtu, M., Grandjean, D., Sienkiewicz, A., Le Faucher, S., Slaveykova, V., Colmenares, J.J.V., Pulgarin, C. y De Alencastro, L.F. (2014). «Degradation of eight relevant micropollutants in different water matrices by neutral photo-Fenton process under UV254 and simulated solar light irradiation - A comparative study». Applied Catalysis B: Environmental, 158, pp. 30-37.

Ovenstone, J. y YanagisawA, K. (1999). «Effect of Hydrothermal Treatment of Amorphous Titania on the Phase Change from Anatase to Rutile during Calcination». Chemistry of Materials, 11, pp. 2770-2774.

Peng, T., Zhao, D., Dal, K., Shl, W. y HiRAo, K. (2005). «Synthesis of Titanium Dioxide Nanoparticles with Mesoporous Anatase Wall and High Photocatalytic Activity». The Journal of Physical Chemistry B, 109, pp. 4947-4952. 


\title{
Caso práctico: aplicaciones $\mathrm{POA}$ mediante tecnología $\mathrm{H}_{2} \mathrm{O}_{2} / \mathrm{UV}$ y foto-Fenton en aguas procedentes de una industria química
}

\author{
R. Duque, J. Donato, S. Ponce, R. Sáez
}

Soluciones Industriales y Tratamientos Ambientales, S.L (SITRA)

Pol. Ind. Ciudad del Transporte

C/ Suiza esquina c/Polonia - naves 19, 20 y 21 Castellón, España

Contacto: rduque@sitra.es

\section{Rodrigo Duque}

Rodrigo Duque es Ingeniero Químico por la Universidad de Valladolid, y Máster en Tratamiento y Reciclaje de Aguas Residuales Industriales. Con más de 10 años de experiencia en el sector del ciclo integral del agua, en 2008 se incorporó a SITRA, del Grupo Gimeno, como Responsable del Departamento de Ingeniería y Proyectos. Ha desarrollado su labor profesional en el tratamiento de aguas tanto potables como residuales, participando en el diseño y desarrollo de diferentes instalaciones con amplio rango de tecnologías de tratamiento.

\section{Resumen}

Muchas de las industrias químicas disponen de un tratamiento para sus aguas residuales, pero requieren de un postratamiento para su vertido debido a la creciente regulación sobre los vertidos de las depuradoras de aguas residuales y a la optimización de la calidad de vertido. Por este motivo, desde SITRA se desarrolló un tratamiento terciario de las aguas residuales para una industria química del sector perfumero, basado en la tecnología foto- 
Fenton, con el objetivo de intentar reducir el valor de la DQo en el efluente de unos niveles de aprox. 500-600 mg/L con una baja biodegradabilidad (baja relación $\mathrm{DBO}_{5} / \mathrm{DQO}$ ) a niveles aproximadamente de $250 \mathrm{mg} / \mathrm{L}$. Los resultados mostraron que esta tecnología ofrecía buenos rendimientos de eliminación de materia orgánica pero con costes de inversión y explotación elevados.

\subsection{Introducción}

En general, cada vez es más frecuente que en las aguas residuales domésticas y en las industriales aparezcan contaminantes con altas cargas orgánicas que no pueden ser tratados por un método convencional. Requieren de un tratamiento específico ya que son numerosos los vertidos residuales en forma de corrientes acuosas que contienen compuestos orgánicos no biodegradables por métodos convencionales y refractarios a la oxidación biológica.

La eliminación efectiva de estos contaminantes orgánicos en las aguas residuales es un problema de gran importancia y cuya solución urge, pues afecta principalmente a los recursos naturales del agua.

La Ley 16/2002 de Prevención y Control Integrados de la Contaminación (IPPC), que transpone la Directiva Europea 96/61/CE del mismo nombre, establece la lista de las principales sustancias contaminantes que se tomarán obligatoriamente en consideración si son pertinentes para fijar valores límite de emisiones. En el caso del agua cabe distinguir:

- Hidrocarburos persistentes y sustancias orgánicas tóxicas persistentes y bioacumulables.

- Sustancias que ejercen una influencia desfavorable sobre el balance de oxígeno (y computables mediante parámetros tales como DBO, DQO y COT).

Generalmente, este tipo de contaminación se debe a la presencia de hidrocarburos aromáticos polinucleados (PAH), compuestos fenólicos, hidrocarburos halogenados (AOX), BTEX, pesticidas, colorantes, etc. Todos ellos pueden ser agrupados de forma común bajo el parámetro de DQo refractaria, la cual engloba toda esta carga orgánica, y también se pueden encontrar clasificados como 
contaminantes emergentes dado que son persistentes y bioacumulativos, policíclicos, recalcitrantes y aromáticos de alto peso molecular, difícilmente asimilables por bacterias, por lo que la necesidad de ser eliminados es apremiante teniendo en cuenta los graves efectos medioambientales que generan al ser vertidos a los cauces de agua.

La Unión Europea, ante este problema, ha establecido diferentes líneas de actuación que deben seguir las empresas para reducir las emisiones al agua y donde se dividen los contaminantes en tres grandes grupos, asignando a cada bloque una serie de técnicas de eliminación (consideradas técnicas de final de tubería):

- Contaminantes insolubles: tratamiento mecánico.

- Contaminantes solubles no biodegradables o inhibitorios: tratamiento fisicoquímico.

- Contaminantes solubles biodegradables: tratamiento biológico.

Los principales grupos de contaminantes a tener en cuenta son: TSS (total de sólidos en suspensión), DBO-DQO-COT, DQO refractaria, AOX, $\mathrm{N}$ total, $\mathrm{NH}_{4}-\mathrm{N}\left(\mathrm{NH}_{3}\right)$, $\mathrm{PO}_{4}-\mathrm{P}$, metales pesados, fenoles y grasas.

En la siguiente tabla, se muestra de forma general las diferentes técnicas de eliminación en función de la contaminación orgánica del agua residual:

Tabla 8.1. Técnicas de eliminación de contaminantes orgánicos de EDAR

\begin{tabular}{|c|c|}
\hline Contaminantes & Técnica de eliminación \\
\hline Orgánicos insolubles & Separadores \\
\hline Orgánicos volátiles & $\begin{array}{r}\text { Stripping con aire/vapor, destilación, adsorción con carbón, } \\
\text { evaporación, oxidación térmica }\end{array}$ \\
\hline Orgánicos refractarios & $\begin{array}{r}\text { Adsorción con carbón, ozonización, oxidación supercrítica, } \\
\text { oxidación húmeda y oxidación química }\end{array}$ \\
\hline Orgánicos biodegradables & Tratamiento aerobio, tratamiento anaerobio \\
\hline Sólidos orgánicos disueltos & $\begin{array}{c}\text { Intercambio iónico, separación por membrana y adsorción con } \\
\text { carbón }\end{array}$ \\
\hline Aceites y grasas & Tratamiento químico y Mop/Skimmers \\
\hline
\end{tabular}


La selección de la técnica de eliminación dependerá de la naturaleza, concentración y caudal de los contaminantes (además de ser un proceso medioambiental aceptable y con un coste económico razonable).

En el caso de la EDAR industrial que se estudia, una instalación química para la fabricación a escala industrial mediante transformación química de productos químicos orgánicos de base, todo parece indicar que existe una alta contaminación residual a la salida del reactor biológico y que esta puede ser debida a la presencia de DQo refractaria (DQO soluble inerte) y que suele deberse principalmente a la presencia de hidrocarburos aromáticos polinucleados (PAH), compuestos fenólicos, hidrocarburos halogenados (AOX), BTEX, colorantes, etc.; todos ellos recogidos en la Ley 16/2002 de Prevención y Control Integrados de la Contaminación (IPPC).

En este sentido, son las técnicas de la siguiente tabla las que mayoritariamente se utilizan en el efluente del reactor para la eliminación de la DQO refractaria. En esta tabla también se indican las técnicas que se utilizan para eliminar tanto la DQO como los fenoles, ya que este último se encuentra muy ligado al parámetro de DQO refractaria; por lo que, además de servir como referente de la DQo no biodegradable, también sirve para que, a partir de la concentración de fenoles, se pueda conocer el valor de DQo inerte.

Tabla 8.2. Técnicas de eliminación de DQo refractaria, DQo y fenoles para final de tubería ( $X^{a}$, contenido volátil orgánico).

\begin{tabular}{|c|c|c|c|}
\hline Técnica & DQO & DQO refractaria & Fenoles \\
\hline Oxidación química & $\mathrm{X}$ & $\mathrm{X}$ & $\mathrm{X}$ \\
\hline Oxidación húmeda & $\mathrm{X}$ & $\mathrm{X}$ & $\mathrm{X}$ \\
\hline SCWO & $\mathrm{X}$ & & $\mathrm{X}$ \\
\hline Adsorción & $\mathrm{X}$ & & \\
\hline Extracción & $\mathrm{X}$ & $\mathrm{X}$ & \\
\hline Stripping & $(\mathrm{X})^{\mathrm{a}}$ & $\mathrm{X}$ & \\
\hline Incineración & $\mathrm{X}$ & $\mathrm{X}$ & $\mathrm{X}$ \\
\hline Biológico anaerobio & $\mathrm{X}$ & & \\
\hline Biológico aerobio & $\mathrm{X}$ & & \\
\hline
\end{tabular}


Por tanto, como la eliminación de la DQo inerte depende del tipo de residuos que genere una empresa dado el proceso de producción en el que se base la misma. Es necesario estudiar qué técnica es la más efectiva para disminuir e incluso eliminar este tipo de contaminación para cada EDAR industrial en particular. Por tanto, para la industria perfumera problema objeto de este estudio, habrá que estudiar la efectividad de las técnicas anteriores, entre las que encontramos los procesos de oxidación avanzada (POA).

Los procesos de oxidación avanzada (POA) pueden definirse como procesos que implican la formación de radicales hidroxilo $(\cdot \mathrm{OH})$ de potencial de oxidación ( $E=2,8$ voltios) mucho mayor que el de otros oxidantes tradicionales [ozono, 2,07 voltios; peróxido de hidrógeno (agua oxigenada), 1,78 voltios; dióxido de cloro, 1,57 voltios, y cloro, 1,36 voltios]. Estos radicales son capaces de oxidar compuestos orgánicos principalmente por abstracción de hidrógeno o por adición electrofílica a dobles enlaces, generándose radicales orgánicos libres $(R \cdot)$ que reaccionan a su vez con moléculas de oxigeno formando un peroxiradical, iniciándose una serie de reacciones de degradación oxidativa que pueden conducir a la completa mineralización de los contaminantes.

Los procesos químicos de oxidación avanzada usan oxidantes (químicos) para reducir los niveles DQO/ DBO y para separar los componentes orgánicos y los componentes inorgánicos oxidables. Los procesos pueden oxidar totalmente los materiales orgánicos como carbón, $\mathrm{CO}_{2}$ y agua aunque no es a menudo necesario operar estos procesos hasta este nivel de tratamiento.

Los procesos de oxidación avanzada son especialmente útiles como pretratamiento antes de un tratamiento biológico frente a contaminantes resistentes a la biodegradación o como proceso de postratamiento para mejorar las características de las aguas antes de la descarga a los cuerpos receptores. La eficiencia de estas técnicas se debe en gran medida, como se ha indicado anteriormente, a la participación del radical hidroxilo que proporciona procesos termodinámicamente más favorables y velocidades de oxidación superiores que empleando otros métodos de oxidación. El radical hidroxilo es capaz de atacar prácticamente a todos los compuestos orgánicos y reaccionar $10^{6}-10^{12}$ veces más rápido que oxidantes alternativos como el ozono.

LoS POA se clasifican en procesos fotoquímicos y no fotoquímicos, en función de la utilización o no de radiaciones luminosas en el proceso. 
Tabla 8.3. POA más utilizados

\begin{tabular}{|c|c|}
\hline Procesos no fotoquímicos & Procesos fotoquímicos \\
\hline Ozonización & Ultravioleta de vacío \\
\hline Ozonización con $\mathrm{H}_{2} \mathrm{O}_{2} / \mathrm{O}_{3}$ & $\mathrm{UV} \mathrm{H}_{2} \mathrm{O}_{2}$ \\
\hline Procesos Fenton $\left(\mathrm{Fe}^{2+} / \mathrm{H}_{2} \mathrm{O}_{2}\right)$ y relacionados & UV/O \\
\hline Oxidación electroquímica & Foto-Fenton y relacionadas \\
\hline $\begin{array}{c}\text { Radiólisis y tratamiento con } \\
\text { haces de electrones }\end{array}$ & $\begin{array}{c}\text { Fotocatálisis heterogénea: con } \\
\text { semiconductores, con sensibilizadores } \\
\text { orgánicos o complejos de metales de } \\
\text { transición }\end{array}$ \\
\hline $\begin{array}{c}\text { Plasma no térmico } \\
\text { Descarga electrohidráulica y } \\
\text { ultrasonidos }\end{array}$ & \\
\hline $\begin{array}{c}\text { Oxidación en agua subcrítica y } \\
\text { supercrítica }\end{array}$ & \\
\hline
\end{tabular}

Otra clasificación de estos procesos es en función del tipo de proceso: homogéneo o heterogéneo, tal y como se puede observar en la figura 8.1.

Algunas de las ventajas de estas nuevas tecnologías frente a los métodos convencionales para el tratamiento de aguas residuales industriales son las siguientes:

- Los contaminantes se destruyen, no se concentran ni cambian de fase.

- Puede alcanzarse la mineralización total de los contaminantes orgánicos.

- Generalmente no generan fangos que requieran tratamiento o eliminación.

- Los reactivos utilizados como oxidantes son sustancias que se descomponen durante el proceso en productos inocuos.

- Son muy útiles para eliminar contaminantes refractarios que resisten otros métodos de tratamiento, principalmente el biológico. Mejoran la biodegradabilidad del agua residual, permitiendo acoplar un tratamiento biológico posterior. 


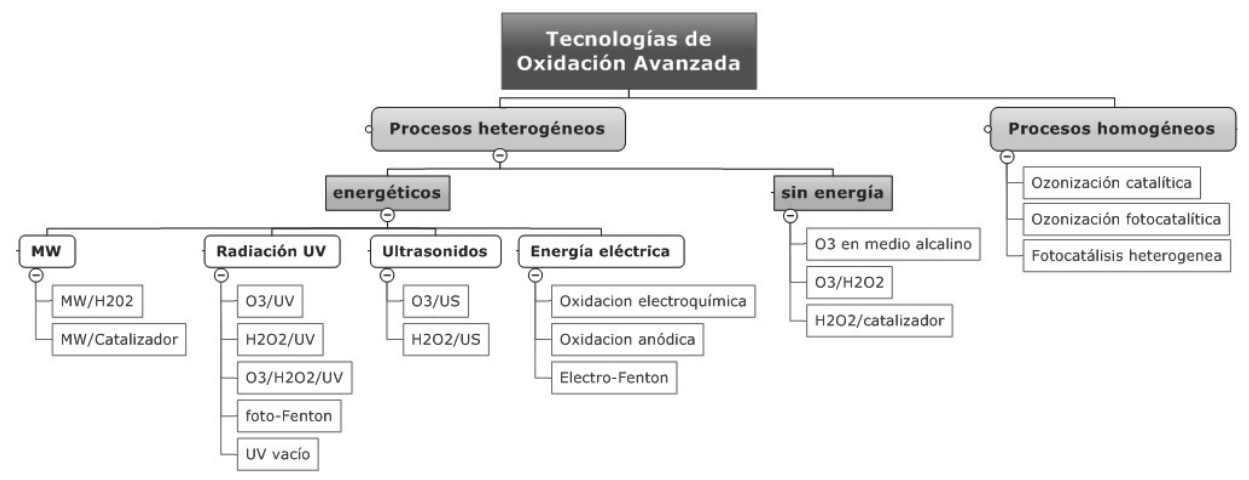

Figura 8.1. Clasificación de los POA en función del proceso

- Sirven para tratar contaminantes a muy baja concentración.

- Generalmente mejoran las características organolépticas de las aguas tratadas.

La revisión bibliográfica realizada sobre los estudios llevados a cabo sobre la eliminación de contaminantes no biodegradables en aguas residuales industriales muestra que diferentes tratamientos fisicoquímicos como coagulación, flotación y cloración se han utilizado para eliminar contaminantes emergentes en este tipo de aguas. Otras investigaciones concuerdan que procesos de adsorción por carbón activado y tratamientos de oxidación son efectivos para eliminar contaminantes emergentes (Filale y otros, 2004; Westerhoff y otros, 2005) y esto se debe a las interacciones hidrofóbicas con los compuestos orgánicos polares (Ying y otros, 2004), aunque diversas causas reducen el alcance de la separación por carbón activado, como la competencia por sitios activos en la superficie o el bloqueo de los poros con otras partículas. Sin duda, resulta ser el adsorbente más eficaz, especialmente para aguas residuales que contienen materia orgánica refractaria y compuestos no biodegradables. Por otro lado, los procesos de oxidación por ozono y cloración resultan ser una buena alternativa; sin embargo, al reaccionar con diferentes químicos, se pueden generar subproductos de efectos desconocidos. Estos procesos se recomiendan para una baja carga de carbono orgánico disuelto (COD) ya que este parámetro 
representa una fuerte influencia en el proceso (Huber y otros, 2006). En los últimos años se han estudiado sistemas de membranas, ya sea biológicos (MBR) o no biológicos (osmosis inversa, ultrafiltración y nanofiltración) y procesos de oxidación avanzada (POA), como sistemas más apropiados para eliminar concentraciones traza de contaminantes emergentes. Los reactores biológicos de membrana (MBR) son considerados como una mejora al tratamiento microbiológico de aguas residuales; sin embargo, debido a cuestiones económicas, es limitada su aplicación en plantas de tratamiento de aguas industriales o municipales. Estos sistemas presentan considerables ventajas a los tratamientos biológicos convencionales debido a que se genera una baja carga de fango en términos de DBO, lo que hace que las bacterias se vean obligadas a mineralizar los compuestos orgánicos de poca biodegradabilidad. Además, el largo tiempo de vida del fango da a las bacterias tiempo suficiente para adaptarse al tratamiento de sustancias resistentes (Cote y otros, 1997).

Los procesos avanzados se postulan como una buena opción para el tratamiento de contaminantes emergentes. Sin embargo, la desventaja se presenta en cuanto a un alto coste comparado con los procesos biológicos. El uso de un proceso avanzado como pretratamiento o postratamiento puede mejorar la biodegradabilidad de aguas residuales o lograr una casi completa eliminación, respectivamente.

\subsection{Objetivo}

El proyecto representa una novedad importante en cuanto al sector de depuración de aguas industriales, ya que buscaba desarrollar un nuevo proceso que permitiera eliminar de sus aguas efluentes los contaminantes no biodegradables de una EDARi que hasta el momento los métodos convencionales no permitían eliminar. Se estudiaron varias tecnologías a escala laboratorio para finalmente implementar un tratamiento piloto a escala industrial con la tecnología seleccionada, en este caso el proceso foto-Fenton, para ver si permitía disminuir la DQO a niveles de 500-600 mg/L del efluente de una industria química hasta valores de 250-125 ppm. 


\subsection{Materiales y método}

Son diversos los tratamientos que son aplicados para la eliminación de los contaminantes emergentes, como adsorción por carbón activado, procesos de oxidación (ozono y peróxido de hidrógeno), coagulación/flotación, procesos biológicos como fangos activados y filtración por membranas. Los procesos por medio de carbón activado y membranas han demostrado ser los más eficientes para la eliminación de contaminantes emergentes. Así también son varias las investigaciones que demuestran el gran potencial de los sistemas avanzados para la eliminación de este tipo de contaminantes, los cuales son principalmente utilizados como un pretratamiento o postratamiento para obtener un agua con mayor biodegradabilidad. Desafortunadamente, la mayoría de las depuradoras de aguas no cuentan con estos tipos de sistemas, por lo que estos contaminantes emergentes están siendo vertidos al medio ambiente y de ahí deriva la importancia de implementar diversas tecnologías para lograr un buen tratamiento de estos compuestos.

SITRA, con el fin de dar solución a una industria química con una DQO elevada, definió un estudio que contemplaba:

1. Caracterización del agua a tratar en el EDARi.

2. Estudiar a escala laboratorio diferentes tecnologías comerciales para ver el grado de eficacia que presentaban frente a la degradación de contaminantes no biodegradables y DQo propios de la EDARi que trata aguas del sector perfumero.

3. Seleccionar la tecnología más eficaz y estudiar su implementación a escala industrial.

4. Ensayos a escala industrial mediante piloto de la tecnología seleccionada.

A continuación, se detallan los métodos y tecnologías utilizados para cada una de estas fases de estudio:

\section{Escala laboratorio}

a) Precipitación química: estos ensayos consistieron en la dosificación de diferentes reactivos (coagulantes, neutralizadores y floculantes) para 
generar una desestabilización del material coloidal y su eliminación en forma de lodos. En estos ensayos se determinó el consumo de reactivos, los rendimientos alcanzados y la generación de lodos.

b) Adsorción mediante carbón activo: el carbón activo permite, sobre todo, la eliminación de compuestos químicos orgánicos refractarios, compuestos orgánicos volátiles y sólidos orgánicos disueltos. Los ensayos consistieron en la dosificación de carbón activo para determinar la adsorción que dicho reactivo presentaba frente a la contaminación presente en el efluente. Además, también se estudió la sinergia de utilizar este carbón activo junto con un tratamiento auxiliar con reactivos químicos. En estos ensayos se determinó el consumo de reactivos, los rendimientos alcanzados y la generación de lodos.

c) Fenton $\left(\mathrm{FeSO}_{4}\right)$ : se ensayó el uso de $\mathrm{Fe}^{2+}$ junto con peróxido de hidrógeno $\left(\mathrm{H}_{2} \mathrm{O}_{2}\right)$ para la eliminación de la DQo en el efluente, estudiando la dosis o ratio óptima para obtener la mayor eficacia posible.

d) Ozonización: los ensayos consistieron en la aplicación de ozono para determinar la oxidación que dicho reactivo presentaba frente a la contaminación presente en el efluente. Además, también se estudió la sinergia de utilizar el ozono junto con un tratamiento auxiliar con reactivos químicos (como, por ejemplo, $\mathrm{H}_{2} \mathrm{O}_{2}$ ). Estos ensayos proporcionaron información cualitativa sobre la viabilidad del tratamiento, así como los rendimientos alcanzados.

e) Radiación ultravioleta: estos ensayos consistieron en la aplicación de tecnología ultravioleta para determinar la oxidación que dicha tecnología presentaba frente a la contaminación presente en el efluente de la EDARi. Además, también se estudió la sinergia de utilizar la radiación ultravioleta junto con un tratamiento auxiliar con reactivos químicos (como, por ejemplo, $\mathrm{H}_{2} \mathrm{O}_{2}$ ). Estos ensayos proporcionaron información cualitativa sobre la viabilidad del tratamiento, así como los rendimientos alcanzados.

Selección de la tecnología más eficaz

La selección del sistema de tratamiento más eficaz implicó la comparación de los resultados obtenidos en cada uno de los ensayos a escala laboratorio 
comparando así eficacias para conocer si los nuevos tratamientos a desarrollar presentaban por sí mismos:

- mayor rendimiento de eliminación;

- consumos energéticos con ratios similares a las tecnologías comerciales;

- bajos costes de operación.

\section{Piloto industrial}

Se realizó la instalación de una planta piloto modular en la EDARi, capaz de operar en batch y en continuo, combinando las siguientes tecnologías:

- Pretratamiento:

- Filtración (se probaron filtros de anillas y carbón activo).

- Ultrafiltración por membrana cerámica.

- Oxidación avanzada:

- UV+ $\mathrm{H}_{2} \mathrm{O}_{2}$.

- Posibilidad de foto-fenton $\left(\mathrm{UV}+\mathrm{H}_{2} \mathrm{O}_{2}+\mathrm{Fe}\right)$.

Cada planta se operaba desde su pantalla de control, donde se introducían los datos de funcionamiento del sistema, que se establecieron según el criterio técnico que se valoró dadas las condiciones del agua a tratar. Dichos parámetros, así como los datos físicos que se representaron en la planta (caudales, volúmenes, presiones, analíticas de campo, etc.), se registraron en pantalla y luego fueron evaluados por personal técnico.

La operativa del piloto que se propuso fue la siguiente:

- Pilotaje del pretratamiento terciario mediante filtración y ultrafiltración, con el objetivo de disponer de un efluente libre de sólidos.

- Tratamiento del efluente con uv mediante lotes, con el fin de determinar las cinéticas de degradación a distintas condiciones de uso y tipo de lámpara, pH y concentración de peróxido. Esta etapa permitiría realizar el siguiente paso de escalado para trabajar con un sistema semicontinuo o continuo dependiendo de los resultados obtenidos. 


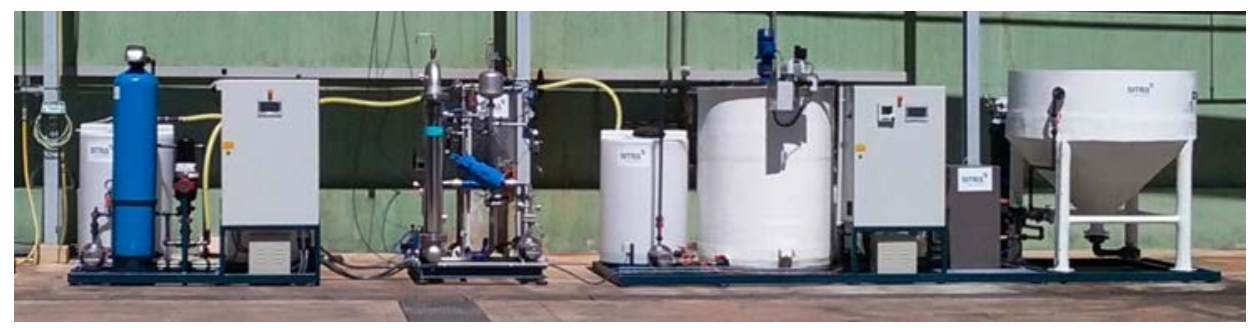

Figura 8.2. Piloto instalado en la EDARi como tratamiento terciario

- Escalado del tratamiento de uva un sistema semicontinuo o continuo para aplicación industrial, con los parámetros óptimos de pH, dosificación de reactivos y tipo de lámpara, comprobando los parámetros de usabilidad de la instalación, tal como el grado de ensuciamiento del cuarzo, la estabilidad de la lámpara, los efectos de compuestos recalcitrantes, etc.

\subsection{Resultados}

La caracterización del agua residual industrial a tratar mostró una variabilidad en cuanto a la DQO con su correspondiente variación del parámetro сот (carbono orgánico total). Como valores de referencia de esta caracterización del agua a tratar, se presenta la tabla 8.4:

Tabla 8.4. Caracterización agua residual industrial sometida a estudio

\begin{tabular}{|c|c|}
\hline Parámetro & Valor \\
\hline Caudal a tratar & $720 \mathrm{~m}^{3} / \mathrm{hora}$ \\
\hline $\mathrm{pH}$ & $6-7$ \\
\hline DQO & $500-600 \mathrm{mg} / \mathrm{L}$ \\
\hline COT & $130-190 \mathrm{mg} / \mathrm{L}$ \\
\hline Conductividad & $20.000 \mu \mathrm{S} / \mathrm{cm}$ \\
\hline Sulfatos & $8.000 \mathrm{mg} / \mathrm{L}$ \\
\hline
\end{tabular}




\section{Escala laboratorio}

a) Precipitación química:

Del análisis de los resultados obtenidos (tabla 8.5) se puede concluir que la DQo del efluente no está ligada, en su mayor parte, a la baja carga en coloides y materia particulada en suspensión presente, por lo que, con un tratamiento fisicoquímico óptimo, no es posible la deseada reducción de DQO. Los ensayos y resultados analíticos apuntaron a un máximo de reducción próximo al $20 \%$ y a un valor absoluto no inferior a $400 \mathrm{mg} / \mathrm{L}$.

Tabla 8.5. Mejores resultados obtenidos con tratamiento fisicoquímico

\begin{tabular}{|c|c|c|}
\hline Parámetro & Agua de aporte & Mejor resultado \\
\hline \multirow{2}{*}{ Reactivos dosificados } & --- & $90 \mathrm{ppm}$ PAC \\
\cline { 2 - 3 } & & $4 \mathrm{ppm}$ SITRAFLOCK SA-405 \\
\hline $\mathrm{pH}($ ud. $\mathrm{pH})$ & 7,15 & 6,50 \\
\hline $\mathrm{DQO}(\mathrm{mg} / \mathrm{L})$ & 513 & 418 \\
\hline Reducción DQO (\%) & --- & 19 \\
\hline Sólidos generados (mg/L) & --- & 150 \\
\hline Observaciones & -- & $\begin{array}{c}\text { Reducción de la coloración } \\
\text { Formación mínima de flóculos }\end{array}$ \\
\hline
\end{tabular}

b) Adsorción mediante carbón activo:

Los ensayos realizados adicionando diferentes dosis de carbón activo no mostraron resultados satisfactorios. La reducción máxima de DQO se situó en un valor inferior al $15 \%$ y superior a $440 \mathrm{mg} / \mathrm{L}$ en valor absoluto. Además, las dosis empleadas, dada la caracterización inicial de la muestra, se consideran demasiado elevadas para una aplicación viable. 
Tabla 8.6. Mejores resultados obtenidos con carbón activo

\begin{tabular}{|c|c|c|}
\hline Parámetro & Agua de aporte & Mejor resultado \\
\hline Carbón activo empleado & --- & $1.000 \mathrm{ppm}$ ccP 80 \\
\hline Tiempo de retención & --- & 30 minutos \\
\hline $\mathrm{pH}($ ud. $\mathrm{pH})$ & 7,15 & 6,95 \\
\hline $\mathrm{DQO}(\mathrm{mg} / \mathrm{L})$ & 513 & 443 \\
\hline Reducción DQO (\%) & -- & 14 \\
\hline Sólidos generados (mg/L) & --- & 1150 \\
\hline Observaciones & -- & $\begin{array}{c}\text { Significativa reducción del color } \\
\text { Interfase definida }\end{array}$ \\
\hline
\end{tabular}

c) Fenton $\left(\mathrm{FeSO}_{4}\right)$ :

Los resultados obtenidos durante los ensayos mostraron un bajo rendimiento. En la tabla 8.7 se presenta el mejor resultado obtenido:

Tabla 8.7. Mejores resultados obtenidos con Fenton

\begin{tabular}{|c|c|c|}
\hline Parámetro & Agua de aporte & Mejor resultado \\
\hline Ratio DQO: $\mathrm{H}_{2} \mathrm{O}_{2}$ & -- & $1: 5$ \\
\hline Ratio $\mathrm{Fe}: \mathrm{H}_{2} \mathrm{O}_{2}$ & --- & $1: 10$ \\
\hline Dosificación $\mathrm{H}_{2} \mathrm{O}_{2}$ al $50 \%(\mathrm{mg} / \mathrm{L})$ & --- & 3.425 \\
\hline Dosificación FeSO $\mathrm{H}_{2} \mathrm{O}(\mathrm{mg} / \mathrm{L})$ & --- & 1.713 \\
\hline $\mathrm{DQO}(\mathrm{mg} / \mathrm{L})$ & 685 & 392 \\
\hline Reducción DQO $(\%)$ & --- & 42,77 \\
\hline
\end{tabular}


d) Ozonización:

Tabla 8.8. Mejores resultados obtenidos con proceso de ozonización

\begin{tabular}{|c|c|c|c|}
\hline Muestra & pH & DQO (mg/l) & Rdto DQO (\%) \\
\hline Condiciones del ensayo & \multicolumn{4}{|c|}{$3000 \mathrm{ppm} \mathrm{O}_{3}$} \\
\hline Agua de aporte & 7,07 & 653 & $-{ }^{--}$ \\
\hline Mejor resultado & 7,18 & 258 & 64,93 \\
\hline
\end{tabular}

e) Radiación ultravioleta:

Tabla 8.9. Mejores resultados obtenidos con proceso $\mathrm{uv}+\mathrm{H}_{2} \mathrm{O}_{2}$

\begin{tabular}{|c|c|c|}
\hline Muestra & DQO (mg/l) & Rdto DQO (\%) \\
\hline Condiciones del ensayo & \multicolumn{2}{|c|}{$\begin{array}{c}\text { Lámpara TNN } 15 / 32 \text { (baja presión Hg) } \\
5 \mathrm{mMol} / \mathrm{L} \mathrm{H}_{2} \mathrm{O}_{2} \text { al } 50 \%\left(6,30 \mathrm{~L} \mathrm{H}_{2} \mathrm{O}_{2} / \mathrm{m}^{3} \text { agua tratada) }\right. \\
\text { Tiempo de reacción: } 120 \text { minutos }\end{array}$} \\
\hline Agua de aporte & 480 & -- \\
\hline Mejor resultado & 73 & 84,79 \\
\hline
\end{tabular}

Cabe decir que durante los ensayos realizados se hizo necesaria la aireación de la muestra previa a los ensayos ya que no disponían del suficiente nivel de oxígeno disuelto.

A partir de los resultados presentados para los diferentes ensayos a escala laboratorio, se llegó a la conclusión del porqué las tecnologías de oxidación avanzadas implantadas no obtuvieron los rendimientos esperados:

- La presencia de compuestos orgánicos azufrados (sulfatos, tioles, etc.), inactivaban los radicales libres.

- La existencia de polímeros de muy alto peso molecular que se descomponen por un proceso de unzipping. 
- El consumo total de oxígeno disuelto en el agua, siendo la formación de $\mathrm{O}_{2}$ debida al peróxido insuficiente para la cinética de degradación adecuada.

- La matriz química del efluente de la EDARi, como ya se conocía en un principio, era muy compleja y dificultaba la obtención de resultados representativos.

\section{Selección de la tecnología más eficaz}

Del análisis de los resultados obtenidos con tratamientos se pudo concluir a escala de laboratorio que:

- El tratamiento fisicoquímico se descartaba como posible tratamiento en EDARi por su bajo rendimiento. La explicación se encontraría en que la DQO del efluente no está ligada, en su mayor parte, a la baja carga en coloides y materia particulada en suspensión presente por lo que, con un tratamiento fisicoquímico óptimo, no era posible la deseada reducción de DQO.

- Con los ensayos realizados adicionando diferentes dosis de carbón activo no se obtuvieron resultados satisfactorios, por lo que también se descartó como tratamiento en EDARi. La reducción máxima de DQO se situó en un valor inferior al $15 \%$ y superior a $440 \mathrm{mg} / \mathrm{L}$ en valor absoluto. Además, las dosis empleadas, dada la caracterización inicial de la muestra, se consideraron demasiados elevadas para una aplicación viable.

- En el caso del tratamiento mediante la oxidación avanzada por ozono $+\mathrm{H}_{2} \mathrm{O}_{2^{\prime}}$ el rendimiento mayor obtenido en la reducción del cot fue de un $7,20 \%$ y de DQo del $66 \%$, con una dosificación de 3000 ppm $\mathrm{O}_{3}$ pero, aún así, no se consiguió el objetivo de obtención de un valor de DQO de $125 \mathrm{mg} / \mathrm{l}$.

- El mayor resultado se obtuvo con el empleo de $u v+\mathrm{H}_{2} \mathrm{O}_{2}$, consiguiendo en el mejor de los casos una reducción de DQO > 74 \%, y fue por la opción que se optó para pilotar.

- El proceso Fenton, atendiendo al rendimiento de eliminación de la DQO, se desestimó como proceso a implantar a escala industrial en la EDARi. 
Atendiendo a los resultados y a las principales observaciones comentadas, en un principio se consideraron como tecnologías a aplicar como tratamiento terciario en la edARi la ozonización y el proceso $\mathrm{uv}+\mathrm{H}_{2} \mathrm{O}_{2}$. Para estos dos procesos, se quiso estudiar qué implicaría pilotar este tipo de tecnología en al EDAR de estudio y, para ello, fue necesario realizar tanto una propuesta del pilotaje como la estimación de los costes de operación y mantenimiento de su implantación a escala industrial, considerando que la planta trataría $30 \mathrm{~m} / \mathrm{h}$ durante $24 \mathrm{~h}$ /día y 220 días/año. Los resultados, que se presentan en la tabla 8.10, hicieron que la empresa seleccionara la tecnología uv $+\mathrm{H}_{2} \mathrm{O}_{2}$ como la óptima para implantar en la EDARi como tratamiento terciario.

Tabla 8.10. Costes estimación implantación tecnologías en EDARi

\begin{tabular}{|c|c|c|c|c|c|}
\hline Tecnología & $\begin{array}{c}\text { DQO aporte } \\
(\mathbf{m g} / \mathbf{L})\end{array}$ & $\begin{array}{c}\text { DQO obtenido } \\
(\mathbf{m g} / \mathbf{L})\end{array}$ & $\%$ DQO & $\begin{array}{c}\text { Inversión } \\
\text { aprox. (€) }\end{array}$ & $\begin{array}{c}\text { Costes } \\
\text { operación y } \\
\text { mantenimiento } \\
\left(€ / \mathbf{m}^{3}\right)\end{array}$ \\
\hline Ozonización & 653 & 258 & 64,93 & $1600000 €$ & 1,649 \\
\hline $\mathrm{UV}+\mathrm{H}_{2} \mathrm{O}_{2}$ & 480 & 73 & 84,79 & $1000000 €$ & 0,916 \\
\hline
\end{tabular}

\section{Piloto industrial}

Durante el pilotaje de la planta en la industria química, se llevó a cabo primero un estudio del sistema de pretratamiento óptimo (filtro de anillas, carbón activo o ultrafiltración) y, después, un segundo estudio de pretratamiento + oxidación (tanto en batch como en continuo). Por lo que respecta a los estudios de pretratamiento, comentar que la filtración con anillas ofrecía un rendimiento despreciable en reducción de sólido y la filtración con carbón activo no pudo evidenciar su efectividad ni velocidad de saturación en la planta piloto debido a que no se dispuso de un caudal de agua suficiente para alimentar en continuo el CAG y su limpieza efectiva. La ultrafiltración presentó un rendimiento medido como reducción de la DQO pequeño (del orden del $5 \%$ ), pero hay que considerar que esta etapa de pretratamiento 
con ultrafiltración era necesaria como etapa de seguridad del tratamiento de oxidación posterior escogido. Por tanto, se seleccionó la ultrafiltración como sistema de seguridad previo a la oxidación.

Como en los primeros ensayos en batch, se concluyó que la matriz química del agua residual a tratar era más compleja que la estimada inicialmente debido a que se evidenció una cinética de reacción lenta, se cambiaron los ensayos de un tratamiento con uv + peróxido de hidrógeno a uv + peróxido de hidrógeno + hierro (proceso foto-Fenton), buscando favorecer la formación de radicales con la presencia de iones metálicos. Por tanto, los resultados que se presentarán serán respecto a la implantación de este proceso en continuo.

Una vez estudiado el efecto del pretratamiento, se realizó el pilotaje del proceso foto-Fenton con la planta piloto que consistía en un pretratamiento de ultrafiltración, seguido de un depósito de inicio para la recepción del agua ultrafiltrada y la recirculación procedente de los reactores de uv y del sulfato ferroso recuperado del sistema. En este depósito es donde se lleva a cabo el ajuste de $\mathrm{pH}$, la dosificación de peróxido y el ajuste de sulfato ferroso si es necesario. Posteriormente, se dispone del reactor con una lámpara uv y de una bomba de alimentación y purga del agua tratada, con su instrumentación individual para el control del mismo. Además, se dispone de un sistema de precipitación y recuperación de sulfato ferroso consistente en un ajuste de $\mathrm{pH}$ a valores básicos, una decantación mediante decantador estático y bomba neumática de impulsión del sulfato ferroso a cabecera.

Tabla 8.11. Condiciones de ensayo con el piloto

\begin{tabular}{|c|c|c|}
\hline Hierro & $\mathbf{H}_{\mathbf{2}} \mathbf{O}_{\mathbf{2}}$ & Purga \\
\hline \multirow{2}{*}{$4 \mathrm{~g} / \mathrm{L}$} & $3 \%$ & $250 \mathrm{~L} / \mathrm{h}$ \\
\hline \multirow{3}{*}{$3,5 \mathrm{~g} / \mathrm{L}$} & \multirow{2}{*}{$1 \%$} & $90 \mathrm{~L} / \mathrm{h}$ \\
\cline { 2 - 3 } & \multirow{3}{*}{$0,50 \%$} & $200 \mathrm{~L} / \mathrm{h}$ \\
\cline { 2 - 3 } & & $200 \mathrm{~L} / \mathrm{h}$ \\
\cline { 2 - 3 } & & $150 \mathrm{~L} / \mathrm{h}$ \\
\cline { 2 - 3 } & \multirow{3}{*}{$0,40 \%$} & $90 \mathrm{~L} / \mathrm{h}$ \\
\cline { 2 - 3 } & & $150 \mathrm{~L} / \mathrm{h}$ \\
\hline
\end{tabular}


Condiciones: $1 \% \mathrm{H}_{2} \mathrm{O}_{2}, 3,5 \mathrm{~g} / \mathrm{I} \mathrm{Fe}, 90 \mathrm{I} / \mathrm{h}$ purga

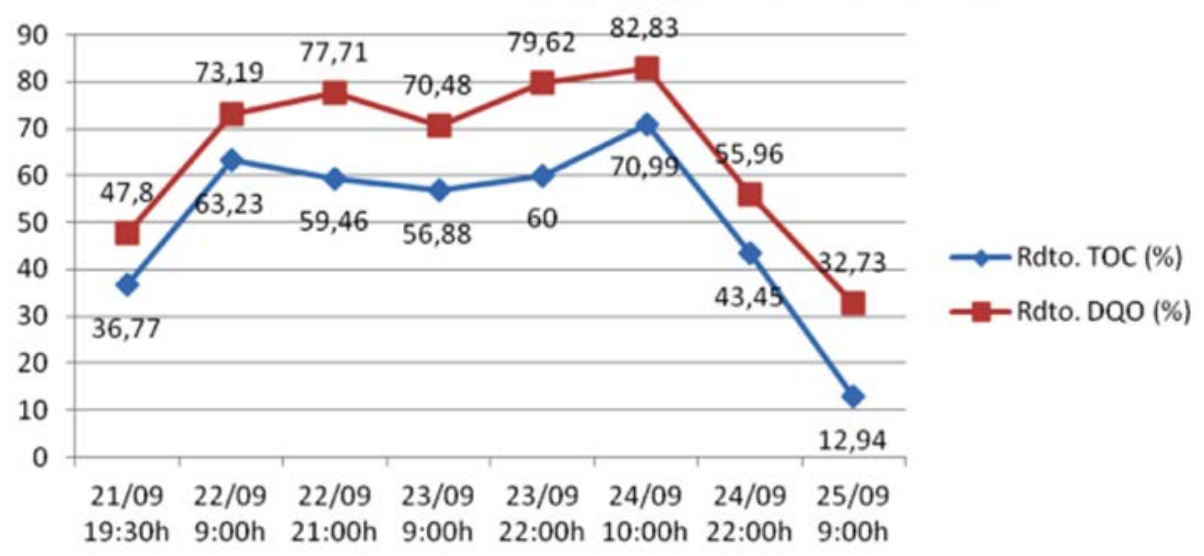

Figura 8.3. Resultados eficacia pilotaje en eliminación de DQo y сот

Tras pilotar la planta en cada una de las condiciones indicadas, se estudiaron los resultados y se observó que los mejores rendimientos en cuanto a la reducción de DQO (у сот) se conseguían con un $1 \%$ de peróxido de hidrógeno (al $50 \%$ de pureza) y 3,5 g/L de hierro con un caudal de tratamiento de $90 \mathrm{~L} / \mathrm{h}$.

En general, los resultados mostraron que, en referencia a la DQO, esta aumentaba y se llegó a la conclusión de que esto ocurría porque:

- Existían interferencias con el método de medida que provocaban errores de medida en numerosas ocasiones.

- Existían polímeros de muy alto peso molecular que se descomponían por un proceso de unzipping. Esto requería de un postratamiento adicional, como podría ser el filtrado con carbón activo.

Con el fin de estudiar la posibilidad de reducir estas interferencias y evaluar el postratamiento con carbón activo, se llevaron a cabo varios ensayos:

- Estudio de la relación del valor del pH y del redox como indicador del transcurso de la reacción que se llevaba a cabo, pero no fue posible. 
- Estudio de la relación experimental entre el valor del COT y DQO, que se encontraba entre unos valores de 2 y 5 a la salida del tratamiento biológico y en torno a 9 a la salida de la oxidación avanzada, por lo que parecía evidente que el tratamiento estaba modificando sustancialmente la naturaleza del agua tratada. Además, los resultados del análisis del cot mostraron que en las aguas residuales había un alto contenido en sales inorgánicas, lo que indicaba una cinética lenta en la oxidación avanzada.

- Eliminación de interferencias en el método de medida de la DQO mediante diferentes métodos: incrementando el $\mathrm{pH}$ y la temperatura de las muestras a analizar ( $\mathrm{pH}: 10-11$ y $\mathrm{T}: 40-50{ }^{\circ} \mathrm{C}$ ), adicionando bisulfito sódico, y diluyendo las muestras. La adición de bisulfito sódico no funcionó debido a que incrementaba aún más las sales presentes en el agua $y$, por tanto, empeoraba las interferencias con el método de medida. En el caso de calentar la muestra y elevar el $\mathrm{pH}$, en algunas ocasiones parecía que se conseguía eliminar la interferencia del $\mathrm{H}_{2} \mathrm{O}_{2}$ y que el incremento de la DQO tras la oxidación avanzada era realmente representativo del proceso realizado. Con las diluciones de $1 / 10$ y 1/20, las concentraciones remanentes se diluían reduciendo sus efectos sobre la medida, pero había que hacer lo posible para su eliminación de las muestras a analizar porque no siempre con la dilución se conseguía.

- Ensayo de biodegradabilidad, primero con una aireación de la muestra durante aproximadamente 20 minutos $y$, después, una adición de otros $20 \mathrm{~mL}$ de muestra procedentes de la oxidación avanzada aireando durante otras 21 horas. Se observó que durante los primeros $20 \mathrm{mi}-$ nutos prácticamente no se consumió oxígeno disuelto, llegando a la conclusión de que el agua residual ya difícilmente se podría degradar biológicamente y que, cuando se dosificaba el agua procedente de la oxidación avanzada, el contenido en oxígeno disuelto en la muestra se disparaba, presumiblemente debido al peróxido remanente en la muestra, pero que, posteriormente se reducía hasta alcanzar valores estables, sin presentar ningún cambio destacable. 
Una vez realizado el pilotaje y atendiendo a los resultados obtenidos, se diseñaron 4 estrategias a implantar en la EDARi atendiendo a las condiciones de DQO de la muestra inicial y tras el tratamiento. Además, para cada una de estas estrategias con unos buenos rendimientos en eliminación en materia orgánica, se estimaron los costes de explotación resultando unos costes de inversión y explotación importantes.

Tabla 8.12. Resumen de costes estimados para cada una de las estrategias diseñadas de cara a su implantación en EDARi

\begin{tabular}{|c|c|c|c|}
\hline \multicolumn{4}{|c|}{ RESUMEN COSTES EXPLOTACIÓN $^{|c|}$} \\
\hline $\mathbf{D Q O}_{\text {inicio }}$ (mg/L) & $\mathbf{D Q O}_{\text {salida }}$ (mg/L) & Estrategia & Coste estimado $\left(\boldsymbol{\epsilon} / \mathbf{m}^{\mathbf{3}}\right)$ \\
\hline \multirow{2}{*}{600} & 200 & 1 & 2,710 \\
\cline { 2 - 4 } & 125 & 2 & 3,054 \\
\hline \multirow{2}{*}{800} & 200 & 3 & 3,195 \\
\cline { 2 - 4 } & 125 & 4 & 3,487 \\
\hline
\end{tabular}

Tabla 8.13. Desglose de costes estimados para cada una de las estrategias diseñadas de cara a su implantación en EDARi

\begin{tabular}{|c|c|c|c|c|c|c|}
\hline \multicolumn{7}{|c|}{ DESGLOSE COSTES EXPLOTACIÓN } \\
\hline Estrategia & $\begin{array}{c}\text { Energía } \\
\left(€ / \mathbf{m}^{\mathbf{3}}\right)\end{array}$ & $\begin{array}{c}\text { Ácido (ajuste } \\
\mathbf{p H})\left(\boldsymbol{\epsilon} / \mathbf{m}^{\mathbf{3}}\right)\end{array}$ & $\begin{array}{c}\text { Sulfato } \\
\mathbf{f e r r o s o} \\
\left(\boldsymbol{\epsilon} / \mathbf{m}^{\mathbf{3}}\right)\end{array}$ & $\begin{array}{c}\text { Peróxido } \\
\left(\boldsymbol{(} / \mathbf{m}^{\mathbf{3}}\right)\end{array}$ & $\begin{array}{c}\text { Sosa (ajuste } \\
\mathbf{p H})\left(\boldsymbol{\epsilon} / \mathbf{m}^{\mathbf{3}}\right)\end{array}$ & $\begin{array}{c}\text { Total }(\boldsymbol{(} / \\
\left.\mathbf{m}^{\mathbf{3}}\right)\end{array}$ \\
\hline 1 & 0,573 & 0,280 & 0,078 & 1,179 & 0,600 & 2,710 \\
\hline 2 & 0,681 & 0,280 & 0,093 & 1,400 & 0,600 & 3,054 \\
\hline 3 & 0,676 & 0,280 & 0,083 & 1,556 & 0,600 & 3,195 \\
\hline 4 & 0,761 & 0,280 & 0,096 & 1,750 & 0,600 & 3,487 \\
\hline
\end{tabular}




\subsection{Conclusiones}

Tras el pilotaje realizado se pudo llegar a las siguientes conclusiones:

- Es recomendable un sistema de pretratamiento con ultrafiltración para minimizar la concentración de sólidos a la salida del tratamiento biológico y evitar así la interferencia de dichos sólidos en la oxidación posterior.

- La matriz química del efluente era muy compleja y variable, lo que no podía garantizar el rendimiento en todo momento por la gran variabilidad del agua a tratar debido a que, para cada caso en particular, habría que ver su efectividad en unas condiciones concretas de contaminación, $\mathrm{pH}$, tiempo de retención, dosis de reactivo, etc.

- Se evidenció una cinética de reacción lenta, cambiando de un proceso uv con peróxido de hidrógeno únicamente a un foto-Fenton con el fin de mejorar los rendimientos obtenidos, además de emplear lámparas de media presión en vez de baja.

- Con los ensayos efectuados se ha podido evidenciar la posibilidad de eliminar la DQO refractaria del agua con unos altos rendimientos con la tecnología foto-Fenton, pero con costes de inversión y explotación importantes.

- No podía aumentarse la biodegradabilidad con el tratamiento recibido.

- Cualquier presencia de peróxido remanente en la muestra podría dificultar la interpretación de los resultados por los altos contenidos en oxígeno disuelto que aporta a la muestra y su carácter biocida (interferencia con los métodos de medida de DQO/DBO).

- La aireación debe estar bien controlada con el fin de no airear en exceso, ya que el rendimiento de la bomba de recirculación se reducía por introducción de aire en el caudal impulsado y por la introducción de un exceso de aire en la lámpara de uv que disminuía la capacidad de contacto del agua residual con el uv.

- Las interferencias con el método de medida y la existencia de polímeros de muy alto peso molecular que se estén descomponiendo por un proceso de unzipping hacían que en muchas ocasiones se consiguieran reducciones apreciables en cot, lo que proporcionaba un aumento de la 
DQo final en vez de una reducción como sería esperable por la eliminación de la materia orgánica.

- Aunque durante las pruebas que se realizaron en laboratorio previamente se detectó la formación de mucha espuma en los reactores durante los primeros momentos, durante el pilotaje se comprobó que, aunque se formaban de manera importante, no parecía que fueran a generar problemas durante el proceso industrial.

- En los ensayos realizados a escala laboratorio se apreció un máximo de degradación con dosificaciones del 1,5\% de $\mathrm{H}_{2} \mathrm{O}_{2}$ con una pureza del $100 \%$, con unos rendimientos que oscilaban entre el 75-80 \% en DQo.

- La conclusión obtenida de todos estos ensayos para la ejecución de la oferta a escala industrial del proceso foto-Fenton era que lo mejor era plantear dos escenarios diferentes, considerando de partida una DQO inicial entre 550-650 mg/l y un valor de сот 130-190 mg/l, debido fundamentalmente a la variabilidad en las muestras a tratar:

- Reducciones en torno al $75 \%$ en DQo y $60-65 \%$ en cot.

- Reducciones en torno al $60 \%$ en DQo y $40-50 \%$ en cot.

- Con el fin de evitar interferencias en el método de medida de la DQO, se debía garantizar la eliminación del sulfato ferroso y peróxido de hidrógeno remanente en el agua residual tratada.

- Conclusión final: el tratamiento de oxidación avanzada propuesto es viable técnicamente para obtener los resultados deseados en cuanto a eliminación de materia orgánica y cumplimiento de los parámetros de vertido marcados. Las consideraciones económicas son las que finalmente marcarán la viabilidad final del proyecto, dado el coste elevado de inversión (CAPEX) y un coste considerable de operación de planta (OPEX). 
